\title{
Probing molecular tracers in geobiological systems using imaging mass spectrometry
}

\author{
Dissertation \\ zur Erlangung des mathematisch-naturwissenschaftlichen Doktorgrades \\ "Doctor rerum naturalium" \\ der Georg-August-Universität Göttingen \\ im Promotionsprogramm Geowissenschaften \\ der Georg-August University School of Science (GAUSS)
}

vorgelegt von

Tim Leefmann

aus Lüneburg

Göttingen 2013 


\section{Betreuungsausschuss}

Prof. Dr. Volker Thiel, Abteilung Geobiologie, GZG

Prof. Dr. Joachim Reitner, Abteilung Geobiologie, GZG

Mitglieder der Prüfungskommission

Dr. Martin Blumenberg, Abteilung Geobiologie, GZG

PD Dr. Gernot Arp, Abteilung Geobiologie, GZG

Prof. Dr. Bent T. Hansen, Abteilung Isotopengeologie, GZG

Prof. Dr. Andreas Pack, Abteilung Isotopengeologie, GZG

$\underline{\text { Referent }}$

Prof. Dr. Volker Thiel

$\underline{\text { Korreferent }}$

Prof. Dr. Joachim Reitner

Tag der mündlichen Prüfung

11.04 .2013 


\section{Acknowledgements}

I cordially thank Volker Thiel for the opportunity to work in this project on this "unconventional" mass spectrometric technique and all the scientific support throughout the last years that greatly helped in finishing this thesis. I furthermore thank Joachim Reitner for being the co-advisor and for the help with the SEM analyses. For being members of the thesis committee I thank Martin Blumenberg, Gernot Arp, Bent T. Hansen and Andreas Pack.

I am grateful to Christine Heim for many constructive discussions during field campaigns in Äspö and Borås. Sincere thanks are given to Peter Sjövall, Jukka Lausmaa, Sandra Siljeström, Anastasiia Kryvenda, Danny Ionescu, Christine Heim, Martin Blumenberg, Joachim Reitner, and Volker Thiel for their constructive comments on the original manuscripts.

For support during laboratory work in Göttingen and Borås I thank Cornelia Conradt, Dorothea Hause-Reitner, Wolfgang Dröse, Alexander Satmari, Peter Sjövall, Jukka Lausmaa, Sandra Siljeström, Per Borchard, and Jakob Malm. The field work in Äspö Hard Rock Laboratory would not have been possible without the logistical support from Emmeli Johannson, Magnus Kronberg, Linda Alakangas, Mats Lundqvist, and Karin Nilsson.

Thomas Bode was always helpful with any kind of computer related problem. Thanks go also to Lothar Laake and his team for constructing the UV-ozone cleaning apparatus and the flow reactors, to Richard Splivallo for the provision of truffle samples, and to Jan Bauermeister for proofreading.

For creating a pleasant working atmosphere in and around room 311 in the last years I would like to thank Juliane Germer, Cornelia Conradt, Katharina Liebenau, Christine Berndmeyer, Jan Bauermeister, and Andrea Hagemann. This thesis was compiled within the frame of the DFG research unit 571, subproject 6 "ToF-SIMS imaging mass spectrometry of microbial systems". 


\section{Preface}

The following manuscripts are part of this doctoral thesis.

Heim C., Sjövall P., Lausmaa J., Leefmann T., Thiel V. (2009) Spectral characterization of eight glycerolipids and their detection in natural samples using time-of-flight secondary ion mass spectrometry. Rapid Communications in Mass Spectrometry, 23, 2741-2753.

Leefmann T., Heim C., Siljeström S., Blumenberg M., Sjövall P., Thiel V. (2013) Spectral characterization of ten cyclic lipids using time-of-flight secondary ion mass spectrometry. Rapid Communications in Mass Spectrometry, 27, 565-581.

Leefmann T., Heim C., Kryvenda A., Siljeström S., Sjövall P., Thiel V. (2013) Biomarker imaging of single diatom cells in a microbial mat using time-of-flight secondary ion mass spectrometry (ToF-SIMS). Organic Geochemistry, 57, 23-33.

Leefmann T., Heim C., Lausmaa J., Sjövall P., Ionescu D., Reitner J., Thiel V. An imaging mass spectrometry study on the formation of conditioning films and biofilms in the subsurface (Äspö Hard Rock Laboratory, SE Sweden). In preparation for Geomicrobiology Journal. 


\section{Contents}

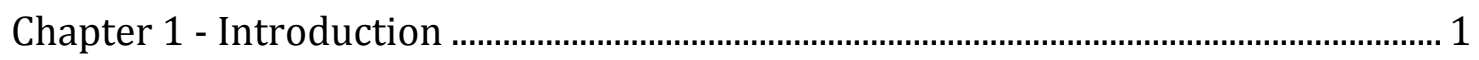

1.1. Imaging mass spectrometry in the field of geobiology ................................... 1

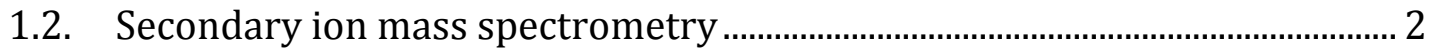

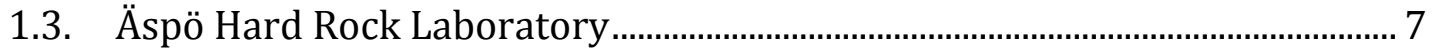

1.4. ToF-SIMS as an new analytical approach for geobiological samples ............ 8

1.5. Introduction to the following chapters .............................................................. 9

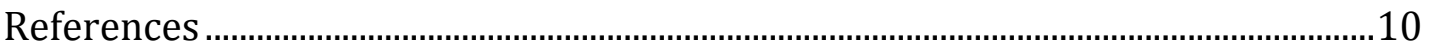

Chapter 2 - "Spectral characterization of eight glycerolipids and their detection in natural samples using time-of-flight secondary ion mass spectrometry"......................13

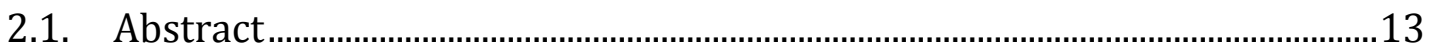



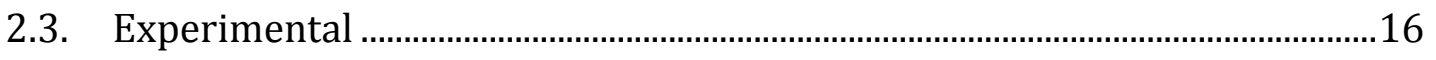

2.4. Results and discussion ................................................................................19

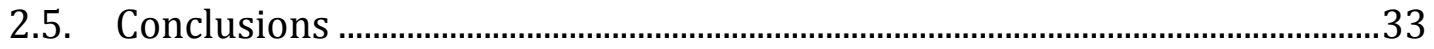

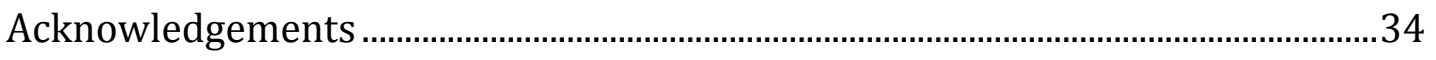

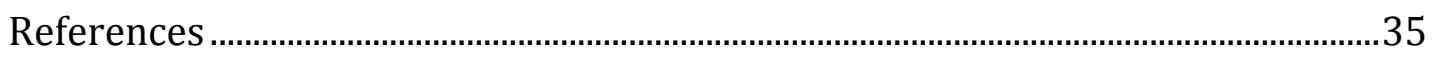

Chapter 3 - "Spectral characterization of ten cyclic lipids using time-of-flight

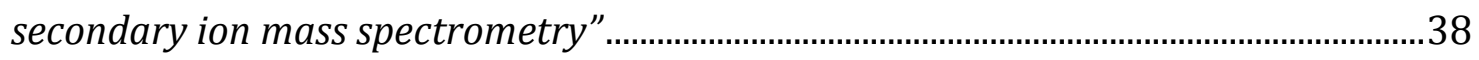

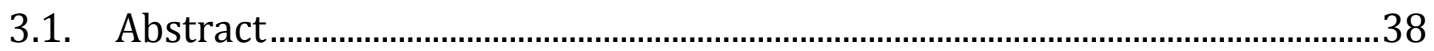

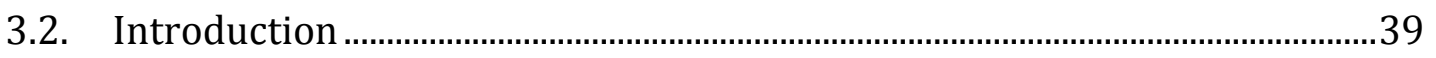

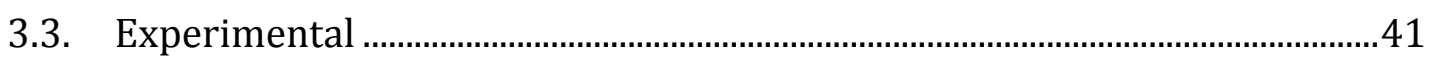

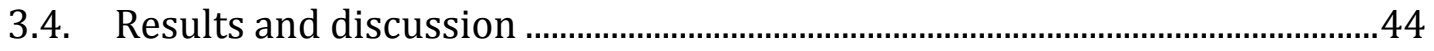

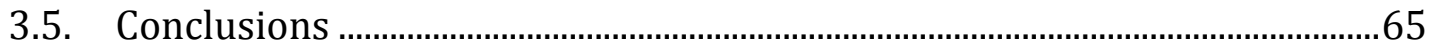

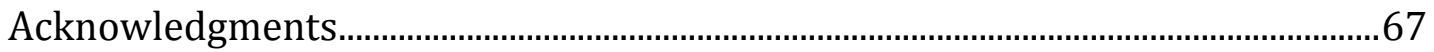




Chapter 4 - "Biomarker imaging of single diatom cells in a microbial mat using time-

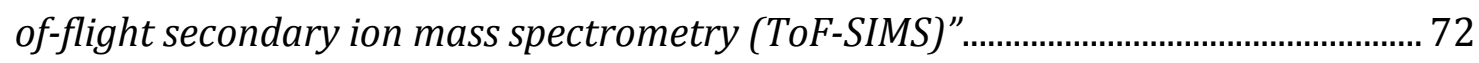

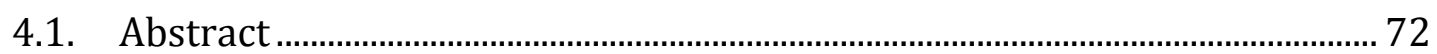

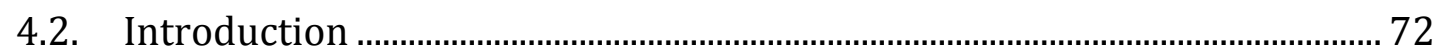

4.3. Materials \& Methods......................................................................................... 74

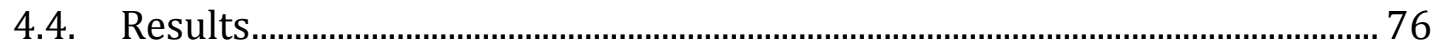

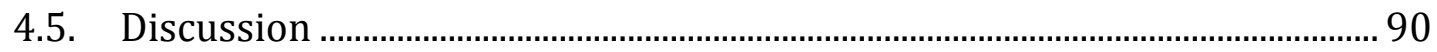

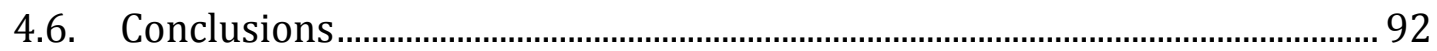

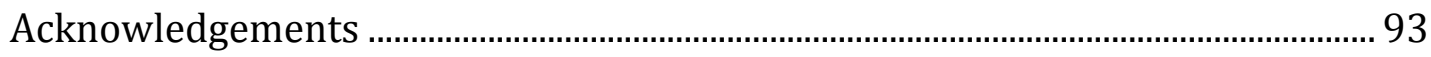

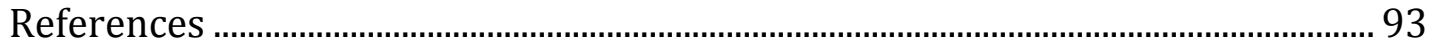

Chapter 5 - "An imaging mass spectrometry study on the formation of conditioning films and biofilms in the subsurface (Äspö Hard Rock Laboratory, SE Sweden)"....... 98

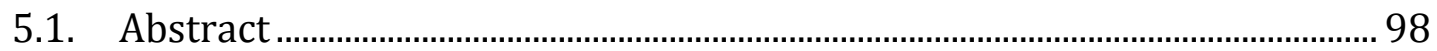

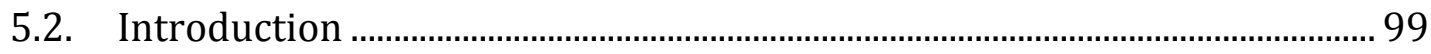

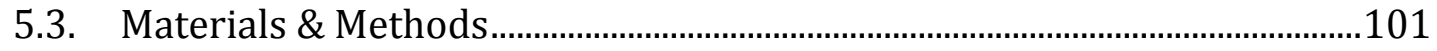

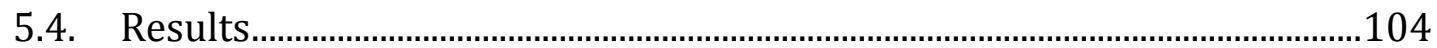

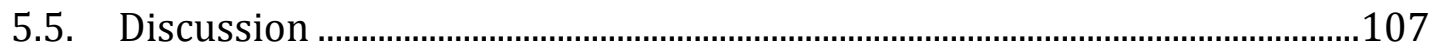

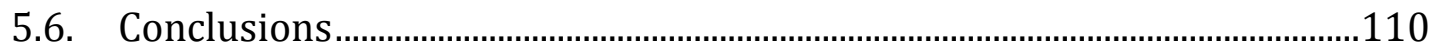



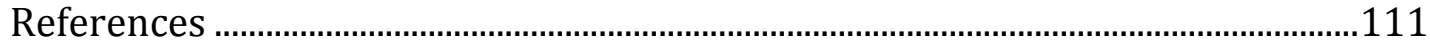

Chapter 6 - Summary and conclusions 
1.

\section{Introduction}

\subsection{Imaging mass spectrometry in the field of geobiology}

Geobiological systems are characterized by the close interaction of the biosphere and the geosphere. The key players in these systems are $\mu \mathrm{m}$-sized organisms which are involved in the formation and transformation of organic matter, gases, minerals, and rocks (Thiel and Sjövall, 2011). For the investigation of recent geobiological systems and their fossil equivalents high-resolution analytical techniques proved to be particularly advantageous (Orphan and House, 2009), due to the low sizes of the involved organisms and their chemical imprints in the fossil record. Whereas highresolution, mass spectrometric techniques such as laser ablation inductively coupled plasma mass spectrometry and ion microprobe are well established for tracing elemental and isotopic anomalies (Sylvester, 2006; Boxer et al., 2009; Orphan and House, 2009), equivalent methods for the chemical analysis of organic molecules have not reached the same level of applicability to environmental samples.

However, in the last decade, imaging mass spectrometric techniques have increasingly been used for the spatially-highly resolved analysis of ions from large organic molecules (Kollmer, 2004) in biological (Brunelle and Laprévote, 2009; Passarelli and Winograd, 2011; Sjövall et al., 2004; Winograd and Garrison, 2010) and, to a lesser degree, in geobiological (Heim et al., 2012; Siljeström et al., 2009; Siljeström et al., 2010; Thiel et al., 2007a; Thiel et al., 2007b; Toporski et al., 2002) , materials. For geobiological applications, the detection of taxonomically specific organic molecules is particularly desirable, as such so-called "biomarkers" can be preserved in sedimentary rocks and thus allow for tracing back organisms and reconstructing ecosystems in the fossil record (Brocks and Peason, 2005). The term biomarker applies to organic molecules from different compound classes, including lipids, nucleic acids, amino acids, lignins, and carbohydrates. While nucleic and amino acids usually have a higher taxonomic specificity as compared to other compound classes, lipids are far more resistant to degradation, and are thus the most widely used biomarkers in the analysis of fossil geobiological systems (Summons et al., 2008). 
Biomarkers are usually analyzed by extraction-based techniques such as coupled gas chromatography- or liquid chromatography-mass spectrometry (GCMS/LC-MS). These methods can provide highly detailed information on the structure of the biomarkers, but the appendant extraction procedure destroys the physical integrity of the sample and thus limits the applicability of these techniques to complex, heterogeneous samples. Furthermore, the destructing sample preparation complicates the combined application of different analytical techniques and thus substantially reduces the information obtainable from a given sample. Imaging mass spectrometric techniques as static time-of-flight secondary ion mass spectrometry (ToF-SIMS; Benninghoven, 1994) can in theory provide non-destructive and laterally highly resolving analyses for organic molecules. In this thesis project, ToFSIMS is therefore tested for its applicability to complex environmental samples.

\subsection{Secondary ion mass spectrometry}

In secondary ion mass spectrometry (SIMS), a high-energy primary ion beam is used to emit particles from the surface of solid state materials. The kinetic energy of the impacting primary ion is distributed in the sample through a collision cascade, and is leading to the breaking of bonds and thus to the emission of particles from the sample. Most of these particles are emitted as neutrals (Vickerman, 2001) and only a small fraction (10-6-10-1; Belu et al., 2003) as charged particles, i.e. secondary ions, which can be analyzed by means of mass spectrometry. By rastering the primary ion beam over the sample surface, SIMS allows for imaging the lateral distribution of specific secondary ions on the surface of the analyzed material with lateral resolution up to the submicron scale (Hagenhoff, 2000). SIMS can be used for the study of elemental ions and their isotopes as well as for the analysis of ions of complex molecules, but each application requires a specific instrument design (Boxer et al., 2009). Molecular ion species are best analyzed by static SIMS (Vickerman, 2001) using the ToF-SIMS technique (Benninghoven, 1994).

\subsubsection{Theoratical background of static SIMS}

The secondary ion yield $I_{m}$ of a chemical species $m$ obtained in a SIMS experiment is defined through the basic SIMS equation

$$
I_{m}=I_{p} Y_{m} \alpha \theta_{m} \eta \text { (Vickerman, 2001) }
$$


where $I_{p}$ is the primary particle flux, $Y_{m}$ is the total yield of sputtered particles of species $m, \alpha$ is the ionization probability of $m, \theta_{m}$ is the concentration of $m$ in the uppermost monolayer, and $\eta$ is the transmission of the spectrometer. The yield of sputtered particles increases with flux, mass, charge, and energy of the primary ions. However, as sputtering is a damaging process, the yield of characteristic particles will decrease with increasing analysis time. For a chemical species $m$ this decrease with analysis time is given through

$$
I_{m}=I_{m 0}^{-\sigma I_{p}}
$$

where $I_{m}$ is the secondary ion intensity, $I_{m 0}$ is the secondary ion intensity at the beginning of the experiment, $I_{p}$ is the primary particle flux, and $\sigma$ is the damage cross section (which is specific for the chemical species analyzed). In a static SIMS analysis, the primary ion dose density (PIDD) applied to the surface is kept below $10^{12}-10^{13}$ ions $\mathrm{cm}^{-2}$, so that less than $1 \%$ of the uppermost monolayer of atoms or molecules is impacted by the ion bombardment (Vickerman, 2001) and no significant fraction of the surface is damaged (Thiel and Sjövall, 2011). Keeping the PIDD below the static limit is crucial for the analysis of molecular ions, as those are susceptible to decomposition under intense ion bombardment.

The ionization of the particles occurs at or close to the emission from the sample surface (Vickerman, 2001). The ionization probability $\alpha$ is thus highly dependent on the electronic state of the chemical environment, i.e. the matrix, from which the particles are emitted. This so-called matrix effect can lead to considerable variations in the yield of secondary ions and thus hampers quantitative analyses by SIMS (Fletcher and Vickerman, 2013; Vickerman, 2011).

Emitted secondary ions of mass $m$ are accelerated by a potential $U$ and travel through a flight tube to the detector of the ToF-SIMS instrument. The equation for the kinetic energy is

$$
z U=\frac{m v^{2}}{2}=\frac{m L^{2}}{2 t^{2}}
$$

with $z$ being the charge and $v$ the velocity of the ion, $L$ being the length of the flight path, and $t$ being the travel time of the ion to the detector. By rearranging this equation to

$$
\frac{m}{z}=\frac{2 U t^{2}}{L^{2}}
$$


it becomes apparent that the $m / z$ ratio of a given ion can be calculated from its travel time $t$ at constant $U$ and $L$.

\subsubsection{ToF-SIMS technique}

A schematic sketch of a ToF-SIMS instrument is shown in Figure 1-1. The main components that determine the field of application of the SIMS instrument are the primary ion sources and the analyzer. Primary ion sources used in ToF-SIMS instruments include surface ionization sources (e.g. $\mathrm{Cs}^{+}$), gas (cluster) ion sources (e.g. $\mathrm{Ar}^{+}, \mathrm{O}_{2}{ }^{+}, \mathrm{C}_{60}{ }^{+}$), and liquid metal ion guns (LMIG; e.g. $\mathrm{Ga}^{+}, \mathrm{Au}^{+}, \mathrm{Bi}^{+}, \mathrm{Bi}^{+}{ }^{+}, \mathrm{Au}_{\mathrm{n}}{ }^{+}$).

(a)

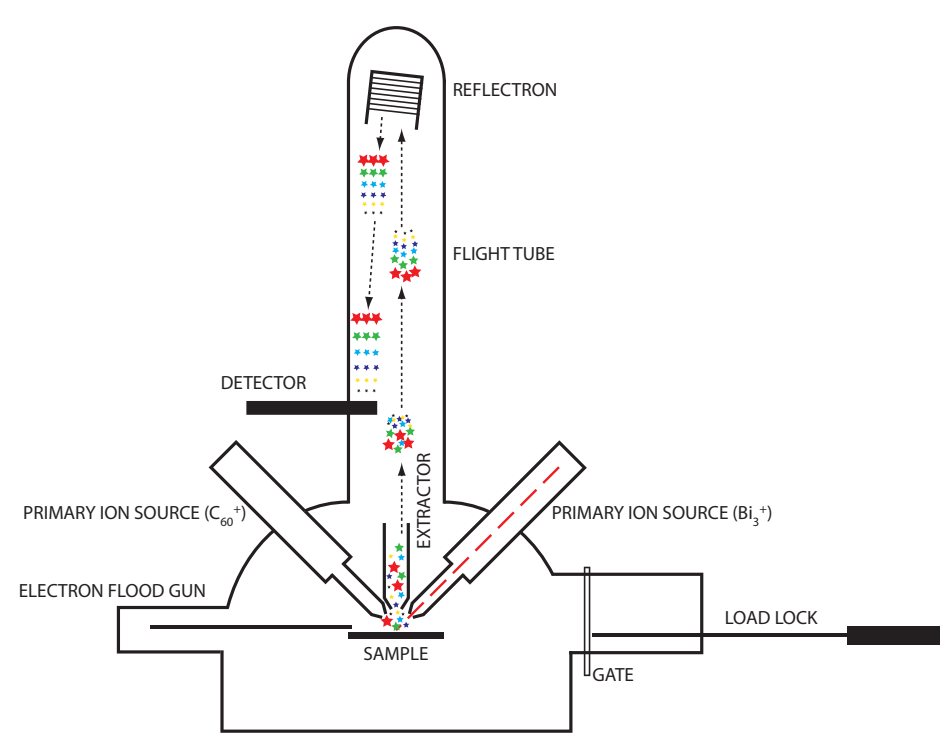

(b)

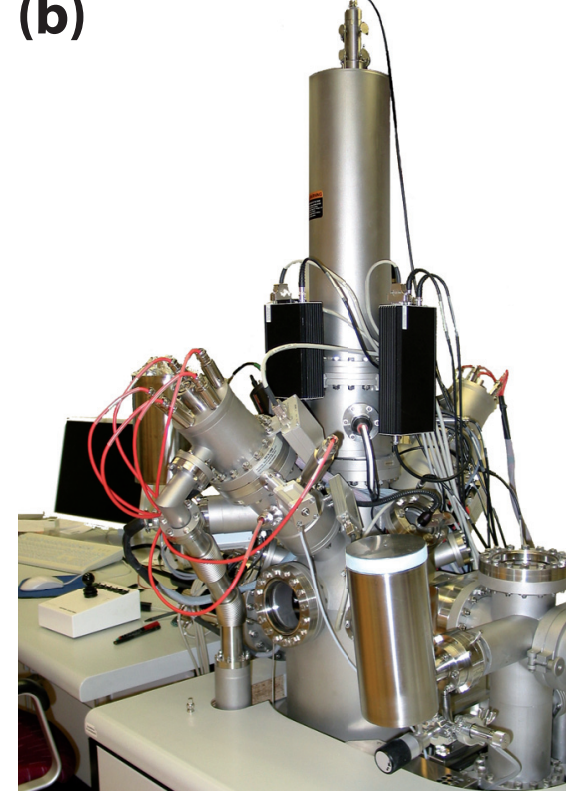

Figure 1-1. The ToF-SIMS instrument used in this study. (a) Schematic sketch and (b) photo of the IONTOF IV instrument at the SP Technical Research Institute of Sweden.

The advantage of LMIGs is that they are capable of producing primary ion beams with diameters as small as $50 \mathrm{~nm}$ (Winograd and Garrison, 2010) while maintaining a high primary ion current. They can thus provide high image resolution combined with a high secondary ion yield. The application of cluster ions such as $\mathrm{Bi}_{\mathrm{n}}{ }^{+}$or $\mathrm{Au}_{\mathrm{n}}{ }^{+}$ significantly increases the yield of high-mass secondary ions as compared to atomic primary ions (e.g. $\mathrm{Au}^{+}$or $\mathrm{Bi}^{+}$; Touboul et al., 2005), as on impact their energy is deposited closer to the sample surface (Colla et al., 2000; Thiel and Sjövall, 2011), which leads to less fragmentation of the emitted molecules.

The continuous beam produced by the ion source is electronically chopped into pulses. In cluster ion sources, a secondary chopper or a Wien-filter is used to remove 
ions of undesired cluster size. If a high mass resolution is required, a buncher is used to compress the pulses, so that all ions of a pulse arrive simultaneously at the sample surface (bunched mode; Sodhi, 2004). If analyses with high lateral resolution are desired, the buncher is turned off and lower ion currents and longer pulses are used (burst alignment mode; Thiel and Sjövall, 2011).

The secondary ions enter the flight tube through the extractor. A reflectron, or ion mirror, positioned in the middle of the flight path (Figure 1-1) corrects secondary ions for small variations in their kinetic energy (Belu et al., 2003). As a result, all ions of the same species arrive at the detector simultaneously.

\subsubsection{Sample preparation for ToF-SIMS}

All kinds of samples with solid surfaces can be analyzed by means of ToF-SIMS. However, two major requirements have to be met in order to generate interpretable data of the surface chemistry:

(i) The sample surface has to be flat to avoid topographic effects such as peak splitting or broadening in the mass spectrum (Thiel and Sjövall, 2011).

(ii) The sample has to be contaminant-free, as all contaminants adhering to the surface can have a major influence on the resulting spectrum.

For the analysis of biological samples such as microbial mats, both requirements can be fulfilled by preparing cryosections. The samples are embedded, frozen in isopentane, sliced into thin sections using a cryomicrotom, and placed on microscopic slides (Figure 1-2). If the ToF-SIMS is combined with other microscopic techniques, microscopic slides with premarked grids allow for easy relocalization of the analyzed area. The embedding agent has to be carefully chosen to avoid isobaric interferences of ions from the agent and from the target compounds. Other protocols commonly used for the preparation of biological materials include freeze fracturing (Lanekoff et al., 2011; Lanekoff et al., 2010) and chemical imprinting on Ag surfaces (Sjövall et al., 2003). A third method for producing flat, contaminant-free surfaces is the use of a sputter ion gun, e.g. $\mathrm{C}_{60^{+}}$, capable of performing molecular depth profiling of biological materials (Fletcher et al., 2007; Fletcher and Vickerman, 2013). 


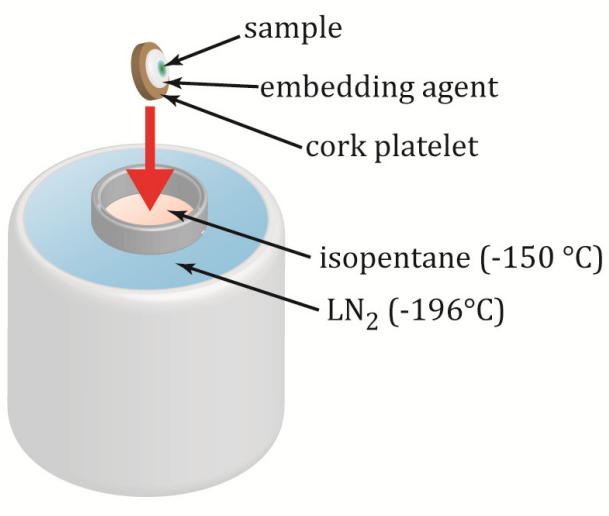

(I) PLUNGE FREEZING $\left(-150^{\circ} \mathrm{C} ; 30 \mathrm{~s}\right)$

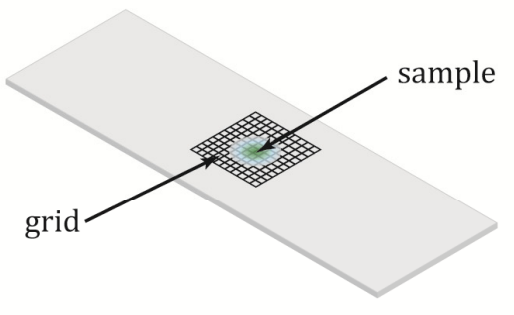

(III) PLACING ON GRIDDED MICROSCOPE SLIDE

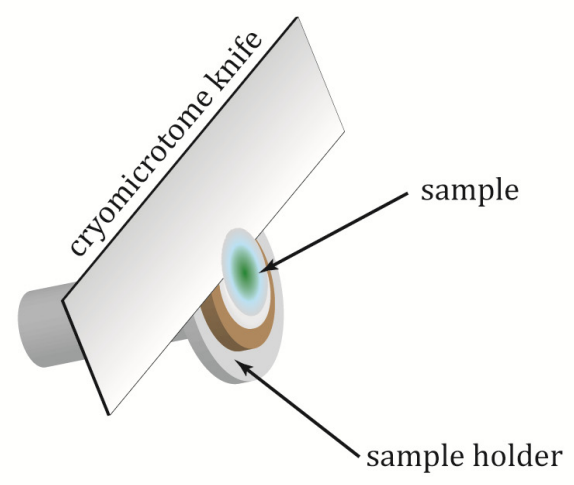

(II) CRYOSECTIONING $\left(-20^{\circ} \mathrm{C} ; 6-8 \mu \mathrm{m}\right)$

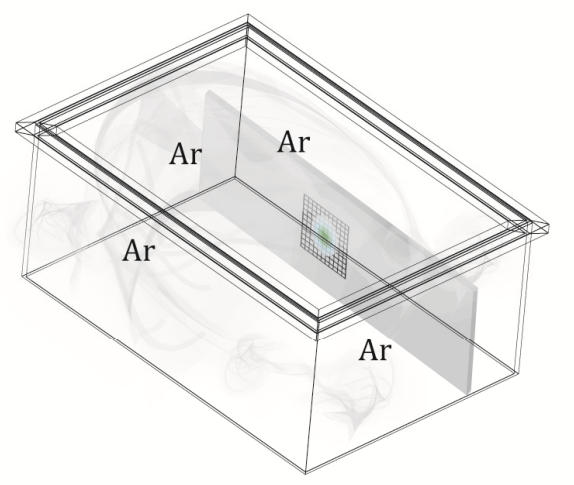

(IV) STORAGE IN CLOSED GLASS CONTAINER UNDER ARGON AT $-18^{\circ} \mathrm{C}$

Figure 1-2. Schematic illustration of the sample preparation protocol used for microbial mat samples in this thesis.

For mineralized geobiological samples, such as microbialites, sample sections with flat surfaces can be produced by the use of precision saws (Heim et al. 2012; Heindel et al., 2012). Due to the water used for cooling of the sawblade during sectioning, the sample surfaces are susceptible to contamination. Rougher but less contaminated surfaces, as compared to the sawed samples, may be generated by the use of microdrill cores, which are broken from the mineralized sample immediately before analysis in the ToF-SIMS instrument (Thiel et al., 2007a).

For keeping the surface to be analysed as free as possible of contaminations, solvent rinsing has to be applied to all tools coming in contact with the samples, e.g. sawblades or microtome knives, independently of the protocol used for sample preparation. 


\section{3. Äspö Hard Rock Laboratory}

The geobiological samples analyzed in this thesis were collected in the Äspö Hard Rock Laboratory (Äspö HRL), located at the coast of the Baltic Sea $20 \mathrm{~km}$ north of Oskarshamn, SE-Sweden. Beside several above-ground facilities, the Äspö HRL comprises a $3.6 \mathrm{~km}$ long research tunnel that extends down to a maximum depth of $450 \mathrm{~m}$ below sea level (bsl). The tunnel was excavated by the Swedish Nuclear Fuel and Waste Management Company (SKB) and serves as a study site for the long-term deposition of radioactive waste. It further provides convenient access to different subterranean ecosystems. Consequently, microbial life in the tunnel has been in the focus of intense geobiological research (Anderson et al., 2006; Anderson and Pedersen, 2003; Kotelnikova and Pedersen, 1998; Pedersen, 1997), e.g. in the context of potential corrosion of canisters enclosing the nuclear waste through acids produced by microorganisms (Pedersen, 1999).

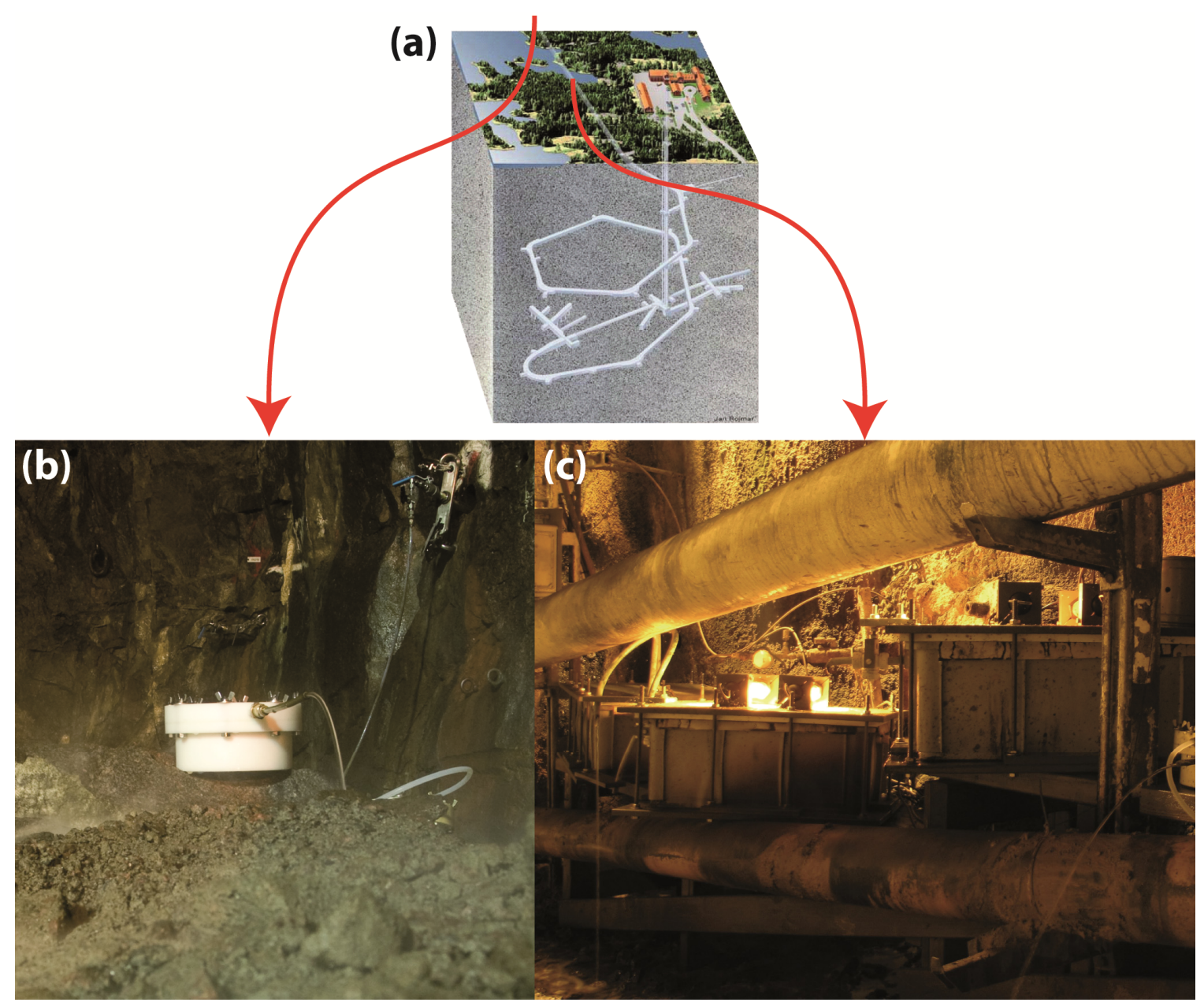

Figure 1-3. Flow reactors installed in Äspö HRL. (a) Sketch of Äspö HRL showing locations of flow reactors connected to fluid outflows (b) at $507 \mathrm{~m}$ (69 m bsl; dark and air tight) and (c) at $1327 \mathrm{~m}$ (183 m bsl, artificially illuminated and aerated) distance from the tunnel entrance. 
Within the frame of the DFG research unit 571 "Geobiology of organo- and biofilms", the microbial ecosystems of the Äspo tunnel have been further investigated through the installation of flow reactors at four different tapped fluid outflows from rock fractures in the tunnel walls (Heim, 2010). These flow reactors provide different environmental conditions (oxic/anoxic, light/dark) and serve for growing and collecting microorganisms of the pristine, subterranean biosphere. The samples analyzed in the frame of this thesis were obtained from two flow reactors installed at $507 \mathrm{~m}(69 \mathrm{~m} \mathrm{bsl})$ and $1327 \mathrm{~m}$ (183m bsl) distance from the tunnel entrance (Figure 1-3), respectively.

\subsection{ToF-SIMS as an new analytical approach for geobiological samples}

The imaging capability of ToF-SIMS may offer a new analytical approach for the direct study of organic ions in geobiological samples.

- Conventional biomarker analyses by liquid extraction-based techniques (GCMS, LC-MS) are well suited to characterize the biomarker content of bulk environmental samples, but the appendant extraction procedure destroys the physical integrity of the sample and the information on the localization of the biomarkers within the sample gets lost. When analyzing heterogeneous geobiological samples, e.g. mineralizing mats comprised of complex microbial consortia, the exact source of the biomarkers may thus remain unclear. In contrast to extraction-based techniques, ToF-SIMS can in theory provide molecular analysis at the microscopic level and may thus reveal the different microbial sources of biomarkers in environmental samples. Consequently, the limits of the latteral resolution of ToF-SIMS imaging have to be explored on environmental samples. Especially the applicability of ToF-SIMS for analyzing the biomarker content of individual microbial cells has to be tested.

However, the application of ToF-SIMS to complex environmental samples is currently hampered by certain drawbacks.

- Due to the ion formation processes, mass spectra obtained by SIMS are not necessarily simmilar to mass spectra obtained by other ionization techniques (Spool, 2004). The reliable detection of a particular compound in SIMS therefore requires a corresponding SIMS reference spectrum of the pure 
standard compound. However, only a limited number of such SIMS reference spectra for biogeochemically relevant compounds have been published as yet.

- In most ToF-SIMS systems recently used, the ion formation is not decoupled from the actual analysis. As a result all ion species produced in a ToF-SIMS experiment are summed in one complex SIMS spectrum, which confronts the analyst with a huge amount of spectral information, especially if it is obtained from a complex environmental samples. The interpretation of such spectra is further complicated by the fact that the sensitivity of the ToF-SIMS technique varies depending on the compound analyzed and the chemical matrix from which the ions are emitted. The analyst must therefore have an idea of which compounds are detectable in complex mixtures of organic compounds to avoid misinterpretations of SIMS spectra.

The analytical capabilities of ToF-SIMS and the appendant drawbacks in the application to environmental samples are addressed in this thesis.

\subsection{Introduction to the following chapters}

For extending the ToF-SIMS spectral library, reference spectra of relevant biogeochemical standard compounds are presented in chapter 2 and chapter 3 , and their direct detection in different environmental samples is demonstrated ("Spectral characterization of eight glycerolipids and their detection in natural samples using time-of-flight secondary ion mass spectrometry" and "Spectral characterization of ten cyclic lipids using time-of-flight secondary ion mass spectrometry").

With the knowledge gained in the standard measurements, a phototrophic microbial mat was analyzed in detail for its pigment and lipid content in chapter 4 ("Biomarker imaging of single diatom cells in a microbial mat using time-of-flight secondary ion mass spectrometry (ToF-SIMS)"). Taking advantage of the nondestructive nature of static ToF-SIMS, the section was imaged for fatty acids in burst alignment mode and subsequently analyzed by light microscopy to reveal sources of the fatty acids in the microbial mat. Thereby the limits of lateral resolution of the ToF-SIMS system were tested on an environmental sample, and the biomarker content of individual diatom cells was analyzed. 
The advantageous feature of static ToF-SIMS as a surface-sensitive technique capable of detecting smallest amounts of organic matter is used in chapter 5 ("An imaging mass spectrometry study on the formation of conditioning films and biofilms in the subsurface (Äspö Hard Rock Laboratory, SE Sweden)”) to study the formation and chemistry of thin conditioning films and biofilms forming on solid surfaces exposed to aquifer waters in Äspö HRL.

\section{References}

Anderson C. R., James R. E., Fru E. C., Kennedy C. B., Pedersen K. (2006) In situ ecological development of a bacteriogenic iron oxide-producing microbial community from a subsurface granitic rock environment. Geobiology 4, 29-42.

Anderson C. R., Pedersen K. (2003) In situ growth of Gallionella biofilms and partitioning of lanthanides and actinides between biological material and ferric oxyhydroxides. Geobiology 1, 169-178.

Belu A. M., Graham D. J., Castner D. G. (2003) Time-of-flight secondary ion mass spectrometry. Biomaterials 24, 3635-3653.

Benninghoven A. (1994) Chemical analysis of inorganic and organic surfaces and thin films by static time-of-flight secondary ion mass spectrometry (TOF-SIMS). Angewandte Chemie International Edition in English 33, 1023-1043.

Boxer S. G., Kraft M. L., Weber P. K. (2009) Advances in imaging secondary ion mass spectrometry for biological samples. Annual Review of Biophysics 38, 53-74.

Brocks J. J., Peason A. (2005) Building the biomarker tree of life. Reviews in Mineralogy and Geochemistry 59, 233-258.

Brunelle A., Laprévote 0. (2009) Lipid imaging with cluster time-of-flight secondary ion mass spectrometry. Analytical and Bioanalytical Chemistry 393, 31-35.

Colla T., Aderjan R., Kissel R., Urbassek H. (2000) Sputtering of Au (111) induced by 16-keV Au cluster bombardment: Spikes, craters, late emission, and fluctuations. Physical Review B 62, 8487-8493.

Fletcher J. S., Lockyer N. P., Vaidyanathan S., Vickerman J. C. (2007) TOF-SIMS 3D biomolecular imaging of Xenopus laevis oocytes using buckminsterfullerene (C-60) primary ions. Analytical Chemistry 79, 2199-2206.

Fletcher J. S., Vickerman J. C. (2013) Secondary ion mass spectrometry: characterizing complex samples in two and three dimensions. Analytical Chemistry. 85, 610-639.

Hagenhoff B. (2000) High resolution surface analysis by TOF-SIMS. Mikrochimica Acta 132, 259-271.

Heim C. (2010) An integrated approach to the study of biosignatures in mineralizing biofilms and microbial mats. doctoral thesis, University of Göttingen, http://resolver.sub.uni-goettingen.de/purl/?webdoc-2799. 
Heim C., Lausmaa J., Sjövall P., Toporski J., Dieing T., Simon K., Hansen B. T., Kronz A., Arp G., Reitner J., Thiel V. (2012) Ancient microbial activity recorded in fracture fillings from granitic rocks (Äspö Hard Rock Laboratory, Sweden). Geobiology 10, 280-297.

Heindel, K., Birgel, D., Brunner, B., Thiel, V., Westphal, H., Gischler, E., Ziegenbalg, S.B., Cabioch, G., Sjövall, P., Peckmann, J. (2012) Post-glacial microbialite formation in coral reefs of the Pacific, Atlantic, and Indian Oceans. Chemical Geology 304-305, 117-130.

Kollmer F. (2004) Cluster primary ion bombardment of organic materials. Applied Surface Science 231-232, 153-158.

Kotelnikova S., Pedersen K. (1998) Distribution and activity of methanogens and homoacetogens in deep granitic aquifers at Äspö Hard Rock Laboratory, Sweden. FEMS Microbiology Ecology 26, 121-134.

Lanekoff I., Kurczy M. E., Adams K. L., Malm J., Karlsson R., Sjövall P., Ewing A. G. (2011) An in situ fracture device to image lipids in single cells using ToF-SIMS. Surface and Interface Analysis 43, 257-260.

Lanekoff I., Kurczy M. E., Hill R., Fletcher J. S., Vickerman J. C., Winograd N., Sjövall P., Ewing A. G. (2010) Time of flight mass spectrometry imaging of samples fractured in situ with a spring-loaded trap system. Analytical Chemistry 82, 6652-6659.

Orphan V. J., House C. H. (2009) Geobiological investigations using secondary ion mass spectrometry. Geobiology 7, 360-372.

Passarelli M. K., Winograd N. (2011) Lipid imaging with time-of-flight secondary ion mass spectrometry (ToF-SIMS). Biochimica et Biophysica Acta (BBA) - Molecular and Cell Biology of Lipids 1811, 976-990.

Pedersen K. (1997) Microbial life in deep granitic rock. FEMS Microbiology Reviews 20, 399-414.

Pedersen K. (1999) Subterranean microorganisms and radioactive waste disposal in Sweden. Engineering Geology 52, 163-176.

Siljeström S., Hode T., Lausmaa J., Sjövall P., Toporski J., Thiel V. (2009) Detection of organic biomarkers in crude oils using ToF-SIMS. Organic Geochemistry 40, 135143.

Siljeström S., Lausmaa J., Sjövall P., Broman C., Thiel V., Hode T. (2010) Analysis of hopanes and steranes in single oil-bearing fluid inclusions using time-of-flight secondary ion mass spectrometry (ToF-SIMS). Geobiology 8, 37-44.

Sjövall P., Lausmaa J., Johansson B. (2004) Mass spectrometric imaging of lipids in brain tissue. Analytical Chemistry 76, 4271-4278.

Sjövall P., Lausmaa J., Nygren H., Carlsson L., Malmberg P. (2003) Imaging of membrane lipids in single cells by imprint-imaging time-of-flight secondary ion mass spectrometry. Analytical Chemistry 75, 3429-3434.

Sodhi R. N. S. (2004) Time-of-flight secondary ion mass spectrometry (TOF-SIMS). Analyst 129, 483-487.

Spool A. M. (2004) Interpretation of static secondary ion spectra. Surface and Interface Analysis 36, 264-274. 
Summons R., Albrecht P., McDonald G., Moldowan J. (2008) Molecular Biosignatures. Space Science Reviews 135, 133-159.

Sylvester P. J. (2006) Trends in analytical developments and earth science applications in LA-ICP-MS and LA-MC-ICP-MS for 2004 and 2005. Geostandards and Geoanalytical Research 30, 197-207.

Thiel V., Toporski J., Schumann G., Sjövall P., Lausmaa J. (2007a) Analysis of archaeal core ether lipids using Time of Flight-Secondary Ion Mass Spectrometry (ToF-SIMS). Geobiology 5, 75-83.

Thiel V., Heim C., Arp G., Hahmann U., Sjövall P., Lausmaa J. (2007b) Biomarkers at the microscopic range. Geobiology 5, 413-421.

Thiel V., Sjövall P. (2011) Using time-of-flight secondary ion mass spectrometry to study biomarkers. Annual Review of Earth and Planetary Sciences 39, 125-156.

Toporski J. K. W., Steele A., Westall F., Avci R., Martill D. M., McKay D. S. (2002) Morphologic and spectral investigation of exceptionally well-preserved bacterial biofilms from the Oligocene Enspel formation, Germany. Geochimica et Cosmochimica Acta 66, 1773-1791.

Touboul D., Kollmer F., Niehuis E., Brunelle A., Laprévote O. (2005) Improvement of biological time-of-flight-secondary ion mass spectrometry imaging with a bismuth cluster ion source. Journal of the American Society for Mass Spectrometry 16, 16081618.

Vickerman J. (2011) Molecular imaging, depth profiling by mass spectrometrySIMS, MALDI or DESI? Analyst 136, 2199-2217.

Vickerman J. C. (2001) ToF-SIMS. In ToF-SIMS (eds. J. C. Vickerman, D. Briggs). IM. Chichester, pp. 1-40.

Winograd N., Garrison B. J. (2010) Biological Cluster Mass Spectrometry. Annual Review of Physical Chemistry 61, 305-322. 
2.

\title{
Spectral characterization of eight glycerolipids and their detection in natural samples using time-of-flight secondary ion mass spectrometry
}

\author{
Christine Heim, Peter Sjövall, Jukka Lausmaa, Tim Leefmann, and Volker Thiel \\ Rapid Communications in Mass Spectrometry (2009), 23, 2741-2753 \\ DOI: 10.1002/rcm.4183; Reprinted with permission of John Wiley and Sons
}

\subsection{Abstract}

In recent years, time-of-flight secondary ion mass spectrometry (ToF-SIMS) with cluster ion sources has opened new perspectives for the analysis of lipid biomarkers in geobiology and organic geochemistry. However, published ToF-SIMS reference spectra of relevant compounds are still sparse, and the influence of the chemical environment (matrix) on the ionisation of molecules and their fragmentation is still not well explored. This study presents ToF-SIMS spectra of eight glycerolipids as common target compounds in biomarker studies, namely ester- and ether-bound phosphatidylethanolamine, ester- and ether-bound phosphatidylcholine, ester-bound phosphatidylglycerol, ester- and ether-bound diglycerides and archaeol, obtained with a $\mathrm{Bi}_{3}{ }^{+}$cluster ion source. For all of these compounds, the spectra obtained in positive and negative analytical modes showed characteristic fragments that could clearly be assigned to e.g. molecular ions, functional groups and alkyl chains. By comparison with the reference spectra, it was possible to track some of these lipids in a pre-characterised organic extract and in cryosections of microbial mats. The results highlight the potential of ToF-SIMS for the laterally resolved analysis of organic biomarkers in environmental materials. The identification of the target compounds, however, may be hampered by matrix effects (e.g. adduct formation) and often require careful consideration of all spectral features and taking advantage of the molecular imaging capability of ToF-SIMS. 


\subsection{Introduction}

Time-of-flight secondary ion mass spectrometry (ToF-SIMS) is a surface analysis technique that allows simultaneous analysis of inorganic and organic molecules on solid surfaces (Benninghoven, 1994; Pacholski and Winograd, 1999). During the last 10-20 years, ToF-SIMS has been used mainly in material sciences (Belu et al., 2003; Vickerman and Briggs, 2001). The introduction of polyatomic cluster ion sources (e.g. $\mathrm{Au}_{\mathrm{n}}{ }^{+}, \mathrm{Bi}_{\mathrm{n}}{ }^{+}, \mathrm{C}_{60^{+}}$) has expanded the capabilities of this technique, opening new possibilities for the analysis of biological materials (Kollmer, 2004; Ostrowski et al., 2004; Sjövall et al., 2004; Touboul et al., 2004; Touboul et al., 2005) and, consequently, the application of ToF-SIMS in geobiology and organic geochemistry (Siljeström et al., 2009; Sjövall et al., 2008; Thiel et al., 2007b). A most advantageous property of ToF-SIMS is its ability to record the intensities of any detected ion in a given area of interest at a microscopic scale (Hagenhoff, 2000). To date, this is not possible with any of the extract-based techniques routinely used in biomarker studies, namely GC/MS and LC/MS (coupled gas chromatography/mass spectrometry, coupled liquid chromatography/mass spectrometry). Whereas GC/MS and LC/MS are effective tools for the identification and quantification of organic compounds, it remains difficult to link the chemical information obtained to specific structures of interest in heterogeneous and structurally complex biological or geological materials. In ToF-SIMS, identification of organic compounds is achieved mainly through precise mass determination, sometimes corroborated by the analysis of the lateral distribution of the species of interest in selected areas on the sample surface. However, the absence or as yet sparse number of published ToFSIMS spectral fragmentation patterns may hamper an accurate structural assignment. Likewise, the influence of the chemical environment (matrix) on the ionisation of molecules and their fragmentation appears to be an important factor (Sostarecz et al., 2004), but is still not well explored.

Studies performed previously on reference compounds of widespread hydrocarbon biomarkers (Steele et al., 2001; Toporski et al., 2002; Toporski and Steele, 2004) showed that ToF-SIMS spectra may, or may not, differ considerably from those obtained with conventional mass spectrometric techniques (see also Vickerman and Briggs, 2001). By comparison with pure reference compounds, it was recently proven possible to detect hydrocarbon biomarkers, namely hopanes and 
steranes, in crude oils by ToF-SIMS (Siljeström et al., 2009). Recent studies on animal tissues, eukaryotic cells or microbial consortia also revealed the potential of ToF-SIMS with cluster ion sources for investigating the distribution of intact lipids in natural samples (Börner et al., 2007; Ostrowski et al., 2005; Ostrowski et al., 2004; Sjövall et al., 2004; Thiel et al., 2007b). Whereas these studies focused on materials with a more or less pre-characterised lipid content, the authors pointed out that the establishment of ToF-SIMS reference data is a major prerequisite for the investigation of organic molecules in barely studied or unknown environmental materials.

This study presents previously unpublished ToF-SIMS spectra of eight functionalised glycerolipids as important members of cell membrane constituents of eukaryotes, bacteria, and archaea. These lipids, or their derivatives, are commonly used as biomarkers in geo- and microbiology, organic geochemistry, and microbial ecology (Börner et al., 2007; Ostrowski et al., 2005; Ostrowski et al., 2004; Sjövall et al., 2004; Thiel et al., 2007b). Our work aims to provide basic information about the ToF-SIMS fragmentation patterns of these compounds in both, positive and negative ion modes. In addition to 'conventional' esterbound glycerolipids, we also included a number of etherbound counterparts, as such compounds may reveal important information on the protagonists in some microbially driven ecosystems (Pancost et al., 2001). Emphasis was placed not only on high (molecular) mass species, but also on characteristic fragments that may enable a robust identification of the respective molecule, or the compound class, in a natural sample. However, detectability of a pure reference substance does not necessarily imply that the compound can be easily identified by the same features when analysed in a complex chemical matrix. To assess the possibility of detecting such lipids in natural samples and the influence of matrix effects, ToF-SIMS spectra of selected glycerolipids (archaeol, phosphoglycerol, diglyceride) were therefore compared with those recorded from the same, or related, compounds in an organic extract and in cryosections of microbial mats. 


\subsection{Experimental}

Eight commercially available glycerolipids (Avanti Lipids, Sigma, Chiron) were selected for analysis, namely; (i) L- $\alpha$-phosphatidylethanolamine (GPEtn), (ii) 1,2 di$O$-hexadecyl-sn-glycero-3-phosphatidylethanolamine (Diether-GPEtn), (iii) L- $\alpha$ phosphatidylcholine (GPCho), (iv) 1,2-di-O-dialkyl-sn-glycerol-3phosphatidylcholine (Diether-GPCho), (v) L- $\alpha$-phosphatidylglycerol (GPGro), (vi) 1palmitoyl-2-oleoyl-sn-glycerol (DG), (vii) 1,2-di-O-hexadecyl-rac-glycerol (DietherDG), and (vii) 1,2-di-O-phytanyl-sn-glycerol (archaeol), see Table 2-1.

All reference lipids were stored cold and dark in glass vials with Teflon septa before, and between, analyses. Each reference lipid (1 mg) was dissolved in $1 \mathrm{~mL}$ pre-distilled solvents (dichloromethane, n-hexane). For ToF-SIMS analysis, the compounds were deposited on silicon wafers. The wafers were rinsed with deionised water and cleaned in a UV ozone apparatus prior to use in order to remove any organic contaminants from the surface. Using a glass pipette, a few $\mathrm{mL}$ of each lipid solution (except for GPCho, see below) were placed on a silicon wafer and the organic solvent was allowed to evaporate. The deposition processes were carried out in a laminar air flow cabinet in order to avoid airborne particulate contamination. The GPCho sample was prepared as a supported lipid bilayer, according to Prinz et al., 2007. As controls, blank silicon wafers were exposed to the same conditions during sample preparation, and analysed in parallel. To assess the presence of contaminants, ToF-SIMS spectra were also obtained from the evaporation residues of the pure solvents. These spectra were used as internal controls for a clean sample processing and are not shown here. Typically, sets of six samples were mounted on a sample holder and introduced into the vacuum chamber of the ToF-SIMS instrument immediately after preparation.

A sample of an iron-oxidising microbial mat dominated by Gallionella ferruginea (Pedersen, 1997) was obtained from a subterranean fluid discharge at $150 \mathrm{~m}$ depth in the Äspö Tunnel, SE Sweden. The mats were stored at $-20^{\circ} \mathrm{C}$ prior to analysis.

A sample of a methanotrophic microbial mat was retrieved from the GHOSTDABS methane seep field on the NW' Black Sea shelf from a water depth of $230 \mathrm{~m}$ (joint project BEBOP, see Acknowledgements). These microbial mats have been studied in detail for their lipid biomarker patterns (Blumenberg et al., 2004; Michaelis et al., 2002; Pape et al., 2005; Thiel et al., 2007b). 
Table 2-1. Glycerolipids studied and ions observed in the molecular weight range.

\begin{tabular}{|c|c|c|c|c|c|c|c|c|}
\hline Compound & Abbreviation & Formula & $\begin{array}{l}\text { Exact } \\
\text { mass }\end{array}$ & $\begin{array}{c}\text { Observed } \\
{[\mathrm{M}+\mathrm{H}]^{+}}\end{array}$ & $\begin{array}{c}\text { Observed } \\
{[\mathrm{M}+\mathrm{Na}]^{+}}\end{array}$ & $\begin{array}{l}\text { Observed } \\
{\left[\mathrm{M}^{-\mathrm{H}}\right]^{-}}\end{array}$ & & Others \\
\hline L- $\alpha$-Phosphatidylethanolamine & GPEtn (16:0/18:2) & $\mathrm{C}_{39} \mathrm{H}_{74} \mathrm{NO}_{8} \mathrm{P}$ & 715.52 & 716.53 & 738.53 & 714.52 & 697.51 & {$\left[\mathrm{M}-\mathrm{NH}_{3}\right]^{-}$} \\
\hline L- $\alpha$-Phosphatidylethanolamine & GPEtn (18:2/18:2) & $\mathrm{C}_{41} \mathrm{H}_{74} \mathrm{NO}_{8} \mathrm{P}$ & 739.52 & 740.55 & 762.54 & 738.52 & - & - \\
\hline $\begin{array}{l}\text { 1,2-Di- } O \text {-Hexadecyl-rac- } \\
\text { phosphatidylethanolamine }\end{array}$ & Diether-GPEtn & $\mathrm{C}_{37} \mathrm{H}_{78} \mathrm{NO}_{6} \mathrm{P}$ & 663.56 & 664.65 & - & 662.49 & 624.67 & {$\left[\mathrm{M}+\mathrm{Na}-\mathrm{C}_{2} \mathrm{H}_{8} \mathrm{NO}\right]^{-}$} \\
\hline L- $\alpha$-Phosphatidylcholine & GPCho & $\mathrm{C}_{42} \mathrm{H}_{82} \mathrm{NO}_{8} \mathrm{P}$ & 759.58 & 760.61 & 782.61 & - & $\begin{array}{l}744.54 \\
699.47 \\
\end{array}$ & $\begin{array}{l}\left.\mathrm{M}-\mathrm{CH}_{3}\right]^{-} \\
{\left[\mathrm{M}-\mathrm{C}_{3} \mathrm{H}_{9} \mathrm{~N}\right]^{-}}\end{array}$ \\
\hline $\begin{array}{l}\text { 1,2-O-Dialkyl-sn-Glycero-3- } \\
\text { Phosphoatidylcholine }\end{array}$ & Diether-GPCho & $\mathrm{C}_{40} \mathrm{H}_{85} \mathrm{NO}_{6} \mathrm{P}$ & 705.60 & 706.75 & - & 704.57 & $\begin{array}{l}690.54 \\
645.47\end{array}$ & $\begin{array}{l}{\left[\mathrm{M}-\mathrm{CH}_{3}\right]^{-}} \\
{\left[\mathrm{M}-\mathrm{C}_{3} \mathrm{H}_{9} \mathrm{~N}\right]^{-}}\end{array}$ \\
\hline L- $\alpha$-Phosphatidylglycerol (sodium salt) & GPGro & $\mathrm{C}_{38} \mathrm{H}_{74} \mathrm{O}_{10} \mathrm{PNa}$ & 744.49 & - & 767.51 & 721.58 & 721.58 & {$[\mathrm{M}-\mathrm{Na}]^{-}$} \\
\hline 1-Palmitoyl-2-Oleoyl-sn-glycerol & DG & $\mathrm{C}_{37} \mathrm{H}_{70} \mathrm{O}_{5}$ & 594.52 & 595.58 & 617.53 & 593.49 & 577.52 & {$\left[\mathrm{M}-\mathrm{H}_{2} \mathrm{O}\right]^{+}$} \\
\hline 1,2 Di-O-Hexadecyl-rac-glycerol & Diether-DG & $\mathrm{C}_{35} \mathrm{H}_{72} \mathrm{O}_{3}$ & 540.55 & 541.63 & 563.58 & 539.54 & 522.59 & {$\left[\mathrm{M}-\mathrm{H}_{2} \mathrm{O}\right]^{+}$} \\
\hline 1,2-Di-O-Phytanyl-sn-glycerol & Archaeol & $\mathrm{C}_{43} \mathrm{H}_{88} \mathrm{O}_{3}$ & 652.67 & 653.72 & 675.68 & 651.66 & 634.69 & {$\left[\mathrm{M}-\mathrm{H}_{2} \mathrm{O}\right]^{+}$} \\
\hline
\end{tabular}


An organic extract of the Black Sea microbial mat was prepared as it would be typically done for LC/MS and GC/MS analyses. An aliquot of each mat (10 mg) was extracted with $15 \mathrm{~mL}$ of dichloromethane/methanol $(3: 1,1: 1,1: 3)$ in a Tefloncapped glass vial (ultrasonication, $20 \mathrm{~min}$ ). After evaporation of the solvent mixture and re-dissolution in pure dichloromethane, the extracts were deposited on silicon wafers and were transferred to the ToF-SIMS instrument as described above.

For the preparation of the cryosections, the Black Sea and the Gallionella microbial mats were allowed to thaw at room temperature, and a small amount (approx. $10 \mathrm{~mm}^{3}$ ) of each mat sample was mounted on a cork sample holder using an embedding agent (Cryo-Gel ${ }^{\circledR}$, Electron Microscopy Sciences, PA, USA). The samples were frozen for $30 \mathrm{~s}$ in cold methyl butane at $-150^{\circ} \mathrm{C}$ and immediately transferred into the cryochamber of a Leica CM 3050 S cryomicrotome (Leica Microsystems, Wetzlar, Germany) that had been pre-cooled to $-20^{\circ} \mathrm{C}$. Using a standard steel knife (Leica Profile D), serial sections of ca. $8 \mathrm{~mm}$ thickness were cut, deposited on standard microscope slides $(76 \times 26 \mathrm{~mm})$, and stored at $-20^{\circ} \mathrm{C}$ in closed glass containers until analysis. Prior to transfer into the ToF-SIMS instrument, the slides were allowed to approach room temperature with the glass container kept closed, in order to avoid condensation of water vapor on the sample.

All glassware (microscope slides, pipettes, vials, beakers, glass containers) was heated to $400^{\circ} \mathrm{C}$ for $2 \mathrm{~h}$ prior to use, and/or cleaned by thoroughly rinsing with deionised water and acetone. Solvent rinsing was also used to clean all steelware (spatula, tweezers, microtome knives) prior to use.

ToF-SIMS images and spectra of positive and negative ions were recorded using a ToF-SIMS IV instrument (ION-TOF GmbH, Münster, Germany) equipped with a liquid bismuth cluster ion source. Data were acquired in bunched mode with a mass resolution of ca. $M / \Delta M 5000$, using $25 \mathrm{keV} \mathrm{Bi}_{3}{ }^{+}$primary ions at a pulsed current of $0.1 \mathrm{pA}$. Low-energy electron flooding was used for charge compensation, when necessary. The analysed areas were $100 \times 100 \mathrm{~mm}^{2}$ or $200 \times 200 \mathrm{~mm}^{2}$ for references and extracts, and $500 \times 500 \mathrm{~mm}^{2}$ for the microbial mat cryosections. The areas were scanned in a raster pattern at $128 \times 128$ pixels for reference lipids and extracts, and $256 \times 256$ pixels for the cryosections. The acquisition times were typically between $50 \mathrm{~s}$ and $100 \mathrm{~s}$ for the pure lipid reference samples and the extracts, and $300 \mathrm{~s}$ to $500 \mathrm{~s}$ for the cryosections. All analyses were thus done under so-called static SIMS 
condition, i.e. with primary ion doses well below those where significant surface damage due to the ion bombardment starts to appear (Sjövall et al., 2008).

\subsection{Results and discussion}

Through comparison of the spectra from the different lipids, it was possible to determine characteristic peaks and fragmentation schemes for the respective lipid classes. In the low-mass range, fragments specifying phospholipids in general were $m / z 78.95\left[\mathrm{PO}_{3}\right]^{-}$and $96.97\left[\mathrm{H}_{2} \mathrm{PO}_{4}\right]^{-}$, as previously reported (e.g. Ostrowski et al., 2005; Sjövall et al., 2004). In addition, other distinctive headgroup fragments are present in the spectra of particular phospholipid classes. Such fragments where reproducibly detected in both ester- and ether-bound phospholipids and are listed in Table 2-2. Fragmentation of ester-bound lipids leads to prominent peaks of the corresponding fatty acid chains whereas the ether-bound lipids exhibited weak fragment ion peaks of the alcohol side chains (Table 2-2). In general, the fragmentation tendency of ether lipids is considerably lower compared to esterbound lipids, probably due to the higher chemical stability of the ether link.

\subsubsection{Phosphatidylethanolamine (GPEtn)}

$\mathrm{C}_{39} \mathrm{H}_{74} \mathrm{NO}_{8} \mathrm{P}$; exact mass $715.52 \mathrm{Da}$; source: eukaryotes (Ostrowski et al., 2005; Ostrowski et al., 2004), bacteria (Mazzella et al., 2005)

Molecular ions are detected at $m / z 716.53$ and 740.55 in the positive spectrum. Whereas the former is in accordance with the $[\mathrm{M}+\mathrm{H}]^{+}$ion of the actual GPEtn molecule containing one $\mathrm{C}_{16: 0}$ and one $\mathrm{C}_{18: 2}$ moiety $\left(\mathrm{C}_{16: 0} / \mathrm{C}_{18: 2}\right)$, the latter seems to originate from GPEtn that carries two $\mathrm{C}_{18: 2}$ chains $\left(\mathrm{C}_{18: 2} / \mathrm{C}_{18: 2}\right)$. The observed distribution is in good agreement with the product specification from the distributor $\left(\mathrm{C}_{16: 0}=24 \%, \mathrm{C}_{18: 2}=60 \%\right)$. Both molecular ions produce sodium adducts $[\mathrm{M}+\mathrm{Na}]^{+}$at $m / z 738.53$ and 762.54, respectively. Characteristic fragments in positive mode are observed at $m / z 575.49$ [M-headgroup] $^{+}, 306.29$ and 282.28 (Table 2-1) and are interpreted to result from cleavage within the glycerol backbone (see fragmentation scheme, Figure 2-1 and Table 2-2). Specific headgroup fragments are observed at $m / z 142.03$ and 182.06 corresponding to $\left[\mathrm{C}_{2} \mathrm{H}_{9} \mathrm{NO}_{4} \mathrm{P}\right]^{+}$and $\left[\mathrm{C}_{5} \mathrm{H}_{13} \mathrm{NO}_{4} \mathrm{P}\right]^{+}$. 
Table 2-2. Characteristic fragments and headgroup ions.

\begin{tabular}{|c|c|c|c|c|c|c|c|c|c|}
\hline Abbreviation & Formula & $\begin{array}{l}\text { Characteristic } \\
\text { fragment ions } \\
\text { (+) observed* }\end{array}$ & $\begin{array}{l}\text { Tentative } \\
\text { formula }\end{array}$ & $\begin{array}{l}\text { Characteristic } \\
\text { fragment ions } \\
\text { (-) observed* }\end{array}$ & $\begin{array}{l}\text { Tentative } \\
\text { formula }\end{array}$ & $\begin{array}{l}\text { Headgroup } \\
\text { ions }(+) \\
\text { observed }^{*} \\
\end{array}$ & Formula & $\begin{array}{l}\text { Headgroup } \\
\text { ions }(-) \\
\text { observed }^{*}\end{array}$ & Formula \\
\hline $\begin{array}{c}\text { GPEtn } \\
\left(\mathrm{C}_{16: 0 / 18: 2}\right)\end{array}$ & $\mathrm{C}_{39} \mathrm{H}_{74} \mathrm{NO}_{8} \mathrm{P}$ & $\begin{array}{l}575.49 \\
282.28 \\
\end{array}$ & $\begin{array}{l}\mathrm{C}_{37} \mathrm{H}_{67} \mathrm{O}_{4}^{+} \\
\mathrm{C}_{18} \mathrm{H}_{34} \mathrm{O}_{2}{ }^{+}\end{array}$ & $\begin{array}{l}279.25 \\
255.24 \\
\end{array}$ & $\begin{array}{l}\mathrm{C}_{18} \mathrm{H}_{31} \mathrm{O}_{2}^{-} \\
\mathrm{C}_{16} \mathrm{H}_{31} \mathrm{O}_{2}^{-} \\
\end{array}$ & $\begin{array}{l}142.03 \\
182.06 \\
\end{array}$ & $\begin{array}{c}\mathrm{C}_{2} \mathrm{H}_{9} \mathrm{NO}_{4} \mathrm{P}^{+} \\
\mathrm{C}_{5} \mathrm{H}_{13} \mathrm{NO}_{4} \mathrm{P}^{+} \\
\end{array}$ & $\begin{array}{l}140.02 \\
180.04 \\
\end{array}$ & $\begin{array}{l}\mathrm{C}_{2} \mathrm{H}_{7} \mathrm{NO}_{4} \mathrm{P}^{-} \\
\mathrm{C}_{5} \mathrm{H}_{11} \mathrm{NO}_{4} \mathrm{P}^{-}\end{array}$ \\
\hline $\begin{array}{c}\text { GPEtn } \\
\left(\mathrm{C}_{18: 2 / 18: 2}\right)\end{array}$ & $\mathrm{C}_{41} \mathrm{H}_{74} \mathrm{NO}_{8} \mathrm{P}$ & $\begin{array}{l}599.50 \\
306.29 \\
\end{array}$ & $\begin{array}{l}\mathrm{C}_{39} \mathrm{H}_{67} \mathrm{O}_{4}{ }^{+} \\
\mathrm{C}_{20} \mathrm{H}_{34} \mathrm{O}_{2}{ }^{+}\end{array}$ & 279.25 & $\mathrm{C}_{18} \mathrm{H}_{31} \mathrm{O}_{2}$ & $\begin{array}{l}142.03 \\
182.06 \\
\end{array}$ & $\begin{array}{c}\mathrm{C}_{2} \mathrm{H}_{9} \mathrm{NO}_{4} \mathrm{P}^{+} \\
\mathrm{C}_{5} \mathrm{H}_{13} \mathrm{NO}_{4} \mathrm{P}^{+}\end{array}$ & $\begin{array}{l}140.02 \\
180.04 \\
\end{array}$ & $\begin{array}{l}\mathrm{C}_{2} \mathrm{H}_{7} \mathrm{NO}_{4} \mathrm{P}^{-} \\
\mathrm{C}_{5} \mathrm{H}_{11} \mathrm{NO}_{4} \mathrm{P}^{-} \\
\end{array}$ \\
\hline Diether-GPEtn & $\mathrm{C}_{37} \mathrm{H}_{78} \mathrm{NO}_{6} \mathrm{P}$ & ?? & $? ?$ & 239.21 & $\mathrm{C}_{16} \mathrm{H}_{31} \mathrm{O}^{-}$ & - & - & $\begin{array}{l}180.04 \\
140.01 \\
\end{array}$ & $\begin{array}{l}\mathrm{C}_{2} \mathrm{H}_{7} \mathrm{NO}_{4} \mathrm{P}^{-} \\
\mathrm{C}_{5} \mathrm{H}_{11} \mathrm{NO}_{4} \mathrm{P}^{-} \\
\end{array}$ \\
\hline GPCho & $\mathrm{C}_{42} \mathrm{H}_{82} \mathrm{NO}_{8} \mathrm{P}$ & $\begin{array}{l}504.38 \\
478.37 \\
\end{array}$ & $\begin{array}{l}\mathrm{C}_{26} \mathrm{H}_{51} \mathrm{NO}_{6} \mathrm{P}^{+} \\
\mathrm{C}_{24} \mathrm{H}_{49} \mathrm{NO}_{6} \mathrm{P}^{+}\end{array}$ & $\begin{array}{l}281.24 \\
255.23 \\
\end{array}$ & $\begin{array}{l}\mathrm{C}_{18} \mathrm{H}_{33} \mathrm{O}_{2}^{-} \\
\mathrm{C}_{16} \mathrm{H}_{31} \mathrm{O}_{2}^{-}\end{array}$ & $\begin{array}{l}184.10 \\
166.08 \\
\end{array}$ & $\begin{array}{l}\mathrm{C}_{5} \mathrm{H}_{15} \mathrm{NO}_{4} \mathrm{P}^{+} \\
\mathrm{C}_{5} \mathrm{H}_{13} \mathrm{NO}_{3} \mathrm{P}^{+}\end{array}$ & - & - \\
\hline Diether-GPCho & $\mathrm{C}_{40} \mathrm{H}_{85} \mathrm{NO}_{6} \mathrm{P}$ & $\begin{array}{l}464.44 \\
450.41 \\
\end{array}$ & $\begin{array}{l}\mathrm{C}_{24} \mathrm{H}_{51} \mathrm{NO}_{5} \mathrm{P}^{+} \\
\mathrm{C}_{23} \mathrm{H}_{49} \mathrm{NO}_{5} \mathrm{P}^{+}\end{array}$ & 239.21 & $\mathrm{C}_{16} \mathrm{H}_{31} \mathrm{O}^{-}$ & 184.11 & $\mathrm{C}_{5} \mathrm{H}_{15} \mathrm{NO}_{4} \mathrm{P}^{+}$ & - & - \\
\hline GPGro & $\mathrm{C}_{38} \mathrm{H}_{74} \mathrm{O}_{10} \mathrm{PNa}$ & $\begin{array}{l}551.52 \\
511.28\end{array}$ & $\begin{array}{c}\mathrm{C}_{35} \mathrm{H}_{67} \mathrm{O}_{4}{ }^{+} \\
\mathrm{C}_{22} \mathrm{H}_{42} \mathrm{Na}_{2} \mathrm{O}_{8} \mathrm{P}^{+}\end{array}$ & 255.24 & $\mathrm{C}_{16} \mathrm{H}_{31} \mathrm{O}_{2}^{-}$ & 198.99 & $\mathrm{C}_{3} \mathrm{H}_{6} \mathrm{Na}_{2} \mathrm{O}_{5} \mathrm{P}^{+}$ & $\begin{array}{l}171.04 \\
211.06 \\
153.02 \\
\end{array}$ & $\begin{array}{c}\mathrm{C}_{3} \mathrm{H}_{8} \mathrm{O}_{6} \mathrm{P}^{-} \\
\mathrm{C}_{6} \mathrm{H}_{12} \mathrm{O}_{6} \mathrm{P}^{-} \\
\mathrm{C}_{3} \mathrm{H}_{6} \mathrm{O}_{5} \mathrm{P} \\
\end{array}$ \\
\hline DG & $\mathrm{C}_{37} \mathrm{H}_{70} \mathrm{O}_{5}$ & $\begin{array}{l}339.31 \\
313.28 \\
265.26 \\
239.24 \\
\end{array}$ & $\begin{array}{l}\mathrm{C}_{21} \mathrm{H}_{39} \mathrm{O}_{3}{ }^{+} \\
\mathrm{C}_{19} \mathrm{H}_{37} \mathrm{O}_{3}{ }^{+} \\
\mathrm{C}_{18} \mathrm{H}_{33} \mathrm{O}^{+} \\
\mathrm{C}_{16} \mathrm{H}_{31} \mathrm{O}^{+} \\
\end{array}$ & $\begin{array}{l}281.24 \\
255.23\end{array}$ & $\begin{array}{l}\mathrm{C}_{18} \mathrm{H}_{33} \mathrm{O}_{2-}^{-} \\
\mathrm{C}_{16} \mathrm{H}_{31} \mathrm{O}_{2}^{-}\end{array}$ & - & - & 91.04 & $\mathrm{C}_{3} \mathrm{H}_{7} \mathrm{O}_{3}^{-}$ \\
\hline Diether-DG & $\mathrm{C}_{35} \mathrm{H}_{72} \mathrm{O}_{3}$ & $\begin{array}{l}297.32 \\
299.33 \\
253.27 \\
\end{array}$ & $\begin{array}{l}\mathrm{C}_{19} \mathrm{H}_{37} \mathrm{O}_{2}{ }^{+} \\
\mathrm{C}_{19} \mathrm{H}_{39} \mathrm{O}_{2}{ }^{+} \\
\mathrm{C}_{17} \mathrm{H}_{33} \mathrm{O}^{+} \\
\end{array}$ & $\begin{array}{l}241.23 \\
239.19\end{array}$ & $\begin{array}{l}\mathrm{C}_{16} \mathrm{H}_{33} \mathrm{O}^{-} \\
\mathrm{C}_{16} \mathrm{H}_{31} \mathrm{O}^{-}\end{array}$ & - & - & 91.02 & $\mathrm{C}_{3} \mathrm{H}_{7} \mathrm{O}_{3}-$ \\
\hline Archaeol & $\mathrm{C}_{43} \mathrm{H}_{88} \mathrm{O}_{3}$ & $\begin{array}{l}373.39 \\
371.27\end{array}$ & $\begin{array}{l}\mathrm{C}_{23} \mathrm{H}_{49} \mathrm{O}_{3}{ }^{+} \\
\mathrm{C}_{23} \mathrm{H}_{47} \mathrm{O}_{3}{ }^{+}\end{array}$ & $\begin{array}{l}371.37 \\
297.32 \\
295.29 \\
\end{array}$ & $\begin{array}{l}\mathrm{C}_{23} \mathrm{H}_{47} \mathrm{O}_{3}^{-} \\
\mathrm{C}_{20} \mathrm{H}_{41} \mathrm{O}^{-} \\
\mathrm{C}_{20} \mathrm{H}_{41} \mathrm{O}^{-} \\
\end{array}$ & - & - & 91.03 & $\mathrm{C}_{3} \mathrm{H}_{7} \mathrm{O}_{3}^{-}$ \\
\hline
\end{tabular}

*: Ostrowski et al. (2005) described further, yet unknown negative ions at $m / z$ 137, 153 and 181 as common phospholipid fragments. These findings were partly confirmed in our study. Both fragments at $m / z 137.01$ and 153.02 where found in the ester bound phospholipids, whereas the ether-bound phospholipids yielded $m / z$ 137.01. An ion at $m / z 181$ was not observed in our spectra. Further positive ions described by Ostrowski et al. (2005), at $m / z 125,143$, and 165 were exclusively observed in the spectrum of GPGro (Na salt) and may represent Na containing fragments. 

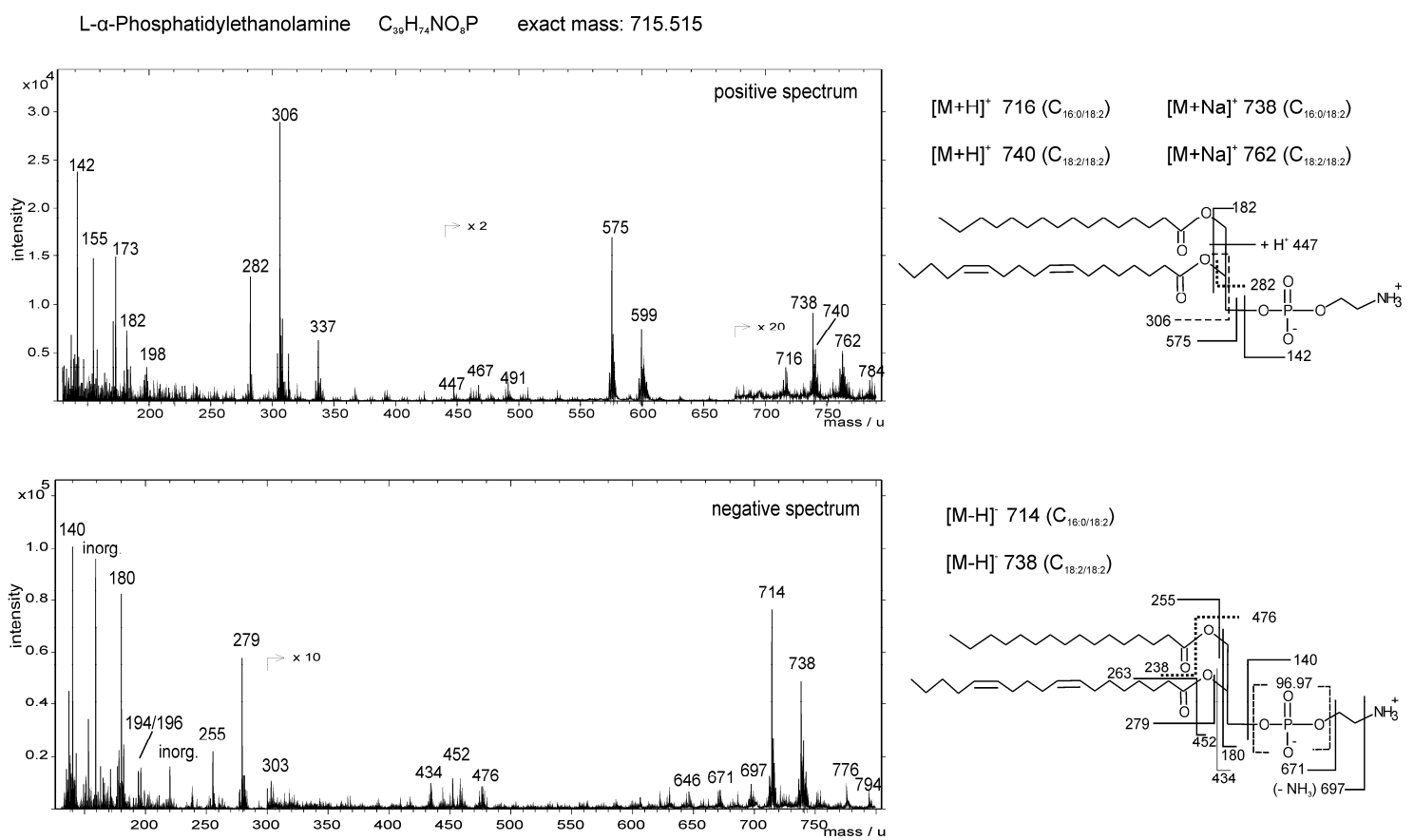

Figure 2-1. Partial positive (top) and negative (bottom) ToF-SIMS spectra (m/z 140-800) of phosphatidylethanolamine (GPEtn). This reference standard mainly contains GPEtn carrying two $\mathrm{C}_{18: 2}$ or each one $C_{16: 0}$ and $C_{18: 2}$ fatty acid chains $\left(C_{16: 0}=24 \% ; C_{18: 2}=60 \%\right.$ of the total fatty acids). See text for a detailed discussion of the spectral patterns. The prominent phosphate peak at $\mathrm{m} / \mathrm{z} 96.97$ is out of the displayed range. Peaks labeled with 'inorg' are inorganic ions and do not belong to the compound spectrum.

In negative mode, deprotonated molecular ions [M-H] ${ }^{-}$occur at $m / z 714.55$ $\left(\mathrm{C}_{16: 0} / \mathrm{C}_{18: 2}\right)$ and $738.55\left(\mathrm{C}_{18: 2} / \mathrm{C}_{18: 2}\right)$. Ions at $\mathrm{m} / z 697.51$ and 671.48 are interpreted as $\left[\mathrm{M}-\mathrm{NH}_{3}\right]^{-}$and $\left[\mathrm{M}-\mathrm{C}_{2} \mathrm{H}_{7} \mathrm{~N}\right]^{-}$. Prominent peaks at $m / z 96.97\left[\mathrm{H}_{2} \mathrm{PO}_{4}\right]^{-}$and 78.96 $\left[\mathrm{PO}_{3}\right]^{-}$(not shown) and at $\mathrm{m} / z 140.02$ clearly specify the phosphate-bearing headgroup, as observed in previous studies (Börner et al., 2007; Ostrowski et al., 2005). Fragments at $m / z 279.25\left(\mathrm{C}_{18: 2}\right)$ and $255.24\left(\mathrm{C}_{16: 0}\right)$ can be assigned to fatty acid chains (according to Börner et al., 2007), whereas fragments at $m / z 476.29$, 452.29 and 434.28 putatively derive from the PE molecule after loss of the fatty acid chains as indicated in Figure 2-1.

\subsubsection{1,2-Di-O-hexadecyl-sn-glycero-3-phosphatidylethanolamine (Diether- GPEtn) \\ $\mathrm{C}_{37} \mathrm{H}_{78} \mathrm{NO}_{6} \mathrm{P}$; exact mass $663.56 \mathrm{Da}$; source: bacteria (Rütters et al., 2001)}

The positive mass spectrum observed for Diether-GPEtn reveals a weak protonated molecular ion $[\mathrm{M}+\mathrm{H}]^{+}$at $m / z 664.65$ (Figure 2-2). A single, most prominent and 
possibly diagnostic peak occurs at $m / z$ 624.67. It is tentatively interpreted as a fragment ion resulting from loss of the ethanolamine group and adduction of $\mathrm{Na}$ [M$\left.\mathrm{C}_{2} \mathrm{H}_{7} \mathrm{NO}+\mathrm{Na}\right]^{+}$(Figure 2-2). Another, less abundant sodium adduct of a fragment ion may occur at $m / z 654.68\left[\mathrm{M}-\mathrm{CH}_{6} \mathrm{~N}+\mathrm{Na}\right]^{+}$.

The negative spectrum shows a clear deprotonated molecular ion $[\mathrm{M}-\mathrm{H}]^{-}$at $m / z$ 662.49. In addition, minor fragments at $m / z 645.47$ and 619.46 can be interpreted as $\left[\mathrm{M}-\mathrm{NH}_{3}\right]^{-}$and $\left[\mathrm{M}-\mathrm{C}_{2} \mathrm{H}_{7} \mathrm{~N}\right]^{-}$, respectively. It is interesting to see that in both positive and negative mode, peaks expected from lyso-fragments or aliphatic side chains (around $m / z$ 224) are weak or even missing. Likewise, headgroup fragments of Diether-GPEtn are only observed in the negative spectrum (Figure 2-2, Table 2-1).

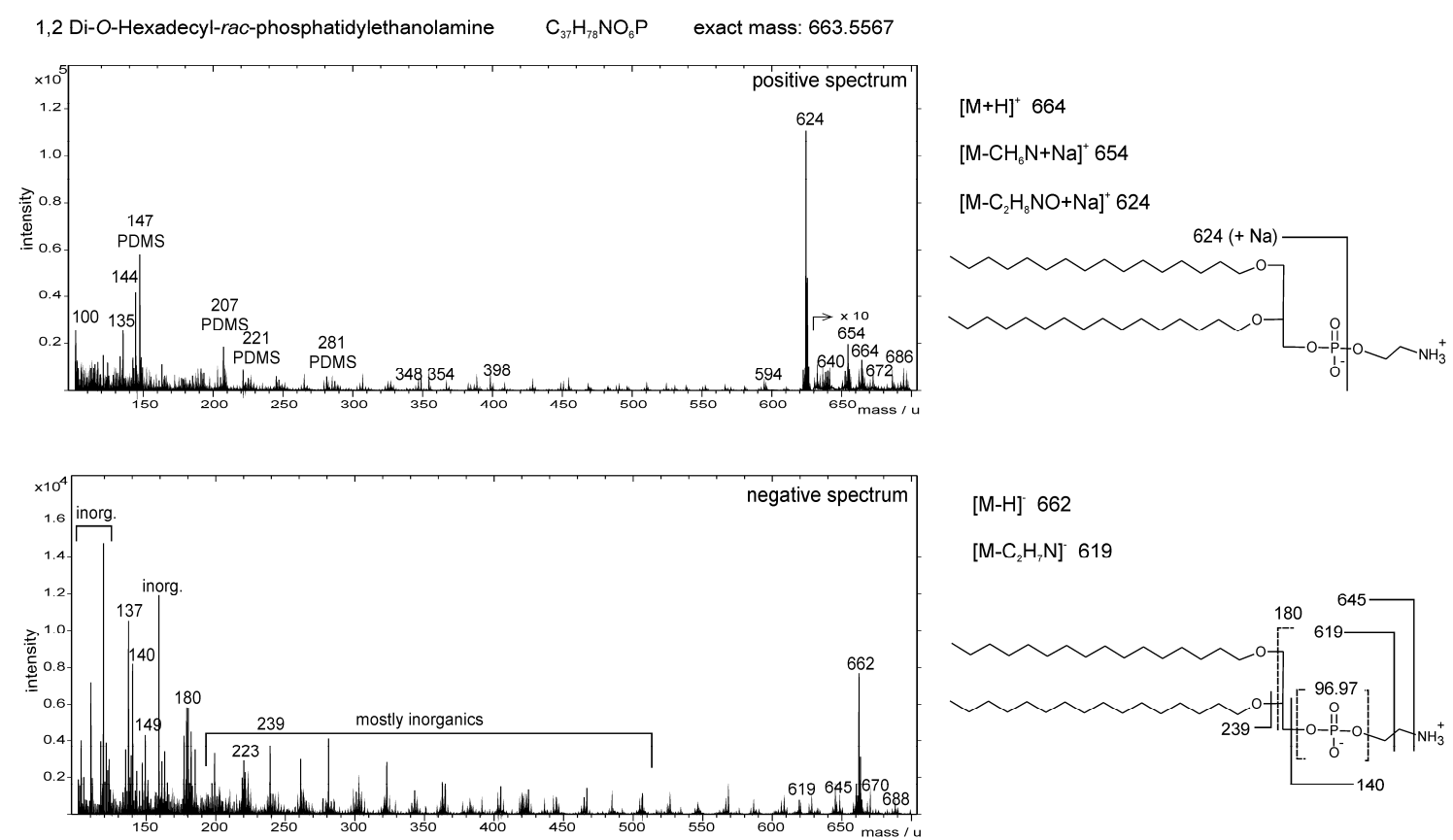

Figure 2-2. Partial positive (top) and negative (bottom) ToF-SIMS spectra ( $\mathrm{m} / \mathrm{z} 100-700)$ of 1,2 -di- $O$ hexadecyl-sn-glycero-3-phosphatidylethanolamine (Diether-GPEtn). See text for a detailed discussion of the spectral patterns. Peaks labeled with inorganics are contaminant ions and do not belong to the compound spectrum.

Generally, the fragmentation pattern of Diether-GPEtn is less prominent than that observed for esterbound GPEtn (Figure 2-1). This is interpreted as reflecting the greater stability of the ether compared to the ester linkage, which appears to hamper rearrangement reactions and cleavage of the side chains under primary ion bombardment. 


\subsubsection{L- $\alpha$-Phosphatidylcholine (GPCho)}

$\mathrm{C}_{42} \mathrm{H}_{82} \mathrm{NO}_{8} \mathrm{P}$; exact mass $759.58 \mathrm{Da}$; source: eukaryotes (Ostrowski et al., 2005; Ostrowski et al., 2004; Sjövall et al., 2004), bacteria (Zink et al., 2003)

Weak molecular ions of GPCho are detected as $[\mathrm{M}+\mathrm{H}]^{+}$and $[\mathrm{M}+\mathrm{Na}]^{+}$at $\mathrm{m} / z$ 760.61 and 782.61 in the positive spectrum (Figure 2-3). Similarly, abundant peaks of Lyso-GPCho fragments occur at $m / z 478.37$ and 504.38. The most prominent peaks in the positive GPCho spectrum are observed at $m / z 166.08$ and 184.10 and correspond to the headgroup fragments $\left[\mathrm{C}_{5} \mathrm{H}_{13} \mathrm{NO}_{3} \mathrm{P}\right]^{+}$and $\left[\mathrm{C}_{5} \mathrm{H}_{15} \mathrm{NO}_{4} \mathrm{P}\right]^{+}$.

The negative spectrum of GPCho does not show a deprotonated molecular ion. Instead, characteristic fragments at $m / z 744.54$ and 699.47 can be assigned to [M$\left.\mathrm{CH}_{3}\right]^{-}$and $\left[\mathrm{M}-\mathrm{C}_{3} \mathrm{H}_{9} \mathrm{~N}\right]^{-}$. Ions at $m / z 255.23$ and 281.24 derive from $\mathrm{C}_{16: 0}$ and $\mathrm{C}_{18: 1}$ fatty acid moieties, respectively.

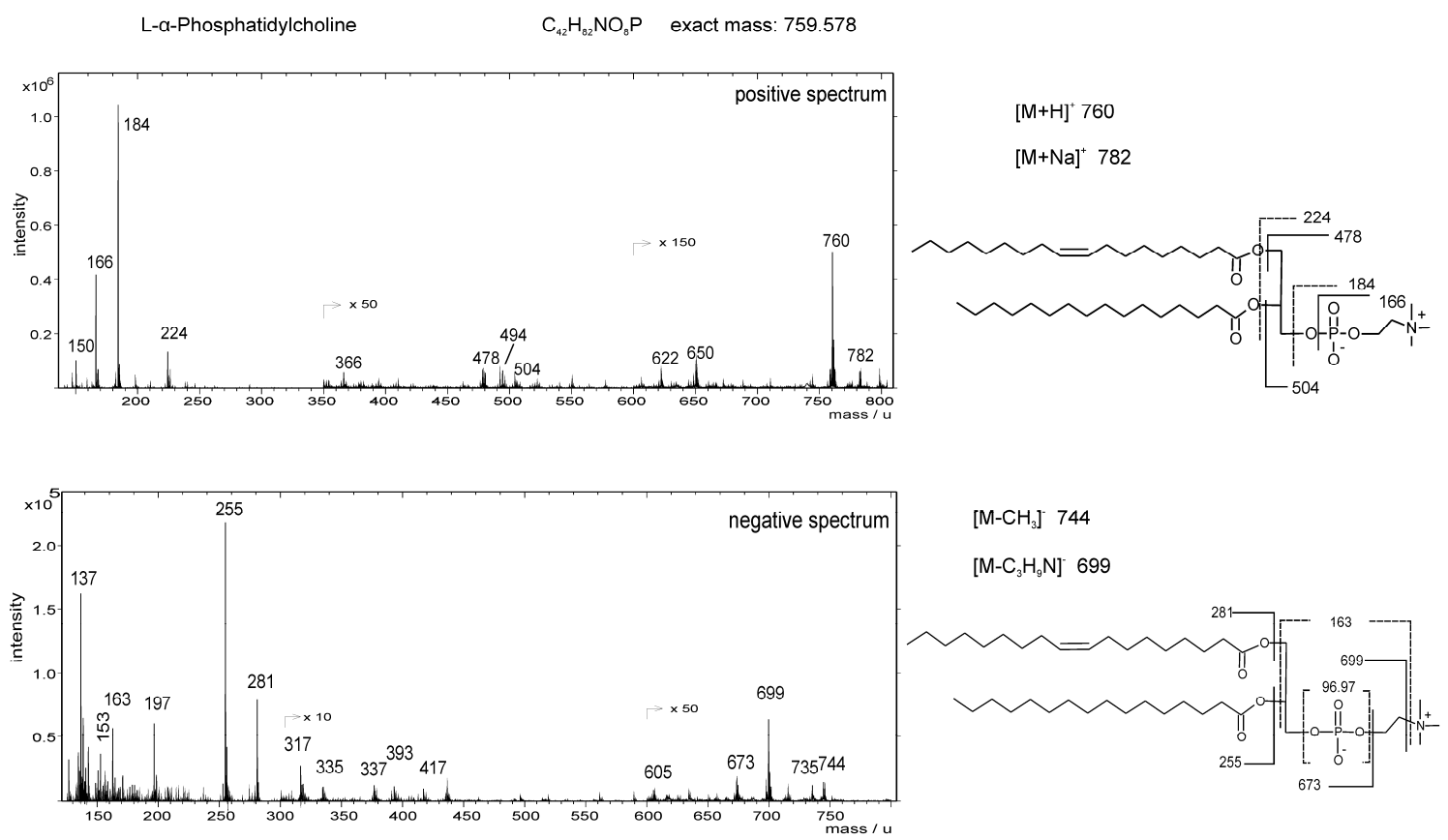

Figure 2-3. Partial positive (top) and negative (bottom) ToF-SIMS spectra $(m / z$ 130-800) of L- $\alpha$ phosphatidylcholine (GPCho). See text for a detailed discussion of the spectral patterns.

The relatively low intensities of the molecular ions and characteristic higher mass fragments make it difficult to use these ions for the analysis of intact GPCho in environmental samples. Furthermore, it has been reported that the intensity of the molecular ion peak is highly sensitive to the structural configuration of the lipid, showing higher intensity in bilayer structures as compared to disordered structures (Prinz et al., 2007) making the lack of a molecular ion a somewhat uncertain 
indicator for the absence of GPCho. Although the detection of molecular GPCho ions has been reported in tissue samples (Sjövall et al., 2004), the headgroup fragment ( $m / z$ 184.07) provides a strong and characteristic peak for phosphocholinecontaining lipids and is therefore frequently used for mapping of these lipids in cell and tissue samples (Börner et al., 2007; Nygren et al., 2005). Comparison of the ToFSIMS spectra of GPEtn and GPCho with published ToF-SIMS and electrospray ionisation (ESI) (LC/MS) mass spectra of phosphatidylcholine (Börner et al., 2007; Mazzella et al., 2005; Ostrowski et al., 2005) suggests similar principles for the fragmentation of complex ester-bound phospholipids. Beside the molecular ion, both methods yield fragment peaks, phospholipid headgroup ions in positive and negative spectra as well as the fatty acid chains in the negative spectra, which may be used to corroborate structural identification.

\subsubsection{1,2-O-Dialkyl-sn-glycerol-3-phosphatidylcholine (Diether-GPCho) \\ $\mathrm{C}_{40} \mathrm{H}_{85} \mathrm{NO}_{6} \mathrm{P}$; exact mass $705.60 \mathrm{Da}$; source: bacteria (Rütters et al., 2001)}

Unlike ester-bound GPCho, Diether-GPCho produces a prominent $[\mathrm{M}+\mathrm{H}]^{+}$ion at $m / z 706.75$ (Figure 2-4). Weak fragment ions occur in the positive spectrum at $m / z$ $450.41,464.44,480.42$ and 494.47 , and may originate from the cleavage of one alkyl moiety at different positions close to the respective ether bond (Figure 2-4). A rather prominent doublet of fragment ions at $m / z 224.15 / 226.13$ can be plausibly explained by loss of both side chains.

In the positive spectrum of Diether-GPCho, the phosphocholine (PC) headgroup fragment is clearly identified at $m / z 184.11$ (Figure 2-4). The observed formation of a strong PC fragment is in good agreement with the results obtained from the esterbound GPCho (Figure 2-3) and other lipid studies that used the PC headgroup fragment at $m / z 184.11$ for GPCho identification in ToF-SIMS spectra of animal cells and tissues (Börner et al., 2007; Sjövall et al., 2004).

The negative spectrum of Diether-GPCho shows a very weak [M-H]- peak at $m / z$ 704.57, whereas strong fragment ions occur at $m / z$ 690.54, 645.47 and 619.47. These fragments most probably result from the molecule after loss of a methyl group from the trimethylamine moiety of the $\mathrm{PC},\left[\mathrm{M}-\mathrm{CH}_{4}\right]^{-}$, loss of the trimethylamine moiety, $\left[\mathrm{M}-\mathrm{C}_{3} \mathrm{H}_{9} \mathrm{~N}\right]^{-}$, or loss of the entire PC headgroup, respectively. 


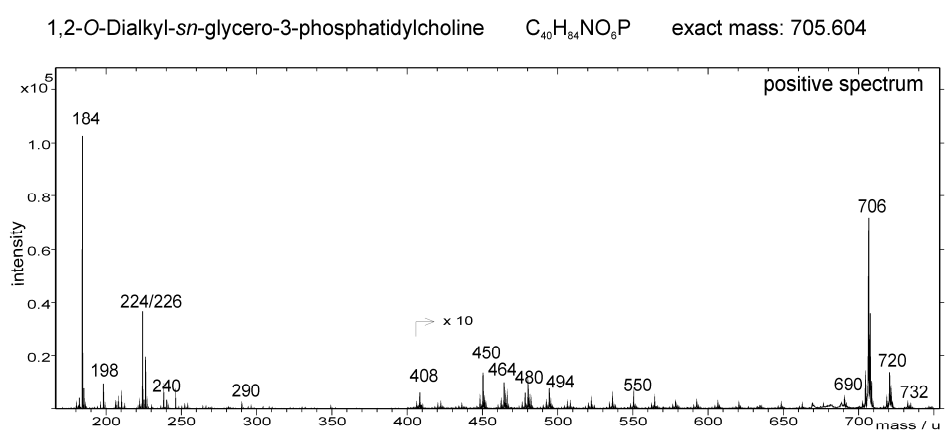

$[\mathrm{M}+\mathrm{H}]^{+} 706$

$[\mathrm{M}+14]^{+} 720$ (less prominent)
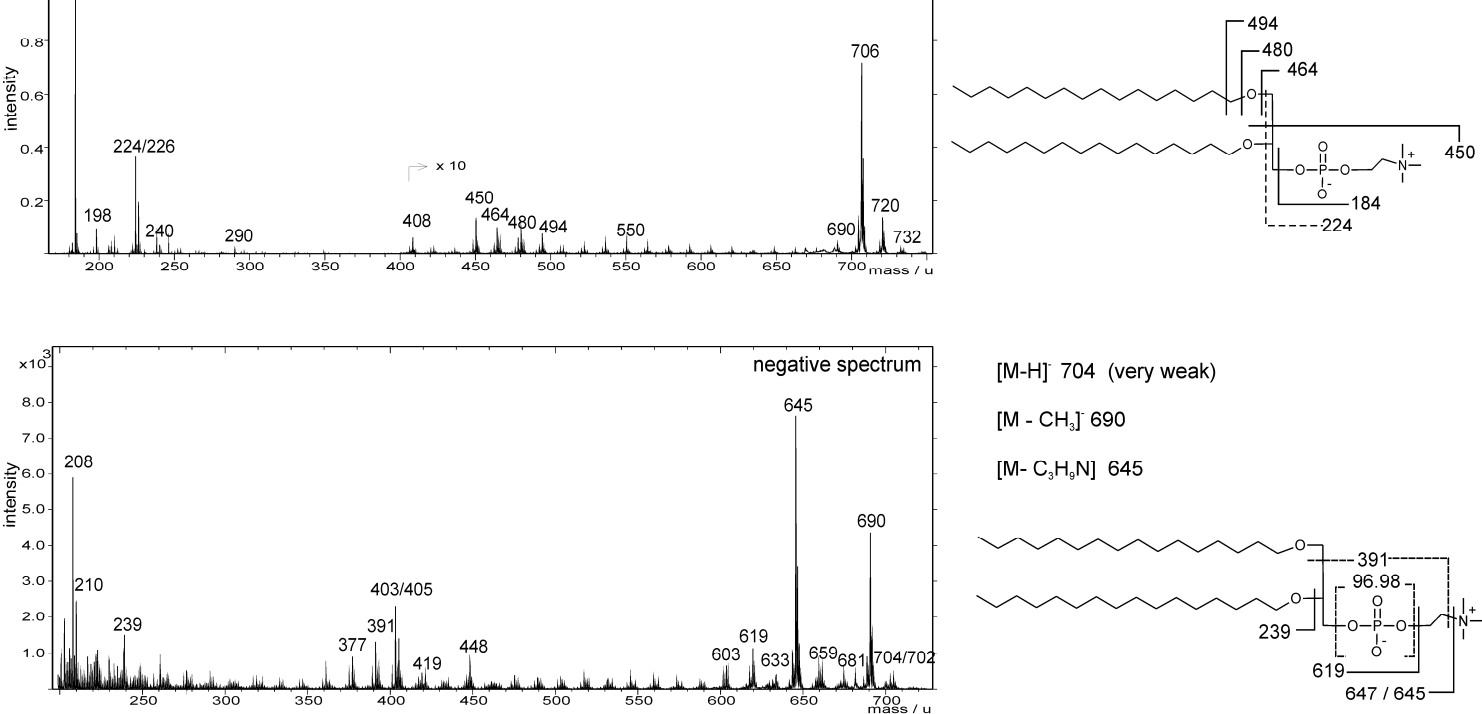

[M-H] 704 (very weak)

$\left[\mathrm{M}-\mathrm{CH}_{3}\right] 690$

$\left[\mathrm{M}-\mathrm{C}_{3} \mathrm{H}_{9} \mathrm{~N}\right] 645$

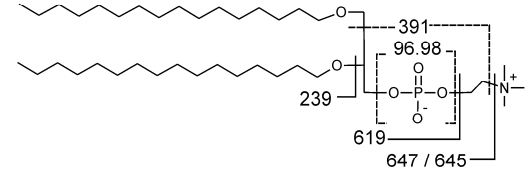

Figure 2-4. Partial positive (top) and negative (bottom) ToF-SIMS spectra (m/z 170-750) of 1,2-Odialkyl-sn-glycerol-3-phosphocholine (Diether-GPCho). See text for a detailed discussion of the spectral patterns.

Notably, this pattern differs considerably from the counterpart lipid with an ethanolamine headgroup (Diether-GPEtn, see above) that shows [M-H]- as the most prominent peak in the molecular mass range. Fragment ions at $m / z$ 391.24, 403.24/405.25 and 448.29 may result from cleavage of the hexadecyl chain, with or without loss of $\mathrm{C}-1$ of the glycerol, and the trimethylamine moiety of the PC headgroup.

\subsubsection{L- $\quad \alpha$-Phosphatidylglycerol (GPGro) sodium salt}

$\mathrm{C}_{38} \mathrm{H}_{74} \mathrm{O}_{10} \mathrm{PNa}$; exact mass $744.49 \mathrm{Da}$; source: eukaryotes (Ostrowski et al., 2005), bacteria (Mazzella et al., 2005; Zink et al., 2003)

GPGro sodium salt produces a prominent $[\mathrm{M}+\mathrm{Na}]^{+}$ion at $m / z 767.51$ in the positive spectrum (Figure 2-5). A protonated molecule $[\mathrm{M}+\mathrm{H}]^{+}$was not observed. Due to the high abundance of sodium, the GPGro fragments including the headgroup are charged with an additional $\mathrm{Na}^{+}$ion, e.g. $m / z 511.28\left(\mathrm{C}_{22} \mathrm{H}_{42} \mathrm{Na}_{2} \mathrm{O}_{8} \mathrm{P}^{+}\right)$and 198.99 $\left(\mathrm{C}_{3} \mathrm{H}_{6} \mathrm{Na}_{2} \mathrm{O}_{5} \mathrm{P}^{+}\right)$. Prominent peaks at $\mathrm{m} / z$ 124.94, 142.96 and 164.94 are putatively $\mathrm{Na}^{+}$adducts.

Beside the weak deprotonated GPGro molecule $[\mathrm{M}-\mathrm{H}]^{-}$at $m / z$ 721.58, the ion at $m / z 255.24$ represents the $C_{16: 0}$ fatty acid moiety. Peaks at $m / z 153.02,171.04$ and 
211.06 can be assigned as fragments involving the PG headgroup. The occurrence of a strong fragment at $m / z 153.02$ is in good agreement with observations reported for ESI-MS (Mazzella et al., 2005). However, for this fragment, Mazzella et al., 2005 proposed a precursor ion at $m / z$ 227, which was not observed in the ToF-SIMS spectra. Ions at $m / z 211.06,171.04$ and 153.02 suggest a preferred fragmentation within the glycerol backbone of the GPGro rather than a scission of the glycerol headgroup (Figure 2-5), as observed for other ester-bound phospholipids (GPEtn, Figure 2-1, and GPCho, Figure 2-3).
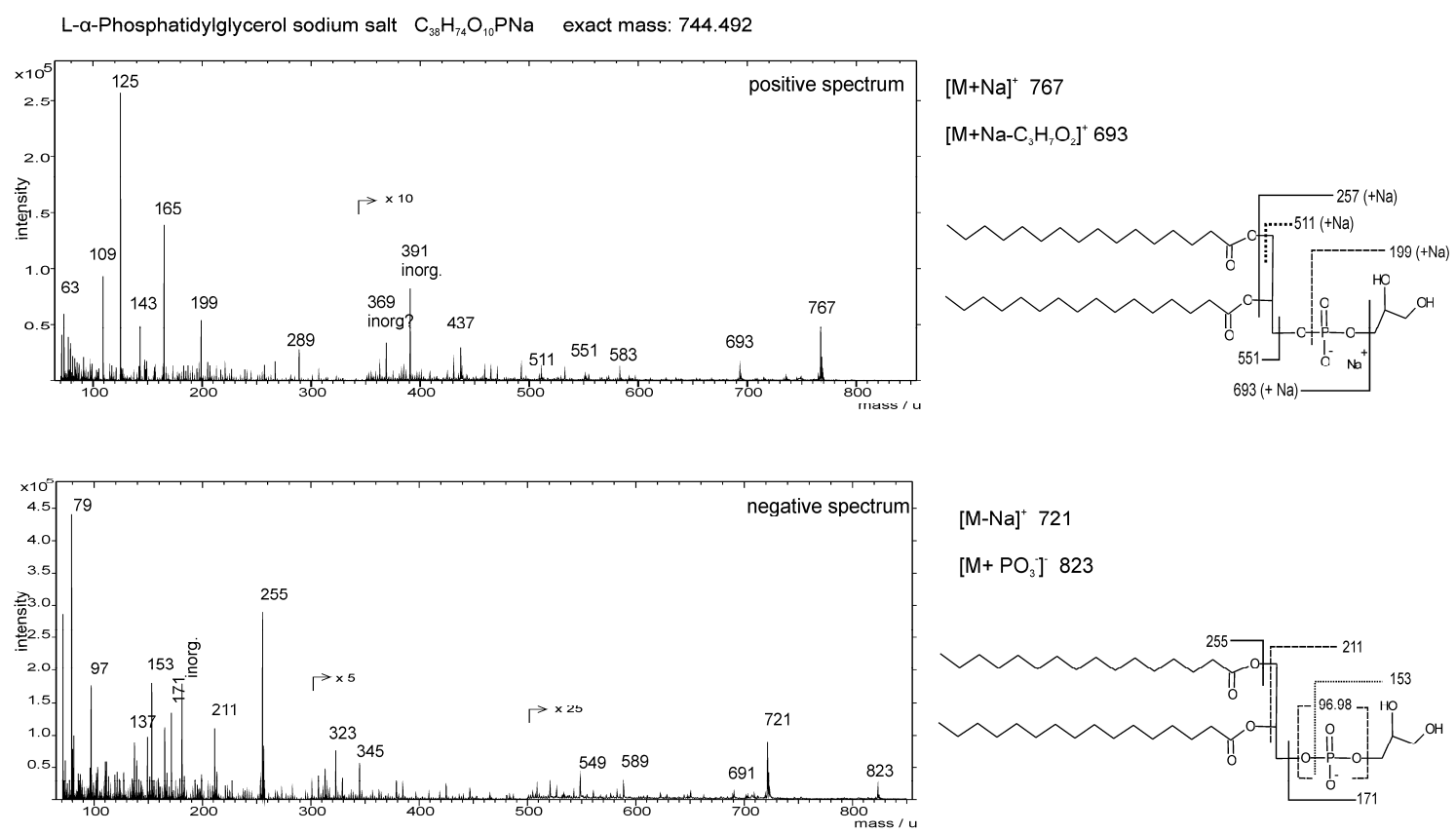

$[\mathrm{M}-\mathrm{Na}]^{+} 721$

$\left[\mathrm{M}+\mathrm{PO}_{3}\right] 823$

Figure 2-5. Partial positive (top) and negative (bottom) ToF-SIMS spectra $(m / z$ 50-850) of L- $\alpha$ phosphatidylglycerol sodium salt (GPGro). Peaks labeled 'inorg' are inorganic ions and do not belong to the compound spectrum. See text for a detailed discussion of the spectral patterns.

\subsubsection{1-Palmitoyl-2-oleoyl-sn-glycerol (DG)}

$\mathrm{C}_{37} \mathrm{H}_{70} \mathrm{O}_{5}$; exact mass $594.52 \mathrm{Da}$; source: eukaryotes (Malmberg et al., 2007; Nygren and Malmberg, 2007), bacteria (Zink et al., 2003)

DG produces very weak molecular ion peaks $[\mathrm{M}+\mathrm{H}]^{+}$and $[\mathrm{M}+\mathrm{Na}]^{+}$at $\mathrm{m} / z 595.58$ and 617.53, but a prominent $\left[\mathrm{M}-\mathrm{H}_{2} \mathrm{O}\right]^{+}$ion at $\mathrm{m} / z$ 577.52 (Figure 2-6). Distinct positive ions at $m / z 339.31$, and 313.28 represent lyso fragments of DG, whereas $\mathrm{m} / \mathrm{z} 265.26$ and 239.24 may originate from fatty acyl fragments. 
In the negative spectrum of DG, a weak molecular ion $[\mathrm{M}-\mathrm{H}]^{-}$is detected at $m / z$ 593.49. Strong fatty acid fragments are observed at $m / z 281.24\left(\mathrm{C}_{18: 1}\right)$ and 255.23 $\left(\mathrm{C}_{16: 0}\right)$.

It should be considered that triacylglycerides (TG) were reported to produce a prominent DG fragment $\left(\left[\mathrm{M}-\mathrm{H}_{2} \mathrm{O}\right]^{+}\right)$in the positive spectrum (Malmberg et al., 2007; Nygren and Malmberg, 2007). Moreover, this fragment was clearly visible in the GPEtn spectrum (Figure 2-1, Table 2-2) and was detectable, though in low abundance, in the spectra of other ester-bound lipids studied. Hence, when analysing natural samples, positive and negative spectra and ion images have to be checked carefully, whether the respective ions can be assigned confidently to DG, TG or phospholipids.
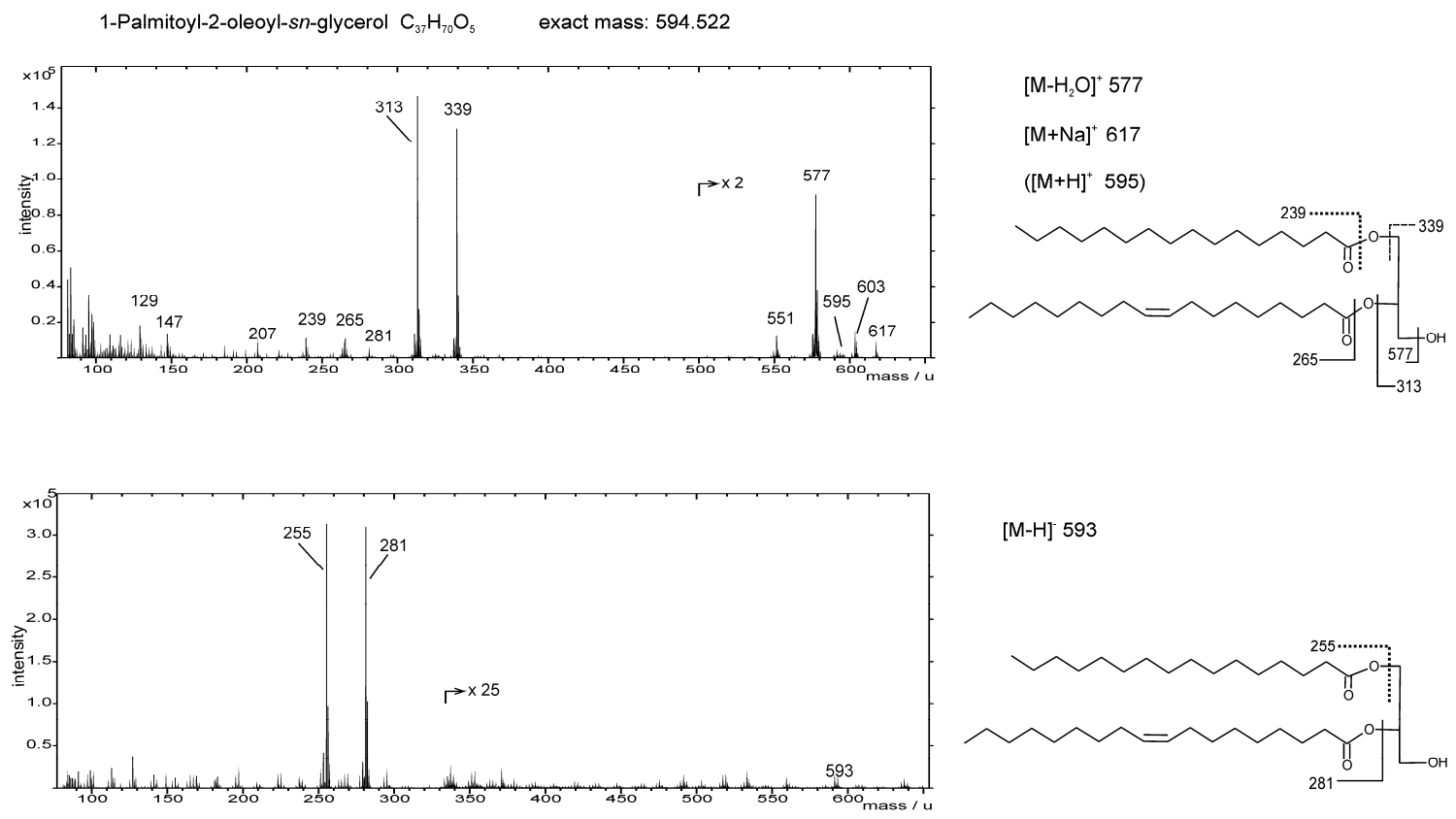

$[\mathrm{M}-\mathrm{H}] 593$



Figure 2-6. Partial positive (top) and negative (bottom) ToF-SIMS spectra ( $m / z$ 80-650) of 1-palmitoyl-2oleoyl-sn-glycerol (DG). See text for a detailed discussion of the spectral patterns.

\subsubsection{1,2-Di-O-hexadecyl-rac-glycerol (Diether-DG)}

$\mathrm{C}_{37} \mathrm{H}_{72} \mathrm{O}_{3}$; exact mass $540.55 \mathrm{Da}$; source: bacteria (Pancost et al., 2001)

The partial positive spectrum of 1,2-di-O-hexadecyl-rac-glycerol (Diether-DG) shows the protonated molecular ion at $m / z 541.63$ as the base peak (Figure 2-7). Loss of the functional group with, or without, the C-3 of glycerol produces additional, less intense peaks at $m / z 522.59$ and 508.57, respectively. Further ions at $m / z 253.27,267.29,297.32$ and 299.33 can be explained by fragmentations within 
the glycerol backbone whereas $m / z 317.34$ most likely results from loss of one of the hydrocarbon side chains $\left[\mathrm{M}-\mathrm{C}_{16} \mathrm{H}_{31}\right]^{+}$(Table 2-2).

In the negative spectrum, the deprotonated molecular ion at $m / z 539.54[\mathrm{M}-$ $\mathrm{H}]^{-}$is very weak, as also observed for the isoprenoid glycerol diether archaeol (see below). The most abundant ion in the higher molecular weight range at $m / z 239.18$ most probably derives from the side chain $\left[\mathrm{C}_{16} \mathrm{H}_{31} \mathrm{O}\right]$. This interpretation is supported by a corresponding, 56 Da heavier, fragment ion observed in the negative spectrum of archaeol at $m / z 295.29$ (see below), that obviously represents the functionalised $\mathrm{C}_{20}$ phytanyl side chain $\left[\mathrm{C}_{20} \mathrm{H}_{39} \mathrm{O}\right]-$ Similar to the positive spectrum, minor ions at $m / z 253.20,255.20,283.22$ and 297.28 indicate fragmentations within the glycerol backbone of Diether-DG.
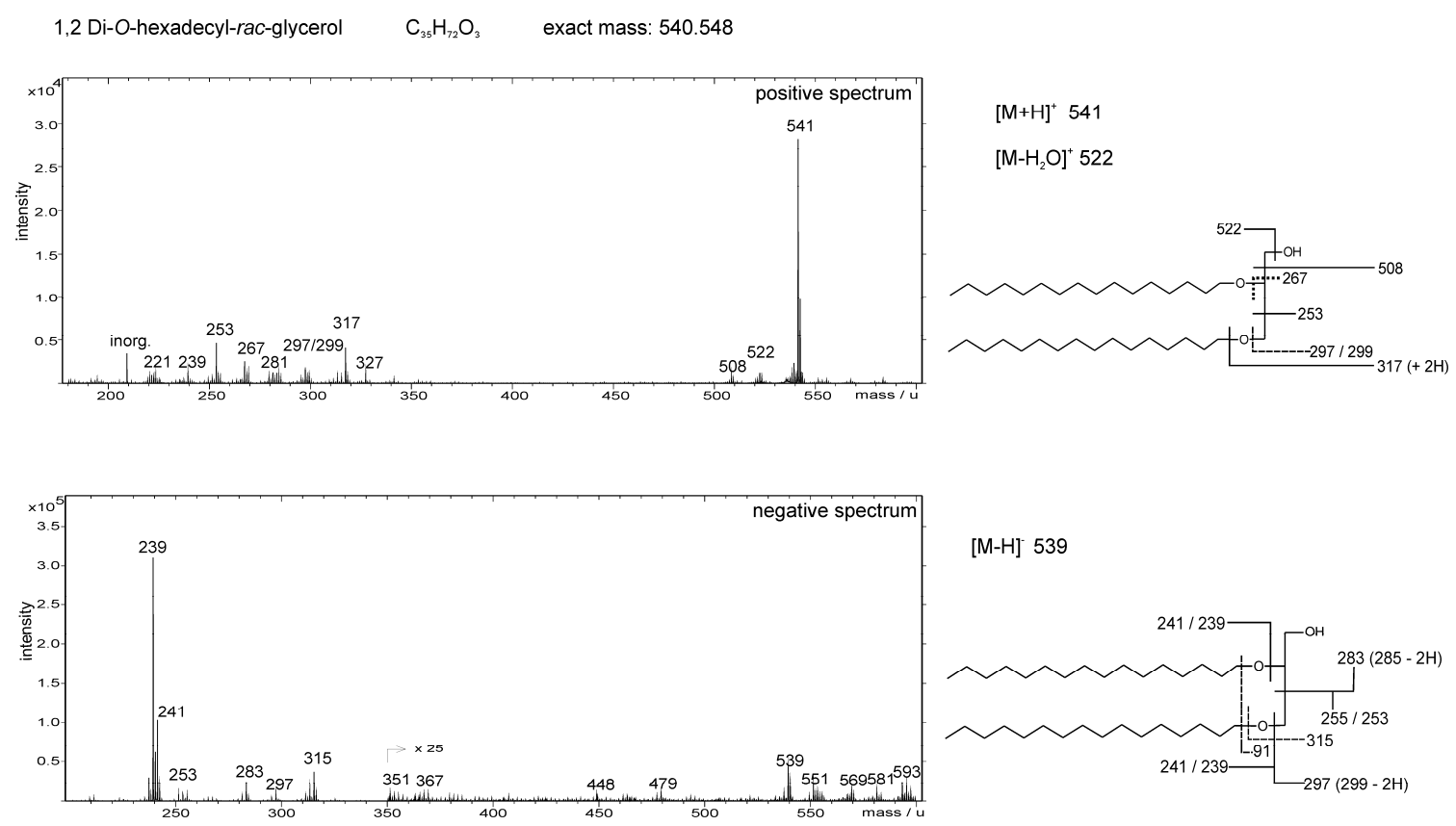

$[\mathrm{M}-\mathrm{H}] 539$



Figure 2-7. Partial positive (top) and negative (bottom) ToF-SIMS spectra $(\mathrm{m} / \mathrm{z} 180-600)$ of 1,2 -di- $O$ hexadecyl-rac-glycerol (Diether-DG). See text for a detailed discussion of the spectral patterns. Peaks labeled 'inorg' are inorganic ions and do not belong to the compound spectrum.

Another significant ion at $m / z 315.26$ most likely results from loss of one of the hydrocarbon side chains $\left[\mathrm{M}-\mathrm{C}_{16} \mathrm{H}_{33}\right]$; , again corroborated by a 56 Da heavier corresponding fragment observed in the negative spectrum of archaeol $(\mathrm{m} / \mathrm{z}$ 371.25).The presence of a glycerol moiety in the Diether-DG molecule is recognised by a prominent $\mathrm{C}_{3} \mathrm{H}_{7} \mathrm{O}_{3}$ fragment ion peak at $m / z 91.03$ (not shown). 


\subsubsection{1,2-Di-O-phytanyl-sn-glycerol (archaeol)}

$\mathrm{C}_{43} \mathrm{H}_{88} \mathrm{O}_{3}$; exact mass $652.67 \mathrm{Da}$; source: archaea (Pape et al., 2005; Thiel et al., 2007a)

The positive spectrum of archaeol displays the protonated molecular ion $[\mathrm{M}+\mathrm{H}]^{+}$ at $m / z 653.72$ as the base peak (Figure 2-8). The formation of a $\mathrm{Na}^{+}$adduct causes a further, yet minor, peak at $m / z$ 675.68. Loss of the hydroxyl group (as $\mathrm{H}_{2} \mathrm{O}$ ) from the glycerol moiety is the most plausible explanation for a fragment peak at $m / z 634.69$ whereas cleavage of the adjacent methyl group results in a peak at $m / z 620.65$. The fragmentation scheme of archaeol producing ions at $m / z$ 620.65, 373.39, 371.27 and 278.23 is similar to the peak formation in GC/MS (data not shown).
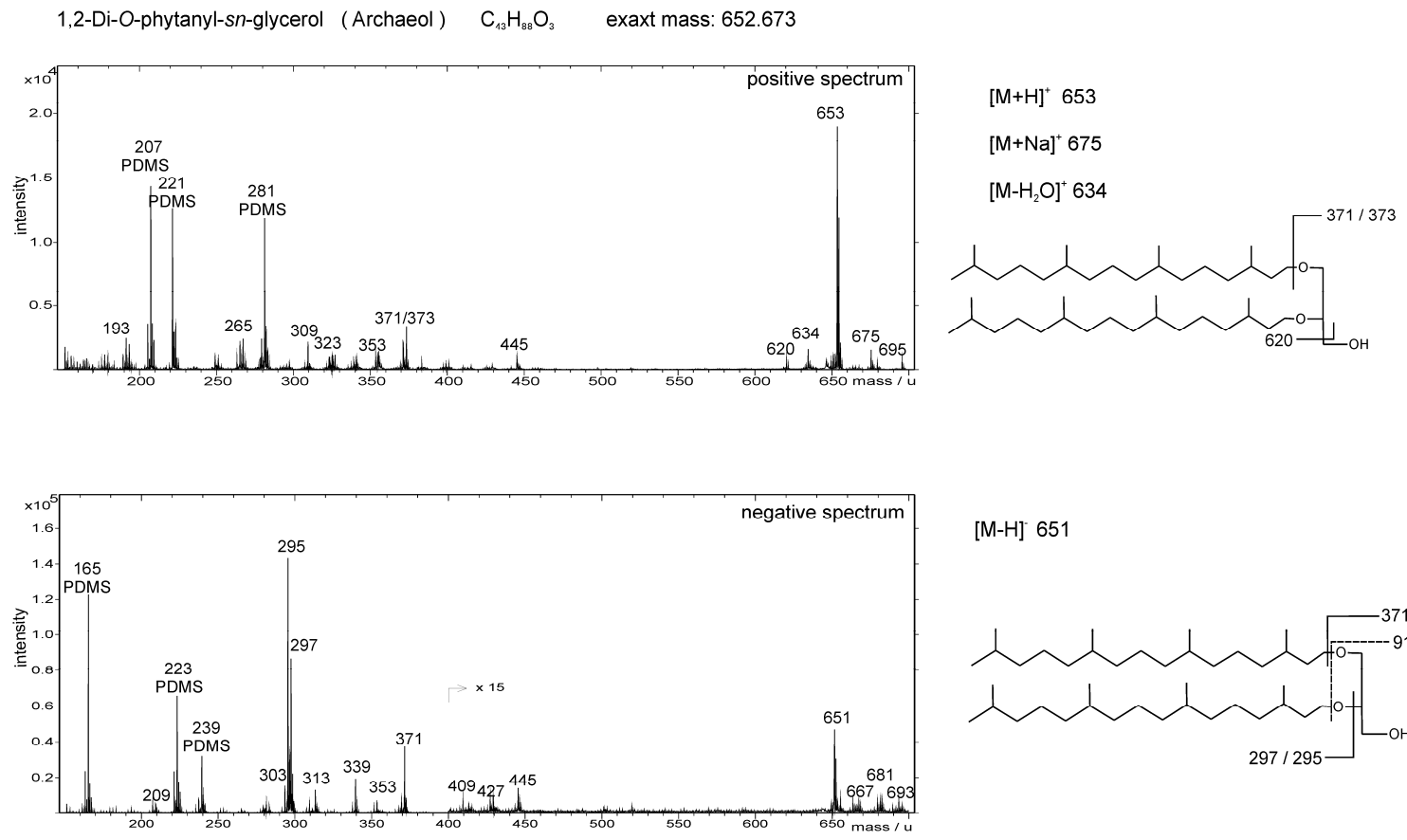

$[\mathrm{M}-\mathrm{H}] 651$

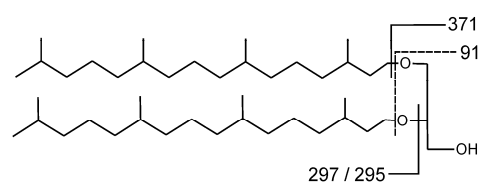

Figure 2-8. Partial positive (top) and negative (bottom) ToF-SIMS spectra (m/z 140-700) of 1,2-di- $O$ phytanyl-sn-glycerol (archaeol). See text for a detailed discussion of the spectral patterns. A peak at $m / z$ 91.02 specifying the glycerol moiety is out of the displayed range of the negative spectrum. Peaks labeled with PDMS are polysiloxane contaminants and do not belong to the compound spectrum.

In the negative ToF-SIMS spectrum, a deprotonated molecular ion $[\mathrm{M}-\mathrm{H}]^{-}$at $\mathrm{m} / \mathrm{z}$ 651.66 is clearly recognised, though much weaker than the $[\mathrm{M}+\mathrm{H}]^{+}$ion observed in positive mode. Pronounced fragment ions occur at $m / z 371.37,297.32,295.29$, 239.07, 223.02 and 165.04. Whereas $m / z$ 371.37, 297.32 and 295.29 can be explained by cleavage of the ether bonds, the latter three are due to polydimethylsiloxane (PDMS) contamination. Additional characteristic fragments 
contributing to clear identification of archaeol as a glycerolipid are the glycerol fragments at $m / z 91.02\left[\mathrm{C}_{3} \mathrm{H}_{7} \mathrm{O}_{3}\right]^{-}$and $57.04\left[\mathrm{C}_{3} \mathrm{H}_{5} \mathrm{O}\right]^{-}$in the negative spectrum (data not shown).

\subsubsection{Archaeol in a methanotrophic microbial mat}

Extracts of the Black Sea microbial mats typically contain archaeol among other lipids derived from methanotrophic archaea (Blumenberg et al., 2004; Michaelis et al., 2002; Pape et al., 2005). Based on these findings, our group recently used ToFSIMS to study the distribution of archaeal lipids, including intact glycerol tetraethers, in microscopic cryosections of the microbial mats (Thiel et al., 2007b).

a) Archaeol comparison

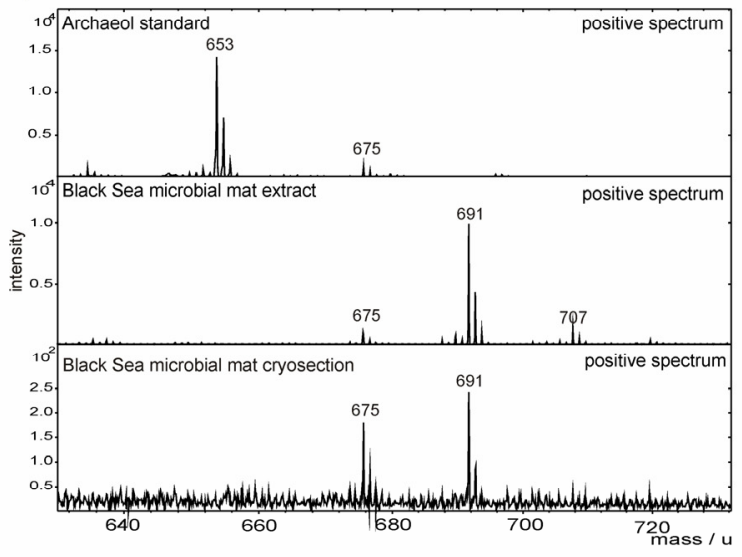

b)
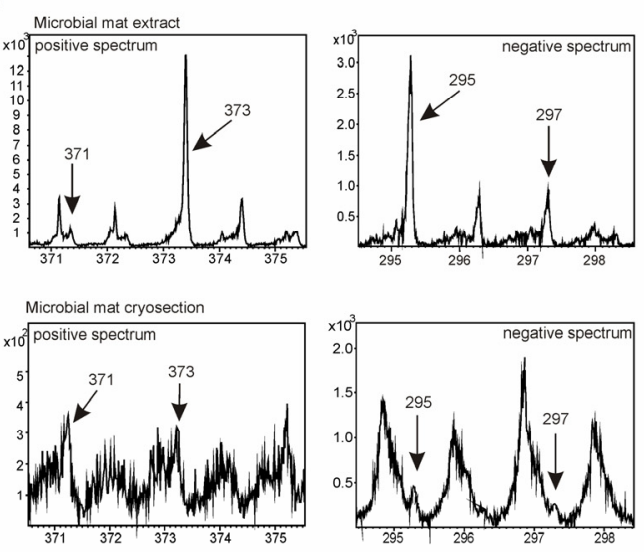

c) Black Sea microbial mat section

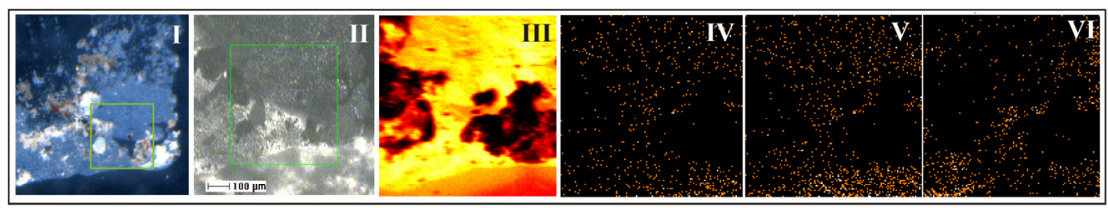

Figure 2-9. (a) Partial positive ToF-SIMS spectra $(\mathrm{m} / \mathrm{z}$ 630-730) showing molecular ions ([M+H]+ and $\left.[\mathrm{M}+\mathrm{Na}]^{+}\right)$of archaeol from the standard, in a complex organic extract of the Black Sea microbial mat, and on a microscopic cryosection of the same microbial mat. The peaks at 691.67 and $707.65 \mathrm{Da}$ in the environmental samples represent the $[\mathrm{M}+\mathrm{Na}]^{+}$of hydroxyarchaeol and dihydroxyarchaeol, respectively. (b) Characteristic archaeol fragments observed in the partial positive and negative spectra of the organic extract and the microbial mat cryosection. (c) Microscopic and ion images of the Black Sea microbial mat section: under reflected light (I), built-in video camera in the ToF-SIMS system (II), total ion image (III), distribution of $\mathrm{m} / \mathrm{z} 371.27$ and 373.39 (IV), distribution of archaeol (V), and distribution of hydroxyarchaeol (VI).

Figure 2-9(a) shows partial positive ToF-SIMS spectra of (i) the archaeol reference (as described above), (ii) a total organic extract of a microbial mat, and 
(iii) a cryosection of the same mat. In fact, the molecular ion as $[\mathrm{M}+\mathrm{Na}]^{+}$of archaeol (Figure 2-9(a)) and some of its characteristic fragments such as $m / z 371.27$ and 373.37 were observed in the spectra of all samples (Figure 2-9(b)). Unlike the reference lipid, the spectra of the extract and the cryosection show $[\mathrm{M}+\mathrm{Na}]^{+}$at $\mathrm{m} / z$ 675.68, rather than $[\mathrm{M}+\mathrm{H}]^{+}$. Clearly, archaeol easily forms the $[\mathrm{M}+\mathrm{Na}]^{+}$ion wherever sodium is present, either from biological material, sea water, or the mineral matrix of a natural sample. The same is evidently the case for the hydroxylated diether, hydroxyarchaeol ( $\mathrm{m} / \mathrm{z}$ 691.68), that co-occurs with archaeol in the Black Sea mats (Figure 2-9(a); see also e.g. Blumenberg et al., 2004). The strong tendency of these isoprenyl diethers to form sodium adduct ions is in full agreement with previous data (Thiel et al., 2007a), thus pointing at the reproducibility of the mass spectral patterns characterizing these important lipid biomarkers.

Although the $[\mathrm{M}+\mathrm{H}]^{+}$and $[\mathrm{M}-\mathrm{H}]^{-}$ions were not detected in the spectra of the organic extract and the microscopic section of the Black Sea microbial mat, characteristic archaeol fragments at $m / z 371.27$ and 373.39 in the positive spectra and at $m / z 295.29$ and 297.32 in the negative spectra (described in Figure 2-8) were clearly present (Figure 2-9(b)). Thus, the cooccurrence of the $[\mathrm{M}+\mathrm{Na}]^{+}$ion in positive mode and these fragment peaks in negative mode corroborate the identification of archaeol in the environmental sample. Microscopic, video and total ion images of the microscopic section (Figure 2-9(c): I, II, III) allow the accurate assignment of the area analysed. IV, V and VI in Figure 2-9(c) show positive ion images

\subsubsection{Diglyceride and phosphatidylglycerol in a Gallionella-dominated microbial mat}

Generally, analyses of environmental samples of iron-oxidising Gallionella mats is hampered by obscuring effects caused by the iron oxide precipitates that commonly make up more than $90 \mathrm{wt} \%$ of the dry sample. It was nonetheless possible to reconstruct partially the lipid pattern of the microbial system using spectra and the imaging capability of ToF-SIMS (Figure 2-10).

In the positive spectrum ions at $m / z 549.50,577.54,603.55,639.47$ and 643.49 are in agreement with the $\left[\mathrm{M}-\mathrm{H}_{2} \mathrm{O}\right]^{+}$ions of diglyceride lipids namely $\mathrm{C}_{32: 1}, \mathrm{C}_{34: 1}$, 
$\mathrm{C}_{36: 2}, \mathrm{C}_{40: 12}$ and $\mathrm{C}_{40: 10}$. This assignment was corroborated through the fragmentation scheme of the DG reference (Figure 2-6) including occurrence of a glycerol-derived

a) Gallionella microbial mat cryosection
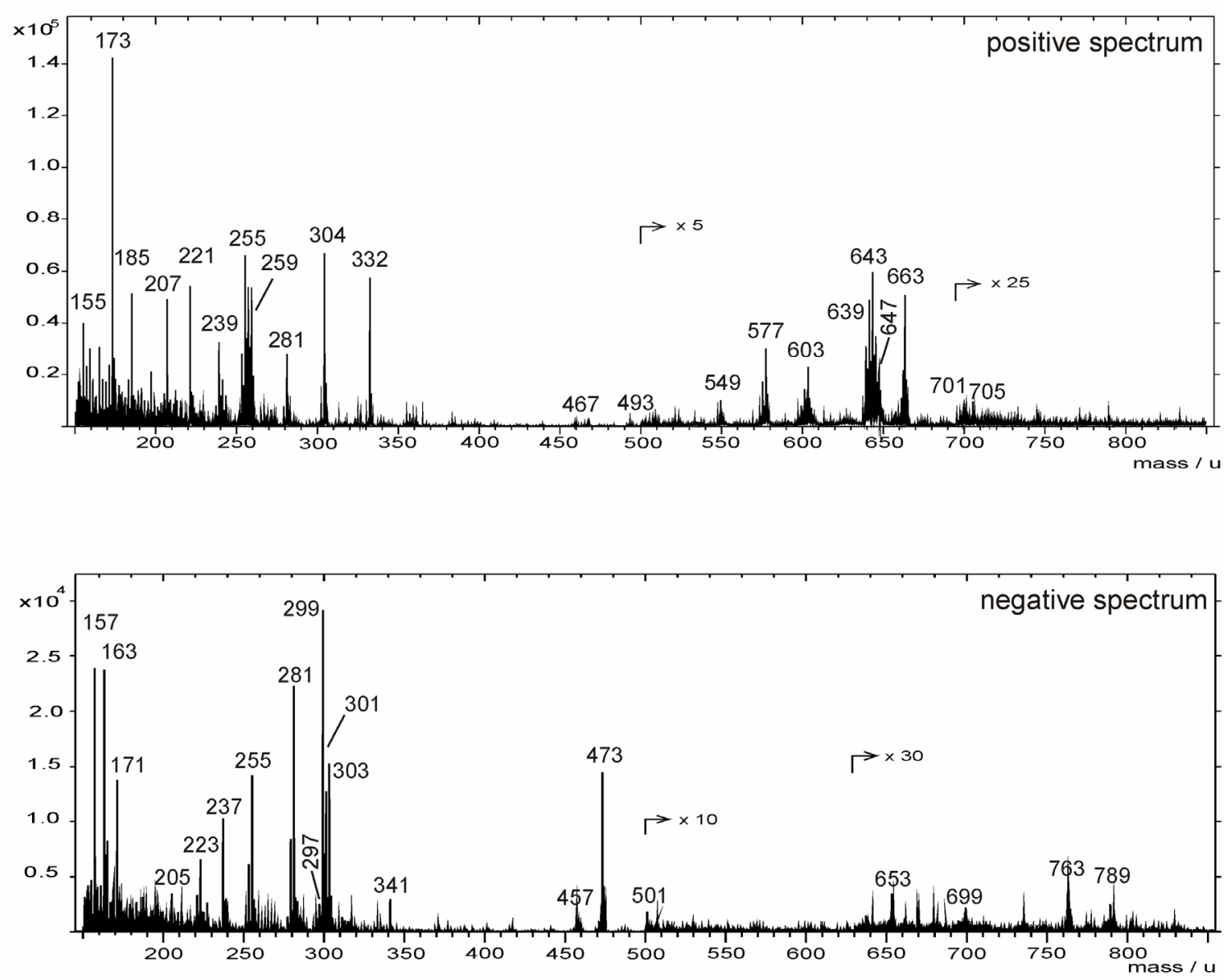

b) Gallionella microbial mat cryosection

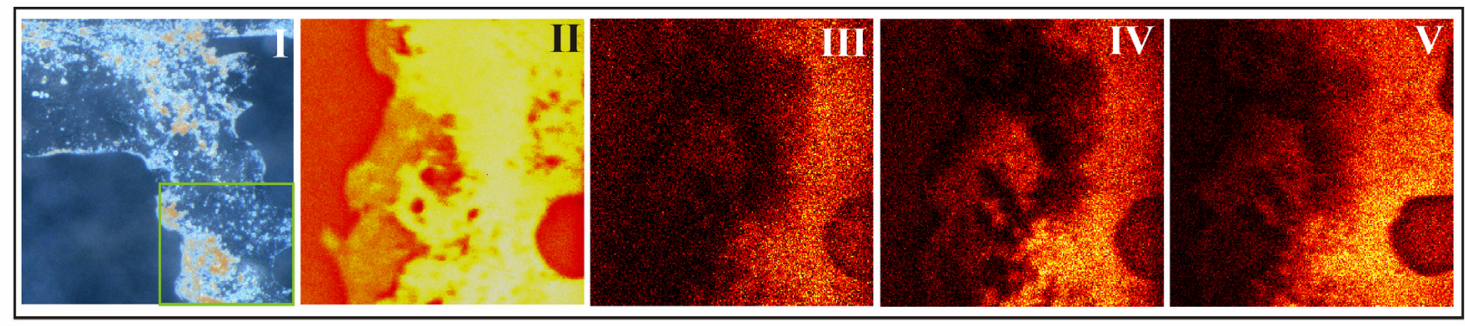

Figure 2-10. (a) Partial positive and negative ToF-SIMS spectra $(\mathrm{m} / \mathrm{z}$ 150-850) of a microscopic section obtained from a Gallionella-rich microbial mat from the tunnel of Äspö. Peaks at $m / z$ 207.04, 221.12 and 281.08 in the positive spectrum belong to PDMS contaminants, and peaks at $m / z 647.47$ and 663.47 in the positive spectrum and at $\mathrm{m} / \mathrm{z} 473.28$ in the negative spectrum most likely derive from contamination by the polymer additive Irgafos 168 . The peaks at $m / z 341.09$ and 163.05 originate from carbohydrate fragments of the embedding agent. See text for a detailed discussion of the spectral patterns. (b) Microscopic and ion images of the Gallionella microbial mat section: under reflected light (I), total ion image (II), the distribution of the PG headgroup (III), fatty acids (IV), and diglycerides (V). 
fragment at $m / z 91.02\left[\mathrm{C}_{3} \mathrm{H}_{7} \mathrm{O}\right]^{-}$and the corresponding fatty acyl moieties in the negative spectrum. Here, fragment ions at $m / z 253.19$ and 255.21 correspond to $\mathrm{C}_{16: 1}$ and $\mathrm{C}_{16: 0}$ moieties, whereas $m / z 279.20$ and 281.215 arise from $\mathrm{C}_{18: 2}$ and $\mathrm{C}_{18: 1}$ moieties, respectively. Additional ions at $m / z$ 299.18, 301.19 and 303.21 are in agreement with hexaenoic, pentaenoic and tetraenoic $\mathrm{C}_{20}$ fatty acids, respectively.These fatty acids were also observed in GC/MS analyses of Gallionelladominated mat bulk extracts (data not shown).

In the phospholipid molecular ion range in the negative spectrum, significant peaks at $m / z 761.55,763.56$ and 789.57 were detected. A distinct ion at $m / z 171.08$ (negative spectrum) corresponding to the GPGro headgroup is also present. The high-mass peaks may therefore be related to the phosphatidylglycerols (GPGro), namely $\mathrm{C}_{35: 1}, \mathrm{C}_{35: 0}$ and $\mathrm{C}_{37: 1}$, thus implying the presence of odd-numbered fatty acyl moieties (Figure 2-10(b)). Although the GPGro headgroup was colocalised with $\mathrm{C}_{17}$ and $\mathrm{C}_{19}$ fatty acids, this relationship remains uncertain, as the latter were observed only in minor abundance on the cryosections. Additional prominent organic ions such as $m / z 332.33,304.29$ and 173.08 in the positive spectrum and $m / z 237.06$ and 157.11 in the negative spectrum still remain to be identified.

\subsection{Conclusions}

Our study showed that ToF-SIMS with a Bi cluster ion source is capable of revealing characteristic mass spectral features of each of the eight glycerolipids investigated. However, a robust assignment of the target compounds in the total ToF-SIMS spectrum of environmental samples should not only rely on the presence of molecular ions (including adducts), but also on specific headgroup fragments and other structural moieties, such as functional groups and alkyl chains. The establishment of characteristic mass spectral features for a range of glycerolipids further expands the range of complex lipids that can be analysed using ToF-SIMS and provides the crucial basis for the identification of these and related biomarkers in environmental materials. Nevertheless, the question whether the patterns reported here represent general rules for the interpretation of ToF-SIMS spectra of environmental samples still has to be corroborated by further studies.

A major advantage of ToF-SIMS is its capacity to provide simultaneous detection, identification and microscopic localisation (mapping) of inorganic and 
organic compounds without the need for bulk sample extraction or labeling. Unlike the more traditional techniques for lipid analysis such as GC/MS and LC/MS, ToFSIMS can be used to study compound distributions within microscopic areas of interest on a sample surface. The imaging capacity of ToF-SIMS can also be used to support the identification of organic compounds and their association with inorganic species through the co-localisation of key ions on the area of interest. As the analytical procedure is virtually non-destructive, subsequent examinations, e.g. microscopy, may allow a further characterisation of the sample in question.

The capability of visualising lipid distributions on a micrometer scale makes ToF-SIMS a promising tool for a wide range of geological, ecological, biological, and medical applications. However, published ToF-SIMS spectra of lipid biomarkers as yet exist for a still limited number of relevant compounds, and little research has been conducted on the effects of substrates and compound concentrations on the quality of ToF-SIMS spectra. Furthermore, structural assignments using the current single-stage TOF analysers are still not satisfactory, and isomers cannot be easily differentiated. Moreover, SIMS is very susceptible to surface contamination.

Further efforts are therefore essential to minimise, or overcome, these limitations and further increase the utility of ToF-SIMS for molecular imaging in bioand geosciences. Such efforts may include the implementation of tandem mass spectrometry, the improvement of preparation techniques particularly for environmental samples, the establishment of further reference data from pure substances, and the validation of the ToF-SIMS results against established knowledge and methods.

\section{Acknowledgements}

We are grateful to Michael Wiedenbeck and Jan Toporski for their constructive reviews that greatly helped to improve the original manuscript. The authors acknowledge Jakob Malm (SP Borås) for constructive discussions and help in the lab. We are also grateful to Walter Michaelis, Richard Seifert (University of Hamburg) and Joachim Reitner (University of Göttingen), who initiated and coordinated the joint projects through which the microbial mats studied here were retrieved. Our study received financial support from the German Research Foundation (DFG) through grants Th 713/4 and FOR 571, the University of Hamburg (joint project 
BEBOP, R/V Poseidon cruise PO 317/2), and the Swedish Governmental Agency for Innovation Systems (VINNOVA). This is publication no. 46 of the DFG Research Unit FOR 571 'Geobiology of Organo- and Biofilms'.

\section{References}

Belu A. M., Graham D. J. and Castner D. G. (2003) Time-of-flight secondary ion mass spectrometry. Biomaterials 24, 3635-3653.

Benninghoven A. (1994) Chemical Analysis of inorganic and organic surfaces and thin films by static time-of-flight secondary ion mass spectrometry (TOF-SIMS). Angewandte Chemie International Edition in English 33, 1023-1043.

Blumenberg M., Seifert R., Reitner J., Pape T., Michaelis W. (2004) Membrane lipid patterns typify distinct anaerobic methanotrophic consortia. Proceedings of the National Academy of Sciences 101, 11111-11116.

Börner K., Malmberg P., Månsson J.-E., Nygren H. (2007) Molecular imaging of lipids in cells and tissues. International Journal of Mass Spectrometry 260, 128-136.

Hagenhoff B. (2000) High resolution surface analysis by TOF-SIMS. Mikrochimica Acta 132, 259-271.

Kollmer F. (2004) Cluster primary ion bombardment of organic materials. Applied Surface Science 231-232, 153-158.

Malmberg P., Nygren H., Richter K., Chen Y., Dangardt F., Friberg P., Magnusson Y. (2007) Imaging of lipids in human adipose tissue by cluster ion TOF-SIMS. Microscopy Research and Technique 70, 828-835.

Mazzella N., Molinet J., Syakti A. D., Dodi A., Bertrand J.-C., Doumenq P. (2005) Use of electrospray ionization mass spectrometry for profiling of crude oil effects on the phospholipid molecular species of two marine bacteria. Rapid Communications in Mass Spectrometry 19, 3579-3588.

Michaelis W., Seifert R., Nauhaus K., Treude T., Thiel V., Blumenberg M., Knittel K., Gieseke A., Peterknecht K., Pape T., Boetius A., Amann R., Jørgensen B. B., Widdel F., Peckmann J., Pimenov N. V., Gulin M. B. (2002) Microbial reefs in the Black Sea fueled by anaerobic oxidation of methane. Science 297, 1013-1015.

Nygren H., Börner K., Hagenhoff B., Malmberg P., Månsson J.-E. (2005) Localization of cholesterol, phosphocholine and galactosylceramide in rat cerebellar cortex with imaging TOF-SIMS equipped with a bismuth cluster ion source. Biochimica et Biophysica Acta (BBA) - Molecular and Cell Biology of Lipids 1737, 102-110.

Nygren H., Malmberg P. (2007) High resolution imaging by organic secondary ion mass spectrometry. Trends in Biotechnology 25, 499-504. 
Ostrowski S., Szakal C., Kozole J., Roddy T., Xu J., Ewing A., Winograd N. (2005) Secondary ion ms imaging of lipids in picoliter vials with a Buckminsterfullerene ion source. Analytical Chemistry 77, 6190-6196.

Ostrowski S. G., Craig T. Van Bell, Winograd N., Ewing A. G. (2004) Mass spectrometric imaging of highly curved membranes during Tetrahymena mating. Science 305, 71-73.

Pacholski M. L., Winograd N. (1999) Imaging with mass spectrometry. Chemical Reviews 99, 2977-3006.

Pancost R. D., Bouloubassi I., Aloisi G., Jaap S. Sinninghe Damsté, the Medinaut Shipboard Party (2001) Three series of non-isoprenoidal dialkyl glycerol diethers in cold-seep carbonate crusts. Organic Geochemistry 32, 695-707.

Pape T., Blumenberg M., Seifert R., Egorov V. N., Gulin S. B., Michaelis W. (2005) Lipid geochemistry of methane-seep-related Black Sea carbonates. Palaeogeography, Palaeoclimatology, Palaeoecology 227, 31-47.

Pedersen K. (1997) Microbial life in deep granitic rock. FEMS Microbiology Reviews 20, 399-414.

Prinz C., Malm J., Hook F., Sjovall P. (2007) Structural effects in the analysis of supported lipid bilayers by time-of-flight secondary ion mass spectrometry. Langmuir 23, 8035-8041.

Rütters H., Sass H., Cypionka H., Rullkötter J. (2001) Monoalkylether phospholipids in the sulfate-reducing bacteria Desulfosarcina variabilis and Desulforhabdus amnigenus. Archives of Microbiology 176, 435-442.

Siljeström S., Hode T., Lausmaa J., Sjövall P., Toporski J., Thiel V. (2009) Detection of organic biomarkers in crude oils using ToF-SIMS. Organic Geochemistry 40, 135143.

Sjövall P., Lausmaa J., Johansson B. (2004) Mass spectrometric imaging of lipids in brain tissue. Analytical Chemistry 76, 4271-4278.

Sjövall P., Thiel V., Siljeström S., Heim C., Hode T., Lausmaa J. (2008) Organic geochemical microanalysis by time-of-flight secondary ion mass spectrometry (ToFSIMS). Geostandards and Geoanalytical Research 32, 267-277.

Sostarecz A. G., Cannon D. M., McQuaw C. M., Sun S., Ewing A. G., Winograd N. (2004) Influence of molecular environment on the analysis of phospholipids by time-offlight secondary ion mass spectrometry. Langmuir 20, 4926-4932.

Steele A., Toporski J. K. W., Avci R., Guidry S., McKay D. S. (2001) Time of flight secondary ion mass spectrometry (ToF-SIMS) of a number of hopanoids. Organic Geochemistry 32, 905-911. 
Thiel V., Toporski J., Schumann G., Sjövall P., Lausmaa J. (2007a) Analysis of archaeal core ether lipids using time of flight-secondary ion mass spectrometry (ToF-SIMS). Geobiology 5, 75-83.

Thiel V., Heim C., Arp G., Hahmann U., Sjövall P., Lausmaa J. (2007b) Biomarkers at the microscopic range. Geobiology 5, 413-421.

Toporski J. K. W., Steele A., Westall F., Avci R., Martill D. M., McKay D. S. (2002) Morphologic and spectral investigation of exceptionally well-preserved bacterial biofilms from the Oligocene Enspel formation, Germany. Geochimica et Cosmochimica Acta 66, 1773-1791.

Toporski J., Steele A. (2004) Characterization of purified biomarker compounds using time of flight-secondary ion mass spectrometry (ToF-SIMS). Organic Geochemistry 35, 793-811.

Touboul D., Halgand F., Brunelle A., Kersting R., Tallarek E., Hagenhoff B., Laprevote O. (2004) Tissue molecular ion imaging by gold cluster ion bombardment. Analytical Chemistry 76, 1550-1559.

Touboul D., Kollmer F., Niehuis E., Brunelle A., Laprévote 0. (2005) Improvement of biological time-of-flight-secondary ion mass spectrometry imaging with a bismuth cluster ion source. Journal of the American Society for Mass Spectrometry 16, 16081618.

Vickerman J. C., Briggs D. (eds.; 2001) ToF-SIMS. IM, Chichester.

Zink K.-G., Wilkes H., Disko U., Elvert M., Horsfield B. (2003) Intact phospholipids-microbial "life markers" in marine deep subsurface sediments. Organic Geochemistry 34, 755-769. 
3.

\section{Spectral characterization of ten cyclic lipids using time-of-flight secondary ion mass spectrometry}

Tim Leefmann, Christine Heim, Sandra Siljeström, Martin Blumenberg, Peter Sjövall, and Volker Thiel

Rapid Communications in Mass Spectrometry (2013), 27, 565-581

DOI: 10.1002/rcm.6483; Reprinted with permission of John Wiley and Sons

\subsection{Abstract}

RATIONALE: Over the last decade, the high lateral resolution and imaging capabilities of time-of-flight secondary ion mass spectrometry (ToF-SIMS) have increasingly stimulated interest in studying organic molecules in complex environmental materials. However, unlike with the established mass spectrometric techniques, the use of ToF-SIMS in the biogeosciences is still hampered by a lack of reference spectra of the relevant biomarker compounds. Here we present and interpret ToF-SIMS reference spectra of ten different cyclic lipids that are frequently used as biological tracers in ecological, organic geochemical and geobiological studies.

METHODS: Standard compounds of $\alpha, \beta, \beta-(20 R, 24 S)-24$-methylcholestane, (22E)ergosta-5,7,22-trien-3 $\beta$-ol, $17 \alpha(\mathrm{H}), 21 \beta(\mathrm{H})$-30-norhopane, hope-17(21)-ene, hop22(29)-ene, $17 \beta(\mathrm{H}), 21 \beta(\mathrm{H})$-bacteriohopane-32,33,34,35-tetrol, $17 \beta(\mathrm{H}), 21 \beta(\mathrm{H})-35$ aminobacteriohopane-32,33,34-triol, $\alpha$-tocopherol, $\beta, \beta$-carotene, chlorophyll $a$, and cryosections of microbial mats and a fungus were analyzed using a ToF-SIMS instrument equipped with a $\mathrm{Bi}_{3}{ }^{+}$cluster ion source.

RESULTS: The spectra obtained from the standard compounds showed peaks in the molecular weight range (molecular ions, protonated and deprotonated molecules, adduct ions) and diagnostic fragment ion peaks in both, positive and negative ion modes. For the cyclic hydrocarbons, however, the positive ion mode spectra typically showed more and stronger characteristic peaks than the negative ion mode spectra. Using real world samples the capability of ToF-SIMS to detect and image 
selected compounds in complex organic matrices was tested. $17 \beta(\mathrm{H}), 21 \beta(\mathrm{H})-35$ aminobacteriohopane-32,33,34-triol, carotene and chlorophyll $a$ were successfully identified in cryosections of microbial mats, and the distribution of ergosterol was mapped at $\mathrm{mm}$ resolution in a cryosection of a fungus (Tuber uncinatum).

CONCLUSIONS: This study further highlights the utility of ToF-SIMS for the identification and localization of biomarkers within environmental samples and as a technique for biomarker-related research in organic geochemistry and geobiology.

\subsection{Introduction}

Time-of-flight secondary ion mass spectrometry (ToF-SIMS; Benninghoven, 1994; Vickerman and Briggs, 2001) offers the ability to image the lateral distribution of organic and inorganic ions on solid surfaces at the microscopic level. Since the advent of cluster ion sources, which provided an improved potential to detect large organic ions and molecular species, ToF-SIMS has increasingly been used to analyze biological materials (Belu et al., 2003; Brunelle and Laprévote, 2009; Sjövall et al., 2004; Touboul et al., 2005a; Touboul et al., 2005b; Winograd and Garrison, 2010). In particular the imaging feature and the high ( $\mathrm{mm}-$ ) lateral resolution have been considered as major advantages of ToF-SIMS compared with conventionally applied mass spectrometric techniques such as coupled gas, or liquid, chromatography and mass spectrometry (GC/MS, LC/MS). These capabilities are of particular interest in the analysis of environmental samples, where individual microstructures of interest, such as different tissues, microbial cell colonies, or fluid inclusions need to be analyzed on a very small spatial scale (Thiel et al., 2007a; Thiel et al., 2007b). Previous studies have shown that ToF-SIMS can be effectively used to study cyclic hydrocarbon biomarkers in extracts and fluid inclusions(Siljeström et al., 2010; Siljeström et al., 2009; Steele et al., 2001) and cyclic membrane lipids in biological tissues (Nygren et al., 2004; Nygren et al., 2006; Sjövall et al., 2004). However, a major obstacle that still hampers the use of ToF-SIMS in fields such as microbial ecology, geobiology, and organic geochemistry, is a lack of reference spectra for biogeochemically relevant compounds. Reference spectra are of particular importance for the interpretation of ToF-SIMS data, because SIMS spectra may significantly differ from published mass spectra generated by conventional GC/MS or LC/MS, as different fragmentation pathways and ionization mechanisms may 
exist (Spool, 2004). In this study we present ToF-SIMS reference spectra of ten cyclic lipid standards, encompassing members from five major compound families, i.e. steroids, hopanoids, tocopherols, carotenoids and porphyrins.

Steroids, in particular steroid alcohols (sterols), are important constituents of eukaryotic cells that regulate the membrane fluidity and permeability (Volkman, 2003). Sterols and their diagenetic products, steranes (Mackenzie et al., 1982), are thus important biomarkers commonly used in geobiology and organic geochemistry. The most common sterol observed in mammalian tissue is cholesterol. By contrast, many fungi instead synthesize ergosterol as their major membrane sterol, a C-24 alkylated compound that cannot be produced by mammals (Volkman, 2003).

Hopanoids (Talbot et al., 2001) are produced by various bacterial species (Pearson et al., 2009; Rohmer et al., 1984; Talbot et al., 2001) and are frequently used as bacterial biomarkers in modern and ancient sediments. Most sediments contain side-chain functionalized bacteriohopanepolyols (BHPs) or their diagenetic derivatives, hopanes (Ourisson and Albrecht, 1992). BHPs with distinctive functional groups or substituents may, in some cases, reflect phylogenic affiliations. Therefore, the concentrations and distributions of BHPs are useful indicators for the reconstruction of recent and ancient bacterial communities (Blumenberg et al., 2009; Coolen et al., 2008; Summons et al., 1999).

Carotenoids are produced by plants, fungi, bacteria and archaea. Except for some aphids (Moran and Jarvik, 2010), no animal has so far been found capable of synthesizing carotenoids (Fraser and Bramley, 2004). Nevertheless, these compounds are taken up with the diet, and are often involved in the animals integumentary coloration. In photosynthetic organisms carotenoids serve as important protection against cellular damage from triplestate chlorophylls, whereas they function as antioxidants in non-photosynthetic bacteria.

Similar to carotenoids, tocopherols are important chainbreaking antioxidants in living organisms, protecting e.g. polyunsaturated fatty acids, important cell membrane constituents, from oxidative stress (Burton and Ingold, 1986). $\alpha$ Tocopherol has been detected with ToF-SIMS in various kinds of tissues (Debois et al., 2009; Monroe et al., 2005; Touboul et al., 2005a).

Chlorophylls, found in all kinds of photosynthetic organisms, are the most abundant tetrapyrroles in the biosphere (Peters et al., 2005). Chlorophyll $a$, which is 
analyzed in this study, is present in the photosystems I and II of cyanobacteria, algae, and higher land plants. Various ionization techniques have been used to obtain mass spectra for chlorophyll $a$ in previous studies, including electron ionization (EI) (Constantin et al., 1981) and plasma desorption (Chait and Field, 1984; Hunt et al., 1981).

The aim of this study is to provide basic information about the ToF-SIMS fragmentation patterns and adduct formation of these cyclic lipids in different (positive and negative) analytical modes. The cyclic lipid standard compounds were analyzed using the high mass resolution mode, and the fragmentation patterns are discussed. In addition, we used the ion imaging capability of ToF-SIMS to identify and precisely localize a BHP, carotene, chlorophyll $a$, and ergosterol in two microbial mats and a fungus. The ToF-SIMS ion imaging data from these environmental samples were then correlated with optical microscopy images of the same areas of interest.

\subsection{Experimental}

Eight reference standards of commercially available cyclic lipids and two BHP standards isolated from microbial biomass were selected for analysis (Table 3-1).

Table 3-1. Cyclic lipid standard compounds analyzed.

\begin{tabular}{|c|c|c|}
\hline Compound & Abbreviation & Producer \\
\hline$\alpha \beta \beta-(20 \mathrm{R}, 24 S)-24$-methylcholestane & ergostane & Chiron AS, Trondheim, Norway \\
\hline (22E)-ergosta-5,7,22-trien-3 $\beta$-ol & ergosterol & Sigma-Aldrich, Steinheim, Germany \\
\hline $17 \alpha(\mathrm{H}), 21 \beta(\mathrm{H})-30$-norhopane & norhopane & Chiron AS, Trondheim, Norway \\
\hline hop-17(21)-ene & - & Chiron AS, Trondheim, Norway \\
\hline hop-22(29)-ene & diploptene & Chiron AS, Trondheim, Norway \\
\hline $\begin{array}{l}17 \beta(\mathrm{H}), 21 \beta(\mathrm{H}) \text {-bacteriohopane- } \\
32,33,34,35 \text {-tetrol }\end{array}$ & BHT & $\begin{array}{l}\text { isolate from Acetobacter xylinum } \\
\text { (provided by Michel Rohmer, } \\
\text { Université Louis-Pasteur de } \\
\text { Strasbourg, Strasbourg, France) }\end{array}$ \\
\hline $\begin{array}{l}17 \beta(\mathrm{H}), 21 \beta(\mathrm{H})-35- \\
\text { aminobacteriohopane-32,33,34-triol }\end{array}$ & ABHT & $\begin{array}{l}\text { isolate from Methylosinus } \\
\text { trichosporium (Strain provided by } \\
\text { Martin Krüger, BGR, Hannover, } \\
\text { Germany) }\end{array}$ \\
\hline$\alpha$-tocopherol & - & Sigma-Aldrich, Steinheim, Germany \\
\hline$\beta, \beta$-carotene & - & $\begin{array}{l}\text { Fluka (Sigma-Aldrich, Steinheim, } \\
\text { Germany) }\end{array}$ \\
\hline chlorophyll $a$ & - & Sigma-Aldrich, Steinheim, Germany \\
\hline
\end{tabular}

All samples were stored at $-18^{\circ} \mathrm{C}$ in the dark, using glass vials with Teflon septa before analysis. A minute (mg) amount of each reference standard was dissolved in pre-distilled solvents (dichloromethane, $n$-hexane). Due to sample limitation only mg amounts of BHT and ABHT were available. For ToF-SIMS analysis, the 
compounds were deposited on silicon wafers. Prior to deposition, the wafers were rinsed with deionized water and cleaned in a UV ozone apparatus in order to remove any organic contaminants from the surface. For each standard, a few mL of solution were placed with a glass pipette on a silicon wafer and the organic solvent was allowed to evaporate. The depositions were carried out in a laminar air flow cabinet in order to avoid airborne contamination. As controls, blank silicon wafers were exposed to the same conditions during sample preparation, and analyzed in parallel. To keep track of contaminants, ToF-SIMS spectra were also obtained from substrate surfaces after the evaporation of the pure solvents. Typically, sets of six samples were mounted on a sample holder and introduced to the vacuum chamber of the ToF-SIMS instrument immediately after preparation.

To check the capability of ToF-SIMS to directly detect carotenoids, chlorophylls, BHPs and sterols in environmental samples, cryosections of microbial mats and a fungus (Tuber uncinatum), were analyzed.

Samples of a mineralizing (iron-oxide forming) microbial mat harboring highly diverse microbial communities consisting mainly of iron-, ammonia- and nitriteoxidizing bacteria, magnetotactic bacteria and crenarchaeota (unpublished data) were retrieved from Äspö Hard Rock Laboratory (Figeholm, Sweden), from a depth of $150 \mathrm{~m}$ below sea level. From the same site, samples of a green (phototrophic) microbial mat harboring mainly diatoms were obtained from an artificially illuminated flow reactor connected to a fluid outflow at $183 \mathrm{~m}$ below sea level. Samples of burgundy truffle (Tuber uncinatum) were kindly provided by Richard Splivallo (Molecular Phytopathology and Mycotoxin Research, University of Göttingen, Germany). The samples were stored at $-18^{\circ} \mathrm{C}$ until the preparation of cryosections. The cryosections were prepared by gluing a piece of sample onto a cork sample holder using Super Cryoembedding Medium (SCEM; SECTION-LAB Co. Ltd., Hiroshima, Japan) for the truffle and Cryo-Gel ${ }^{\circledR}$ (Electron Microscopy Sciences, Hatfield, PA, USA) for the green and the mineralizing microbial mat. The truffle sample was stored at $-18^{\circ} \mathrm{C}$ in the cryochamber of a Leica CM1100 cryomicrotome (Leica Microsystems, Wetzlar, Germany) until solidification of the embedding agent whereas the mat samples were frozen for $30 \mathrm{~s}$ in cold isopentane at $-150^{\circ} \mathrm{C}$ before transfer into the cryochamber. Thick cryosections $(6-9 \mathrm{~mm})$ were cut from the samples and deposited on standard microscopic slides $(76 \times 26 \mathrm{~mm})$. The sections 
were stored at $-20^{\circ} \mathrm{C}$ in closed glass containers under an argon atmosphere until analysis. Prior to transfer into the ToF-SIMS instrument, the slides were allowed to approach room temperature with the glass container kept closed, in order to avoid condensation of water vapor on the sample.

All glassware (microscope slides, pipettes, vials, beakers, glass containers) was heated to $400^{\circ} \mathrm{C}$ for $2 \mathrm{~h}$ prior to use, and/or cleaned by intensive rinsing in deionized water and acetone. Solvent rinsing was also used to clean all steelware (spatula, tweezers, microtome knives) prior to use.

ToF-SIMS images and spectra of positive and negative ions were recorded using a ToF-SIMS IV instrument (ION-TOF GmbH, Münster, Germany) equipped with a bismuth cluster metal ion source. $25 \mathrm{keV} \mathrm{Bi}_{3}{ }^{+}$cluster primary ions were used at accumulated dose densities of between $2.5 \times 10^{10}$ and $4.6 \times 10^{12}$ ions $/ \mathrm{cm}^{2}$. Lowenergy electron flooding was used for charge compensation on the cryosections. The analyzed areas were between $100 \times 100 \mathrm{~mm}^{2}$ and $500 \times 500 \mathrm{~mm}^{2}$. For peak identification, spectra of all standard compounds and environmental samples were obtained in bunched mode (high mass resolution), resulting in a mass resolution, $m / \Delta m$, of 3000-5000 and a lateral resolution of 3-4 mm. In addition, ion images of the green microbial mat cryosection were produced using the burst alignment mode (high spatial resolution) with a lateral resolution of $0.4 \mathrm{~mm}$. The areas were scanned in a raster pattern at $128 \times 128$ and $256 \times 256$ pixels for the standards, and at $256 \times 256$ pixels for the cryosections.

Using the burst alignment mode, the mass resolution was considerably reduced to $\sim 300$. Differentiating overlapping peaks, in particular in higher mass regions, could thus become impossible. Therefore, all areas analyzed in burst alignment mode were also analyzed in bunched mode, i.e. at high mass resolution $(\mathrm{m} / \Delta \mathrm{m}$ 4000), and carefully checked for the contributions of other ions to those of the target compounds.

The assignments of spectral peaks to specific ions were based on the exact mass of the peaks, measured in bunched mode, and by comparing the measured with the theoretical isotope distributions of the ions. 


\subsection{Results and discussion}

The main characteristic peaks obtained from the positive and negative ion mode spectra of the different standard compounds are listed in Table 3-2. In SIMS, the mass spectra originate from secondary ions that are generated during high-energy collisions of the primary ions with the sample surface. These high-energy collisions produce a highly energized region around the point of impact, where secondary ions can be formed by a multitude of mechanisms involving fragmentation, recombination, ionization and desorption. The size and type of the primary (cluster) ion used can have a major influence on the fragmentation pattern observed for a specific compound in the secondary ion mass spectrum (Muramoto et al., 2011). Likewise, the chemical environment, i.e. the matrix from which the secondary ion is emitted, can impact the intensity of fragment or adduct ion peaks in the secondary ion mass spectrum (Vickerman, 2011). This has to be taken into account when comparing the data presented in the following with data obtained using other than $\mathrm{Bi}_{3}{ }^{+}$primary ions, or other sample matrices. The tentative ion assignments in Table 3-2 provide 'theoretical' chemical compositions of ions consistent with (i) the observed peak position measured at high mass resolution, (ii) the molecular structure of the standard compound, and (iii) previously reported assignments in ToF-SIMS and other mass spectrometric ionization methods (e.g. EI). However, the assignments given in the table and the following discussion should not be understood as descriptions of the actual structures or formation mechanisms, but rather give the theoretical compositions of the ions. In particular, while the assignments of ions in the mass region around and above the molecular weight of the analyte are given with reference to the molecular mass (e.g., $\left.\left[\mathrm{M}+\mathrm{CH}_{5}\right]^{+}\right)$, these assignments are not necessarily intended to suggest a formation mechanism (in this case the formation of an adduct between the molecule and $\mathrm{CH}_{5}{ }^{+}$) of the secondary ion, but rather to describe the chemical composition of the ion. The actual ion formation mechanism may involve multiple fragmentation and recombination processes of which our results only provide limited information. As the multiply charged ions are significantly less abundant in ToF-SIMS than single charged ions, all spacings between spectral peaks are in the following given in ' $u$ ' 
Table 3-2. Characteristic peaks observed for the cyclic lipid standard compounds and tentative ion assignments.

\begin{tabular}{|c|c|c|c|c|c|c|c|c|}
\hline $\begin{array}{l}\text { Compound } \\
\text { (abbreviation; formula; exact mass) }\end{array}$ & $\begin{array}{l}\text { Measured } \\
m / z(+)\end{array}$ & $\begin{array}{l}\text { Calculate } \\
\text { d } m / z(+)\end{array}$ & $\begin{array}{l}\text { Error } \\
\text { (ppm) }\end{array}$ & $\begin{array}{l}\text { Tentative } \\
\text { formula }\end{array}$ & $\begin{array}{l}\text { Measured } \\
m / z(-)\end{array}$ & $\begin{array}{l}\text { Calculate } \\
\text { d } m / z(-)\end{array}$ & $\begin{array}{l}\text { Error } \\
\text { (ppm) }\end{array}$ & $\begin{array}{l}\text { Tentative } \\
\text { formula }\end{array}$ \\
\hline $\begin{array}{l}\alpha \beta \beta-(20 R, 24 S)-24-\text { Methylcholestane } \\
\text { (ergostane; } \mathrm{C}_{28} \mathrm{H}_{50} ; 386.39 \text { ) }\end{array}$ & $\begin{array}{l}149.14 \\
163.16 \\
203.19 \\
217.20 \\
218.21 \\
257.23 \\
259.25 \\
369.36 \\
371.37 \\
385.39 \\
\end{array}$ & $\begin{array}{l}149.13 \\
163.15 \\
203.18 \\
217.20 \\
218.20 \\
257.23 \\
259.24 \\
369.35 \\
371.37 \\
385.38 \\
\end{array}$ & $\begin{array}{l}50.73 \\
46.41 \\
31.48 \\
31.13 \\
37.53 \\
34.60 \\
26.96 \\
13.32 \\
18.08 \\
20.74 \\
\end{array}$ & $\begin{array}{l}{\left[\mathrm{C}_{11} \mathrm{H}_{17}\right]^{+}} \\
{\left[\mathrm{C}_{12} \mathrm{H}_{19}\right]^{+}} \\
{\left[\mathrm{C}_{15} \mathrm{H}_{23}\right]^{+}} \\
{\left[\mathrm{C}_{16} \mathrm{H}_{25}\right]^{+}} \\
{\left[\mathrm{C}_{16} \mathrm{H}_{26}\right]^{+}} \\
{\left[\mathrm{C}_{19} \mathrm{H}_{29}\right]^{+}} \\
{\left[\mathrm{C}_{19} \mathrm{H}_{31}\right]^{+}} \\
{\left[\mathrm{C}_{27} \mathrm{H}_{45}\right]^{+}} \\
{\left[\mathrm{C}_{27} \mathrm{H}_{47}\right]^{+}} \\
{[\mathrm{M}-\mathrm{H}]^{+}}\end{array}$ & & & & \\
\hline $\begin{array}{l}\text { (22E)-Ergosta-5,7,22-trien-3 } \beta \text {-ol } \\
\text { (ergosterol; } \mathrm{C}_{28} \mathrm{H}_{44} \mathrm{O} ; 396.34 \text { ) }\end{array}$ & $\begin{array}{l}269.19 \\
271.21 \\
299.24 \\
363.28 \\
377.31 \\
379.34 \\
396.33 \\
\end{array}$ & $\begin{array}{l}269.19 \\
271.21 \\
299.24 \\
363.31 \\
377.32 \\
379.34 \\
396.34 \\
\end{array}$ & $\begin{array}{l}1.00 \\
0.34 \\
-7.44 \\
62.13 \\
-25.36 \\
-0.84 \\
-13.23 \\
\end{array}$ & $\begin{array}{l}{\left[\mathrm{C}_{19} \mathrm{H}_{25} \mathrm{O}\right]^{+}} \\
{\left[\mathrm{C}_{19} \mathrm{H}_{27} \mathrm{O}\right]^{+}} \\
{\left[\mathrm{C}_{21} \mathrm{H}_{31} \mathrm{O}\right]^{+}} \\
{\left[\mathrm{C}_{27} \mathrm{H}_{39}\right]^{+}} \\
{\left[\mathrm{C}_{28} \mathrm{H}_{41}\right]^{+}} \\
{\left[\mathrm{C}_{28} \mathrm{H}_{43}\right]^{+}} \\
{[\mathrm{M}]^{+\bullet}}\end{array}$ & $\begin{array}{l}377.29 \\
395.32\end{array}$ & $\begin{array}{l}377.32 \\
395.33\end{array}$ & $\begin{array}{l}-73.18 \\
-18.99\end{array}$ & $\begin{array}{l}{\left[\mathrm{C}_{28} \mathrm{H}_{41}\right]^{-}} \\
{[\mathrm{M}-\mathrm{H}]^{-}}\end{array}$ \\
\hline $\begin{array}{l}17 \alpha(\mathrm{H}), 21 \beta(\mathrm{H}) \text {-Norhopane } \\
\text { (norhopane; } \mathrm{C}_{29} \mathrm{H}_{50} ; 398.39 \text { ) }\end{array}$ & $\begin{array}{l}149.14 \\
163.15 \\
177.17 \\
191.18 \\
205.21 \\
219.22 \\
259.25 \\
367.35 \\
369.36 \\
383.38 \\
397.40 \\
\end{array}$ & $\begin{array}{l}149.13 \\
163.15 \\
177.16 \\
191.18 \\
205.20 \\
219.21 \\
259.24 \\
367.34 \\
369.35 \\
383.37 \\
397.38 \\
\end{array}$ & $\begin{array}{l}28.51 \\
27.67 \\
35.58 \\
36.98 \\
45.57 \\
52.53 \\
31.67 \\
35.84 \\
31.54 \\
36.75 \\
44.29 \\
\end{array}$ & $\begin{array}{l}{\left[\mathrm{C}_{11} \mathrm{H}_{17}\right]^{+}} \\
{\left[\mathrm{C}_{12} \mathrm{H}_{19}\right]^{+}} \\
{\left[\mathrm{C}_{13} \mathrm{H}_{21}\right]^{+}} \\
{\left[\mathrm{C}_{14} \mathrm{H}_{23}\right]^{+}} \\
{\left[\mathrm{C}_{15} \mathrm{H}_{25}\right]^{+}} \\
{\left[\mathrm{C}_{16} \mathrm{H}_{27}\right]^{+}} \\
{\left[\mathrm{C}_{19} \mathrm{H}_{31}\right]^{+}} \\
{\left[\mathrm{C}_{27} \mathrm{H}_{43}\right]^{+}} \\
{\left[\mathrm{C}_{27} \mathrm{H}_{45}\right]^{+}} \\
{\left[\mathrm{C}_{28} \mathrm{H}_{47}\right]^{+}} \\
{[\mathrm{M}-\mathrm{H}]^{+}}\end{array}$ & & & & \\
\hline
\end{tabular}


Table 3-2. Characteristic peaks observed for the cyclic lipid standard compounds and tentative ion assignments (continued).

\begin{tabular}{|c|c|c|c|c|c|c|c|c|}
\hline $\begin{array}{l}\text { Compound } \\
\text { (abbreviation; formula; exact mass) }\end{array}$ & $\begin{array}{l}\text { Measured } \\
m / z(+)\end{array}$ & $\begin{array}{l}\text { Calculate } \\
\text { d } m / z(+)\end{array}$ & $\begin{array}{l}\text { Error } \\
\text { (ppm) }\end{array}$ & $\begin{array}{l}\text { Tentative } \\
\text { formula }\end{array}$ & $\begin{array}{l}\text { Measured } \\
m / z(-)\end{array}$ & $\begin{array}{l}\text { Calculate } \\
\text { d } m / z(-)\end{array}$ & $\begin{array}{l}\text { Error } \\
\text { (ppm) }\end{array}$ & $\begin{array}{l}\text { Tentative } \\
\text { formula }\end{array}$ \\
\hline $\begin{array}{l}\text { Hop-17(21)-ene } \\
\left(\mathrm{C}_{30} \mathrm{H}_{50} ; 410.39\right)\end{array}$ & $\begin{array}{l}149.13 \\
161.14 \\
175.15 \\
189.17 \\
191.18 \\
203.18 \\
217.20 \\
231.21 \\
367.32 \\
395.37 \\
409.40 \\
\end{array}$ & $\begin{array}{l}149.13 \\
161.13 \\
175.15 \\
189.16 \\
191.18 \\
203.18 \\
217.20 \\
231.21 \\
367.34 \\
395.37 \\
409.38 \\
\end{array}$ & $\begin{array}{l}33.08 \\
14.68 \\
4.32 \\
5.34 \\
8.21 \\
16.95 \\
24.29 \\
12.58 \\
-36.43 \\
27.65 \\
32.19 \\
\end{array}$ & $\begin{array}{l}{\left[\mathrm{C}_{11} \mathrm{H}_{17}\right]^{+}} \\
{\left[\mathrm{C}_{12} \mathrm{H}_{17}\right]^{+}} \\
{\left[\mathrm{C}_{13} \mathrm{H}_{19}\right]^{+}} \\
{\left[\mathrm{C}_{14} \mathrm{H}_{21}\right]^{+}} \\
{\left[\mathrm{C}_{14} \mathrm{H}_{23}\right]^{+}} \\
{\left[\mathrm{C}_{15} \mathrm{H}_{23}\right]^{+}} \\
{\left[\mathrm{C}_{16} \mathrm{H}_{25}\right]^{+}} \\
{\left[\mathrm{C}_{17} \mathrm{H}_{27}\right]^{+}} \\
{\left[\mathrm{C}_{27} \mathrm{H}_{43}\right]^{+}} \\
{\left[\mathrm{C}_{29} \mathrm{H}_{47}\right]^{+}} \\
{[\mathrm{M}-\mathrm{H}]^{+}}\end{array}$ & & & & \\
\hline $\begin{array}{l}\text { Hop-22(29)-ene } \\
\text { (diploptene; } \mathrm{C}_{30} \mathrm{H}_{50} ; 410.39 \text { ) }\end{array}$ & $\begin{array}{l}149.13 \\
161.13 \\
177.17 \\
189.16 \\
191.18 \\
203.18 \\
205.20 \\
217.20 \\
219.21 \\
231.21 \\
367.33 \\
369.36 \\
393.35 \\
395.37 \\
409.39 \\
411.40\end{array}$ & $\begin{array}{l}149.13 \\
161.13 \\
177.16 \\
189.16 \\
191.18 \\
203.18 \\
205.20 \\
217.20 \\
219.21 \\
231.21 \\
367.34 \\
369.35 \\
393.35 \\
395.37 \\
409.38 \\
411.40\end{array}$ & $\begin{array}{l}-7.38 \\
-4.72 \\
8.13 \\
-3.99 \\
7.02 \\
-4.37 \\
-2.66 \\
9.94 \\
7.57 \\
9.38 \\
-9.61 \\
16.27 \\
6.44 \\
4.85 \\
4.86 \\
3.24\end{array}$ & $\begin{array}{l}{\left[\mathrm{C}_{11} \mathrm{H}_{17}\right]^{+}} \\
{\left[\mathrm{C}_{12} \mathrm{H}_{17}\right]^{+}} \\
{\left[\mathrm{C}_{13} \mathrm{H}_{21}\right]^{+}} \\
{\left[\mathrm{C}_{14} \mathrm{H}_{21}\right]^{+}} \\
{\left[\mathrm{C}_{14} \mathrm{H}_{23}\right]^{+}} \\
{\left[\mathrm{C}_{15} \mathrm{H}_{23}\right]^{+}} \\
{\left[\mathrm{C}_{15} \mathrm{H}_{25}\right]^{+}} \\
{\left[\mathrm{C}_{16} \mathrm{H}_{25}\right]^{+}} \\
{\left[\mathrm{C}_{16} \mathrm{H}_{27}\right]^{+}} \\
{\left[\mathrm{C}_{17} \mathrm{H}_{27}\right]^{+}} \\
{\left[\mathrm{C}_{27} \mathrm{H}_{43}\right]^{+}} \\
{\left[\mathrm{C}_{27} \mathrm{H}_{45}\right]^{+}} \\
{\left[\mathrm{C}_{29} \mathrm{H}_{45}\right]^{+}} \\
{\left[\mathrm{C}_{29} \mathrm{H}_{47}\right]^{+}} \\
{[\mathrm{M}-\mathrm{H}]^{+}} \\
{[\mathrm{M}+\mathrm{H}]^{+}}\end{array}$ & & & & \\
\hline
\end{tabular}


Table 3-2. Characteristic peaks observed for the cyclic lipid standard compounds and tentative ion assignments (continued).

\begin{tabular}{|c|c|c|c|c|c|c|c|c|}
\hline $\begin{array}{l}\text { Compound } \\
\text { (abbreviation; formula; exact mass) }\end{array}$ & $\begin{array}{l}\text { Measured } \\
m / z(+)\end{array}$ & $\begin{array}{l}\text { Calculate } \\
\text { d } m / z(+)\end{array}$ & $\begin{array}{l}\text { Error } \\
\text { (ppm) }\end{array}$ & $\begin{array}{l}\text { Tentative } \\
\text { formula }\end{array}$ & $\begin{array}{l}\text { Measured } \\
m / z(-)\end{array}$ & $\begin{array}{l}\text { Calculate } \\
\mathrm{d} m / z(-)\end{array}$ & $\begin{array}{l}\text { Error } \\
\text { (ppm) }\end{array}$ & $\begin{array}{l}\text { Tentative } \\
\text { formula }\end{array}$ \\
\hline $\begin{array}{l}17 \beta(\mathrm{H}), 21 \beta(\mathrm{H}) \text {-Bacteriohopane-32,33,34,35- } \\
\text { tetrol } \\
\left(\mathrm{BHT} ; \mathrm{C}_{35} \mathrm{H}_{62} \mathrm{O}_{4} ; 546.47\right)\end{array}$ & $\begin{array}{l}369.38 \\
547.52\end{array}$ & $\begin{array}{l}369.35 \\
547.47\end{array}$ & $\begin{array}{l}61.97 \\
92.22\end{array}$ & $\begin{array}{l}{\left[\mathrm{C}_{27} \mathrm{H}_{45}\right]^{+}} \\
{[\mathrm{M}+\mathrm{H}]^{+}}\end{array}$ & & & & \\
\hline $\begin{array}{l}17 \beta(\mathrm{H}), 21 \beta(\mathrm{H})-35 \text {-Aminobacteriohopane- } \\
32,33,34 \text {-triol } \\
\left(\mathrm{ABHT} ; \mathrm{C}_{35} \mathrm{H}_{63} \mathrm{NO}_{3} ; 545.48\right)\end{array}$ & $\begin{array}{l}191.19 \\
272.26 \\
392.32 \\
546.51 \\
\end{array}$ & $\begin{array}{l}191.18 \\
272.25 \\
392.32 \\
546.49 \\
\end{array}$ & $\begin{array}{l}69.65 \\
39.47 \\
15.47 \\
50.14 \\
\end{array}$ & $\begin{array}{l}{\left[\mathrm{C}_{14} \mathrm{H}_{23}\right]^{+}} \\
{\left[\mathrm{C}_{20} \mathrm{H}_{32}\right]^{+}} \\
{\left[\mathrm{C}_{24} \mathrm{H}_{42} \mathrm{NO}_{3}\right]^{+}} \\
{[\mathrm{M}+\mathrm{H}]^{+}}\end{array}$ & & & & \\
\hline $\begin{array}{l}\alpha \text {-Tocopherol } \\
\left(\mathrm{C}_{29} \mathrm{H}_{50} \mathrm{O}_{2} ; 430.38\right)\end{array}$ & $\begin{array}{l}151.08 \\
165.09 \\
175.07 \\
189.09 \\
203.10 \\
205.12 \\
217.12 \\
415.36 \\
430.37 \\
\end{array}$ & $\begin{array}{l}151.08 \\
165.09 \\
175.08 \\
189.09 \\
203.11 \\
205.12 \\
217.12 \\
415.36 \\
430.38 \\
\end{array}$ & $\begin{array}{l}22.14 \\
18.03 \\
-12.05 \\
-27.31 \\
-21.40 \\
-18.09 \\
-8.60 \\
-4.77 \\
-24.54 \\
\end{array}$ & $\begin{array}{l}{\left[\mathrm{C}_{9} \mathrm{H}_{11} \mathrm{O}_{2}\right]^{+}} \\
{\left[\mathrm{C}_{10} \mathrm{H}_{13} \mathrm{O}_{2}\right]^{+}} \\
{\left[\mathrm{C}_{11} \mathrm{H}_{11} \mathrm{O}_{2}\right]^{+}} \\
{\left[\mathrm{C}_{12} \mathrm{H}_{13} \mathrm{O}_{2}\right]^{+}} \\
{\left[\mathrm{C}_{13} \mathrm{H}_{15} \mathrm{O}_{2}\right]^{+}} \\
{\left[\mathrm{C}_{13} \mathrm{H}_{17} \mathrm{O}_{2}\right]^{+}} \\
{\left[\mathrm{C}_{14} \mathrm{H}_{17} \mathrm{O}_{2}\right]^{+}} \\
{\left[\mathrm{C}_{28} \mathrm{H}_{47} \mathrm{O}_{2}\right]^{+}} \\
{[\mathrm{M}]^{+\bullet}}\end{array}$ & $\begin{array}{l}149.06 \\
163.08 \\
175.08 \\
189.09 \\
203.10 \\
218.13 \\
414.34 \\
429.37\end{array}$ & $\begin{array}{l}149.06 \\
163.08 \\
175.08 \\
189.09 \\
203.11 \\
218.13 \\
414.35 \\
429.37\end{array}$ & $\begin{array}{l}5.54 \\
-28.77 \\
-2.28 \\
-20.74 \\
-18.17 \\
-16.09 \\
-22.94 \\
-15.06\end{array}$ & $\begin{array}{l}{\left[\mathrm{C}_{9} \mathrm{H}_{9} \mathrm{O}_{2}\right]^{-}} \\
{\left[\mathrm{C}_{10} \mathrm{H}_{11} \mathrm{O}_{2}\right]^{-}} \\
{\left[\mathrm{C}_{11} \mathrm{H}_{11} \mathrm{O}_{2}\right]^{-}} \\
{\left[\mathrm{C}_{12} \mathrm{H}_{13} \mathrm{O}_{2}\right]^{-}} \\
{\left[\mathrm{C}_{13} \mathrm{H}_{15} \mathrm{O}_{2}\right]^{-}} \\
{\left[\mathrm{C}_{14} \mathrm{H}_{18} \mathrm{O}_{2}\right]^{-}} \\
{\left[\mathrm{C}_{28} \mathrm{H}_{46} \mathrm{O}_{2}\right]^{-}} \\
{[\mathrm{M}-\mathrm{H}]^{-}}\end{array}$ \\
\hline $\begin{array}{l}\beta, \beta \text {-Carotene } \\
\left(\mathrm{C}_{40} \mathrm{H}_{56} ; 536.44\right)\end{array}$ & $\begin{array}{l}444.35 \\
521.42 \\
536.43\end{array}$ & $\begin{array}{l}444.38 \\
521.41 \\
536.44\end{array}$ & $\begin{array}{l}-67.20 \\
10.05 \\
-6.57\end{array}$ & $\begin{array}{l}{\left[\mathrm{C}_{33} \mathrm{H}_{48}\right]^{+}} \\
{\left[\mathrm{C}_{39} \mathrm{H}_{53}\right]^{+}} \\
{[\mathrm{M}]^{+\bullet}}\end{array}$ & 536.43 & 536.44 & -18.75 & {$[\mathrm{M}]^{-\bullet}$} \\
\hline $\begin{array}{l}\text { Chlorophyll } a \\
\left(\mathrm{C}_{55} \mathrm{H}_{72} \mathrm{MgN}_{4} \mathrm{O}_{5} ; 892.54\right)\end{array}$ & $\begin{array}{l}453.15 \\
467.16 \\
481.16 \\
555.22 \\
614.26 \\
893.61 \\
915.61 \\
931.60 \\
\end{array}$ & $\begin{array}{l}453.16 \\
467.17 \\
481.19 \\
555.22 \\
614.24 \\
893.54 \\
915.53 \\
931.50 \\
\end{array}$ & $\begin{array}{l}-14.26 \\
-30.35 \\
-6.02 \\
-7.77 \\
30.13 \\
73.04 \\
90.12 \\
105.55 \\
\end{array}$ & $\begin{array}{l}{\left[\mathrm{C}_{28} \mathrm{H}_{21} \mathrm{MgN}_{4} \mathrm{O}\right]^{+}} \\
{\left[\mathrm{C}_{29} \mathrm{H}_{23} \mathrm{MgN}_{4} \mathrm{O}\right]^{+}} \\
{\left[\mathrm{C}_{30} \mathrm{H}_{25} \mathrm{MgN}_{4} \mathrm{O}\right]^{+}} \\
{\left[\mathrm{C}_{33} \mathrm{H}_{31} \mathrm{MgN}_{4} \mathrm{O}_{3}\right]^{+}} \\
{\left[\mathrm{C}_{35} \mathrm{H}_{34} \mathrm{MgN}_{4} \mathrm{O}_{5}\right]^{+}} \\
{[\mathrm{M}+\mathrm{H}]^{+}} \\
{[\mathrm{M}+\mathrm{Na}]^{+}} \\
{[\mathrm{M}+\mathrm{K}]^{+}}\end{array}$ & $\begin{array}{l}451.09 \\
467.14 \\
481.15 \\
525.17 \\
540.19 \\
613.29 \\
893.61\end{array}$ & $\begin{array}{l}451.14 \\
467.17 \\
481.19 \\
525.18 \\
540.20 \\
613.23 \\
893.54\end{array}$ & $\begin{array}{l}-93.33 \\
-59.60 \\
-72.52 \\
-22.78 \\
-19.53 \\
94.62 \\
71.51\end{array}$ & $\begin{array}{l}{\left[\mathrm{C}_{28} \mathrm{H}_{19} \mathrm{MgN}_{4} \mathrm{O}\right]^{-}} \\
{\left[\mathrm{C}_{29} \mathrm{H}_{23} \mathrm{MgN}_{4} \mathrm{O}\right]^{-}} \\
{\left[\mathrm{C}_{30} \mathrm{H}_{25} \mathrm{MgN}_{4} \mathrm{O}\right]^{-}} \\
{\left[\mathrm{C}_{31} \mathrm{H}_{25} \mathrm{MgN}_{4} \mathrm{O}_{3}\right]^{-}} \\
{\left[\mathrm{C}_{32} \mathrm{H}_{28} \mathrm{MgN}_{4} \mathrm{O}_{3}\right]^{-}} \\
{\left[\mathrm{C}_{35} \mathrm{H}_{33} \mathrm{MgN}_{4} \mathrm{O}_{5}\right]^{-}} \\
{[\mathrm{M}+\mathrm{H}]^{-}}\end{array}$ \\
\hline
\end{tabular}




\section{Reference compounds}

\subsection{1. $\alpha \beta \beta-(20 R, 24 S)-24-M e t h y l c h o l e s t a n e ~(E r g o s t a n e)$}

$\mathrm{C}_{28} \mathrm{H}_{50}$, exact mass: $386.39 \mathrm{u}$

The positive ion mode spectrum of ergostane (Figure 3-1) showed a strong $[\mathrm{M}-\mathrm{H}]^{+}$ ion at $m / z 385.39$ and a lower intensity peak at $m / z$ 399.41. The $[\mathrm{M}-\mathrm{H}]^{+}$peak might have been formed by ejection of an electron, which is a typical reaction mechanism for apolar hydrocarbon molecules (Delcorte and Bertrand, 1998), and subsequent elimination of a $\mathrm{H}^{\bullet}$ radical from one of the tertiary carbons of the odd-electron ion $\mathrm{M}^{+}$, as previously reported for other cyclic hydrocarbons (Siljeström et al., 2009; Steele et al., 2001). The lower intensity peak at $m / z 399.41$ fits very well with the mass of a $[\mathrm{M}+\mathrm{CH}]^{+}$ion. Such theoretical adduct ions have been reported before from the mass spectra of aromatic hydrocarbons (Spool, 2004) and the author proposed, in addition to the presence of an impurity in the standard, two possible sources, namely (i) fragment ions from dimers and (ii) collision with other fragments or with a hydrocarbon rich-surface after ion formation (Cooks et al., 1990). Both sources cannot be ruled out here, as the $\left(\mathrm{C}_{56} \mathrm{H}_{97} ;\left[\mathrm{M}_{2}-\mathrm{H}_{3}\right]^{+}\right)$dimer was detected at $\mathrm{m} / z$ 769.79 and a weak $[\mathrm{CH}]^{+}$ion was detected at $m / z 13.01$ (both not shown). However, compared with the $[\mathrm{M}-\mathrm{H}]^{+}$peak, the intensity of the potential adduct ion peak was very low in the standard spectrum, and it might thus be irrelevant for compound identification within environmental samples, where formation of such ions is probably suppressed by lower compound concentrations. The peak doublet at $\mathrm{m} / \mathrm{z}$ $369.36 / 371.37$ was consistent with the masses of $\left[\mathrm{M}-\mathrm{CH}_{5}\right]^{+}$and $\left[\mathrm{M}-\mathrm{CH}_{3}\right]^{+}$, respectively. Fragment ions at $m / z 371$ have been reported from EI spectra of ergostane (Reed, 1958) and were probably formed from the loss of a terminal $\mathrm{CH}_{3}$ group from the molecular ion. The peaks at $\mathrm{m} / z 257.23$ and 259.25 were consistent with the masses of $\left[\mathrm{C}_{19} \mathrm{H}_{29}\right]^{+}$and $\left[\mathrm{C}_{19} \mathrm{H}_{31}\right]^{+}$, respectively. The composition of these ions fitted to the mass of the sterane backbone after loss of the side chain (Figure 3-1; Peters et al., 2005). In the EI spectra of other 17ß-steranes (Gallegos and Moldowan, 1992), the $m / z 259$ peak typically had a higher intensity than the $m / z$ 257 peak and this difference was therefore used to distinguish the $17 \beta$ - from the $17 \alpha$-sterane isomer (Peters et al., 2005). The positive ion mode SIMS spectrum of 
ergostane showed, in contrast to the published EI spectra, a higher intensity of the peak at $m / z 257.23$ than that at $m / z 259.25$, suggesting a lower potential of ToFSIMS to differentiate between the two isomers. The peaks at $m / z 217.20$ and 218.21 were approximately equally intense and they were consistent with the $\left[\mathrm{C}_{16} \mathrm{H}_{25}\right]^{+}$and $\left[\mathrm{C}_{16} \mathrm{H}_{26}\right]^{+}$fragment ions, respectively. In the sterane EI spectra, the $m / z 217$ peak is diagnostic for $14 \alpha$-configuration, whereas $\mathrm{m} / z 218$ indicates the $14 \beta$-configuration (Gallegos and Moldowan, 1992). Both peaks were interpreted as originating from fragmentation in the D-ring (Peters et al., 2005), which further corroborated the ion assignment proposed above for the secondary ion spectrum. Similarly, the peak at $m / z 149.14$ was consistent with the mass of the $\left[\mathrm{C}_{11} \mathrm{H}_{17}\right]^{+}$fragment ion commonly observed in the EI spectra of $5 \alpha$-steranes and was interpreted as a product of fragmentation in the C-ring (Figure 3-1; Peters et al., 2005; Siljeström et al., 2009). Additional ions detected at $m / z 203.19$ and 163.16 probably corresponded to the characteristic sterane peaks observed in the EI spectra of other $5 \alpha, 14 \beta, 17 \beta$-steranes (Gallegos and Moldowan, 1992).

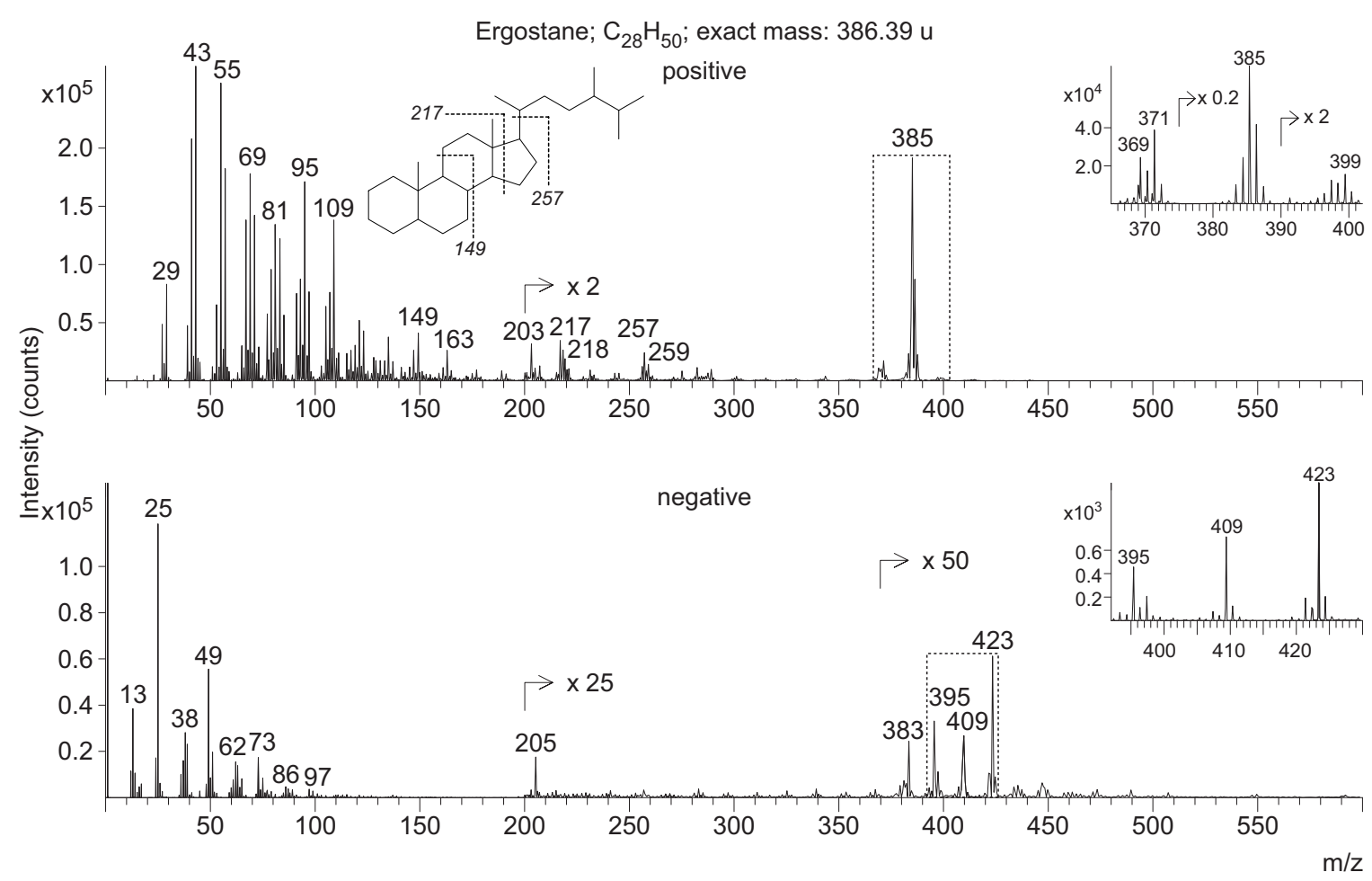

Figure 3-1. Partial positive and negative ion mode ToF-SIMS spectra $(m / z$ 0-600) of $\alpha, \beta, \beta-(20 R, 24 S)-24-$ methylcholestane (ergostane) standard. Dashed frames mark mass regions enlarged in insets. See text for a detailed discussion of the spectral patterns. 
In the negative ion mode spectrum, no distinctive molecular ions or deprotonated molecules of ergostane were present (Figure 3-1). However, an ion detected at $m / z 423.39$ might be explained as corresponding to the mass of a $\left[\mathrm{M}+\mathrm{C}_{3} \mathrm{H}\right]^{-}$ion. Such ions might originate from adduction of smaller hydrocarbon fragments such as $\left[\mathrm{C}_{3} \mathrm{H}_{2}\right]^{-}$, which was detected as a strong ion at $m / z 38.02$ (Figure $3-1$ ), to a neutral [M-H] fragment. However, it should be noted that the formation of such adduct ions would involve complex fragmentations and recombination processes, which are as yet poorly understood in SIMS and which might depend on the nature of the sample matrix and the primary ion source used. This interpretation therefore remains, with the information available, rather speculative. Further low intensity peaks, which were clearly organic, occurred at $m / z 409.37$, 395.36, and 383.36.

In conclusion, our results suggest that ergostane is best analyzed in positive ion mode due to the formation of a strong $[\mathrm{M}-\mathrm{H}]^{+}$peak and the characteristic fragment ion peak pattern similar to the mass spectral pattern produced by EI.

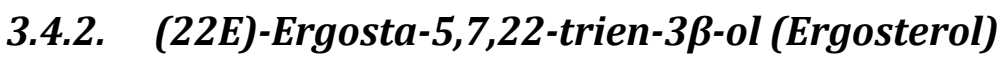

$\mathrm{C}_{28} \mathrm{H}_{44} \mathrm{O}$, exact mass: $396.34 \mathrm{u}$

In the positive ion mode spectrum of ergosterol (Figure 3-2), the [M] $]^{+\bullet}$ peak at $m / z$ 396.33 predominates. Lower intensity peaks in the molecular mass range were observed at $\mathrm{m} / \mathrm{z} 408.33$ and 411.33 . Similar to the ergostane spectrum, these peaks might represent impurities in the standard, but might also be the products of dimer fragment ions or of adduct ions originating from collision with smaller hydrocarbon species. An intense peak doublet at $\mathrm{m} / z$ 377.31/379.34 was consistent with the masses of $\left[\mathrm{M}-\mathrm{H}_{3} \mathrm{O}\right]^{+}$and $[\mathrm{M}-\mathrm{HO}]^{+}$fragment ions. Fragment ions originating from loss of water produce strong peaks in the EI spectra of $\Delta^{5,7}$-sterols owing to the presence of the C-5/C-6 double bond (Goad and Akihisa, 1997). Furthermore, cleavage of the terminal methyl group (Knights, 1967) plausibly explained the formation of the $\left[\mathrm{C}_{27} \mathrm{H}_{39}\right]^{+}$ion at $m / z$ 363.28, which is also very abundant in EI spectra of ergosterol (Kohlhase and Pohl, 1988). The weak peak at $m / z 299.24$ was consistent with the mass of a $\left[\mathrm{C}_{21} \mathrm{H}_{31} \mathrm{O}\right]^{+}$ion. Such an ion could originate from a pathway proposed for free 4-desmethylsterol monoenes in EI spectra (Wyllie and Djerassi, 1968) involving the breaking of the C-20/C-22 bond (Figure 3-2). Similarly, 
breaking of the $\mathrm{C}-17 / \mathrm{C}-20$ bond might lead to the formation of the peak doublet at $m / z 269.19 / 271.21$ as reported previously in the EI spectra of $\Delta^{22}-5 \alpha$-cholestene (Wyllie and Djerassi, 1968).

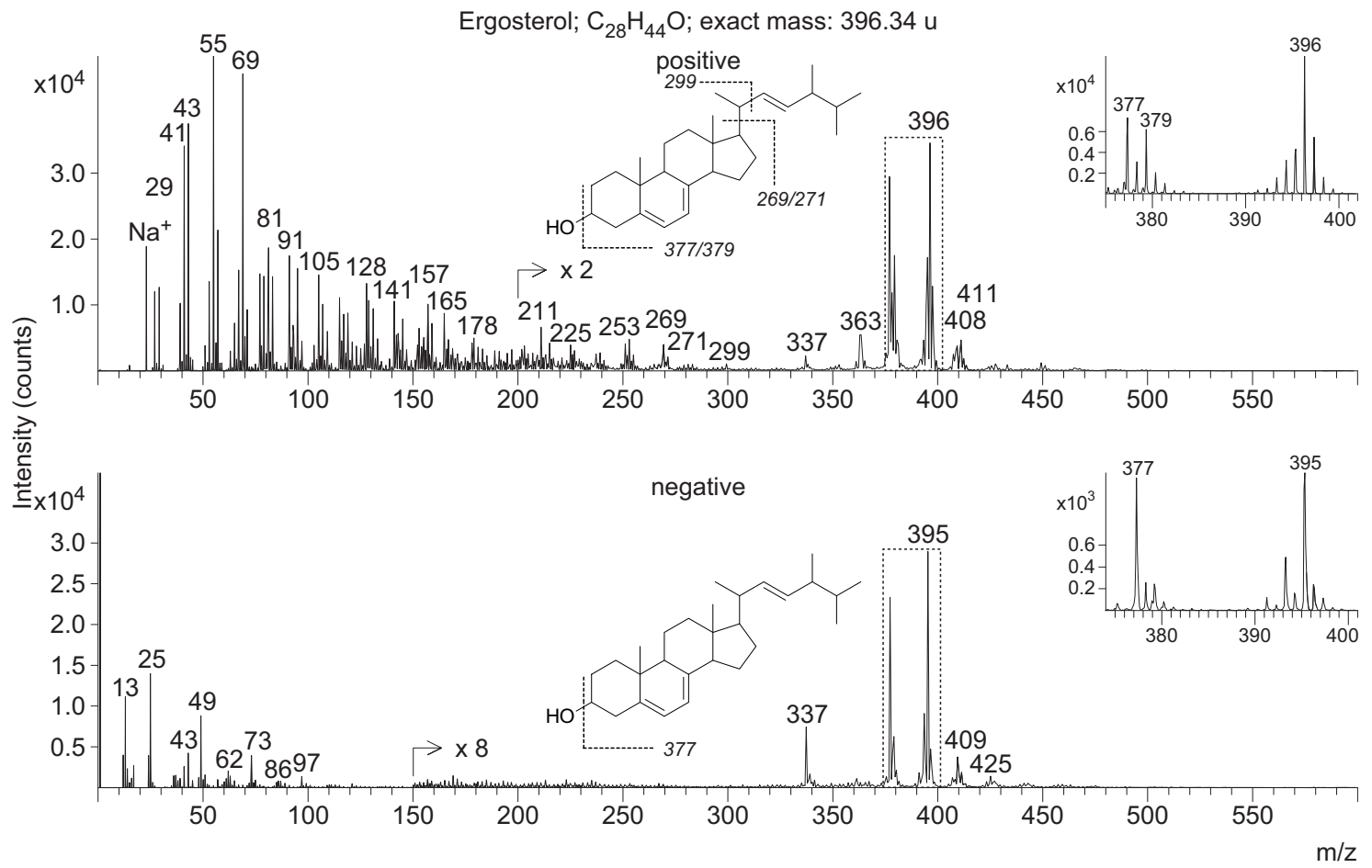

Figure 3-2. Partial positive and negative ion mode ToF-SIMS spectra $(\mathrm{m} / \mathrm{z}$ 0-600) of $(22 E)$-ergosta5,7,22-trien-3 $\beta$-ol (ergosterol) standard. Dashed frames mark mass regions enlarged in insets. See text for a detailed discussion of the spectral patterns.

In the negative ion mode spectrum, a strong $[\mathrm{M}-\mathrm{H}]^{-}$ion was detected at $\mathrm{m} / \mathrm{z}$ 395.32 (Figure 3-2). Lower intensity peaks were observed at $\mathrm{m} / \mathrm{z} 409.28$ and 425.29. Given their slightly lower decimal place values than the $[\mathrm{M}-\mathrm{H}]^{-}$ion, they might evolve from a partly oxidized standard, or originate from a yet unknown adduct formation pathway involving oxygen. Similar to the positive ion mode spectrum, a strong peak at $m / z 377.29$ could be attributed to the loss of $\mathrm{H}_{2} \mathrm{O}$ from the deprotonated molecule (Figure 3-2).

Thus, the positive and negative ion modes both proved to be suitable for the analysis of ergosterol. However, the positive mode showed a significantly higher yield for the molecular ion and also more characteristic fragment ions than the negative mode, and might thus be preferentially used for the analysis of ergosterol. 


\subsection{3. $17 \alpha(H), 21 \beta(H)-30-N o r h o p a n e(N o r h o p a n e)$}

$\mathrm{C}_{29} \mathrm{H}_{50}$, exact mass: $398.39 \mathrm{u}$

In the positive ion mode spectrum, norhopane produced a strong $[\mathrm{M}-\mathrm{H}]^{+}$ion at $m / z$ 397.40 (Figure 3-3). Less intense peaks observed at $m / z 409.41$ and 411.42 could not unambiguously be assigned to a specific ion. However, their $m / z$ values were consistent with the masses of $[\mathrm{M}-\mathrm{H}+\mathrm{C}]^{+}$and $[\mathrm{M}+\mathrm{CH}]^{+}$ions, suggesting a similar formation as proposed above for ergostane. A peak at $m / z 383.38$ was plausibly explained by the loss of a terminal $\mathrm{CH}_{3}$ group. The weak peaks at $m / z 367.35$ and 369.36 were consistent with $\left[\mathrm{C}_{27} \mathrm{H}_{43}\right]^{+}$and $\left[\mathrm{C}_{27} \mathrm{H}_{45}\right]^{+}$ions, and might originate from cleavage of the side chain from the pentacyclic hopane skeleton (Peters et al., 2005; Siljeström et al., 2009). The pronounced peaks at $m / z 259.25$ and 219.22 were consistent with $\left[\mathrm{C}_{19} \mathrm{H}_{31}\right]^{+}$and $\left[\mathrm{C}_{16} \mathrm{H}_{27}\right]^{+}$(Steele et al., 2001), respectively. Peaks observed at $m / z 177.17,191.18$, and 205.21 corresponded to $\left[\mathrm{C}_{13} \mathrm{H}_{21}\right]^{+},\left[\mathrm{C}_{14} \mathrm{H}_{23}\right]^{+}$, and $\left[\mathrm{C}_{15} \mathrm{H}_{25}\right]^{+}$, respectively, and probably originated from fragmentation in the $\mathrm{C}$ ring (Figure 3-3).

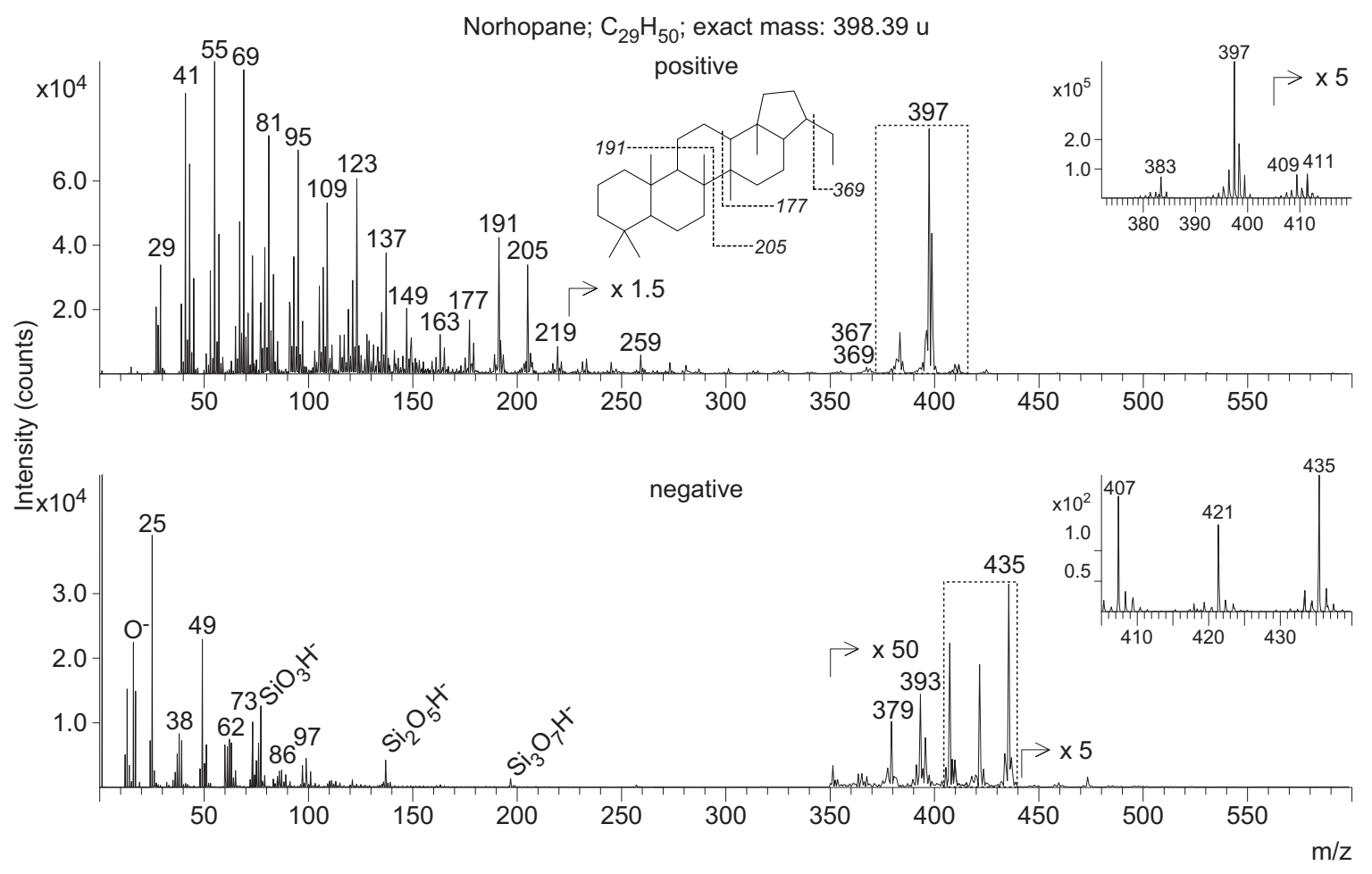

Figure 3-3. Partial positive and negative ion mode ToF-SIMS spectra $(m / z \quad 0-600)$ of $17 \alpha(H), 21 \beta(H)-30-$ norhopane (norhopane) standard. Dashed frames mark mass regions enlarged in insets. See text for a detailed discussion of the spectral patterns. Peaks labeled with $\mathrm{Si}_{\mathrm{x}} \mathrm{O}_{\mathrm{y}} \mathrm{H}$ are inorganic ions from the silicon wafer and do not belong to the compound spectrum. 
These characteristic peaks have been previously observed in the SIMS spectra (Siljeström et al., 2010; Steele et al., 2001) and the EI mass spectra of hopanes (Ourisson et al., 1979; Peters et al., 2005). Further peaks observed at $m / z 149.14$ and 163.15 were consistent with $\left[\mathrm{C}_{11} \mathrm{H}_{17}\right]^{+}$and $\left[\mathrm{C}_{12} \mathrm{H}_{19}\right]^{+}$fragment ions, respectively (Siljeström et al., 2010; Steele et al., 2001).

In the negative ion mode spectrum, no molecular ions or deprotonated molecules were observed, although weak peaks occurred at $m / z 379.34,393.34$, 407.35, and 421.37. A somewhat stronger peak observed at $m / z 435.39$ was in agreement with the mass of a $\left[\mathrm{M}+\mathrm{C}_{3} \mathrm{H}\right]^{-}$ion. This might point to a similar formation pathway as suggested above for the $m / z 423.39$ peak of ergostane, i.e. adduction of $\left[\mathrm{C}_{3} \mathrm{H}_{2}\right]^{-}$to a neutral $[\mathrm{M}-\mathrm{H}]$ fragment. In support of this, norhopane showed a strong peak at $m / z$ 38.02, corresponding to the $\left[\mathrm{C}_{3} \mathrm{H}_{2}\right]^{-}$ion.

Taken together, the lack of characteristic peaks in the negative ion mode spectrum and the strong and plausible peak pattern in the positive ion mode spectrum showed that norhopane is best analyzed in the positive ion mode.

\subsubsection{Hop-17(21)-ene}

$\mathrm{C}_{30} \mathrm{H}_{50}$, exact mass: $410.39 \mathrm{u}$

The positive ion mode ToF-SIMS spectrum of hop-17(21)-ene (Figure 3-4) showed a strong $[\mathrm{M}-\mathrm{H}]^{+}$ion at $\mathrm{m} / \mathrm{z}$ 409.40.A weaker peak at $\mathrm{m} / \mathrm{z} 425.37$ was best explained as a $[\mathrm{M}-\mathrm{H}+\mathrm{O}]^{+}$ion, which might suggest a partly oxidized standard compound (see the above comments for ergosterol). A similarly intense peak at $m / z 395.37$ plausibly corresponded to the loss of a terminal $\mathrm{CH}_{3}$ group from the molecular ion, whereas the peak at $m / z 367.32$ was consistent with the mass of $\left[\mathrm{M}-\mathrm{C}_{3} \mathrm{H}_{7}\right]^{+}$, and probably originated from cleavage of the propyl side chain. The peak at $m / z 191.18$ was a well-known diagnostic hopane fragment ion $\left[\mathrm{C}_{14} \mathrm{H}_{23}\right]^{+}$in EI (Ourisson and Albrecht, 1992) and SIMS spectra (Siljeström et al., 2009; Steele et al., 2001), originating from the ring $\mathrm{A}+\mathrm{B}$ fragment (Peters et al., 2005) after cleavage in the $\mathrm{C}$ ring (Figure 3-4). The peaks at $m / z 189.17$ and 217.20 (Figure 3-4) were consistent with the corresponding ring $\mathrm{D}+\mathrm{E}$ fragments whose double bond caused a shift by 2 u compared with the corresponding peak in the norhopane spectrum (Figure 3-3). Similarly, the peaks at $m / z 161.14,175.15$, and 203.18 (Figure 3-4) were shifted by 
2 u compared with the norhopane spectrum, and were thus also likely to represent double-bond-containing fragment ions.

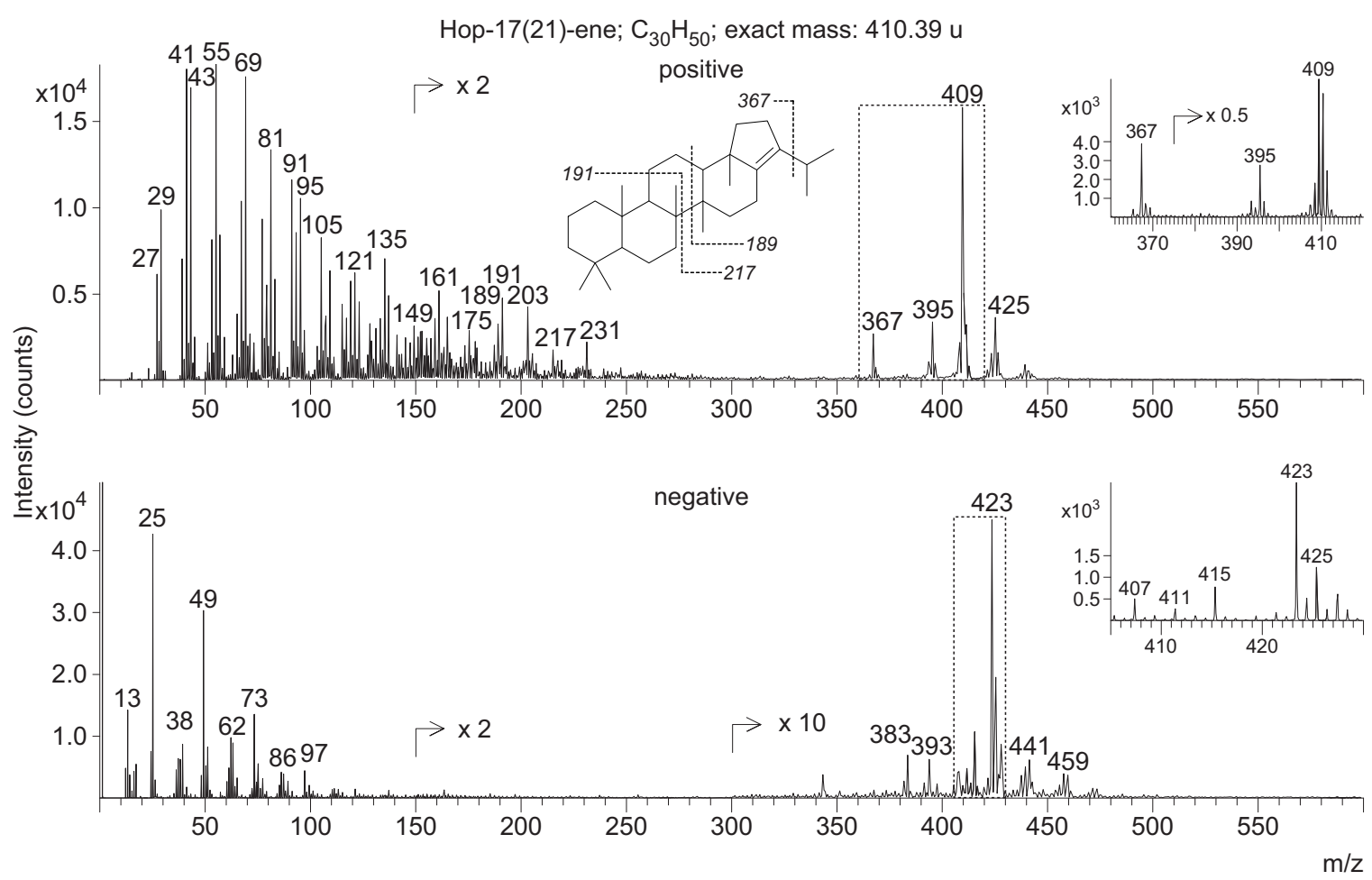

Figure 3-4. Partial positive and negative ion mode ToF-SIMS spectra $(\mathrm{m} / \mathrm{z}$ 0-600) of hop-17(21)-ene standard. Dashed frames mark mass regions enlarged in insets. See text for a detailed discussion of the spectral patterns.

In the negative ion mode spectrum (Figure 3-4) a weak peak was observed at $m / z$ 411.36. Slightly stronger peaks were observed at $m / z 415.33,423.37$, and 425.39. All these peaks clearly originated from organic species, but their exact masses did not fit very well to a pure hydrocarbon composition. Again it seemed that oxygen had been incorporated into these ions, thus suggesting that they originated from a partly oxidized standard. Further minor, not clearly assignable peaks in the molecular weight range included $m / z$ 393.35, 383.34, 407.37, 441.40, and 459.40. The latter was consistent with the mass of a $\left[\mathrm{M}+\mathrm{C}_{4} \mathrm{H}\right]^{-}$ion. It should be noted that the strong peak observed at $m / z 49.01$ (Figure 3-4) exactly corresponded to a $\left[\mathrm{C}_{4} \mathrm{H}\right]^{-}$ion, which might combine with the hop-17(21)-ene molecule to form the peak at $m / z 459.40$.

As for norhopane, the positive ion mode proved to be much more suitable for the analysis of hop-17(21)-ene than the negative ion mode, given the presence of 
several diagnostic ions and the high yield of the $[\mathrm{M}-\mathrm{H}]^{+}$peak observed at $m / z$ 409.40 .

\subsubsection{Hop-22(29)-ene(Diploptene)}

$\mathrm{C}_{30} \mathrm{H}_{50}$, exact mass: $410.39 \mathrm{u}$

Diploptene produced a strong $[\mathrm{M}-\mathrm{H}]^{+}$peak at $m / z 409.39$ in the positive ion mode spectrum (Figure 3-5), like its isomer hop-17-(21)-ene discussed in the previous section. In contrast to hop-17(21)-ene, however, diploptene produced an additional $[\mathrm{M}+\mathrm{H}]^{+}$peak at $m / z$ 411.40. In addition, like the hop-17(21)-ene spectrum, the diploptene spectrum showed a lower intensity peak at $m / z 425.40$ which might originate from a partly oxidized standard compound, as discussed above. Loss of $\mathrm{CH}_{3}$ and $\mathrm{CH}_{5}$ from the molecular structure might explain the formation of the weak peaks at $m / z 395.37$ and, 393.35, whereas the peak at $m / z 369.36$ was consistent with loss of the side chain. Interestingly, as in the case of hop-17(21)-ene, the diploptene spectrum also showed a strong $\mathrm{m} / \mathrm{z} 367.33$ peak, which might indicate a fragmentation pathway involving the formation of a double bond within the hopane skeleton. A partial transformation of the diploptene standard into hop-17(21)-ene (Ageta et al., 1987) before analysis could be excluded, as EI spectra obtained from the standard used did not show any signal from hop-17(21)-ene (data not shown). Ions attributable to fragmentation in the C-ring (Peters et al., 2005) were detected at $m / z$ 189.16, 191.18, 203.18, 205.20, 217.20, and 219.21 (Figure 3-5). In comparison with the spectrum of hop-17(21)-ene reported above, diploptene showed a lower yield of the $[\mathrm{M}-\mathrm{H}]^{+}$ion, but a higher abundance of the $\mathrm{m} / z$ 189.16/191.18 pair which probably resulted from a more pronounced C-ring fragmentation. However, the spectra of diploptene and hop-17(21)-ene were very similar and it is unlikely that these compounds could be reliably distinguished with ToF-SIMS in environmental samples.

In the negative ion mode spectrum, ions were detected in the molecular mass range at $m / z 383.32,411.35,423.36$, and 425.36 . Similar to the observations made for hop-17(21)-ene, the $m / z$ values of these peaks indicated the incorporation of oxygen.

Thus, like the other non-extended hopanoids studied, hop-22(29)-ene was best analyzed in the positive ion mode. 


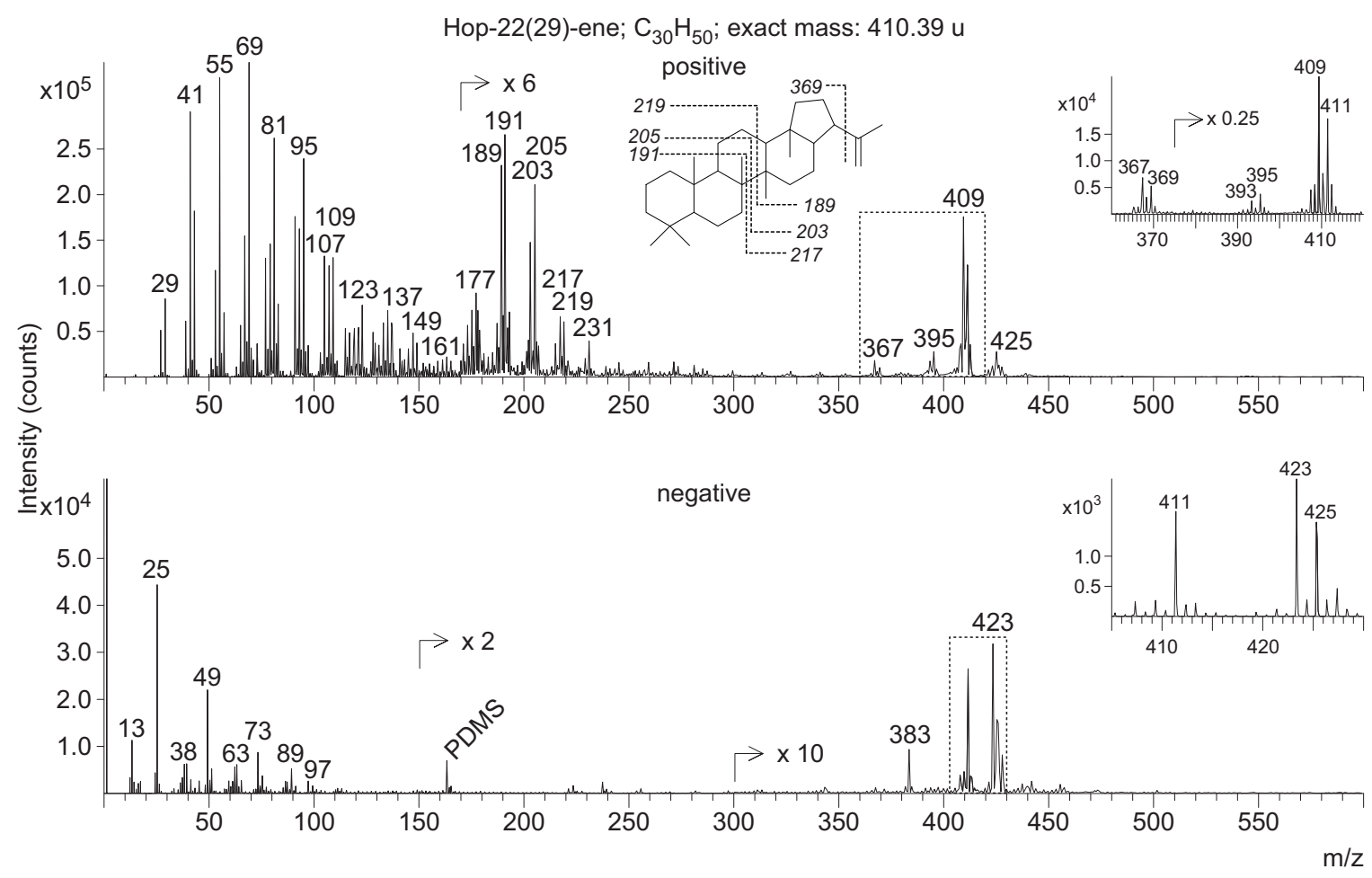

Figure 3-5. Partial positive and negative ion mode ToF-SIMS spectra ( $m / z$ 0-600) of hop-22(29)-ene (diploptene) standard. Dashed frames mark mass regions enlarged in insets. See text for a detailed discussion of the spectral patterns. The peak labeled with PDMS is an organic ion from polydimethylsiloxane contamination and does not belong to the compound spectrum.

\subsection{6. $17 \beta(H), 21 \beta(H)$-bacteriohopane-32,33,34,35-tetrol (BHT)}

$\mathrm{C}_{35} \mathrm{H}_{62} \mathrm{O}_{4}$, exact mass: $546.47 \mathrm{u}$

The positive ion mode spectrum of the multifunctionalized BHT (Figure 3-6) included only some minor fragment ions. A peak consistent with a $[\mathrm{M}+\mathrm{H}]^{+}$ion was observed at $m / z$ 547.52.

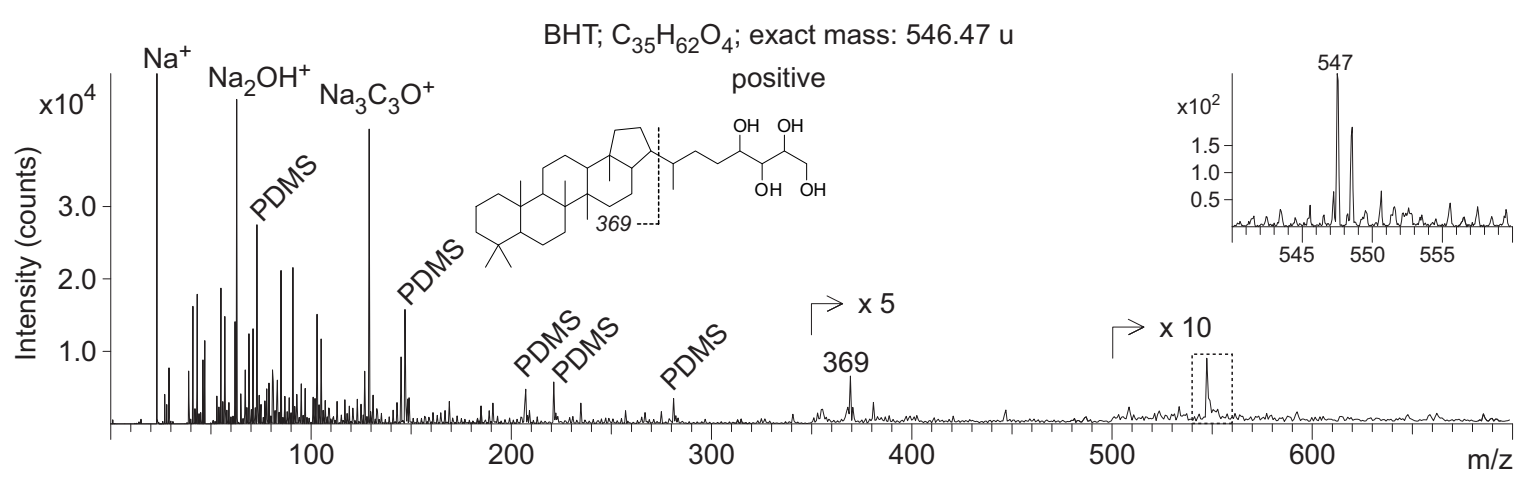

Figure 3-6. Partial positive ion mode ToF-SIMS spectrum ( $m / z$ o-700) of $17 \beta(H), 21 \beta(H)$ bacteriohopane-32,33,34,35-tetrol (BHT) standard. Dashed frames mark mass regions enlarged in insets. See text for a detailed discussion of the spectral patterns. Peaks labeled with PDMS are organic ions from polydimethylsiloxane contamination and do not belong to the compound spectrum. 
The prominent peak at $m / z 369.38$ was probably due to the loss of the side chain (Figure 3-6), and has also been observed in the EI spectra of hopanoids (Watson and Farrimond, 2000).

Due to low amounts of BHT and ABHT available, only spectra in the positive ion mode were recorded.

\subsection{7. $17 \beta(H), 21 \beta(H)-35$-aminobacteriohopane-32,33,34-triol (ABHT)}

$\mathrm{C}_{35} \mathrm{H}_{63} \mathrm{NO}_{3}$, exact mass: $545.48 \mathrm{u}$

The positive ion mode spectrum of ABHT (Figure 3-7) revealed a strong $[\mathrm{M}+\mathrm{H}]^{+}$ion at $m / z 546.51$. Further lower intensity peaks were observed at $m / z 588.53,596.46$, and 610.48. A possible pathway for the formation of these peaks would include the adduction of smaller hydrocarbon fragment ions detected at $m / z 43.06\left(\left[\mathrm{C}_{3} \mathrm{H}_{7}\right]^{+}\right)$, $51.02\left(\left[\mathrm{C}_{4} \mathrm{H}_{3}\right]^{+}\right)$, and $65.04\left(\left[\mathrm{C}_{5} \mathrm{H}_{5}\right]^{+}\right)$to the molecule. Weak fragment ions detected at $m / z$ 191.19, 272.26, and 392.32 might correspond to fragmentations within the B-, C-, and D-ring, respectively (Table 3-2, Figure 3-7).

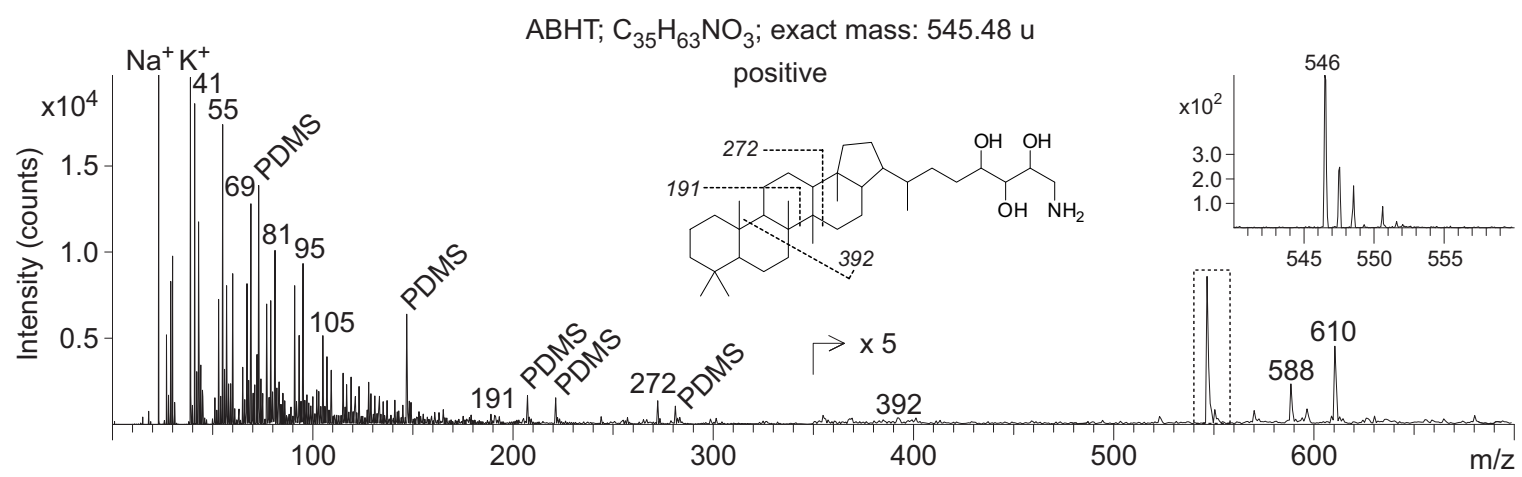

Figure 3-7. Partial positive ion mode ToF-SIMS spectrum $(m / z$ 0-700) of $17 \beta(H), 21 \beta(H)-35-$ aminobacteriohopane-32,33,34-triol (ABHT) standard. Dashed frame marks mass region enlarged in inset. See text for a detailed discussion of the spectral pattern. Peaks labeled with PDMS are organic ions from polydimethylsiloxane contamination and do not belong to the compound spectrum.

Compared with BHT, ABHT showed less intense fragmentation under the conditions used. This general difference is in agreement with the LC/MS analyses of peracetylated BHT and ABHT using atmospheric pressure chemical ionization in positive ion mode, which revealed strong fragmentation and a weak molecular ion of BHT, and vice versa for ABHT (Talbot et al., 2003). The combined results indicate a higher resilience against mass spectral fragmentation of BHPs with side chains containing an amino group. 


\subsection{8. $\alpha$-Tocopherol}

$\mathrm{C}_{29} \mathrm{H}_{50} \mathrm{O}_{2}$, exact mass: $430.38 \mathrm{u}$

The positive ion mode spectrum of $\alpha$-tocopherol (Figure 3-8) showed a strong [M] ${ }^{+\bullet}$ ion at $m / z$ 430.37. A less intense peak at $m / z 415.36$ probably resulted from loss of a terminal $\mathrm{CH}_{3}$ group. The peak at $m / z 443.38$ was consistent with the mass of $[\mathrm{M}+\mathrm{CH}]^{+}$, and might be a product of dimer fragmentation (dimer detected at $m / z$ 858.76), of an adduct of a neutral molecular fragment with a small hydrocarbon ion (Spool, 2004), or of an impurity within the standard. Peaks at $m / z 203.10$ and 205.12 were consistent with fragments generated by loss of the side chain (Figure 3-8). A very intense peak at $m / z 165.09$ and a weaker peak at $m / z 151.08$ were probably produced by fragmentation in the B-ring (Monroe et al., 2005).

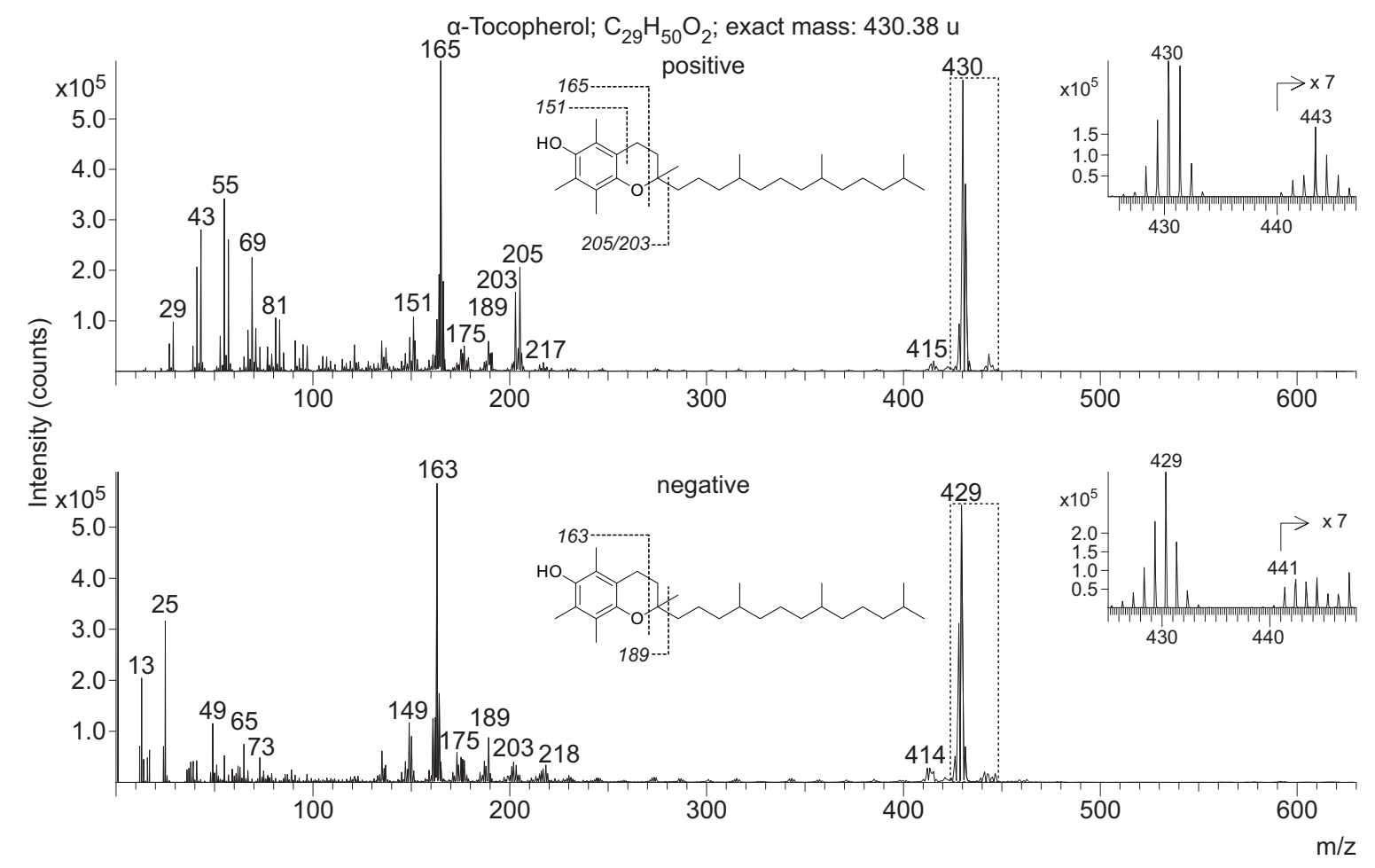

Figure 3-8. Partial positive and negative ion mode ToF-SIMS spectra $(m / z$ 0-630) of $\alpha$-tocopherol standard. Dashed frames mark mass regions enlarged in insets. See text for a detailed discussion of the spectral patterns.

In the negative ion mode spectrum, a strong $[\mathrm{M}-\mathrm{H}]^{-}$ion was detected at $\mathrm{m} / \mathrm{z}$ 429.37 (Figure 3-8). A peak at $m / z 414.34$ was consistent with the loss of $\mathrm{CH}_{3}$ from the $[\mathrm{M}-\mathrm{H}]^{-}$ion. A weak peak observed at $m / z 441.37$ was shifted by 2 u compared with the $m / z 443.38$ peak in the positive ion mode spectrum and it might thus evolve from a similar pathway (see above). Analogous to the positive ion mode 
spectrum, the negative ion mode spectrum showed various peaks in the region between $m / z 140$ and 220. Compared with the positive ion mode spectrum, some of these peaks are shifted by $2 \mathrm{u}$ towards lower $m / z$ values, viz. $m / z 163.08$ and 149.06. According to the discussion of the positive ion mode spectrum, these peaks were consistent with loss of the alkyl chain or fragmentation in the second ring (Figure 3-8).

Because both the positive and the negative ion mode spectra showed strong peaks from molecular species (molecular ions and deprotonated molecules, respectively) and characteristic fragment ions, both polarities are suitable for the detection of $\alpha$-tocopherol.

\subsection{9. $\beta, \beta$-carotene}

$\mathrm{C}_{40} \mathrm{H}_{56}$, exact mass: $536.44 \mathrm{u}$

The positive ion mode spectrum of $\beta, \beta$-carotene (Figure 3-9) showed a strong molecular ion $[\mathrm{M}]^{+\bullet}$ peak at $m / z 536.43$.

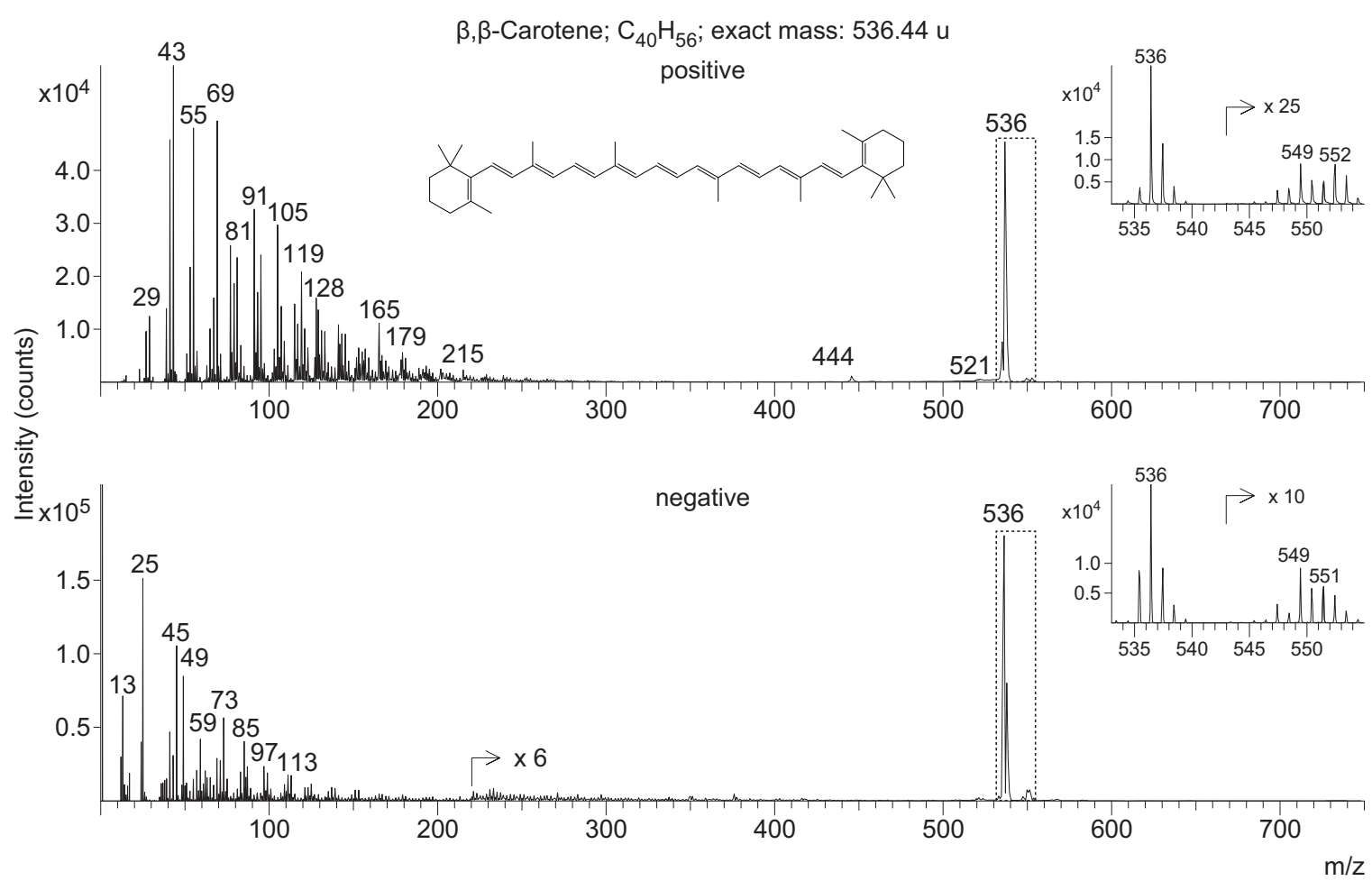

Figure 3-9. Partial positive and negative ion mode ToF-SIMS spectra $(m / z \quad 0-750)$ of $\beta, \beta$-carotene standard. Dashed frames mark mass regions enlarged in insets. See text for a detailed discussion of the spectral patterns. 
Weaker peaks observed at $\mathrm{m} / z 549.47$ and 552.44 were consistent with the masses of $[\mathrm{M}+\mathrm{CH}]^{+}$and $[\mathrm{M}+\mathrm{O}]^{+}$, respectively. The $[\mathrm{M}+\mathrm{CH}]^{+}$ion might evolve from the same pathways as described above for the other standards (Spool, 2004), whereas the $[\mathrm{M}+\mathrm{O}]^{+}$ion might again be derived from a partly oxidized standard. It should be noted that a peak showing the same shift $\left([\mathrm{M}+16]^{+}\right)$was reported in the ToF-SIMS analysis of the fully saturated $\beta, \beta$-carotane (Toporski and Steele, 2004). A low intensity peak at $m / z 521.42$ probably originated from the loss of a terminal $\mathrm{CH}_{3}$ moiety from the molecular ion, consistent with observations of a corresponding $[\mathrm{M}-15]^{+}$peak for $\beta, \beta$-carotane (Toporski and Steele, 2004). At $m / z 444.35$, a typical fragment ion of carotenoids, corresponding to the neutral elimination of a toluene molecule (Caccamese and Garozzo, 1990; van Breemen et al., 1995), was detected.

The negative ion mode spectrum (Figure 3-9) showed a molecular ion [M] • peak at $m / z 536.43$, as similarly observed in the positive ion mode spectrum. Analogous to the positive ion mode spectrum, a weak peak at $m / z 549.44$ was consistent with the mass of $[\mathrm{M}+\mathrm{CH}]^{-}$. Another minor peak at $m / z 551.43$ was shifted by $1 \mathrm{u}$ to the putative $[\mathrm{M}+0]^{+}$peak in the positive ion mode, and it was tentatively interpreted as $[\mathrm{M}-\mathrm{H}+\mathrm{O}]^{-}$.

Given the high yield of the molecular ions, $\beta, \beta$-carotene can be reliably analyzed in both ionization modes.

\subsubsection{Chlorophyll a}

$\mathrm{C}_{55} \mathrm{H}_{72} \mathrm{MgN}_{4} \mathrm{O}_{5}$, exact mass: $892.54 \mathrm{u}$

The positive ion mode spectrum of chlorophyll a (Figure 3-10) showed a $[\mathrm{M}+\mathrm{H}]^{+}$ peak at $m / z 893.61$ and a $[\mathrm{M}+\mathrm{Na}]^{+}$adduct ion at $\mathrm{m} / z$ 915.61. A weak ion at $\mathrm{m} / z$ 931.60 might be assigned to a $[\mathrm{M}+\mathrm{K}]^{+}$adduct ion. This interpretation was consistent with the observation of intense $[\mathrm{Na}]^{+}$and $[\mathrm{K}]^{+}$peaks (Figure 3-10). The intense peak at $m / z 614.26$ probably results from the porphyrin ring after cleavage of the phytyl side chain (Hunt et al., 1981; van Breemen et al., 1991) The peak at $m / z 555.22$ was consistent with the mass of $\left[\mathrm{M}-\mathrm{C}_{22} \mathrm{H}_{41} \mathrm{O}_{2}\right]^{+}$and it might evolve from cleavage at $\mathrm{C}$ $171 / \mathrm{C}-17^{2}$ (van Breemen et al., 1991). The spectrum showed further peaks at $\mathrm{m} / \mathrm{z}$ $481.16,467.16$, and 453.15 which could be attributed to porphyrin ring fragments that differ by varying numbers of $\mathrm{CH}_{2}$ units. Similar fragmentation patterns have been reported from analyses of chlorophyll $a$ by fast atom bombardment tandem 
mass spectrometry (FAB-MS/MS; van Breemen et al., 1991) and ${ }^{252}$ Cf-plasma desorption mass spectrometry (Chait and Field, 1982; Hunt et al., 1981) and from ToF-SIMS analyses of related porphyrins (Suo et al., 2007).



Figure 3-10. Partial positive and negative ion mode ToF-SIMS spectra $(m / z$ 0-950) of chlorophyll $a$ standard. Dashed frames mark mass regions enlarged in insets. See text for a detailed discussion of the spectral patterns.

The negative ion mode spectrum (Figure 3-10) showed a $[\mathrm{M}+\mathrm{H}]^{-}$peak at $m / z$ 893.61 and weaker peaks at $m / z 924.57$ and 937.61. The latter peaks might result from the adduction of smaller $\mathrm{C}_{\mathrm{x}} \mathrm{H}_{\mathrm{y}} \mathrm{O}_{\mathrm{z}}$ fragment ions, observed in the low-mass range of the spectrum, to neutrals. The most intense peaks in the mass range between $\mathrm{m} / \mathrm{z}$ 300 and 700 were observed at $m / z$ 613.29, 540.19, 525.17, 481.15, 467.14, and 451.09. In accordance with the interpretations made for the positive ion mode, the peak at $m / z 613.29$ probably resulted from cleavage of the phytyl group ([M$\left.\mathrm{C}_{20} \mathrm{H}_{40}\right]^{-}$). Peaks at $m / z 540.19$ and 525.17 corresponded to ions formed from cleavage of $\mathrm{C}_{3} \mathrm{H}_{4} \mathrm{O}_{2}$ from the $\left[\mathrm{M}-\mathrm{C}_{20} \mathrm{H}_{40}\right]^{-}$ion and further loss of $\mathrm{CH}_{3}$, respectively. The peaks at $m / z 481.15,467.14$, and 451.09 were interpreted as resulting from the porphyrin ring after cleavage of the functional groups in the D- and E-ring. 
As for $\beta, \beta$-carotene and $\alpha$-tocopherol, both polarities can be used for the detection of chlorophyll $a$. The negative mode, however, might be preferable, due to the higher yield of diagnostic ions in the high mass range.

\section{Environmental samples}

\subsubsection{Cryosection of burgundy truffle (Tuber uncinatum)}

The positive ion mode spectrum of the analyzed truffle cryosection is shown in Figure 3-11(a). Clear signals from characteristic ergosterol peaks at $\mathrm{m} / \mathrm{z} 363.30$, 377.32, and 396.35 (Figs. 11(a) and 11(b)) corresponded to [M] $]^{+\bullet},\left[\mathrm{M}-\mathrm{H}_{3} \mathrm{O}\right]^{+}$, and $\left[\mathrm{M}-\mathrm{CH}_{5} \mathrm{O}\right]^{+}$, with the center masses differing by $14.52,-9.02$, and $36.16 \mathrm{ppm}$, respectively, from the calculated exact masses and by 43.49, 34.19, and $49.45 \mathrm{ppm}$, respectively, from the measured masses of the standard compound (Figure 3-11(b)). In the higher mass range a strong peak was observed at $m / z$ 766.57. The exact mass and the isotope pattern suggested that this was a potassium adduct of a glucosphingolipid $\left(\mathrm{C}_{41} \mathrm{H}_{77} \mathrm{NO}_{9} \mathrm{~K}\right)$, which has been previously identified in the truffle species Tuber indicum using FAB-MS (Gao et al., 2004). This interpretation was further corroborated by intense peaks at $\mathrm{m} / z$ 726.58 [M-H]- and 564.51 [M$\left.\mathrm{C}_{6} \mathrm{H}_{11} \mathrm{O}_{5}\right]^{-}$in the negative ion mode spectrum (data not shown) and a strong $\mathrm{K}^{+}$peak at $m / z 38.97$ in the positive ion mode spectrum (Figure 3-11(a)).

In the optical microscopy images (Figure 3-11(c)I) three different features of the truffle, namely the yellow to brown spores, the translucent mycelial mass, and openings around the spores, which were probably formed from the Asci, i.e. the spore-containing cells of the truffle, during the sectioning process, could be visually distinguished. The total ion image showed the highest intensities from the openings (Figure 3-11(c)II), whereas the lowest ion counts were observed from the spores. The color coded map (Figure 3-11(c)IV) clearly showed that ergosterol was evenly distributed in the mycelial mass whereas highest intensities of the glucosphingolipid were localized in the spore cells. Sodium was co-localized with the openings in the section and thus probably came from the underlying microscopic glass slide. The results demonstrated that the distribution of ergosterol could be imaged on a micrometer scale in an environmental biological sample, using selected, suitable peaks from the analysis of the standard compound. 


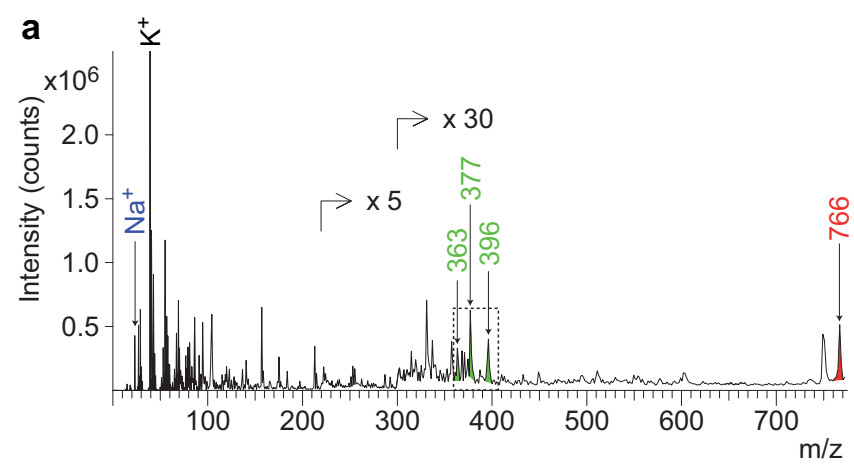

b

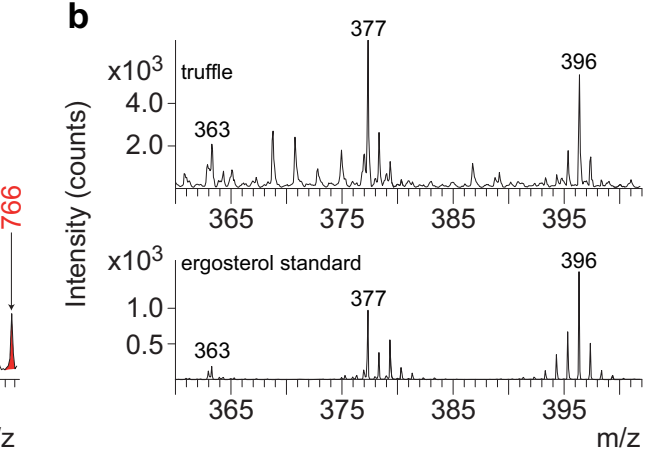

C
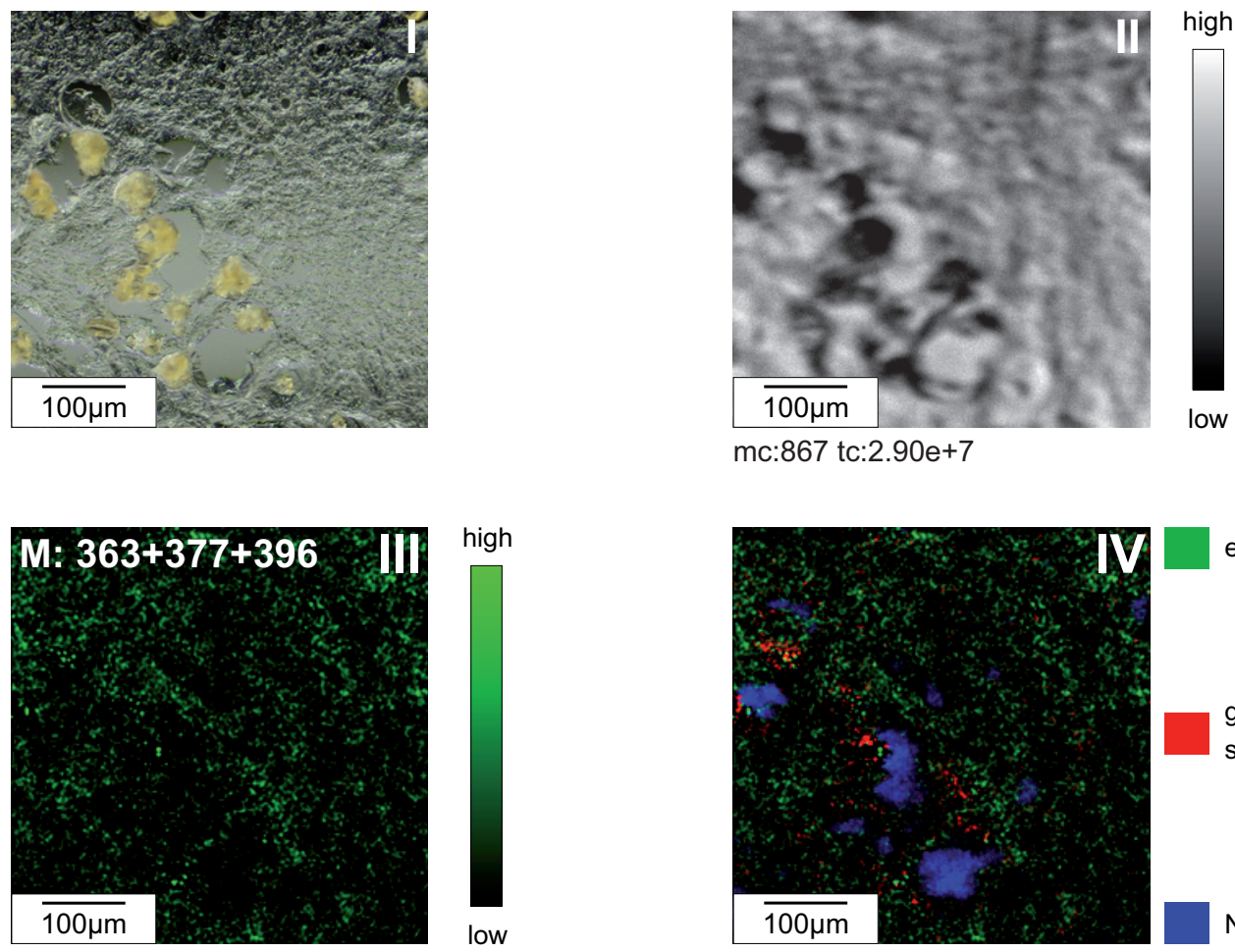

mc: 867 tc: $2.90 \mathrm{e}+7$

mc:4900 tc: $3.48 \mathrm{e}+4$

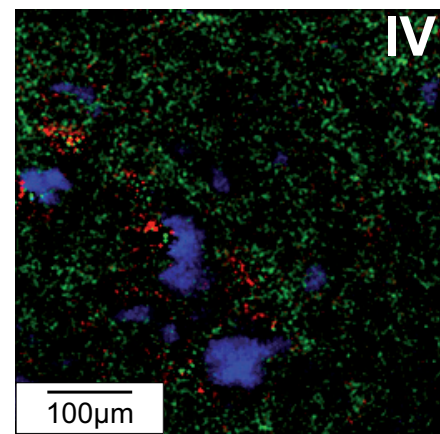

ergosterol

gluco-

sphingolipid

Figure 3-11. Ergosterol in a burgundy truffle (Tuber uncinatum) cryosection: (a) partial positive ion mode ToF-SIMS spectrum $\left(\mathrm{m} / \mathrm{z}\right.$ 0-775) of a $500 \times 500 \mathrm{~mm}^{2}$ analysis area on a truffle cryosection with marked sodium (blue), ergosterol (green), and glucosphingolipid ( $m / z 766$, red) peaks, the dashed frame highlights the mass range enlarged in (b); (b) partial positive ion mode ToF-SIMS spectra $(\mathrm{m} / \mathrm{z}$ 360-402) of truffle cryosection (top) and ergosterol standard (bottom); (c) optical microscopy and ToFSIMS ion images of truffle cryosection, corresponding to the spectra above, (I) fluorescence microscopic image of the analysis area, (II) total ion image, (III) ion image showing the distribution of the summed ergosterol fragment ions $(m / z 363+377+396)$, (IV) color coded ion image showing the distribution of ergosterol (green), glucosphingolipid (red) and sodium (blue).

\subsubsection{Cryosection of a mineralizing (iron-oxide forming) microbial mat}

The positive ion mode spectrum of the mineralizing microbial mat cryosection (Figure 3-12(a)) showed an intense signal from the embedding agent (Cryo-Gel ${ }^{\circledR}$ ) at $m / z$ 365.11. Peaks probably representing ABHT were observed at $m / z 392.32$ and 
546.52 (Figure 3-12(b)I, II), in very good agreement with the spectrum of the ABHT standard (Figure 3-12(b)I, II).
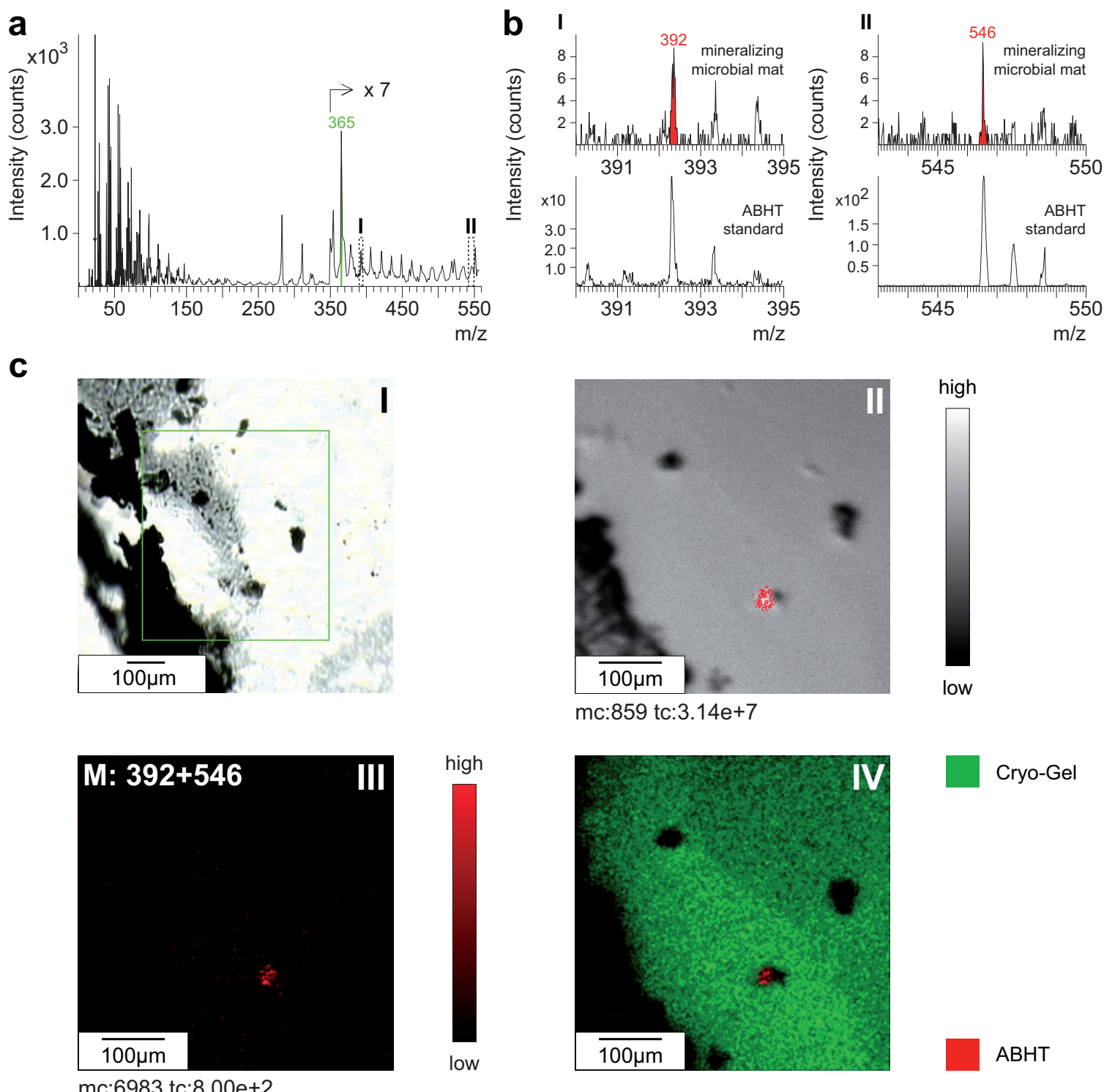

Cryo-Gel

Figure 3-12. ABHT in a mineralizing (iron-oxide forming) microbial mat cryosection: (a) partial positive ion mode ToF-SIMS spectrum $\left(\mathrm{m} / \mathrm{z}\right.$ 0-560) of a $500 \times 500 \mathrm{~mm}^{2}$ analysis area on a mat cryosection with major embedding agent peak marked in green, dashed frames highlight mass ranges enlarged in (b); (b) partial positive ion mode ToF-SIMS spectra of the microbial mat (top) and the ABHT standard (bottom), (I) (m/z 390-395), (II) ( $m / z$ 543-550), characteristic ABHT peaks are marked in red; (c) optical microscopy and ToF-SIMS ion images of the analysis area on the mat cryosection corresponding to the spectra above, (I) ToF-SIMS built-in video camera image with the analysis area marked by a green frame, (II) total ion image with region of interest (red) from which the above spectra were retrieved, (III) ion image showing the distribution of the summed ABHT ions $(m / z$ 392+546), (IV) color coded ion image overlay showing the distributions of the summed ABHT ions (see (b), red), and the major embedding agent ion (green). 
The ion images produced using these peaks showed that ABHT was localized in a very small spot of approximately $20 \times 20 \mathrm{~mm}^{2}$ (Figure 3-12(c)III, IV). The absence of peaks derived from the embedding agent and the strong ABHT signal indicated that the section exposed a microbial colony within the actual microbial mat (Figure 3-12 (c)III, IV). These data revealed that ToF-SIMS was capable of detecting ABHT in environmental samples, after suitable peaks had been properly defined in the analysis of the standard compound.

\subsubsection{Cryosection of a green (phototrophic) microbial mat}

The spectrum obtained from the green microbial mat in negative ion mode showed the presence of the molecular ion $[\mathrm{M}]^{-\bullet}$ of carotene at $m / z 536.43$ and the $[\mathrm{M}+\mathrm{H}]^{-}$ ion of chlorophyll $a$ at $m / z 893.51$ (Figs. 13(a) and 13(b)). However, whereas the $[\mathrm{M}+\mathrm{H}]^{-}$ion of chlorophyll $a$ was clearly detected, no further diagnostic fragments from the standard spectrum were observed. This might be due either to an overall low concentration of chlorophyll $a$ on the sample surface, or to a matrix effect suppressing the fragmentation compared with the pure standard compound. The ion images of carotene (Figure 3-13(c)III) and chlorophyll a (Figure 3-13(c)IV) obtained in burst alignment mode showed that these compounds were partly colocalized with white to translucent, 10-20 mm long structures in the corresponding fluorescence microscopic image (Figure 3-13(c)I) which were identified as diatoms. Diatoms are single-cell, photoautotrophic, primary producers in marine and nonmarine, aquatic environments and are a known source of chlorophylls and carotenes (Strain et al., 1944). Contributions of peaks from other substances to the carotene and chlorophyll $a$ signal in the burst alignment mode spectrum were rather unlikely as no such peaks were observed in the bunched mode spectrum obtained from the same area.

\subsection{Conclusions}

Our study provided reference spectra for a number of important cyclic lipid biomarkers, and showed that most of these compounds should be preferably analyzed in one of the two polarity modes depending on their compound class. Sterane and hopane hydrocarbons were better detected using positive rather than negative polarity due to the formation of strong $[\mathrm{M}-\mathrm{H}]^{+}$peaks and characteristic 
fragmentation patterns in the positive ion mode, and the lack of diagnostic peaks in the molecular mass range in the negative ion mode.

a



C
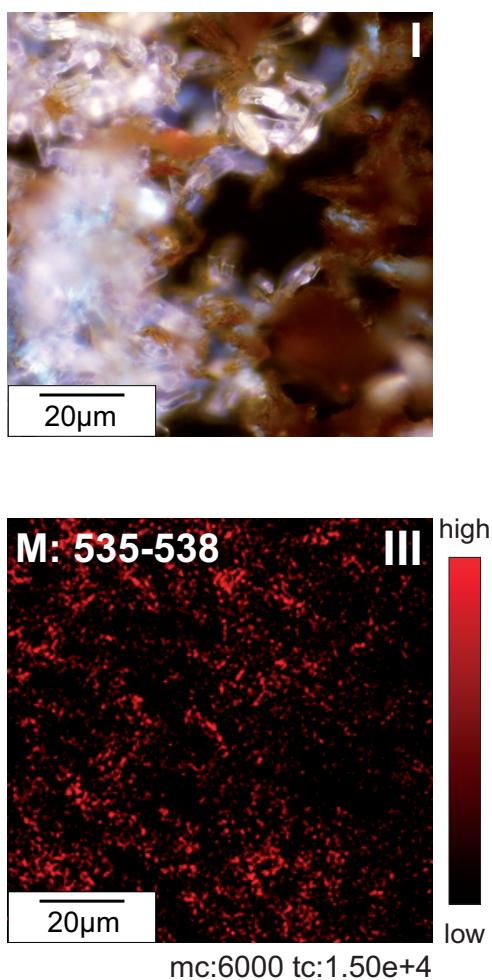

b
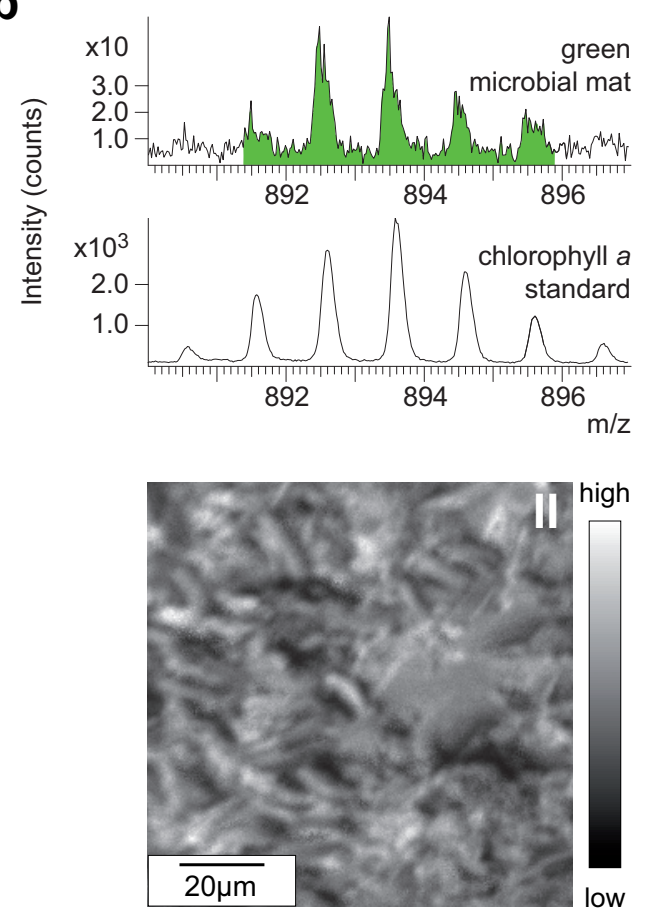

mc:935 tc: $2.27 \mathrm{e}+7$

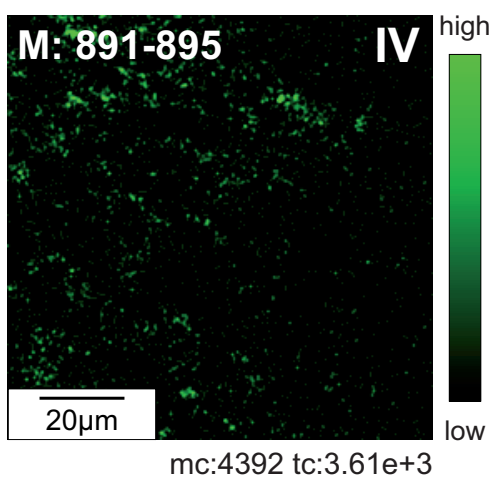

Figure 3-13. Carotene and chlorophyll $a$ in the green (phototrophic) microbial mat cryosection: (a) Partial negative ion mode ToF-SIMS spectra $(\mathrm{m} / \mathrm{z} 534-540)$ of a $100 \times 100 \mathrm{~mm}^{2}$ analysis area on the green mat cryosection (top) and the $\beta, \beta$-carotene standard (bottom). (b) Partial negative ion mode ToFSIMS spectra $\left(\mathrm{m} / \mathrm{z}\right.$ 890-897) of a $100 \times 100 \mathrm{~mm}^{2}$ analysis area on the green mat cryosection (top) and the chlorophyll $a$ standard (bottom). (c) Optical microcopy and ToF-SIMS ion images of the analyzed area on the mat cryosection corresponding to the spectra above, (I) fluorescence microscopic image of the $100 \times 100 \mathrm{~mm}^{2}$ analysis area showing individual diatom cells, (II) total ion image of the analysis area, (III) ion image showing the distribution of the summed carotene ions (see (a)), (IV) ion image showing the distribution of the summed chlorophyll $a$ ions (see (b)).

Similarly, sterols and carotenes were best identified in the positive ion mode, as a result of the strong molecular ion peaks observed. However, unlike hopanes and 
steranes, these compounds also produced negative molecular ions or deprotonated molecules and they might therefore also be detectable using the negative ion mode. Chlorophylls and tocopherols could be well analyzed in both modes of polarity. It is notable that chlorophyll $a$ tended to form an even stronger $[\mathrm{M}+\mathrm{H}]^{-}$peak in the negative ion mode than a $[\mathrm{M}+\mathrm{H}]^{+}$peak in the positive ion mode.

Using the characteristic molecular and fragment ions observed in the analysis of different cyclic lipids standards, ToF-SIMS was successfully employed to detect and image these compounds in cryosections of environmental samples. Our experiments demonstrated that various classes of cyclic lipid biomarkers could be directly identified in complex biogeochemical matrices using ToF-SIMS, and that these biomarkers could be localized on sample surfaces at a micrometer scale. These capabilities open interesting perspectives for the use of ToF-SIMS in the biogeosciences, but clearly more studies on different molecules and sample types are needed to further validate and develop the potential of ToF-SIMS for the direct observation of biomarker molecules in environmental materials.

\section{Acknowledgments}

We acknowledge with gratitude the detailed comments provided by four anonymous journal reviewers. We are also grateful to Jukka Lausmaa and Per Borchard (Chemistry and Materials, SP Technical Research Institute of Sweden, Borås) for analytical assistance during ToF-SIMS measurements. We furthermore wish to thank Richard Splivallo for providing us with samples of Tuber uncinatum, and for helpful comments concerning the microscopy and analysis of truffles. This study is part of the Research Unit 571 "Geobiology of Organo- and Biofilms" (publication 59). The project received financial support from the German Research Foundation (DFG; Grants Th 713/5-1 and BL 971/1-3), and the Swedish Governmental Agency for Innovation Systems (VINNOVA).

\section{References}

Ageta H., Shiojima K., Arai Y. (1987) Acid-induced rearrangement of triterpenoid hydrocarbons belonging to the hopane and migrated hopane series. Chemical and Pharmaceutical Bulletin 35, 2705-2716.

Belu A. M., Graham D. J., Castner D. G. (2003) Time-of-flight secondary ion mass spectrometry. Biomaterials 24, 3635-3653. 
Benninghoven A. (1994) Chemical analysis of inorganic and organic surfaces and thin films by static time-of-flight secondary ion mass spectrometry (TOF-SIMS). Angewandte Chemie International Edition in English 33, 1023-1043.

Blumenberg M., Seifert R., Kasten S., Bahlmann E., Michaelis W. (2009) Euphotic zone bacterioplankton sources major sedimentary bacteriohopanepolyols in the Holocene Black Sea. Geochimica et Cosmochimica Acta 73, 750-766.

Brunelle A., Laprévote O. (2009) Lipid imaging with cluster time-of-flight secondary ion mass spectrometry. Analytical and Bioanalytical Chemistry 393, 31-35.

Burton G. W., Ingold K. U. (1986) Vitamin E. Accounts of Chemical Research 19, 194201.

Caccamese S., Garozzo D. (1990) Odd-electron molecular ion and loss of toluene in fast atom bombardment mass spectra of some carotenoids. Organic Mass Spectrometry 25, 137-140.

Chait B. T., Field F. H. (1982) Californium-252 fission fragment ionization mass spectrometry of chlorophyll a. Journal of the American Chemical Society 104, 55195521.

Chait B. T., Field F. H. (1984) Californium-252 fission fragment ionization mass spectrometry of chlorophyll a. Journal of the American Chemical Society 106, 19311938.

Constantin E., Nakatani Y., Teller G., Hueber R., Ourisson G. (1981) Electron-impact and chemical ionization mass spectrometry of chlorophylls, phaeophytins and phaeophorbides by fast desorption on a gold support. Bulletin de la Societe Chimique de France, II303-II305.

Cooks R. G., Ast T., Mabud M. A. (1990) Collisions of polyatomic ions with surfaces. International Journal of Mass Spectrometry and Ion Processes 100, 209-265.

Coolen M. J. L., Talbot H. M., Abbas B. A., Ward C., Schouten S., Volkman J. K., Damsté J. S. S. (2008) Sources for sedimentary bacteriohopanepolyols as revealed by $16 \mathrm{~S}$ rDNA stratigraphy. Environmental Microbiology 10, 1783-1803.

Debois D., Bralet M.-P., Le Naour F., Brunelle A., Laprévote O. (2009) In Situ lipidomic analysis of nonalcoholic fatty liver by cluster TOF-SIMS imaging. Analytical Chemistry 81, 2823-2831.

Delcorte A., Bertrand P. (1998) Sputtering of parent-like ions from large organic adsorbates on metals under keV ion bombardment. Surface Science 412-413, 97 124.

Fraser P. D., Bramley P. M. (2004) The biosynthesis and nutritional uses of carotenoids. Progress in Lipid Research 43, 228-265.

Gallegos E. J., Moldowan M. J. (1992) The effect of injection hold time on GC resolution and the effect of collision gas on mass spectra in geochemical 
"biomarker" research. In Biological Markers in Sediments and Petroleum (eds. M. J. Moldowan, P. Albrecht and P. R. Philp). Prentice-Hall. New Jersey, pp. 156-181.

Gao J.-M., Zhu W.-M., Zhang S.-Q., Zhang X., Zhang A.-L., Chen H., Sun Y.-K., Tang M. (2004) Molecular species of ceramides from the ascomycete truffle Tuber indicum. Chemistry and Physics of Lipids 131, 205-213.

Goad L. J., Akihisa T. (1997) Analysis of Sterols. Chapman \& Hall, London.

Hunt J. E., Macfarlane R. D., Katz J. J., Dougherty R. C. (1981) High-energy fragmentation of chlorophyll $a$ and its fully deuterated analog by californium- 252 plasma desorption mass spectrometry. Journal of the American Chemical Society 103, 6775-6778.

Knights B. A. (1967) Identification of plant sterols using combined GLC/Mass Spectrometry. Journal of Chromatographic Science 5, 273-282.

Kohlhase M., Pohl P. (1988) Saturated and unsaturated sterols of nitrogen-fixing blue-green algae (cyanobacteria). Phytochemistry 27, 1735-1740.

Mackenzie A. S., Brassell S. C., Eglinton G., Maxwell J. R. (1982) Chemical fossils. Science 217, 491-504.

Monroe E. B., Jurchen J. C., Lee J., Rubakhin S. S., Sweedler J. V. (2005) Vitamin E imaging and localization in the neuronal membrane. Journal of the American Chemical Society 127, 12152-12153.

Moran N. A., Jarvik T. (2010) Lateral transfer of genes from fungi underlies carotenoid production in aphids. Science 328, 624-627.

Muramoto S., Graham D. J., Wagner M. S., Lee T. G., Moon D. W., Castner D. G. (2011) ToF-SIMS analysis of adsorbed proteins. Journal of Physical Chemistry C 115, 2424724255.

Nygren H., Bengt R. Johansson, Malmberg P. (2004) Bioimaging TOF-SIMS of tissues by gold ion bombardment of a silver-coated thin section. Microscopy Research and Technique 65, 282-286.

Nygren H., Börner K., Malmberg P., Hagenhoff B. (2006) Localization of cholesterol in rat cerebellum with imaging TOF-SIMS. Applied Surface Science 252, 6975-6981.

Ourisson G., Albrecht P. (1992) Hopanoids. 1. geohopanoids. Accounts of Chemical Research 25, 398-402.

Ourisson G., Albrecht P.,, Rohmer M. (1979) The hopanoids. Palaeochemistry and biochemistry of a group of natural products. Pure and Applied Chemistry 51, 709729.

Pearson A., Leavitt W. D., Sáenz J. P., Summons R. E., Tam M. C. M., Close H. G. (2009) Diversity of hopanoids and squalene-hopene cyclases across a tropical land-sea gradient. Environmental Microbiology 11, 1208-1223. 
Peters K., Walters C., Moldowan J. (2005) The Biomarker Guide. Cambridge University Press, Cambridge, U.K.

Reed R. I. (1958) 692. Electron impact and molecular dissociation. Part I. Some steroids and triterpenoids. Journal of the Chemical Society (Resumed), 3432-3436.

Rohmer M., Bouvier-Nave P., Ourisson G. (1984) Distribution of hopanoid triterpenes in prokaryotes. Journal of General Microbiology 130, 1137-1150.

Siljeström S., Lausmaa J., Sjövall P., Broman C., Thiel V., Hode T. (2010) Analysis of hopanes and steranes in single oil-bearing fluid inclusions using time-of-flight secondary ion mass spectrometry (ToF-SIMS). Geobiology 8, 37-44.

Siljeström S., Hode T., Lausmaa J., Sjövall P., Toporski J., Thiel V. (2009) Detection of organic biomarkers in crude oils using ToF-SIMS. Organic Geochemistry 40, 135143.

Sjövall P., Lausmaa J., Johansson B. (2004) Mass Spectrometric imaging of lipids in brain tissue. Analytical Chemistry 76, 4271-4278.

Spool A. M. (2004) Interpretation of static secondary ion spectra. Surface and Interface Analysis 36, 264-274.

Steele A., Toporski J. K. W., Avci R., Guidry S., McKay D. S. (2001) Time of flight secondary ion mass spectrometry (ToF-SIMS) of a number of hopanoids. Organic Geochemistry 32, 905-911.

Strain H. H., Manning W. M., Hardin G. (1944) Xantophylls and carotenes of diatoms, brown algae, dinoflagellates, and sea-anemones. The Biological Bulletin 86, 169191.

Summons R., Jahnke L., Hope J., Logan G. (1999) 2-Methylhopanoids as biomarkers for cyanobacterial oxygenic photosynthesis. Nature 400, 554-557.

Suo Z., Avci R., Schweitzer M. H., Deliorman M. (2007) Porphyrin as an ideal biomarker in the search for extraterrestrial life. Astrobiology 7, 605-615.

Talbot H. M., Summons R., Jahnke L., Farrimond P. (2003) Characteristic fragmentation of bacteriohopanepolyols during atmospheric pressure chemical ionisation liquid chromatography/ion trap mass spectrometry. Rapid Communications in Mass Spectrometry 17, 2788-2796.

Talbot M., Watson D., Murrell J., Carter J., Farrimond P. (2001) Analysis of intact bacteriohopanepolyols from methanotrophic bacteria by reversed-phase highperformance liquid chromatography-atmopheric pressure chemical ionisation mass spectrometry. Journal of Chromatography A 921, 175-185.

Thiel V., Toporski J., Schumann G., Sjövall P., Lausmaa J. (2007a) Analysis of archaeal core ether lipids using time of flight-secondary ion mass spectrometry (ToF-SIMS). Geobiology 5, 75-83. 
Thiel V., Heim C., Arp G., Hahmann U., Sjövall P., Lausmaa J. (2007b) Biomarkers at the microscopic range. Geobiology 5, 413-421.

Toporski J., Steele A. (2004) Characterization of purified biomarker compounds using time of flight-secondary ion mass spectrometry (ToF-SIMS). Organic Geochemistry 35, 793-811.

Touboul D., Brunelle A., Halgand F., La Porte S. de, Laprevote O. (2005a) Lipid imaging by gold cluster time-of-flight secondary ion mass spectrometry. Journal of Lipid Research. 46, 1388-1395.

Touboul D., Kollmer F., Niehuis E., Brunelle A., Laprévote O. (2005b) Improvement of biological time-of-flight-secondary ion mass spectrometry imaging with a bismuth cluster ion source. Journal of the American Society for Mass Spectrometry 16, 1608-1618.

van Breemen R. B., Canjura F. L., Schwartz S. J. (1991) Identification of chlorophyll derivatives by mass spectrometry. Journal of Agricultural and Food Chemistry 39, 1452-1456.

van Breemen R. B., Schmitz H. H., Schwartz S. J. (1995) Fast atom bombardment tandem mass spectrometry of carotenoids. Journal of Agricultural and Food Chemistry 43, 384-389.

Vickerman J. (2011) Molecular imaging and depth profiling by mass spectrometrySIMS, MALDI or DESI? Analyst 136, 2199-2217.

Vickerman J. C., Briggs D. (eds.; 2001) ToF-SIMS. IM, Chichester.

Volkman J. K. (2003) Sterols in microorganisms. Applied Microbiology and Biotechnology 60, 495-506.

Watson D. F., Farrimond P. (2000) Novel polyfunctionalised geohopanoids in a recent lacustrine sediment (Priest Pot, UK). Organic Geochemistry 31, 1247-1252.

Winograd N., Garrison B. J. (2010) Biological Cluster Mass Spectrometry. Annual Review of Physical Chemistry 61, 305-322.

Wyllie S. G., Djerassi C. (1968) Mass spectrometry in structural and stereochemical problems. CXLVI. Mass spectrometric fragmentations typical of sterols with unsaturated side chains. The Journal of Organic Chemistry 33, 305-313. 


\section{4.}

\section{Biomarker imaging of single diatom cells in a microbial mat using time-of-flight secondary ion mass spectrometry (ToF-SIMS)}

Tim Leefmann, Christine Heim, Anastasia Kryvenda, Sandra Siljeström, Peter Sjövall, and Volker Thiel

Organic Geochemistry (2013), 57, 23-33

DOI: 10.1016/j.orggeochem.2013.01.005; Reprinted with permission of Elsevier

\subsection{Abstract}

Time-of-flight secondary ion mass spectrometry (ToF-SIMS) is a surface sensitive MS technique that offers a new way of studying lipid biomarkers at the microscopic level, without the need to destroy the physical integrity of the sample by extraction. We applied ToF-SIMS to a cryosection of a microbial mat and compared the results with ToF-SIMS and gas chromatography-MS (GC-MS) analysis of extracts from the same material. A wide range of lipid biomarkers was identified with ToF-SIMS in the microbial mat cryosection. Spectra and ion images revealed that individual biomarkers, including fatty acids, mono-, di- and triacylglycerols, carotenoids and chlorophyll were localized with diatom cells identified as Planothidium lanceolatum using optical microscopy. This diatom species can thus be regarded as a major lipid source within the microbial mat system. The results underpin the idea that ToFSIMS has the potential to become an important technique for future biomarker studies, in particular for the clear cut assignment of biomarkers to distinctive morphological structures and specific microorganisms within complex biogeochemical samples.

\subsection{Introduction}

Lipid biomarkers are traditionally analyzed and identified using extraction based techniques, namely coupled gas chromatography- or liquid chromatographymass spectrometry (GC-MS; LC-MS). Whereas GC-MS and LC-MS provide detailed structural information on lipids, the sample amount needed for extraction often 
exceeds the mass of many structures of interest in the sample, such as small particles, microbial colonies, or even single cells. In such cases, a clear cut assignment of lipid signals to such microstructures would require sophisticated separation techniques or the availability of cultured microorganisms. However, most environmental microorganisms cannot be isolated and grown in the laboratory as pure cultures. An ideal technique for the differential analysis of the lipid content of real world samples would provide direct MS analysis of microscopic target structures at the $\mu \mathrm{m}$ level, e.g. single cells under the microscope. Time-of-flight secondary ion mass spectrometry (ToF-SIMS; Benninghoven, 1994) is, in principle, capable of providing MS lipid analysis (Touboul et al., 2011) and simultaneously imaging the distribution of inorganic and organic ions on solid surfaces at a lateral resolution of $<1 \mu \mathrm{m}$. Initially used mainly in material sciences (Vickerman and Briggs, 2001), ToF-SIMS has, after the advent of cluster ion sources, been increasingly applied in life sciences (Belu et al., 2003; Winograd and Garrison, 2010) including the analysis of lipids (Brunelle and Laprévote, 2009; Passarelli and Winograd, 2011).

Several studies of mammal tissue sections have shown that a wide range of lipids, e.g. sterols (Nygren et al., 2004), phospholipids (Sjövall et al., 2004), or glycerolipids (Sjövall et al., 2008; Debois et al., 2009), can be reliably detected and imaged at the mammalian cell level. However, only a few ToF-SIMS studies have focussed on unicellular organisms (Colliver et al., 1997; Ostrowski et al., 2004; Kurczy et al., 2010) and microbial communities (Tyler et al., 2006; Thiel et al., 2007), or employed ToF-SIMS in the analysis of biomarkers in environmental samples (e.g. Toporski et al., 2002; Guidry and Chafetz, 2003; Siljeström et al., 2009, 2010; Jetter and Sodhi, 2011; Heim et al., 2012; Lindgren et al., 2012; see Thiel and Sjövall (2011) for a review).

In this study, we report a ToF-SIMS analysis of a cryosection of a phototrophic microbial mat. Spectra and ion images of organic compounds are presented for single diatom cells thriving within the mat. To assess the analytical capabilities and selectivity of ToF-SIMS, we compared data from the cryosection with ToF-SIMS and GC-MS analyses of bulk extracts from the same mat. Diatoms are important primary producers in marine and non-marineaquatic environments and thus play a crucial role in $\mathrm{C}$ fixation. Microalgae such as diatoms are particularly effective at turning 
light and nutrient energy into lipids and have therefore been attracting increasing attention as potential producers of biofuel ( $\mathrm{Hu}$ et al., 2008; Yu et al., 2009; Hildebrand et al., 2012).

\subsection{Materials \& Methods}

\subsubsection{Sample material}

Microbial mats were retrieved from the Äspö Hard Rock Laboratory, a $450 \mathrm{~m}$ deep research tunnel operated by the Swedish Nuclear Fuel and Waste Management Company (Svensk Kärnbränslehantering, SKB) near Oskarshamn, SE Sweden. An artificially illuminated flow reactor with air supply located at a fluid outflow at 1327 $\mathrm{m}$ from the tunnel entrance and $183 \mathrm{~m}$ below sea level was sampled for green, phototrophic microbial mats in March 2010. Samples were immediately frozen on site using dry ice and storedin glass vials at $-18^{\circ} \mathrm{C}$.

\subsubsection{Cryosection for ToF-SIMS}

Part of the frozen microbial mat was allowed to thaw at room temperature and mounted on top of a cork sample holder using an embedding agent (Cryo-Gel ${ }^{\circledR}$, Electron Microscopy Sciences, PA, USA). The sample was frozen for $30 \mathrm{~s}$ in cold isopentane at $-150{ }^{\circ} \mathrm{C}$ and quickly transferred to the cryochamber of a Leica $\mathrm{CM}$ 1100 cryomicrotome (Leica Microsystems, Wetzlar, Germany) pre-cooled to $-20^{\circ} \mathrm{C}$. Thick cryosections (6-8 $\mu \mathrm{m})$ were prepared and placed on gridded microscope slides. Sections were stored in closed glass containers under $\mathrm{Ar}$ at $-18{ }^{\circ} \mathrm{C}$ until analysis. Prior to transfer to the ToF-SIMS instrument, the slides were allowed to approach room temperature with the glass container kept closed, in order to avoid condensation of water vapor on the sample.

All glassware (microscope slides, pipettes, vials, beakers, glass containers) were heated to $400{ }^{\circ} \mathrm{C}$ for $2 \mathrm{~h}$ prior to use, and/or cleaned by intensive rinsing with deionized water and acetone. Solvent rinsing was also applied to clean all steelware (spatula, tweezers, microtome knives) prior to use.

\subsubsection{Extract preparation for GC-MS and ToF-SIMS}

Part of the frozen microbial mat was freeze dried and the dried material (68.7 $\mathrm{mg}$ ) extracted (3x; ultrasonication; $20 \mathrm{~min} ; 40{ }^{\circ} \mathrm{C}$ ) using $20 \mathrm{ml} \mathrm{CH}_{2} \mathrm{Cl}_{2} / \mathrm{MeOH}(1 / 1, \mathrm{v} / \mathrm{v})$, 
$20 \mathrm{ml} \mathrm{CH} \mathrm{Cl}_{2} / \mathrm{MeOH}(2 / 1, \mathrm{v} / \mathrm{v})$, and $20 \mathrm{ml} \mathrm{CH}_{2} \mathrm{Cl}_{2}$, respectively. After each step the mixture was centrifuged ( $5 \mathrm{~min}$ ) and the supernatant decanted off. The extracts were combined into a total extract. The total extract was split into halves.

For ToF-SIMS analysis, a piece of silicon wafer was cleaned using solvent rinsing with $\mathrm{Me}_{2} \mathrm{CO}$, EtOH and $n$-heptane. Subsequently it was placed in a UV ozone apparatus for $15 \mathrm{~min}$ and afterwards rinsed with deionized water to remove the salts. Immediately before ToF-SIMS analysis, a few $\mu$ l of one half of the extract were deposited on the wafer and the solvent was allowed to evaporate in a laminar flow cabinet.

For GC-MS, the other half of the extract was saponified using 6\% $\mathrm{KOH}$ in $\mathrm{MeOH}$ $\left(70{ }^{\circ} \mathrm{C}, 2 \mathrm{~h}\right)$. Deionized water and $\mathrm{CH}_{2} \mathrm{Cl}_{2}$ were added and the mixture acidified ( $\mathrm{HCl}$, $10 \%$ ). Using a separation funnel, the $\mathrm{CH}_{2} \mathrm{Cl}_{2}$ phase, containing the compounds of interest, was extracted from the aqueous phase. The separation procedure was repeated $(2 \times)$ and the combined extracts dried under a gentle stream of $\mathrm{N}_{2}$. The fatty acids (FAs) were methylated by adding $1 \mathrm{ml}$ trimethylchlorosilane/MeOH $\left(1 / 10, v / v ; 80{ }^{\circ} \mathrm{C}, 2 \mathrm{~h}\right)$. Using a chromatographic column filled with $0.6 \mathrm{~g}$ silica gel, the compounds in the extract were separated into hydrocarbons and FA methyl esters (FAMEs) by elution with $7 \mathrm{ml}$ hexane and $7 \mathrm{ml} \mathrm{CH}_{2} \mathrm{Cl}_{2}$, respectively. The hydrocarbon fraction was desulfurized with activated elemental $\mathrm{Cu}$.

\subsubsection{ToF-SIMS}

ToF-SIMS images and spectra of positive and negative ions were recorded using a ToF-SIMS IV instrument (ION-TOF GmbH, Münster, Germany) equipped with a liquid Bi cluster ion source. $\mathrm{Bi}_{3}^{+}$cluster primary ions $(25 \mathrm{keV})$ were used at a dose between $7.5 \times 10^{10}$ and $4.6 \times 10^{12}$ ions $/ \mathrm{cm}^{2}$ for the cryosection and between $5.0 \times 10^{10}$ and $1.2 \times 10^{12}$ ions $/ \mathrm{cm}^{2}$ for the extract. Low energy electron flooding was used for charge compensation on the cryosection. The area analyzed $(100 \mu \mathrm{m} \times 100 \mu \mathrm{m}$ to $500 \mu \mathrm{m} \times 500 \mu \mathrm{m}$ ) was scanned in a raster pattern at $128 \times 128$ pixels for the extract, and $256 \times 256$ pixels for the cryosection. Compound assignment was based on the exact mass and the normal isotopic distribution of the respective peaks, as well as comparison with published mass spectral data (Steele et al., 2001; Toporski and Steele, 2004; Perkins et al., 2005; Heim et al., 2009; Jetter and Sodhi, 2011; Levine et al., 2011; Leefmann et al., 2013). 
To obtain lateral highly resolved ion images of the cryosection, the burst alignment mode of the instrument (high lateral resolution, ca. $300 \mathrm{~nm}$, low mass resolution, $m / \Delta m$ ca. 300 ) was used complementarily with the bunched mode (low lateral resolution, 3-5 $\mu \mathrm{m}$, high mass resolution, $\mathrm{m} / \Delta \mathrm{m}$ ca. 5000; Sodhi, 2004; Thiel and Sjövall, 2011). Peaks in burst alignment mode spectra were assigned by comparison with bunchedmode spectra obtained from the same area.

\subsubsection{GC-MS}

The system was a Varian CP-3800 gas chromatograph coupled to a Varian 1200 quadrupole mass spectrometer operated in electron ionization mode at $70 \mathrm{eV}$. Samples were injected on-column into a fused silica column (Phenomenex ZB-5; 30 $\mathrm{m} \times 0.32 \mathrm{~mm}$ i.d.; $0.25 \mu \mathrm{m}$ film thickness). The GC oven was programmed from $80{ }^{\circ} \mathrm{C}$ (3 min) to $310{ }^{\circ} \mathrm{C}$ (held $20 \mathrm{~min}$ ) at $6{ }^{\circ} \mathrm{C} / \mathrm{min}$. He was used as carrier gas at 1.5 $\mathrm{ml} / \mathrm{min}$. Compounds were assigned by comparison with published mass spectral data and parallel analysis of a standard mixture (Supelco ${ }^{\text {TM }} 37$ Component FAME Mix, Sigma-Aldrich, Steinheim, Germany).

\subsubsection{Microscopy}

For morphological identification of the diatoms, frustules were prepared according to a protocol modified from Battarbee (1986), treated with $35 \% \mathrm{H}_{2} \mathrm{O}_{2}$ and $10 \% \mathrm{HCl}$, and mounted with Naphrax (index nD 1.73; Brunel Microscopes, UK). The material was examined using an Olympus BX60 microscope (Olympus Europe, Hamburg, Germany) with Nomarski DIC optics. Pictures were taken with a ColorView III camera using the imaging software Cell D ( $\mathrm{v}$ 3.4). Diatom species was assigned according to Krammer and Lange-Bertalot (1991).

\subsection{Results}

\subsubsection{ToF-SIMS, cryosection}

\subsubsection{Positive ion mode}

The positive ion spectrum of the cryosection is dominated by peaks in the $m / z 300-$ 340 and the $m / z$ 540-600 range, respectively (Figure 4-1; Table 4-1). Studies using ToF-SIMS have reported these peaks to represent $\left[\mathrm{M}+\mathrm{H}-\mathrm{H}_{2} \mathrm{O}\right]^{+}$ions of mono- and 
diacylglycerols (MAGs; DAGs; Malmberg et al., 2007; Sjövall et al., 2008; Debois et al., 2009). The peaks all fit with the calculated masses of MAGs and DAGs (Table 4-1) and the respective natural isotope distribution of the assigned ions.
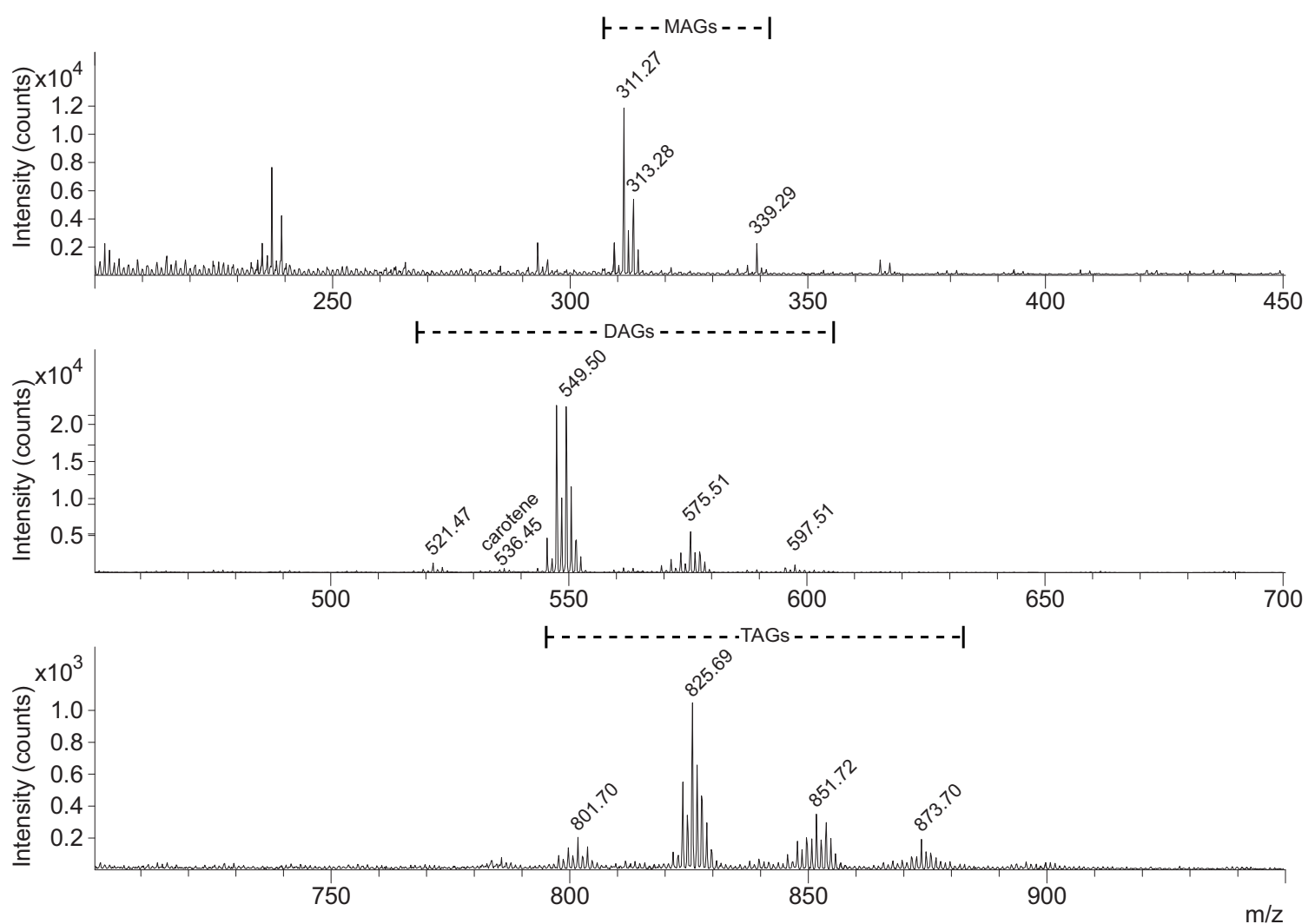

Figure 4-1. Partial positive ion ToF-SIMS spectrum $(\mathrm{m} / \mathrm{z} 200-950)$ of a $100 \mu \mathrm{m} \times 100 \mu \mathrm{m}$ area on the cryosection of the phototrophic microbial mat. MAGs, monoacylglycerols; DAGs, diacylglycerols; TAGs, triacylglycerols.

Moreover previous ToF-SIMS analyses aimed at comparing the extracellular polymeric substances of cultured diatoms reported abundant, yet unassigned, peaks in similar ranges $(\mathrm{m} / \mathrm{z} 309-313$ and $\mathrm{m} / \mathrm{z}$ 547-551) for two out of three species studied (de Brouwer et al., 2006). Further intense peaks in the $m / z$ 790-880 range are consistent with $[\mathrm{M}+\mathrm{Na}]^{+}$ions of triacylglycerols (TAGs; Debois et al., 2009; Figure 4-1; Table 4-1). A low intensity peak at $m / z 536.45$ is consistent with the calculated mass of a carotene $[\mathrm{M}]^{+}$ion (Table 4-1), which has been found to be one of the strongest ions in ToF-SIMS analysis of a $\beta, \beta$-carotene standard (Leefmann et al., 2013).

In the analysis area no ions that could be robustly assigned to sterols or hopanoids, as observed with standards, tissue sections and environmental samples (e.g. Steele et al., 2001; Sjövall et al., 2004; Leefmann et al., 2013), were detected. 
Table 4-1. Characteristic ions in positive ion ToF-SIMS spectra of total extract and cryosection from the phototrophic microbial mat. MAG, monoacylglycerol; DAG, diacylglycerol.

\begin{tabular}{|c|c|c|c|c|c|c|}
\hline & & \multirow[t]{2}{*}{ Theoretical $\mathrm{m} / \mathrm{z}$} & \multicolumn{3}{|c|}{ Tentative assignment } \\
\hline & \multicolumn{2}{|c|}{\begin{tabular}{l|l} 
Experimental $m / z$ \\
Extract
\end{tabular}} & & Compound & Formula & Ion \\
\hline \multirow{7}{*}{\begin{tabular}{|c|} 
Ion species \\
MAG \\
\end{tabular}} & 309.25 & 309.24 & 309.24 & MAG 16:2 & $\mathrm{C}_{19} \mathrm{H}_{33} \mathrm{O}_{3}$ & {$\left[\mathrm{M}+\mathrm{H}-\mathrm{H}_{2} \mathrm{O}\right]^{+}$} \\
\hline & 311.27 & 311.27 & 311.26 & MAG 16:1 & $\mathrm{C}_{19} \mathrm{H}_{35} \mathrm{O}_{3}$ & {$\left[\mathrm{M}+\mathrm{H}-\mathrm{H}_{2} \mathrm{O}\right]^{+}$} \\
\hline & 313.28 & 313.28 & 313.27 & MAG 16:0 & $\mathrm{C}_{19} \mathrm{H}_{37} \mathrm{O}_{3}$ & {$\left[\mathrm{M}+\mathrm{H}-\mathrm{H}_{2} \mathrm{O}\right]^{+}$} \\
\hline & - & 333.25 & 333.24 & MAG 18:4 & $\mathrm{C}_{21} \mathrm{H}_{33} \mathrm{O}_{3}$ & {$\left[\mathrm{M}+\mathrm{H}-\mathrm{H}_{2} \mathrm{O}\right]^{+}$} \\
\hline & - & 335.27 & 335.26 & MAG 18:3 & $\mathrm{C}_{21} \mathrm{H}_{35} \mathrm{O}_{3}$ & {$\left[\mathrm{M}+\mathrm{H}-\mathrm{H}_{2} \mathrm{O}\right]^{+}$} \\
\hline & - & 337.28 & 337.27 & MAG 18:2 & $\mathrm{C}_{21} \mathrm{H}_{37} \mathrm{O}_{3}$ & {$\left[\mathrm{M}+\mathrm{H}-\mathrm{H}_{2} \mathrm{O}\right]^{+}$} \\
\hline & 339.30 & 339.29 & 339.29 & MAG 18:1 & $\mathrm{C}_{21} \mathrm{H}_{39} \mathrm{O}_{3}$ & {$\left[\mathrm{M}+\mathrm{H}-\mathrm{H}_{2} \mathrm{O}\right]^{+}$} \\
\hline Carotenoids & 536.43 & 536.45 & 536.44 & carotene & $\mathrm{C}_{40} \mathrm{H}_{56}$ & {$[\mathrm{M}]^{+}$} \\
\hline DAG & - & 517.44 & 517.43 & DAG 30:3 & $\mathrm{C}_{33} \mathrm{H}_{57} \mathrm{O}_{4}$ & {$\left[\mathrm{M}+\mathrm{H}-\mathrm{H}_{2} \mathrm{O}\right]^{+}$} \\
\hline & - & 519.45 & 519.44 & DAG 30:2 & $\mathrm{C}_{33} \mathrm{H}_{59} \mathrm{O}_{4}$ & {$\left[\mathrm{M}+\mathrm{H}-\mathrm{H}_{2} \mathrm{O}\right]^{+}$} \\
\hline & - & 521.47 & 521.46 & DAG 30:1 & $\mathrm{C}_{33} \mathrm{H}_{61} \mathrm{O}_{4}$ & {$\left[\mathrm{M}+\mathrm{H}-\mathrm{H}_{2} \mathrm{O}\right]^{+}$} \\
\hline & - & 523.48 & 523.47 & DAG 30:0 & $\mathrm{C}_{33} \mathrm{H}_{63} \mathrm{O}_{4}$ & {$\left[\mathrm{M}+\mathrm{H}-\mathrm{H}_{2} \mathrm{O}\right]^{+}$} \\
\hline & - & 531.46 & 531.44 & DAG $31: 3$ & $\mathrm{C}_{34} \mathrm{H}_{59} \mathrm{O}_{4}$ & {$\left[\mathrm{M}+\mathrm{H}-\mathrm{H}_{2} \mathrm{O}\right]^{+}$} \\
\hline & - & 533.48 & 533.46 & DAG 31:2 & $\mathrm{C}_{34} \mathrm{H}_{61} \mathrm{O}_{4}$ & {$\left[\mathrm{M}+\mathrm{H}-\mathrm{H}_{2} \mathrm{O}\right]^{+}$} \\
\hline & - & 535.48 & 535.47 & DAG $31: 1$ & $\mathrm{C}_{34} \mathrm{H}_{63} \mathrm{O}_{4}$ & {$\left[\mathrm{M}+\mathrm{H}-\mathrm{H}_{2} \mathrm{O}\right]^{+}$} \\
\hline & - & 537.47 & 537.49 & DAG 31:0 & $\mathrm{C}_{34} \mathrm{H}_{65} \mathrm{O}_{4}$ & {$\left[\mathrm{M}+\mathrm{H}-\mathrm{H}_{2} \mathrm{O}\right]^{+}$} \\
\hline & - & 543.46 & 543.44 & DAG $32: 4$ & $\mathrm{C}_{35} \mathrm{H}_{59} \mathrm{O}_{4}$ & {$\left[\mathrm{M}+\mathrm{H}-\mathrm{H}_{2} \mathrm{O}\right]^{+}$} \\
\hline & 545.46 & 545.47 & 545.46 & DAG 32:3 & $\mathrm{C}_{35} \mathrm{H}_{61} \mathrm{O}_{4}$ & {$\left[\mathrm{M}+\mathrm{H}-\mathrm{H}_{2} \mathrm{O}\right]^{+}$} \\
\hline & 547.48 & 547.49 & 547.47 & DAG $32: 2$ & $\mathrm{C}_{35} \mathrm{H}_{63} \mathrm{O}_{4}$ & {$\left[\mathrm{M}+\mathrm{H}-\mathrm{H}_{2} \mathrm{O}\right]^{+}$} \\
\hline & 549.50 & 549.50 & 549.49 & DAG $32: 1$ & $\mathrm{C}_{35} \mathrm{H}_{65} \mathrm{O}_{4}$ & {$\left[\mathrm{M}+\mathrm{H}-\mathrm{H}_{2} \mathrm{O}\right]^{+}$} \\
\hline & 551.50 & 551.51 & 551.50 & DAG 32:0 & $\mathrm{C}_{35} \mathrm{H}_{67} \mathrm{O}_{4}$ & {$\left[\mathrm{M}+\mathrm{H}-\mathrm{H}_{2} \mathrm{O}\right]^{+}$} \\
\hline
\end{tabular}


Table 4-1. Characteristic ions in positive ion ToF-SIMS spectra of total extract and cryosection from the phototrophic microbial mat. DAG, diacylglycerol (continued).

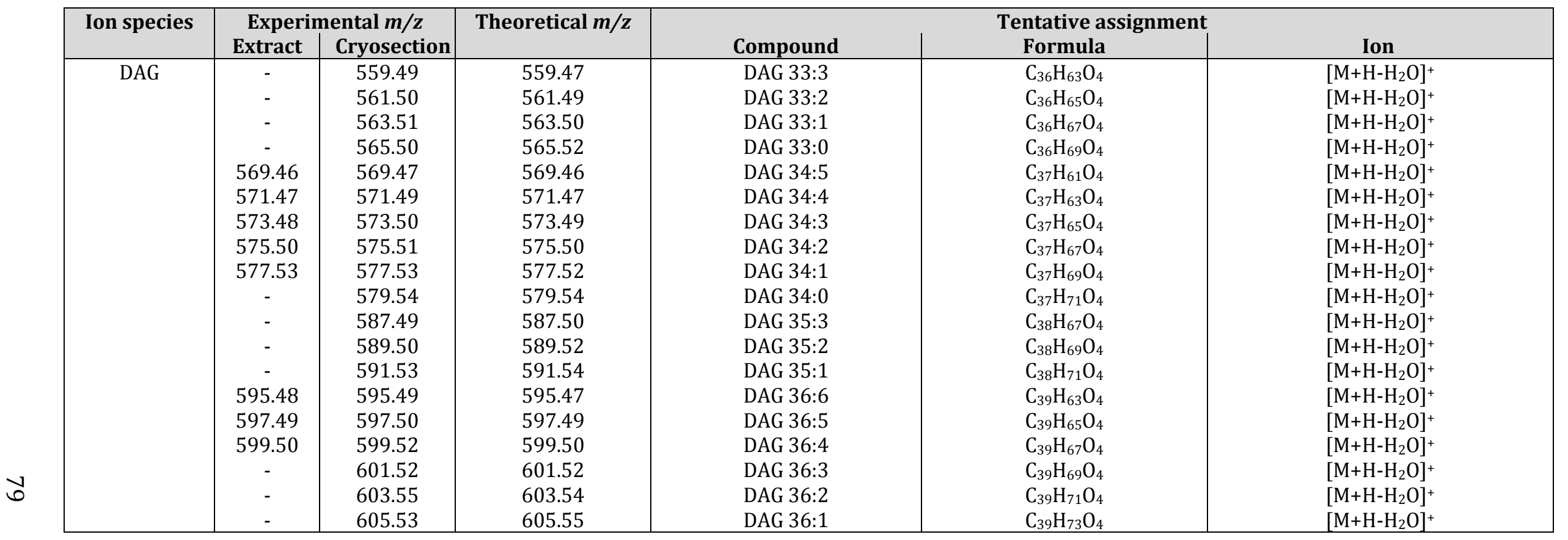


Table 4-1. Characteristic ions in positive ion ToF-SIMS spectra of total extract and cryosection from the phototrophic microbial mat. TAG, triacylglycerol (continued).

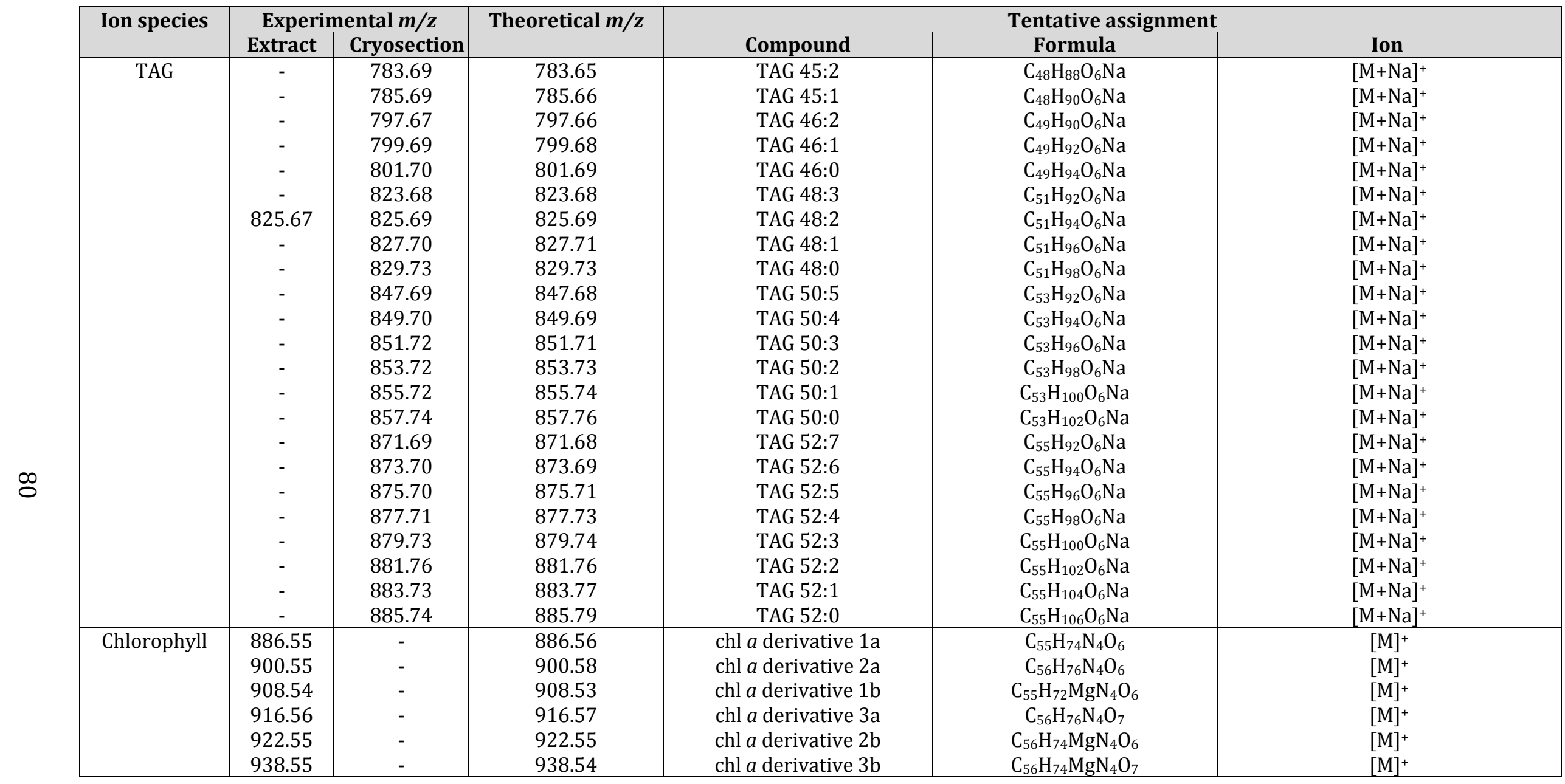


Table 4-2. Characteristic ions in negative ion ToF-SIMS spectra of total extract and cryosection from the phototrophic microbial mat. FA, fatty acid.

\begin{tabular}{|c|c|c|c|c|c|c|}
\hline \multirow[t]{2}{*}{ Ion species } & \multicolumn{2}{|c|}{ Experimental $m / z$} & \multirow[t]{2}{*}{ Theoretical $\mathrm{m} / \mathrm{z}$} & \multicolumn{3}{|c|}{ Tentative assignment } \\
\hline & Extract & Cryosection & & Compound & Formula & Ion \\
\hline FA & 223.16 & 223.16 & 223.17 & FA 14:2 & $\mathrm{C}_{14} \mathrm{H}_{23} \mathrm{O}_{2}$ & {$[\mathrm{M}-\mathrm{H}]^{-}$} \\
\hline & 225.18 & 225.17 & 225.19 & FA $14: 1$ & $\mathrm{C}_{14} \mathrm{H}_{25} \mathrm{O}_{2}$ & {$[\mathrm{M}-\mathrm{H}]^{-}$} \\
\hline & 227.19 & 227.19 & 227.20 & FA 14:0 & $\mathrm{C}_{14} \mathrm{H}_{27} \mathrm{O}_{2}$ & {$[\mathrm{M}-\mathrm{H}]^{-}$} \\
\hline & 239.19 & 239.20 & 239.20 & FA $15: 1$ & $\mathrm{C}_{15} \mathrm{H}_{27} \mathrm{O}_{2}$ & {$[\mathrm{M}-\mathrm{H}]^{-}$} \\
\hline & 241.21 & 241.21 & 241.22 & FA 15:0 & $\mathrm{C}_{15} \mathrm{H}_{29} \mathrm{O}_{2}$ & {$[\mathrm{M}-\mathrm{H}]^{-}$} \\
\hline & 247.17 & 247.17 & 247.17 & FA $16: 4$ & $\mathrm{C}_{16} \mathrm{H}_{23} \mathrm{O}_{2}$ & {$[\mathrm{M}-\mathrm{H}]^{-}$} \\
\hline & 249.18 & 249.18 & 249.19 & FA $16: 3$ & $\mathrm{C}_{16} \mathrm{H}_{25} \mathrm{O}_{2}$ & {$[\mathrm{M}-\mathrm{H}]^{-}$} \\
\hline & 251.19 & 251.19 & 251.20 & FA $16: 2$ & $\mathrm{C}_{16} \mathrm{H}_{27} \mathrm{O}_{2}$ & {$[\mathrm{M}-\mathrm{H}]^{-}$} \\
\hline & 253.21 & 253.21 & 253.22 & FA $16: 1$ & $\mathrm{C}_{16} \mathrm{H}_{29} \mathrm{O}_{2}$ & {$[\mathrm{M}-\mathrm{H}]^{-}$} \\
\hline & 255.22 & 255.22 & 255.23 & FA 16:0 & $\mathrm{C}_{16} \mathrm{H}_{31} \mathrm{O}_{2}$ & {$[\mathrm{M}-\mathrm{H}]^{-}$} \\
\hline & 265.21 & 265.21 & 265.22 & FA 17:2 & $\mathrm{C}_{17} \mathrm{H}_{29} \mathrm{O}_{2}$ & {$[\mathrm{M}-\mathrm{H}]^{-}$} \\
\hline & 267.22 & 267.22 & 267.23 & FA $17: 1$ & $\mathrm{C}_{17} \mathrm{H}_{31} \mathrm{O}_{2}$ & {$[\mathrm{M}-\mathrm{H}]^{-}$} \\
\hline & 269.24 & 269.23 & 269.25 & FA 17:0 & $\mathrm{C}_{17} \mathrm{H}_{33} \mathrm{O}_{2}$ & {$[\mathrm{M}-\mathrm{H}]^{-}$} \\
\hline & - & 273.19 & 273.19 & FA 18:5 & $\mathrm{C}_{18} \mathrm{H}_{25} \mathrm{O}_{2}$ & {$[\mathrm{M}-\mathrm{H}]^{-}$} \\
\hline & 275.20 & 275.20 & 275.20 & FA 18:4 & $\mathrm{C}_{18} \mathrm{H}_{27} \mathrm{O}_{2}$ & {$[\mathrm{M}-\mathrm{H}]^{-}$} \\
\hline & 277.21 & 277.20 & 277.22 & FA $18: 3$ & $\mathrm{C}_{18} \mathrm{H}_{29} \mathrm{O}_{2}$ & {$[\mathrm{M}-\mathrm{H}]^{-}$} \\
\hline & 279.22 & 279.22 & 279.23 & FA $18: 2$ & $\mathrm{C}_{18} \mathrm{H}_{31} \mathrm{O}_{2}$ & {$[\mathrm{M}-\mathrm{H}]^{-}$} \\
\hline & 281.24 & 281.24 & 281.25 & FA $18: 1$ & $\mathrm{C}_{18} \mathrm{H}_{33} \mathrm{O}_{2}$ & {$[\mathrm{M}-\mathrm{H}]^{-}$} \\
\hline & 283.25 & 283.26 & 283.26 & FA 18:0 & $\mathrm{C}_{18} \mathrm{H}_{35} \mathrm{O}_{2}$ & {$[\mathrm{M}-\mathrm{H}]^{-}$} \\
\hline & 301.21 & 301.22 & 301.22 & FA 20:5 & $\mathrm{C}_{20} \mathrm{H}_{29} \mathrm{O}_{2}$ & {$[\mathrm{M}-\mathrm{H}]^{-}$} \\
\hline & 367.34 & 367.34 & 367.36 & FA 24:0 & $\mathrm{C}_{24} \mathrm{H}_{47} \mathrm{O}_{2}$ & {$[\mathrm{M}-\mathrm{H}]^{-}$} \\
\hline & 393.36 & 393.36 & 393.37 & FA 26:1 & $\mathrm{C}_{26} \mathrm{H}_{49} \mathrm{O}_{2}$ & {$[\mathrm{M}-\mathrm{H}]^{-}$} \\
\hline Carotenoids & $\begin{array}{l}536.42 \\
658.40\end{array}$ & $\begin{array}{l}536.43 \\
658.41\end{array}$ & $\begin{array}{l}536.44 \\
658.42\end{array}$ & $\begin{array}{c}\text { carotene } \\
\text { fucoxanthin }\end{array}$ & $\begin{array}{c}\mathrm{C}_{40} \mathrm{H}_{56} \\
\mathrm{C}_{42} \mathrm{H}_{58} \mathrm{O}_{6}\end{array}$ & $\begin{array}{l}{[\mathrm{M}]^{-}} \\
{[\mathrm{M}]^{-}}\end{array}$ \\
\hline
\end{tabular}


Table 4-2. Characteristic ions in negative ion ToF-SIMS spectra of total extract and cryosection from the phototrophic microbial mat. FA, fatty acid.

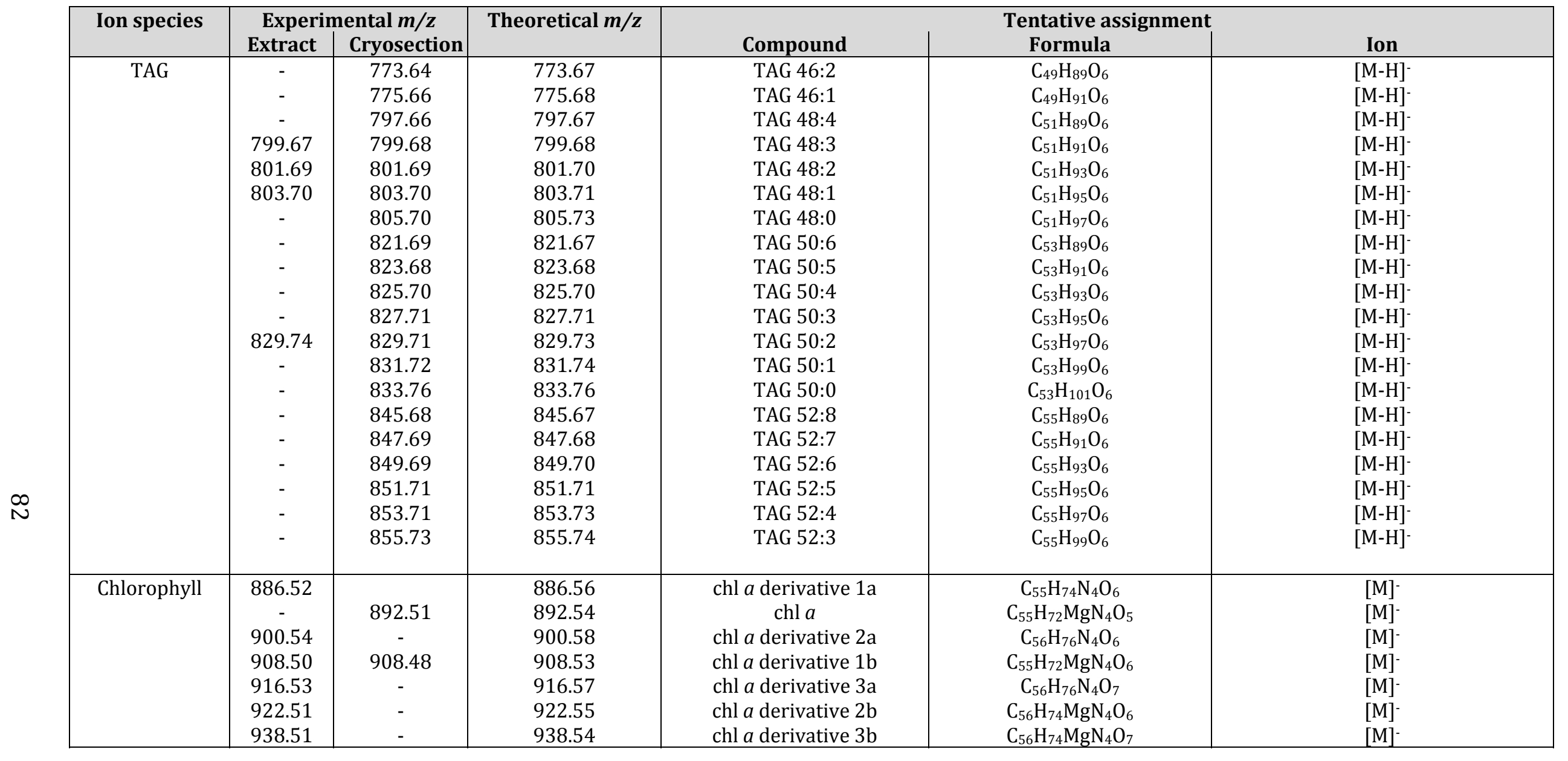




\subsubsection{Negative ion mode}

The negative ToF-SIMS spectrum shows very strong peaks in the $m / z$ 200-300 range (Figure 4-2), consistent with [M-H]- ions of saturated and unsaturated $\mathrm{C}_{14}$ to $\mathrm{C}_{26}$ FAs (Figure 4-2; Table 4-2; Touboul et al., 2005; Passarelli and Winograd, 2011), with $16: 1,16: 0,18: 1$ and 20:5 the most abundant.

In the typical mass range of intact polar lipids, a peak doublet was observed at $m / z 748.57$ and 749.58. The exact mass suggests a phosphatidylglycerol (PG; Pelizzi et al., 2002; Vieler et al., 2007; Heim et al., 2009) with two saturated side chains comprising 34 carbons in total (PG 34:0). This is supported by the presence of the PG head group ion at $m / z 153.00\left(\mathrm{C}_{3} \mathrm{H}_{6} \mathrm{O}_{5} \mathrm{P}-;\right.$ Heim et al., 2009). However, taking into account the strong predominance of unsaturated fatty acids (FAs) on the sample surface, an assignment of these peaks to a PG with saturated FA tail groups appears not plausible. The identity of the putative lipid at $m / z$ 748.57/749.58 must therefore remain open.
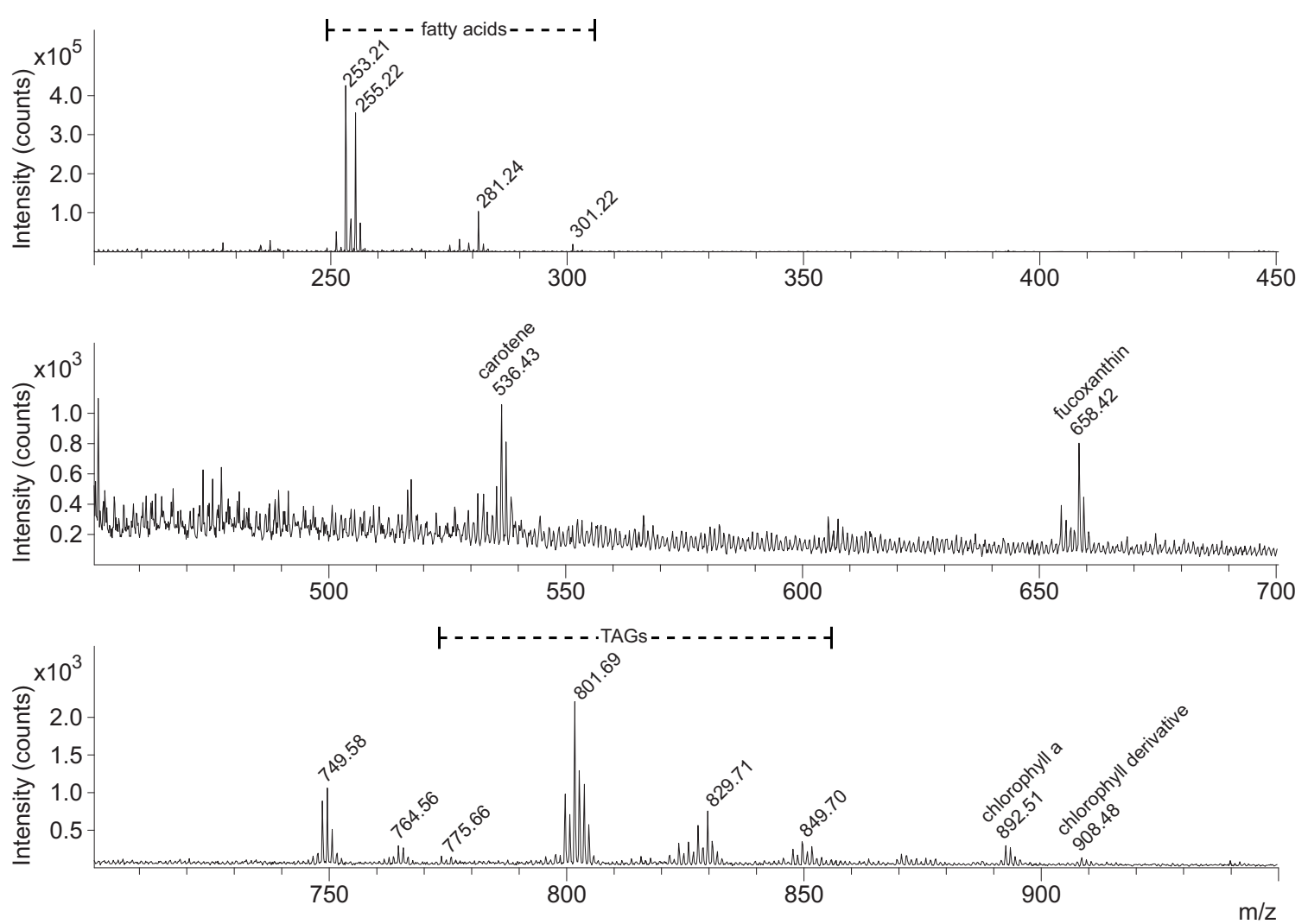

Figure 4-2. Partial negative ion ToF-SIMS spectrum (m/z 200-950) of a $100 \mu \mathrm{m} \times 100 \mu \mathrm{m}$ area of the cryosection of the phototrophic microbial mat. TAGs, triacylglycerols. 
In addition to this unknown lipid, we observed another intact polar lipid candidate peak cluster at $m / z 764.56$ (Figure 4-2). This peak is in good agreement with phosphatidylethanolamine (PE) 38:5 ( $\left.\mathrm{C}_{43} \mathrm{H}_{75} \mathrm{NO}_{8} \mathrm{P}^{-},[\mathrm{M}-\mathrm{H}]^{-}\right)$, which may plausibly include the 20:5 FA tail group. As expected from published PE standard spectra, the compound shows a substantial signal only in the negative ion mode (Heim et al., 2009). However, no PE-derived head group fragments reported from standard spectra $\left(\mathrm{C}_{2} \mathrm{H}_{7} \mathrm{NO}_{4} \mathrm{P}-;\right.$ Heim et al., 2009) were observed, so again the identity of this ion must remain speculative. Careful inspection of the spectrum revealed no robust indications for the expected presence of further intact polar lipids.

In accord with the positive ion spectrum, peaks consistent with $[\mathrm{M}-\mathrm{H}]^{-}$of various TAGs were observed in the $m / z$ 770-860 range. Further distinctive peaks at $m / z$ $536.43,658.41$ and 892.51 are consistent with [M]- ions of the pigments carotene, fucoxanthin (Akimoto et al., 2000, see Section 3.2.2), and chlorophyll $a$, respectively. A lower intensity peak at $\mathrm{m} / z 908.48$ is consistent with the mass of oxidized chlorophyll $a$ (chl $a$ derivative 1b; Figure 4-2; Table 4-2). Diagnostic ions from sterols, as reported from standards (Leefmann et al., 2013), were not observed in the negative ion mode spectrum.

\subsubsection{Compound imaging}

The imaging capability of ToF-SIMS allows displaying the lateral distribution of the ions on the surface of the cryosection. The spectra (Figure 4-1 and Figure 4-2) are summed from 65536 individual point measurements (256 × 256 pixels), i.e. spectra obtained from an area of $100 \mu \mathrm{m} \times 100 \mu \mathrm{m}$. Using the instrument software, the intensity of specific ions in each point measurement can be displayed in two dimensional maps, resulting in 'ion images' of the area analyzed. Subsequent to the actual ToF-SIMS measurement, specific regions of interest (ROIs), such as visible cells, can be selected in the ion images and mass spectra of these ROIs can be calculated from the raw data file (see Thiel and Sjövall (2011) for a more detailed description of the theory).

The ion images from the cryosection of the phototrophic mat showed high signal intensity for $\mathrm{C}_{16}$ and $\mathrm{C}_{18}$ FAs (Figure 4-3a II and III) that were co-localized with 10$15 \mu \mathrm{m}$ elongated cells (Figure 4-3a IV, a V). These cells were identified as diatoms of the species Planothidium lanceolatum (Figure 4-3a VI; Lange-Bertalot, 1999). 
The negative ion, burst alignment mode spectrum produced from a single cell of P. lanceolatum within the mat showed peaks consistent with $\mathrm{C}_{16}$ and $\mathrm{C}_{18}$ FAs, carotene, fucoxanthin, TAGs, chlorophyll $a$, and an unknown putative intact polar lipid ion at $m / z 749$ (Figure 4-3a IV and V, b).

a
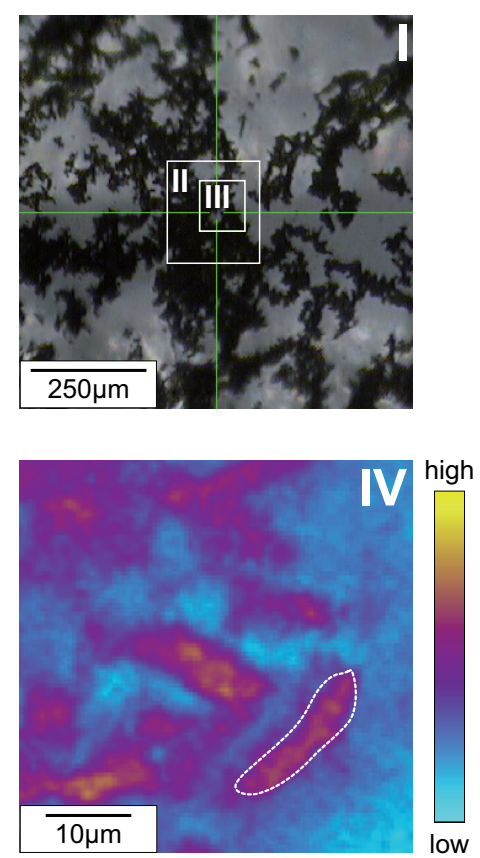
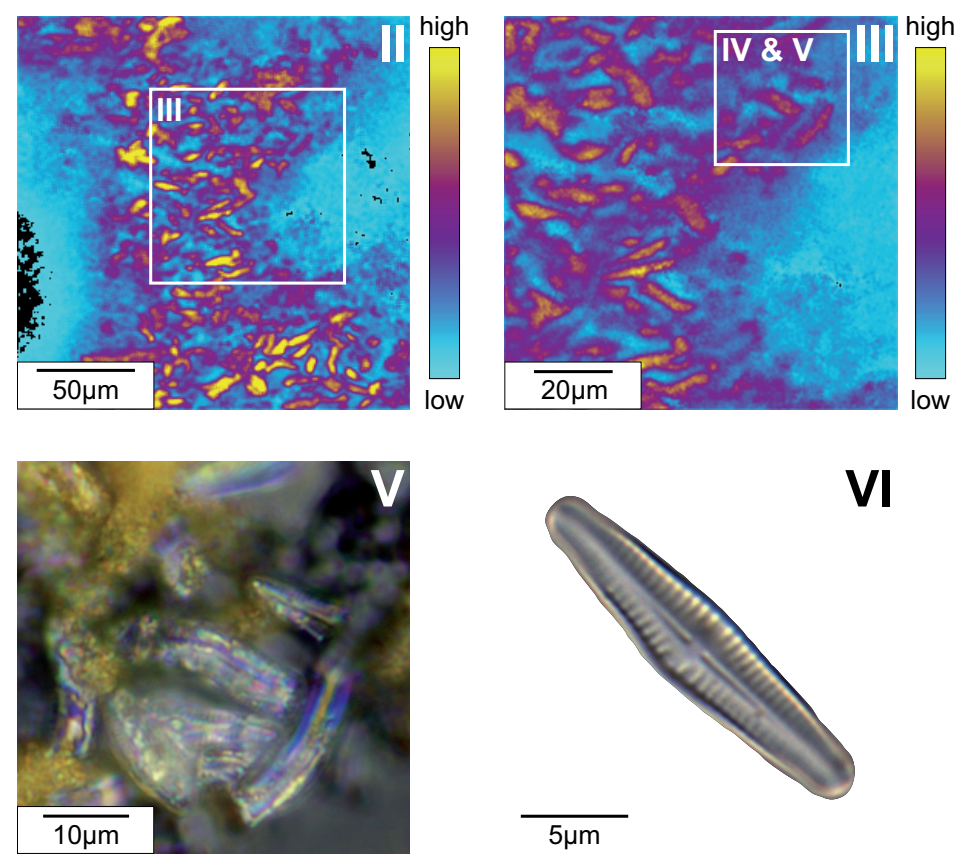

VI

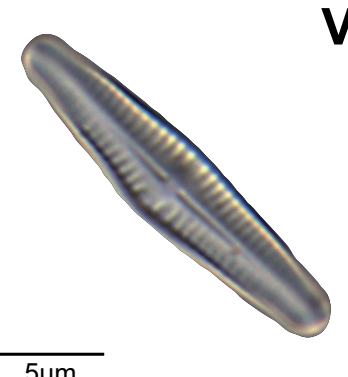

b

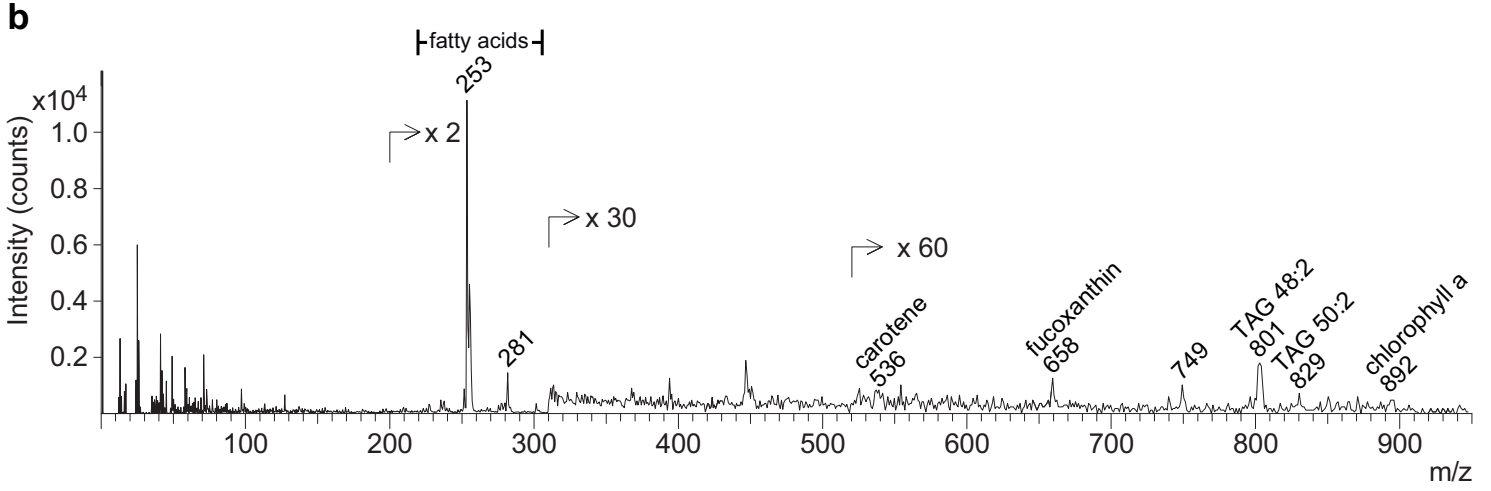

Figure 4-3. Single cell biomarker imaging: (a) Microscopic and ion images of microbial mat cryosection analyzed in burst alignment mode (I) ToF-SIMS built-in video camera image with areas analyzed marked by white frames, (II) ion image of $200 \mu \mathrm{m} \times 200 \mu \mathrm{m}$ area showing distribution of summed $\mathrm{C}_{16}$ and $\mathrm{C}_{18}$ FAs (negative ion mode, $\mathrm{m} / \mathrm{z} 251-258+\mathrm{m} / \mathrm{z} 275-284$ ), (III) ion image of $100 \mu \mathrm{m} \times 100 \mu \mathrm{m}$ area showing distribution of summed $\mathrm{C}_{16}$ and $\mathrm{C}_{18}$ FAs, (IV) enlarged detail of III showing enrichment in $\mathrm{C}_{16}$ and $\mathrm{C}_{18}$ FAs in diatom cell (white, dashed line marks area from which the spectrum in (b) was calculated), (V) fluorescence microscopic image from area corresponding to IV after ToF-SIMS measurements, showing accumulation of diatom cells, (VI) single cell of predominant diatom, Planothidium lanceolatum, in the phototrophic microbial mat. (b) Partial negative burst alignment mode ToF-SIMS spectrum (m/z 0-950) of single diatom cell in the microbial mat cryosection corresponding to the area marked in (a) IV. TAG, triacylglycerol. Note the predominance of $16: 1(\mathrm{~m} / \mathrm{z} 253)$ and 16:0 FA which is a typical feature of diatom FA distributions. 


\subsubsection{ToF-SIMS, total organic extract}

\subsubsection{Positive ion mode}

The positive ion mode ToF-SIMS spectrum (Figure 4-4; Table 4-1) of the microbial mat extract showed strong peaks at $m / z$ 886.55, 900.55, 908.54, 916.56, 922.55 and 938.55. Given the mass region and detection of chl $a$ in the cryosection, chlorophyll derivatives are the most likely source of these ions. The peaks at $m / z 908.54$ and 922.55 are consistent with $13^{2}$-hydroxychlorophyll $a$ (chl $a$ derivative $1 \mathrm{~b}$ ) and $13^{2}$ methoxychlorophyll $a$ (chl $a$ derivative 2b; Mínguez-Mosquera and Gandul-Rojas, 1995), respectively. These chl $a$ derivatives are known to form via allomerization of chlorophyll $a$ in alcohol solution (Schaber et al., 1984) and can thus be plausibly expected in the methanolic extract prepared from the mat. The peaks at $m / z 886.55$ and 900.55 are consistent with ions of chl a derivatives $1 \mathrm{~b}$ and $2 \mathrm{~b}$, respectively, where $\mathrm{Mg}^{2+}$ is replaced by two Hs.
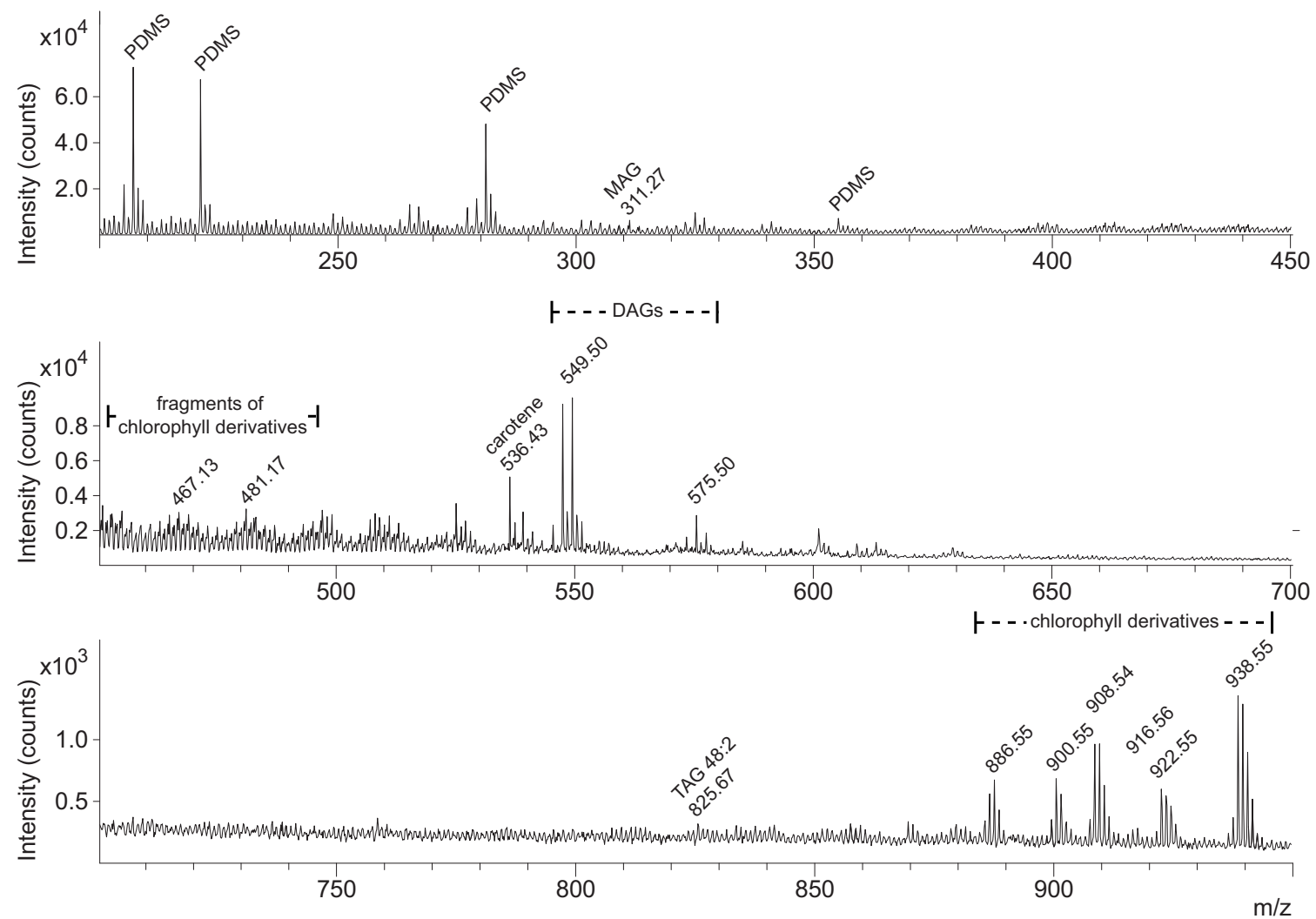

Figure 4-4. Partial positive ion ToF-SIMS spectrum $(\mathrm{m} / \mathrm{z} 200-950)$ of total extract of the phototrophic microbial mat. MAG, monoacylglycerol; PDMS, polydimethylsiloxane; DAGs, diacylglycerols; TAG, triacylglycerol. 
This replacement is a common reaction of chlorophylls under acidic conditions (Mínguez-Mosquera and Gandul-Rojas, 1995), but may also proceed at $\mathrm{pH} \geq 7$ through enzymatic reactions during senescence or grazing (Keely, 2006). Likewise, the peaks at $m / z$ 938.55/916.57 may represent ions of an $\mathrm{C}\left(15^{1}\right)-0 M e$ lactone chl $a$ (chl $a$ derivative 3b; Woolley et al., 1998) and the corresponding ion in where the $\mathrm{Mg}^{2+}$ has been replaced by two Hs (chl $a$ derivative 3a).The above assignments are corroborated by peaks at $m / z 481.14$ and 467.13 the values of which are consistent with the chlorin backbone (Figure 4-5; Hunt et al., 1981; van Breemen et al., 1991). Similarly, the peak at $m / z 629.23$ is plausibly explained by the mass of OH-Chl $a$ (cf. Mínguez-Mosquera and Gandul-Rojas, 1995; Chl $a$ derivative 1b; Table 4-1) after loss of the phytyl side chain $\left[\mathrm{M}-\mathrm{C}_{20} \mathrm{H}_{39}\right]^{+}$.

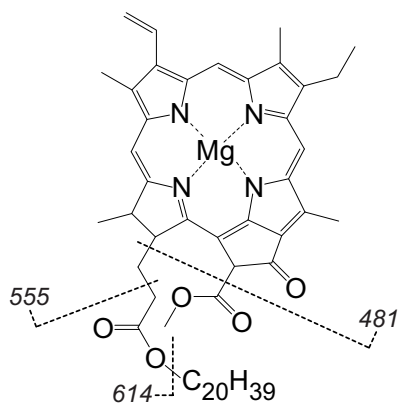

Figure 4-5. Putative chlorophyll $a$ fragmentation scheme from positive ion fast atom bombardment (FAB) tandem mass spectrometry (MS²) according to van Breemen et al. (1991).

A peak corresponding to the $[\mathrm{M}]^{+}$of carotene was observed at $\mathrm{m} / \mathrm{z} 536.45$ (Figure 4-4; Table 4-1). Apart from the pigments, the positive ion spectrum of the extract is, as in the cryosection, dominated by peaks corresponding to $\left[\mathrm{M}+\mathrm{H}-\mathrm{H}_{2} \mathrm{O}\right]^{+}$ ions of MAGs and DAGs (Figure 4-4; Table 4-1). A small peak at $m / z 825.67$ is consistent with a $[\mathrm{M}+\mathrm{Na}]^{+}$ion of a TAG (Figure 4-2; Table 4-1) containing three $\mathrm{C}_{16}$ acyl chains and two double bonds. Compared with the spectrum obtained from the cryosection, the peaks corresponding to MAGs, DAGs and TAGs were lower in intensity and fewer individual compounds were detected (Figure 4-4; Table 4-1). No positive ions that could be unambiguously assigned to sterols or hopanoids were detected in the extract with ToF-SIMS.

\subsubsection{Negative ion mode}

The negative ToF-SIMS spectrum is dominated by strong peaks from FAs in the $\mathrm{C}_{14}$ to $\mathrm{C}_{26}$ range (Figure 4-6; Table 4-2). Furthermore, as in the positive ion mode, strong 
$\mathrm{M}^{-}$ions of chl $a$ derivatives were detected $(\mathrm{m} / \mathrm{z}$ 886.52, 900.54, 908.50, 916.53, 922.51 and 938.51) with corresponding chlorin fragment peaks at $m / z 467.10$ and 482.12. Further peaks at $m / z 629.20$ (also observed in the positive spectrum), 643.21, and 659.21 are consistent with ions of chl $a$ derivatives after loss of the phytyl side chain (corresponding to $m / z 614$ in Figure 4-5).

In spectra obtained with atmospheric pressure chemical ionization LC-MS ions differing by 2 Da from these peaks have been assigned to fragments of the described chl $a$ derivatives (Walker et al., 2003). Another peak at $m / z 658.40$ is in accord with the negative ion spectrum of the cryosection, consistent with the $[\mathrm{M}]$ - of fucoxanthin $\left(\mathrm{C}_{42} \mathrm{H}_{58} \mathrm{O}_{6}\right)$. At the given resolution of $m / \Delta m$ ca. 5000 this peak can clearly be distinguished from the $[\mathrm{M}-1]^{-}$peak of the adjacent chl derivative fragment. Furthermore, as calculated using the instrument software, the natural isotopic abundance of fucoxanthin is fully explained and the isotope peaks have the size (area) expected for natural fucoxanthin.



Figure 4-6. Partial negative ion mode ToF-SIMS spectrum $(\mathrm{m} / \mathrm{z} 200-950)$ of total extract of the phototrophic microbial mat. TAG, triacylglycerols. 
Corresponding to the positive ion mode, a peak consistent with [M]- of carotene was detected at $m / z$ 536.42. In addition, [M-H]- ions of various TAGs (Figure 4-6; Table 4-2; Sjövall et al., 2008; Seyer et al., 2010) were detected in the negative ion spectrum. Notably, fewer individual TAGs, with respect to carbon number and unsaturation pattern, were observed in the extract than in the cryosection. Furthermore the peak in the cryosections at $m / z 748.57$ was also present in the extract, but could not be assigned to a specific lipid, as discussed in Section 4.4.1.2. Again, diagnostic ions from sterols or hopanoids were not detected in the negative ion mode.

\subsubsection{GC-MS, total organic extract}

The methyl ester fraction of the extract from the mat showed high amounts of even FAs in the $C_{14}$ to $C_{20}$ range (Figure 4-7). The most prominent were a saturated $\mathrm{C}_{14} \mathrm{FA}$ (14:0), saturated and monounsaturated $C_{16}$ FAs $(16: 0,16: 1 \omega 7)$, mono- and

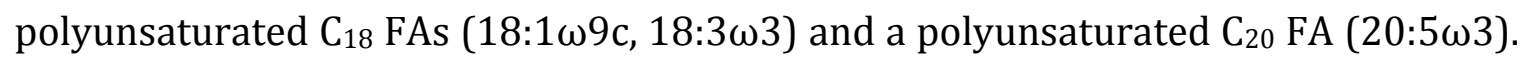
Further saturated (18:0) and unsaturated FAs $(16: 3 ; 18: 3 \omega 6,18: 4,18: 2 \omega 6 \mathrm{c}$,

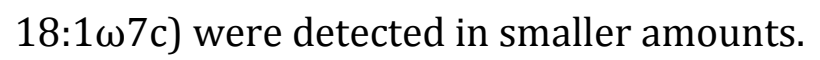

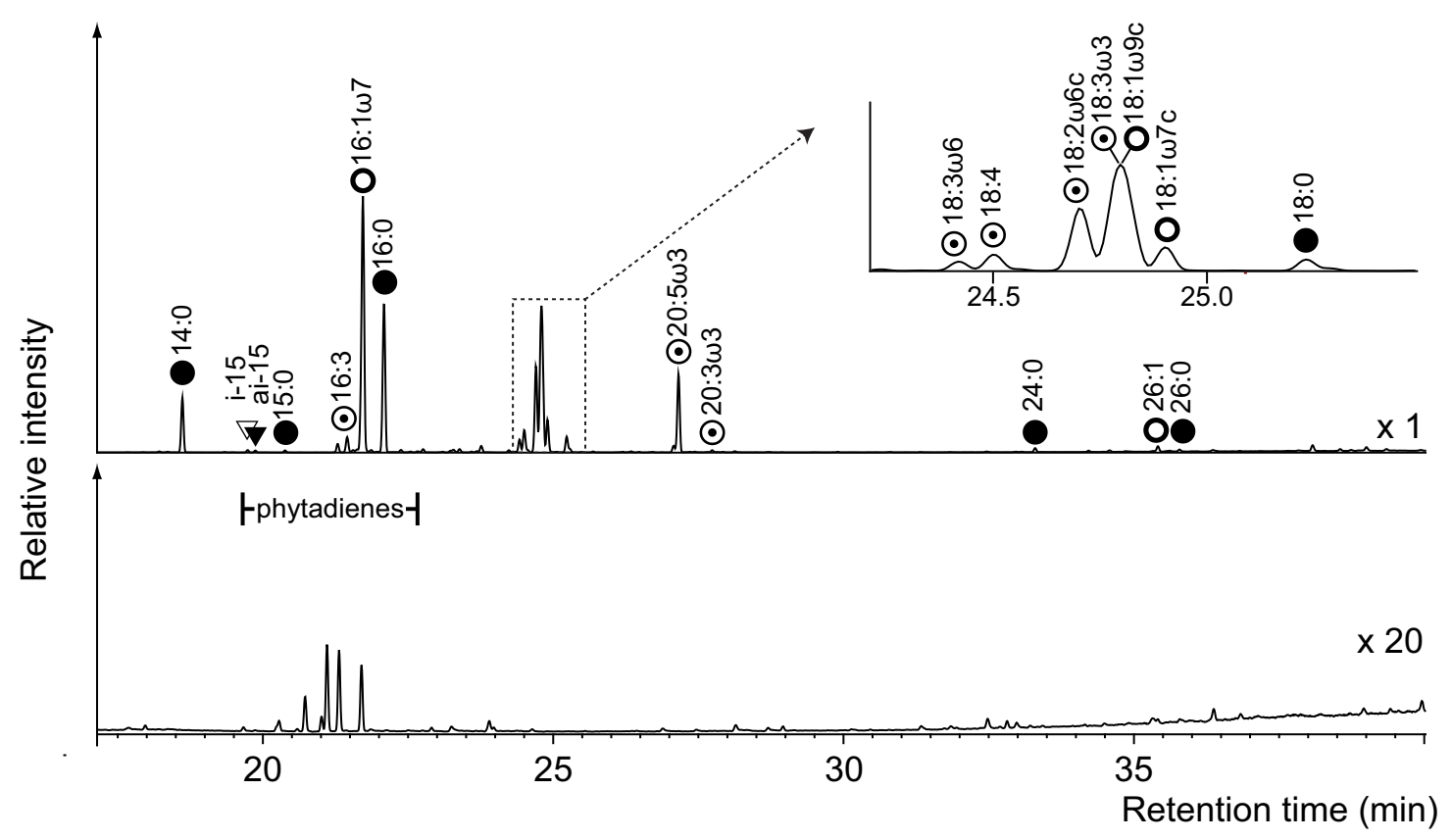

Figure 4-7. GC-MS chromatograms (total ion current) of FAs (as Me esters, top) and hydrocarbon fraction (bottom) from total extract of the phototrophic microbial mat. $\bullet$, saturated FA; 0 , monounsaturated FA; $\odot$, polyunsaturated FA; $\nabla$, iso-FA; $\nabla$, anteiso-FA. 
In addition iso- and anteiso pentadecanoic acids and $n$-FAs with higher carbon number $(24: 0,26: 1,26: 0)$ were present at very low abundance.

Compared with the methyl ester fraction, the hydrocarbon fraction afforded much lower amounts of compounds. The most prominent peaks consisted of phytadienes that most likely originated from the isoprenoid (phytol) side chain of chorophyll (Figure 4-7) upon acidic extract treatment. Unlike ToF-SIMS, the GC-MS analysis detected cholesterol and brassicasterol in the alcohol fraction separated from the extract, although in small amounts (data not shown).

\subsection{Discussion}

Comparison of the ToF-SIMS spectra from the extract samples and the cryosection showed that intact chl $a$ was exclusively detected in the latter, whereas the extracts revealed a variety of $\operatorname{chl} a$ derivatives that seem to result from the extraction procedure (Mínguez-Mosquera and Gandul-Rojas, 1995; Woolley et al., 1998). Such artifacts have to be taken into account, when comparing ToF-SIMS spectra from extracts with those measured directly on the sample surface. For analysis explicitly aimed at pigments, extraction with acetone may help avoid the formation of allomerization products (Keely, 2006).

A small but clearly recognizable peak in the ToF-SIMS spectrum of the single diatom cell (Figure 4-3) shows that the predominant species, P. lanceolatum, is a source of the chl $a$ in the mat system. However, given the comparably low signal from the chl $a$ in the single cell spectrum, contributions from other organisms present in the mat, such as cyanobacteria, cannot be excluded as an additional source of chl $a$ in the extract. Such a contribution may become sizeable when integrating a larger volume of microbial mat, as done by solvent extraction.

FAs are the predominant ion species in the cryosection (Figure 4-2) and the extracts (Figure 4-6 and Figure 4-7). The ions likely derive from the glycerol based lipids - MAGs, DAGs and TAGs. Other sources of FAs may have been the putative intact polar lipids observed at $m / z 748.57 / 749.58$ and 764.56 in the negative ion spectrum of the cryosection. Due to their high signal intensity within the cryosection, it was possible to produce ion images showing the exact localization of $\mathrm{C}_{16}$ and $\mathrm{C}_{18} \mathrm{FA}$ moieties with cells of $P$. lanceolatum (Figure 4-3a). This is further illustrated by the strong signal of these compounds, particularly 16:1 and 16:0, in 
the single cell mass spectrum (Figure 4-3b) and unequivocally reveals $P$. lanceolatum as a major source of these biomarkers in the mat system. The FA pattern in the extract and the cryosection detected with ToF-SIMS is consistent with a typical diatom FA distribution (Volkman et al., 1989).

Due to the workup involving methanolytic cleavage of the FAs from the glycerol backbone, MAGs, DAGs and TAGs were not detected with GC-MS. However, it can be anticipated that a major portion of the $\mathrm{C}_{16}$ and $\mathrm{C}_{18}$ FAs dominating the GC-MS FA (methyl ester) fraction is derived from these acylglycerols. Indeed, the ToF-SIMS spectra of the extract and the cryosections showed clear signals from MAGs, DAGs and TAGs. The greater abundance and diversity of these compounds in the cryosections vs. the extract is likely an effect of a higher localized concentration within the studied area of the cryosection. It is unclear as to whether or not the MAGs and DAGs are produced de novo by the diatoms, or whether they originate from the decomposition of TAGs. The single cell mass spectrum indicates, nevertheless, that all these compounds occur in P. lanceolatum. This is consistent with reports stating that up to $60 \%$ of the biomass of diatoms may consist of TAGs (Sheehan et al., 1998). The signals from MAGs, DAGs, and TAGs in the cryosection were, however, not intense enough to produce high-contrast ion images illustrating the exact co-localization of these compounds with the diatom cells. Likewise, the presence of the unassigned ion at $m / z 749$ in the single cell spectrum (Figure 4-3 3b) suggests that $P$. lanceolatum is a major source of this putative intact polar lipid in the microbial mat.

The unexpectedly low diversity of intact polar lipids in our experiment may simply be explained by the concentrations on the exposed cryosection surface being below detection limit of ToF-SIMS. Likewise, the detection of some of these compounds may have been hampered by their susceptibility to decomposition under primary ion bombardment. Indeed, it has been stated that several phospholipids are difficult to analyze with the current ToF-SIMS design, including PE, phosphosphingolipids and all lipids with polyunsaturated FA chains (for a comprehensive list of polar lipids that have successfully been analyzed using ToFSIMS, see Passarelli and Winograd, 2011). Likewise, matrix effects may alter the secondary ion yield, depending on the immediate chemical environment of the lipid studied (Ostrowski et al., 2005) and may, under unfavourable circumstances, evoke 
substantial differences among the sensitivity to different ion species. Consequently, it has been pointed out that the absence of a given analyte in a sample can hardly be proved using ToF-SIMS (Fletcher and Vickerman, 2013). The abovementioned factors may also account for the lack of cholesterol and brassicasterol in the ToFSIMS spectra of the extract and the cryosection, while both compounds, albeit in small amount, were observed in the alcohol fraction of the extract using GC-MS.

In this context it should also be noted that uncertainties in the identification of non-presupposed compounds, such as the unknown putative lipid at $m / z 749$ (see above), highlight an analytical limitation of the current single analyzer ToF-SIMS designs. An MS/MS capability that would allow producing diagnostic fragment ions from the compounds in question is not yet available. However, recent technical advances have introduced the MS/MS option (Piehowski et al., 2008), together with a continuous beam design that decouples the ion formation event from the actual mass analysis (reviewed by Fletcher and Vickerman (2013)). It can thus be foreseen that future analytical developments will considerably enhance the utility of ToFSIMS in the biogeosciences, particularly for the investigation of complex environmental samples.

\subsection{Conclusions}

The results clearly revealed the capability of ToF-SIMS to detect and localize a broad variety of relevant biomarker compounds in microscopic compartments of a microbial mat system. Individual algal cells within a phototrophic microbial mat, belonging to the diatom P. lanceolatum, were analyzed for their lipid biomarkers, including FAs, carotenoids, chlorophyll $a$ and TAGs. However, when ToF-SIMS is applied to complex environmental materials it has to be considered that a sufficient secondary ion yield of the diagnostic biomarker ions is a prerequisite for localizing the compounds of interest in the sample. This may be difficult to achieve particularly for high mass or less abundant ions. Nevertheless, ToF-SIMS may become a valuable tool for biomarker studies at the microscopic level, particularly when used in conjunction with established techniques providing complementary morphological and molecular information, such as microscopy, and GC-MS and LC-MS. 


\section{Acknowledgements}

We acknowledge with gratitude the reviewers, B.J. Keely, K. Mangelsdorf and H. Volk, for constructive comments that helped improve the manuscript. We also thank E. Johansson and M. Lundqvist from SKB for technical and logistic support at the Äspö Hard Rock Laboratory. The project received financial support from the German Research Foundation (DFG; grants Th 713/3 and -/5), and the Swedish Governmental Agency for Innovation Systems (VINNOVA). The study is part of the DFG Research Unit 571 “Geobiology of Organo- and Biofilms” (publication 60).

\section{References}

Akimoto N., Maoka T., Fujiwara Y., Hashimoto K. (2000) Analysis of carotenoids by FAB CID-MS/MS. Journal of the Mass Spectrometry Society of Japan 48, 32-41.

Battarbee R. (1986) Diatom analysis. In Handbook of Holocene Palaeoecology and Palaeohydrology (ed. B. E. Berglund). John Wiley \& Sons. London, pp. 527-570.

Belu A. M., Graham D. J., Castner D. G. (2003) Time-of-flight secondary ion mass spectrometry. Biomaterials 24, 3635-3653.

Benninghoven A. (1994) Chemical analysis of inorganic and organic surfaces and thin films by static time-of-flight secondary ion mass spectrometry (TOF-SIMS). Angewandte Chemie International Edition in English 33, 1023-1043.

Brunelle A., Laprévote 0. (2009) Lipid imaging with cluster time-of-flight secondary ion mass spectrometry. Analytical and Bioanalytical Chemistry 393, 31-35.

Colliver T., Brummel C., Pacholski M., Swanek F., Ewing A., Winograd N. (1997) Atomic and molecular imaging at the single-cell Level with TOF-SIMS. Analytical Chemistry 69, 2225-2231.

de Brouwer J. F. C., Cooksey K. E., Wigglesworth-Cooksey B., Staal M. J., Stal L. J., Avci R. (2006) Time of flight-secondary ion mass spectrometry on isolated extracellular fractions and intact biofilms of three species of benthic diatoms. Journal of Microbiological Methods 65, 562-572.

Debois D., Bralet M.-P., Le Naour F., Brunelle A., Laprévote O. (2009) In situ lipidomic analysis of nonalcoholic fatty liver by cluster TOF-SIMS imaging. Analytical Chemistry 81, 2823-2831.

Fletcher J. S., Vickerman J. C. (2013) Secondary ion mass spectrometry: characterizing complex samples in two and three dimensions. Analytical Chemistry 85, 610-639.

Guidry S. A., Chafetz H. S. (2003) Depositional facies and diagenetic alteration in a relict siliceous hot-spring accumulation. Journal of Sedimentary Research 73, 806823. 
Heim C., Sjövall P., Lausmaa J., Leefmann T., Thiel V. (2009) Spectral characterization of eight glycerolipids and their detection in natural samples using time-of-flight secondary ion mass spectrometry. Rapid Communications in Mass Spectrometry 23, 2741-2753.

Heim C., Lausmaa J., Sjövall P., Toporski J., Dieing T., Simon K., Hansen B. T., Kronz A., Arp G., Reitner J., Thiel V. (2012) Ancient microbial activity recorded in fracture fillings from granitic rocks (Äspö Hard Rock Laboratory, Sweden). Geobiology 10, 280-297.

Hildebrand M., Davis A. K., Smith S. R., Traller J. C., Abbriano R. (2012) The place of diatoms in the biofuels industry. Biofuels 3, 221-240.

Hu Q., Sommerfeld M., Jarvis E., Ghirardi M., Posewitz M., Seibert M., Darzins A. (2008) Microalgal triacylglycerols as feedstocks for biofuel production. The Plant Journal 54, 621-639.

Hunt J. E., Macfarlane R. D., Katz J. J., Dougherty R. C. (1981) High-energy fragmentation of chlorophyll $a$ and its fully deuterated analog by californium-252 plasma desorption mass spectrometry. Journal of the American Chemical Society 103, 6775-6778.

Jetter R., Sodhi R. (2011) Chemical composition and microstructure of waxy plant surfaces. Surface and Interface Analysis 43, 326-330.

Keely B. J. (2006) Geochemistry of chlorophylls. In Chlorophylls and Bacteriochlorophylls (eds. B. Grimm, R. J. Porra, W. Rüdiger, H. Scheer). Springer Netherlands. Dordrecht, pp. 535-561.

Krammer K., Lange-Bertalot H. (1991) Suesswasserflora von Mitteleuropa. Band 2, Bacillariophyceae. 4. Teil, Achnanthaceae, kritische Ergaenzungen zu Navicula (Lineolatae) und Gomphonema Gesamtliteraturverzeichnis Teil 1-4. Gustav Fischer Verlag, Stuttgart, Germany.

Kurczy M. E., Piehowski P. D., van Bell C. T., Heien M. L., Winograd N., Ewing A. G. (2010) Mass spectrometry imaging of mating Tetrahymena show that changes in cell morphology regulate lipid domain formation. Proceedings of the National Academy of Sciences of the United States of America 107, 2751-2756.

Lange-Bertalot H. (1999) Neue Kombinationen von Taxa aus Achnanthes Bory (sensu lato). In Iconographia Diatomologica. Annotated Diatom Micrographs. (ed. H. Lange-Bertalot). Koeltz Scientific Books. Königstein, pp. 276-289.

Leefmann T., Heim C., Siljeström S., Blumenberg M., Sjövall P., Thiel V. (2013) Spectral characterization of ten cyclic lipids using time-of-flight secondary ion mass spectrometry. Rapid Communications in Mass Spectrometry, 27, 565-581.

Levine J., Billeter J. C., Krull U., Sodhi R. (2011) The cuticular surface of $D$. melanogaster. Surface and Interface Analysis 43, 317-321. 
Lindgren J., Uvdal P., Sjövall P., Nilsson D. E., Engdahl A., Schultz B. P., Thiel V. (2012) Molecular preservation of the pigment melanin in fossil melanosomes. Nature Communications 3, 824.

Malmberg P., Nygren H., Richter K., Chen Y., Dangardt F., Friberg P., Magnusson Y. (2007) Imaging of lipids in human adipose tissue by cluster ion TOF-SIMS. Microscopy Research and Technique 70, 828-835.

Mínguez-Mosquera M. I., Gandul-Rojas B. (1995) High-performance liquid chromatographic study of alkaline treatment of chlorophyll. Journal of Chromatography A 690, 161-176.

Nygren H., Malmberg P., Kriegeskotte C., Arlinghaus H. F. (2004) Bioimaging TOFSIMS. FEBS Letters 566, 291-293.

Ostrowski S. G., Craig T. Van Bell, Winograd N., Ewing A. G. (2004) Mass spectrometric imaging of highly curved membranes during Tetrahymena mating. Science 305, 71-73.

Ostrowski S., Szakal C., Kozole J., Roddy T., Xu J., Ewing A., Winograd N. (2005) Secondary ion ms imaging of lipids in picoliter vials with a buckminsterfullerene ion source. Anaytical. Chemistry. 77, 6190-6196.

Passarelli M. K., Winograd N. (2011) Lipid imaging with time-of-flight secondary ion mass spectrometry (ToF-SIMS). Biochimica et Biophysica Acta (BBA) - Molecular and Cell Biology of Lipids 1811, 976-990.

Pelizzi N., Catinella S., Barboso S., Zanol M. (2002) Different electrospray tandem mass spectrometric approaches for rapid characterization of phospholipid classes of Curosurf ${ }^{\circledR}$, a natural pulmonary surfactant. Rapid Communications in Mass Spectrometry 16, 2215-2220.

Perkins M., Roberts C., Briggs D., Davies M., Friedmann A., Hart C., Bell G. (2005) Surface morphology and chemistry of Prunus laurocerasus L. leaves. Planta 221, 123-134.

Piehowski P. D., Carado A. J., Kurczy M. E., Ostrowski S. G., Heien M. L., Winograd N., Ewing A. G. (2008) MS/MS methodology to improve subcellular mapping of cholesterol using TOF-SIMS. Analytical Chemistry 80, 8662-8667.

Schaber P. M., Hunt J. E., Fries R., Katz J. J. (1984) High-performance liquid chromatographic study of the chlorophyll allomerization reaction. Journal of Chromatography A 316, 25-41.

Seyer A., Einhorn J., Brunelle A., Laprévote O. (2010) Localization of flavonoids in seeds by cluster time-of-flight secondary ion mass spectrometry imaging. Analytical Chemistry 82, 2326-2333.

Sheehan J., Dunahay T., Benemann J., Roessler P. (1998) A look back at the U.S. Department of Energy's Aquatic Species program: Biodiesel from Algae. National Renewable Energy Laboratory, Golden, USA. 
Siljeström S., Hode T., Lausmaa J., Sjövall P., Toporski J., Thiel V. (2009) Detection of organic biomarkers in crude oils using ToF-SIMS. Organic Geochemistry 40, 135143.

Siljeström S., Lausmaa J., Sjövall P., Broman C., Thiel V., Hode T. (2010) Analysis of hopanes and steranes in single oil-bearing fluid inclusions using time-of-flight secondary ion mass spectrometry (ToF-SIMS). Geobiology 8, 37-44.

Sjövall P., Lausmaa J., Johansson B. (2004) Mass spectrometric imaging of lipids in brain tissue. Analytical Chemistry 76, 4271-4278.

Sjövall P., Johansson B., Belazi D., Stenvinkel P., Lindholm B., Lausmaa J., Schalling M. (2008) TOF-SIMS analysis of adipose tissue from patients with chronic kidney disease. Applied Surface Science 255, 1177-1180.

Sodhi R. N. S. (2004) Time-of-flight secondary ion mass spectrometry (TOF-SIMS). Analyst 129, 483-487.

Steele A., Toporski J. K. W., Avci R., Guidry S., McKay D. S. (2001) Time of flight secondary ion mass spectrometry (ToFSIMS) of a number of hopanoids. Organic Geochemistry 32, 905-911.

Thiel V., Heim C., Arp G., Hahmann U., Sjövall P., Lausmaa J. (2007) Biomarkers at the microscopic range. Geobiology 5, 413-421.

Thiel V., Sjövall P. (2011) Using time-of-flight secondary ion mass spectrometry to study biomarkers. Annual Review of Earth and Planetary Sciences 39, 125-156.

Toporski J. K. W., Steele A., Westall F., Avci R., Martill D. M., McKay D. S. (2002) Morphologic and spectral investigation of exceptionally well-preserved bacterial biofilms from the Oligocene Enspel formation, Germany. Geochimica et Cosmochimica Acta 66, 1773-1791.

Toporski J., Steele A. (2004) Characterization of purified biomarker compounds using time of flight-secondary ion mass spectrometry (ToF-SIMS). Organic Geochemistry 35, 793-811.

Touboul D., Brunelle A., Halgand F., La Porte S. de, Laprevote O. (2005) Lipid imaging by gold cluster time-of-flight secondary ion mass spectrometry. Journal of Lipid Research 46, 1388-1395.

Touboul D., Brunelle A., Laprévote O. (2011) Mass spectrometry imaging: towards a lipid microscope? Biochimie 93, 113-119.

Tyler B. J., Rangaranjan S., Möller J., Beumer A., Arlinghaus H. F. (2006) TOF-SIMS imaging of chlorhexidine-digluconate transport in frozen hydrated biofilms of the fungus Candida albicans. Applied Surface Science 252, 6712-6715.

van Breemen R. B., Canjura F. L., Schwartz S. J. (1991) Identification of chlorophyll derivatives by mass spectrometry. Journal of Agricultural and Food Chemistry 39, 1452-1456. 
Vickerman J. C., Briggs D. (eds.; 2001) ToF-SIMS. IM, Chichester.

Vieler A., Wilhelm C., Goss R., Süß R., Schiller J. (2007) The lipid composition of the unicellular green alga Chlamydomonas reinhardtii and the diatom Cyclotella meneghiniana investigated by MALDI-TOF MS and TLC. Chemistry and Physics of Lipids 150, 143-155.

Volkman J., Jeffrey S., Nichols P., Rogers G., Garland C. (1989) Fatty acid and lipid composition of 10 species of microalgae used in mariculture. Journal of Experimental Marine Biology and Ecology 128, 219-240.

Walker J. S., Jie C., Keely B. J. (2003) Identification of diastereomeric chlorophyll allomers by atmospheric pressure chemical ionisation liquid chromatography/tandem mass spectrometry. Rapid Communications in Mass Spectrometry 17, 1125-1131.

Winograd N., Garrison B. J. (2010) Biological cluster mass spectrometry. Annual Review of Physical Chemistry 61, 305-322.

Woolley P. S., Moir A. J., Hester R. E., Keely B. J. (1998) A comparative study of the allomerization reaction of chlorophyll $a$ and bacteriochlorophyll $a$. Journal of the Chemical Society, Perkin Transactions 2, 1833-1840.

Yu E., Zendejas F., Lane P., Gaucher S., Simmons B., Lane T. (2009) Triacylglycerol accumulation and profiling in the model diatoms Thalassiosira pseudonana and Phaeodactylum tricornutum (Baccilariophyceae) during starvation. Journal of Applied Phycology 21, 669-681. 


\section{5.}

\section{An imaging mass spectrometry study on the formation of conditioning films and biofilms in the subsurface (Äspö Hard Rock Laboratory, SE Sweden)}

Tim Leefmann, Christine Heim, Jukka Lausmaa, Peter Sjövall, Danny Ionescu, Joachim

Reitner, and Volker Thiel

In preparation for Geomicrobiology Journal

\subsection{Abstract}

Biofilms play a key role in biomineralization and rock weathering and consequently, in the interaction between the geo- and biospheres. Before a biofilm can evolve, individual microbial cells need to attach to a surface. The attachment of cells can be enhanced by conditioning films forming on surfaces whenever a solid material is exposed in an aqueous medium. In this study, time-of-flight secondary ion mass spectrometry (ToFSIMS) and scanning electron microscopy (SEM) were used to investigate the formation and chemistry of conditioning films and biofilms forming on a pristine substrate exposed to aquifer water in a subsurface environment on a time sacle from minutes to months..

Experiments were conducted in the tunnel of Äspö (Äspö Hard Rock Laboratory, SESweden). Dark, airtight flow reactors simulating the environmental conditions in the fractures of the surrounding granodioritic rock were equipped with silicon wafers and connected to a fluid outflow at $69 \mathrm{~m}$ below sea level. Samples taken after $10 \mathrm{~min}, 1000$ min, $10 \mathrm{~d}$, and $90 \mathrm{~d}$, respectively, were analyzed by ToF-SIMS and SEM. The detection of fragment ions of amino acids, carbohydrates, and carboxylic acids revealed that different types of organic compounds adhered to the silicon surface already after a few minutes of exposure to the fluids. Mapping their lateral distribution showed that these compounds formed small accumulations after a few minutes and subsequently started to cover the wafer surface more homogenously. SEM demonstrated that first solitary microorganisms had attached to the surface after $1000 \mathrm{~min}$ and had formed larger biofilm-like, cell accumulations after 3 month. 
The application of ToF-SIMS analysis in combination with SEM in this study provided an insight into the chemistry and growth rate of conditioning films and biofilms forming on fluid-exposed surfaces in a subsurface environment.

\subsection{Introduction}

Biofilms, consisting of microbial cells enclosed in extracellular polymeric substances (EPS), are of major interest to various scientific fields as they may form on nearly every solid surface. They can cause serious health problems when growing on indwelling medical devices like catheters and prostheses (Donlan, 2001) lead to increased corrosion damage of the colonized substratum (Beech et al., 2006), and by growing on hulls they can considerably increase power needed to maintain ships at a given speed (Cooksey and Wigglesworth-Cooksey, 1995). From a geobiological point of view, biofilms are a particularly important phenomenon as they play a key role in microbial biomineralization and rock weathering and consequently, as essential mediators of the interaction between the geo- and biospheres. Biofilms, form on interfaces of hard substrates and the aquatic or atmospheric environment, respectively. They may grow endolithically within the outer few centimeters of rocks (Walker and Pace, 2007), colonize aquatic environments from shallow waters (Montaggioni and Camoin, 1993) to the deep sea (Jørgensen and Boetius, 2007), and even inhabit the Earth's crust (Amend and Teske, 2005). As constructors of microbialites, e.g. stromatolites, biofilms can be traced back in the geological record to the Archean (Schopf et al., 2007; Tice et al., 2011) thus suggesting that microorganisms have been organizing themselves in this form since the early Earth.

The formation of biofilms can be divided into four steps, namely (i) transport, (ii) adhesion, and (iii) attachment of cells to a solid surface, followed by (iv) colonization of the surface (van Loosdrecht et al., 1990). Apart from the characteristics of the substratum, aqueous medium, and cell surfaces, the rate and extent of cell attachment is affected by so-called conditioning films (Donlan and Costerton, 2002). These thin organic films form from dissolved organic matter quickly after the exposure of a solid surface to an aqueous medium and are considered as important mediators for the establishment of complex biofilms (Cooksey and Wigglesworth-Cooksey, 1995; Loeb and Neihof, 1975). 
Using techniques like fluorescent spectroscopy (Loeb and Neihof, 1975), infrared spectroscopy (Baier, 1980), and X-ray photoelectron spectroscopy (Taylor et al., 1997) compound groups like proteins, lipids, nucleic acids, polysaccharides, amino acids (Taylor et al., 1997) glycoproteins (Baier, 1980) and humic material have been identified in conditioning films. However, these methods are limited in their ability to provide detailed information on the molecular composition of conditioning films. Mass spectrometric techniques, like time-of-flight secondary ion mass spectrometry (Benninghoven, 1994), offer greater chemical selectivity, greater surface sensitivity, and the ability to laterally resolve the chemical compositions of surfaces at the microscopic level.

ToF-SIMS, when used in static mode, is a quasi-non-destructive technique that allows analyzing the chemical composition of the uppermost atomic or molecular monolayer of a solid surface with high mass resolution (Belu et al., 2003; Benninghoven, 1994). A pulsed primary ion beam is rastered over the sample surface and leads to the emission of secondary ions. These ions are then analyzed according to their flight time, which is a function of their $m / z$ ratio.

The advantageous features of ToF-SIMS have prompted workers to study the chemical composition of conditioning films and biofilms (Beech et al., 1999; Poleunis et al., 2002; Poleunis et al., 2003; Pradier et al., 2000). These earlier studies, using $\mathrm{Cs}^{+}$and $\mathrm{Ga}^{+}$ion sources, focused on the short-term (24h) formation of conditioning films on stainless steel panels immersed in sea water. The observation of various small, amino acid-derived fragments suggested that proteins were the first compounds to adsorb on these surfaces. In recent years the invention of cluster ion sources (e.g. $\mathrm{Au}_{\mathrm{n}}{ }^{+} ; \mathrm{Bi}_{\mathrm{n}}{ }^{+}$) in liquid metal ion guns (LMIGs) has led to considerable improvements in the analysis of large biological molecules by ToF-SIMS as these sources provide dramatically higher secondary ion yields and primary ion beams with a narrow focus as small as $50 \mathrm{~nm}$ (Winograd and Garrison, 2010). A recent study on microbial biofilms from the Black Sea demonstrated the advantageous capabilities of cluster ion sources by detecting intact, archaea-derived glycolipids with masses up to $1648 \mathrm{Da}$ (Thiel et al., 2007).

Our study aimed to examine on an extended time scale (minutes to months) the chemistry changes involved in the evolution of an initially forming conditioning film to a biofilm in the continental subsurface. Microorganism forming biofilms the 
subsurface are of particular interest for geobiological research as the growth conditions and surrounding environment probably resembles the environments under which early life on earth developed (Trevors, 2002).

Growing experiments were conducted in Äspö Hard Rock Laboratory (Äspö HRL), a research tunnel operated by the Swedish Nuclear Fuel and Waste Management Company (SKB) as a testing site for the long-term deposition of nuclear waste. The $3.6 \mathrm{~km}$ long tunnel extends to a depth of $450 \mathrm{~m}$ below sea level under the island of Äspö located about $400 \mathrm{~km}$ south of Stockholm in SE-Sweden.. The Äspö HRL offers a unique window into the deep continental biosphere, where the growth of different microbial consortia strongly depends on the flow, oxygen content and the chemical composition of the feeder fluids employed. Groundwaters sampled from boreholes in the tunnel have been reported to contain among others homoacetogens, methanogens (Kotelnikova and Pedersen, 1998), iron oxidizing bacteria (Anderson and Pedersen, 2003) and sulphate reducing bacteria SRB; (Pedersen et al., 1996).

\subsection{Materials \& Methods}

\subsubsection{Flow reactor setup}

Dark, airtight flow reactors $(20 \mathrm{~cm}$ i.d. $\times 9.5 \mathrm{~cm}$ ) with an effective volume of $77 \mathrm{~mL}$ were constructed from highly inert PTFE (Teflon®) to avoid contaminations with organic plasticiser (Figure 5-1). Sample holders inside the flow reactor were manufactured from stainless steel bolts and PTFE washers, and are located within the reactor cap, so that samples were immersed from the top into the fluid. The inflow was installed below the outflow to keep the reactor free of air. Prior to use, all flow reactors were rinsed with acetone, sterilized with ethanol (70\%) and autoclaved for $20 \mathrm{~min}$ at $121^{\circ} \mathrm{C}$.

Silicon wafers $(\sim 30 \mathrm{~mm} \times \sim 10 \mathrm{~mm} \times 0.525 \mathrm{~mm}$, Si-Mat, Silicon Materials, Landsberg/Lech, Germany) were rinsed with deionized water purified by a Milli-Q Plus 185 system and cleaned from both sides under an ozone producing mercury grid lamp (emission wavelength: $185-579 \mathrm{~nm}$, irradiance: $\sim 7.5 \mathrm{~mW} / \mathrm{cm}^{2}$, B.H.K. Incorporated, Ontario, CA, USA). PTFE (Teflon®) flow reactors were equipped with as much as 10 clean silicon wafers and filled with purified, autoclaved water. Flow 
reactors were connected with flexible PTFE tubes to a tapped fluid outflow at a depth of $69 \mathrm{~m}$ below sea level (Site 507A, REDOX-Site) in the tunnel of Äspö. Wafers were exposed to the aquifer water for $10 \mathrm{~min}, 1000 \mathrm{~min}, 10 \mathrm{~d}$, and $90 \mathrm{~d}$, respectively.

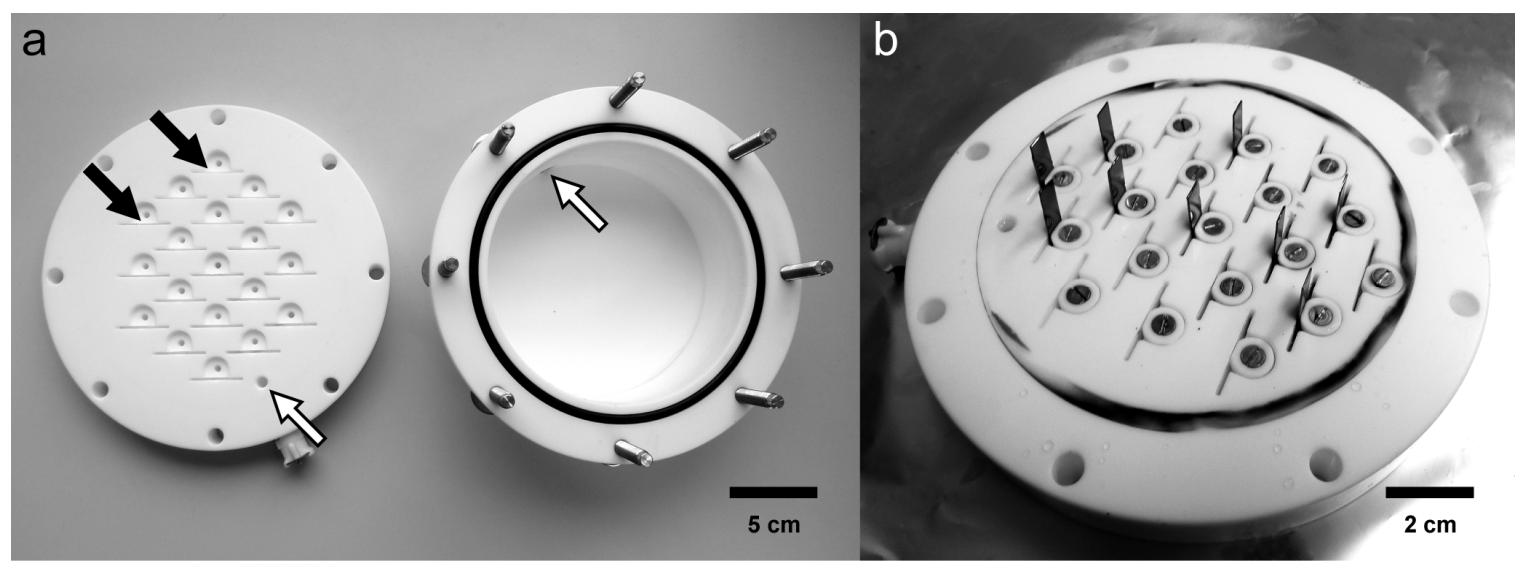

Figure 5-1. Flow reactors: a) open flow reactor with lid (view from inside), black arrows mark sample holders whereas white arrows indicate the in- and outflow openings. b) wafer samples in sample holders of flow reactor lid.

After $10 \mathrm{~min}$ and $1000 \mathrm{~min}$, samples were taken out of the flow-reactors on site, gently immersed in purified, autoclaved water $(3 \times)$, and covered with a second, clean silicon wafer. The sandwiched wafers were plunge frozen in liquid nitrogen, and stored and transported at $-80^{\circ} \mathrm{C}$ on dry ice. Samples with longer exposition times were kept inside the water-filled flow reactors for transport to the ToF-SIMS laboratory. Immediately before ToF-SIMS analysis, the samples were taken out of the reactors, gently immersed in purified, autoclaved water $(3 \times)$, and dried at room temperature in a laminar flow box. Parallel samples for scanning electron microscopy (SEM) were fixed in glutaraldehyde $(2 \%)$ and stored at $4^{\circ} \mathrm{C}$. Prior to SEM-analysis, samples were rinsed with purified water, dehydrated in a rising ethanol concentration (15\% to 99\%), dried in hexamethyldisilazane, glued on SEM sample holders, and sputtered with Au until a film thickness of $\sim 10 \mathrm{~nm}$ was reached. Control samples were immersed for $1000 \mathrm{~min}$ in purified, autoclaved water and prepared in the same way as described above for ToF-SIMS and SEM analyses.

\subsubsection{ToF-SIMS}

Wafer samples were analyzed with a ToF-SIMS IV instrument (ION-ToF, Münster, Germany). Analyses were conducted using $\mathrm{Bi}_{3}{ }^{+}$primary ions with a pulsed current of $0.1 \mathrm{pA}$ and an acquisition time of $100 \mathrm{~s}$. Areas of $500 \mu \mathrm{m} \times 500 \mu \mathrm{m}$ were analyzed 
with a resolution of $128 \times 128$ pixels (lateral resolution $\sim 4 \mu \mathrm{m}$ ) and a mass resolution of ca. $m / \Delta m 5000$. Each analysis was conducted in positive and negative ion mode. Spectra were internally calibrated using $\mathrm{CH}_{2}{ }^{+}, \mathrm{C}_{2} \mathrm{H}_{2}{ }^{+}, \mathrm{C}_{3} \mathrm{H}_{2}{ }^{+}, \mathrm{C}_{4} \mathrm{H}_{3}{ }^{+}$, and $\mathrm{C}^{-}$, $\mathrm{CH}^{-}, \mathrm{C}_{2}^{-}, \mathrm{C}_{3}^{-}, \mathrm{C}_{4}^{-}, \mathrm{C}_{4} \mathrm{H}^{-}$peaks, respectively. The primary ion dose was kept well below the static SIMS limit of $10^{13}$ ions $\mathrm{cm}^{-2}$, thereby preventing the sample from substantial surface damage.

Table 5-1. Peaks and tentatively assigned ions summed for ion images in Figure 5-4 ( $x=$ detected; $-=$ not detected)

\begin{tabular}{|c|c|c|c|c|c|c|c|}
\hline $\begin{array}{l}\text { Compound } \\
\text { class }\end{array}$ & $m / z$ & $\begin{array}{l}\text { tentative } \\
\text { assignment }\end{array}$ & $10 \mathrm{~min}$ & $1000 \mathrm{~min}$ & $10 \mathrm{~d}$ & $90 \mathrm{~d}$ & control \\
\hline \multirow[t]{18}{*}{ amino acids } & 30 & $\mathrm{CH}_{4} \mathrm{~N}^{+}$ & $\mathrm{x}$ & $\mathrm{x}$ & $\mathrm{x}$ & $\mathrm{x}$ & $\mathrm{x}$ \\
\hline & 44 & $\mathrm{C}_{2} \mathrm{H}_{6} \mathrm{~N}^{+}$ & $\mathrm{x}$ & $\mathrm{x}$ & $\mathrm{x}$ & $\mathrm{x}$ & $\mathrm{x}$ \\
\hline & 58 & $\mathrm{C}_{3} \mathrm{H}_{8} \mathrm{~N}^{+}$ & $\mathrm{x}$ & $\mathrm{x}$ & $\mathrm{x}$ & $\mathrm{x}$ & - \\
\hline & 61 & $\mathrm{C}_{2} \mathrm{H}_{5} \mathrm{~S}^{+}$ & $\mathrm{x}$ & $\mathrm{x}$ & $\mathrm{x}$ & $\mathrm{x}$ & $\mathrm{x}$ \\
\hline & 72 & $\mathrm{C}_{4} \mathrm{H}_{10} \mathrm{~N}^{+}$ & $\mathrm{x}$ & - & - & $\mathrm{x}$ & - \\
\hline & 83 & $\mathrm{C}_{5} \mathrm{H}_{7} \mathrm{O}^{+}$ & $\mathrm{x}$ & $\mathrm{x}$ & - & $\mathrm{x}$ & $\mathrm{x}$ \\
\hline & 84 & $\mathrm{C}_{4} \mathrm{H}_{6} \mathrm{NO}^{+}$ & $\mathrm{x}$ & $\mathrm{x}$ & $\mathrm{x}$ & $\mathrm{x}$ & - \\
\hline & 84 & $\mathrm{C}_{5} \mathrm{H}_{10} \mathrm{~N}^{+}$ & $\mathrm{x}$ & $\mathrm{x}$ & $\mathrm{x}$ & $\mathrm{x}$ & $\mathrm{x}$ \\
\hline & 86 & $\mathrm{C}_{5} \mathrm{H}_{12} \mathrm{~N}^{+}$ & $\mathrm{x}$ & - & - & $\mathrm{x}$ & $\mathrm{x}$ \\
\hline & 87 & $\mathrm{C}_{3} \mathrm{H}_{7} \mathrm{~N}_{2} \mathrm{O}^{+}$ & $\mathrm{x}$ & - & - & $\mathrm{x}$ & $\mathrm{x}$ \\
\hline & 88 & $\mathrm{C}_{3} \mathrm{H}_{6} \mathrm{NO}_{2}{ }^{+}$ & $\mathrm{x}$ & - & - & $\mathrm{x}$ & $\mathrm{x}$ \\
\hline & 102 & $\mathrm{C}_{4} \mathrm{H}_{8} \mathrm{NO}_{2}{ }^{+}$ & $\mathrm{x}$ & - & - & $\mathrm{x}$ & $\mathrm{x}$ \\
\hline & 107 & $\mathrm{C}_{7} \mathrm{H}_{7} \mathrm{O}^{+}$ & $\mathrm{x}$ & $\mathrm{x}$ & $\mathrm{x}$ & $\mathrm{x}$ & $\mathrm{x}$ \\
\hline & 110 & $\mathrm{C}_{5} \mathrm{H}_{8} \mathrm{~N}_{3}{ }^{+}$ & $\mathrm{x}$ & - & - & $\mathrm{x}$ & - \\
\hline & 120 & $\mathrm{C}_{8} \mathrm{H}_{10} \mathrm{~N}^{+}$ & $\mathrm{x}$ & $\mathrm{x}$ & $\mathrm{x}$ & $\mathrm{x}$ & $\mathrm{x}$ \\
\hline & 130 & $\mathrm{C}_{9} \mathrm{H}_{8} \mathrm{~N}^{+}$ & $\mathrm{x}$ & - & $\mathrm{x}$ & $\mathrm{X}$ & $\mathrm{x}$ \\
\hline & 136 & $\mathrm{C}_{8} \mathrm{H}_{10} \mathrm{NO}^{+}$ & $\mathrm{x}$ & $\mathrm{x}$ & - & $\mathrm{x}$ & $\mathrm{x}$ \\
\hline & 145 & $\mathrm{C}_{10} \mathrm{H}_{11} \mathrm{~N}^{+}$ & $\mathrm{x}$ & - & - & - & - \\
\hline \multirow[t]{11}{*}{ carbohydrates } & 31 & $\mathrm{CH}_{3} \mathrm{O}^{+}$ & $\mathrm{x}$ & $\mathrm{x}$ & $\mathrm{x}$ & $\mathrm{x}$ & $\mathrm{x}$ \\
\hline & 43 & $\mathrm{C}_{2} \mathrm{H}_{3} \mathrm{O}^{+}$ & $\mathrm{x}$ & $\mathrm{x}$ & $\mathrm{x}$ & $\mathrm{x}$ & $\mathrm{x}$ \\
\hline & 45 & $\mathrm{C}_{2} \mathrm{H}_{5} \mathrm{O}^{+}$ & $\mathrm{x}$ & - & - & $\mathrm{X}$ & $\mathrm{X}$ \\
\hline & 55 & $\mathrm{C}_{3} \mathrm{H}_{3} \mathrm{O}^{+}$ & $\mathrm{x}$ & $\mathrm{x}$ & $\mathrm{x}$ & $\mathrm{x}$ & $\mathrm{x}$ \\
\hline & 57 & $\mathrm{C}_{3} \mathrm{H}_{5} \mathrm{O}^{+}$ & $\mathrm{x}$ & $\mathrm{x}$ & $\mathrm{x}$ & $\mathrm{x}$ & $\mathrm{X}$ \\
\hline & 59 & $\mathrm{C}_{3} \mathrm{H}_{7} \mathrm{O}^{+}$ & $\mathrm{x}$ & $\mathrm{x}$ & - & $\mathrm{x}$ & $\mathrm{x}$ \\
\hline & 69 & $\mathrm{C}_{4} \mathrm{H}_{5} \mathrm{O}^{+}$ & $\mathrm{x}$ & $\mathrm{x}$ & - & $\mathrm{x}$ & $\mathrm{X}$ \\
\hline & 81 & $\mathrm{C}_{5} \mathrm{H}_{5} \mathrm{O}^{+}$ & - & - & - & $\mathrm{X}$ & $\mathrm{X}$ \\
\hline & 85 & $\mathrm{C}_{4} \mathrm{H}_{5} \mathrm{O}_{2}{ }^{+}$ & $\mathrm{x}$ & $\mathrm{x}$ & - & - & - \\
\hline & 87 & $\mathrm{C}_{4} \mathrm{H}_{7} \mathrm{O}_{2}{ }^{+}$ & $\mathrm{x}$ & - & - & $\mathrm{x}$ & - \\
\hline & 105 & $\mathrm{C}_{7} \mathrm{H}_{5} \mathrm{O}^{+}$ & $\mathrm{x}$ & $\mathrm{x}$ & - & $\mathrm{x}$ & - \\
\hline \multirow{12}{*}{$\begin{array}{l}\text { carboxylic } \\
\text { acids }\end{array}$} & 141 & $\mathrm{C}_{8} \mathrm{H}_{13} \mathrm{O}_{2}^{-}$ & $\mathrm{x}$ & $\mathrm{x}$ & - & - & - \\
\hline & 143 & $\mathrm{C}_{8} \mathrm{H}_{15} \mathrm{O}_{2}^{-}$ & $\mathrm{x}$ & $\mathrm{x}$ & $\mathrm{x}$ & $\mathrm{x}$ & - \\
\hline & 157 & $\mathrm{C}_{9} \mathrm{H}_{17} \mathrm{O}_{2}^{-}$ & $\mathrm{x}$ & $\mathrm{x}$ & $\mathrm{x}$ & $\mathrm{x}$ & - \\
\hline & 171 & $\mathrm{C}_{10} \mathrm{H}_{19} \mathrm{O}_{2}^{-}$ & $\mathrm{x}$ & $\mathrm{x}$ & $\mathrm{x}$ & - & - \\
\hline & 181 & $\mathrm{C}_{11} \mathrm{H}_{17} \mathrm{O}_{2}^{-}$ & $\mathrm{x}$ & $\mathrm{x}$ & - & - & - \\
\hline & 199 & $\mathrm{C}_{12} \mathrm{H}_{23} \mathrm{O}_{2}^{-}$ & $\mathrm{x}$ & $\mathrm{x}$ & $\mathrm{x}$ & $\mathrm{x}$ & - \\
\hline & 213 & $\mathrm{C}_{13} \mathrm{H}_{25} \mathrm{O}_{2}^{-}$ & $\mathrm{x}$ & $\mathrm{x}$ & $\mathrm{x}$ & - & - \\
\hline & 227 & $\mathrm{C}_{14} \mathrm{H}_{27} \mathrm{O}_{2}^{-}$ & $\mathrm{x}$ & $\mathrm{X}$ & $\mathrm{X}$ & $\mathrm{X}$ & $\mathrm{x}$ \\
\hline & 253 & $\mathrm{C}_{16} \mathrm{H}_{29} \mathrm{O}_{2}^{-}$ & - & $\mathrm{x}$ & $\mathrm{x}$ & - & - \\
\hline & 255 & $\mathrm{C}_{16} \mathrm{H}_{31} \mathrm{O}_{2^{-}}^{-}$ & $\mathrm{x}$ & $\mathrm{x}$ & $\mathrm{x}$ & $\mathrm{x}$ & $\mathrm{x}$ \\
\hline & 281 & $\mathrm{C}_{18} \mathrm{H}_{33} \mathrm{O}_{2}^{-}$ & - & - & $\mathrm{x}$ & $\mathrm{x}$ & $\mathrm{x}$ \\
\hline & 283 & $\mathrm{C}_{18} \mathrm{H}_{35} \mathrm{O}_{2}^{-}$ & $\mathrm{x}$ & $\mathrm{X}$ & $\mathrm{x}$ & $\mathrm{x}$ & $\mathrm{X}$ \\
\hline
\end{tabular}


Ion images were acquired for summed fragment ions of three different compound classes, namely amino acids, carbohydrates, and carboxylic acids. The fragment ions which were summed up for the ion images are listed in Table 5-1.

\subsubsection{SEM}

SEM analyses were conducted using a field emission SEM (LEO 1530 Gemini). Images were taken using a voltage of $3.8 \mathrm{kV}$.

\subsection{Results}

\subsubsection{ToF-SIMS}

\subsubsection{Positive ion mode}

The partial positive ion mode spectra $(\mathrm{m} / z 20-80)$ of $500 \mu \mathrm{m} \times 500 \mu \mathrm{m}$ areas on the wafers sampled after $10 \mathrm{~min}, 1000 \mathrm{~min}, 10 \mathrm{~d}$, and $90 \mathrm{~d}$, and the control wafer, respectively, are shown in Figure 5-2. All wafers displayed similar major peaks in the low-mass range. Ions of the silicon substrate were detected at $m / z 28$ and 45 corresponding to $\mathrm{Si}^{+}$and $\mathrm{SiOH}^{+}$, respectively.

Except for the samples exposed for $10 \mathrm{~min}$ in the flow reactors, all spectra had $\mathrm{Na}^{+}$at $m / z 23$ as base peak. Other major peaks of inorganic species were displayed at $m / z 39,40$, and 56 corresponding to $\mathrm{K}^{+}, \mathrm{Ca}^{+}$, and $\mathrm{CaOH}^{+}$, respectively. Major peaks consistent with the hydrocarbon fragments $\mathrm{C}_{2} \mathrm{H}_{3}{ }^{+}, \mathrm{C}_{2} \mathrm{H}_{5}{ }^{+}, \mathrm{C}_{3} \mathrm{H}_{5}{ }^{+}, \mathrm{C}_{3} \mathrm{H}_{7}{ }^{+}, \mathrm{C}_{4} \mathrm{H}_{7}{ }^{+}$and $\mathrm{C}_{4} \mathrm{H}_{9}{ }^{+}$.were displayed at $m / z 27,29,41,43,55$ and 57 , respectively.

Minor peaks corresponding to fragment ions of amino acids (Wald et al., 2010) and carbohydrates (Sjövall et al., 2004) were detectable by ToF-SIMS, but to weak in intensity to be displayed in the partial positive ion mode spectra (Figure 5-2).

Furthermore, all spectra showed the polydimethylsiloxane (PDMS) peak at $\mathrm{m} / \mathrm{z} 73$ consistent with the $\mathrm{SiC}_{3} \mathrm{H}_{9}{ }^{+}$fragment ion.

\subsubsection{Negative ion mode}

As in the positive ion mode, no major differences were observed for the partial negative ion mode spectra $(\mathrm{m} / \mathrm{z} 10-80)$ of the wafers sampled after different times of exposition to the aquifer water (Figure 5-3). All spectra showed major substrate peaks at $m / z 60$ and 77, corresponding to $\mathrm{SiO}_{2}{ }^{-}$and $\mathrm{SiOH}_{3}$. Further major inorganic ions detected at $m / z 16,17,35$, and 79 are consistent with $\mathrm{O}^{-}, \mathrm{OH}^{-}, \mathrm{Cl}^{-}$, and $\mathrm{PO}_{3}^{-}$, 
respectively. Intense organic fragment ions detected at $m / z 25,26$, and 42 are consistent with $\mathrm{C}_{2} \mathrm{H}^{-}, \mathrm{CN}^{-}$, and $\mathrm{CNO}^{-}$, respectively. Minor organic ions detected in the negative ion mode include carboxylic acids in the $\mathrm{C}_{8}$ to $\mathrm{C}_{18}$ range (Passarelli and Winograd, 2011). These ions are listed in Table 5-1.
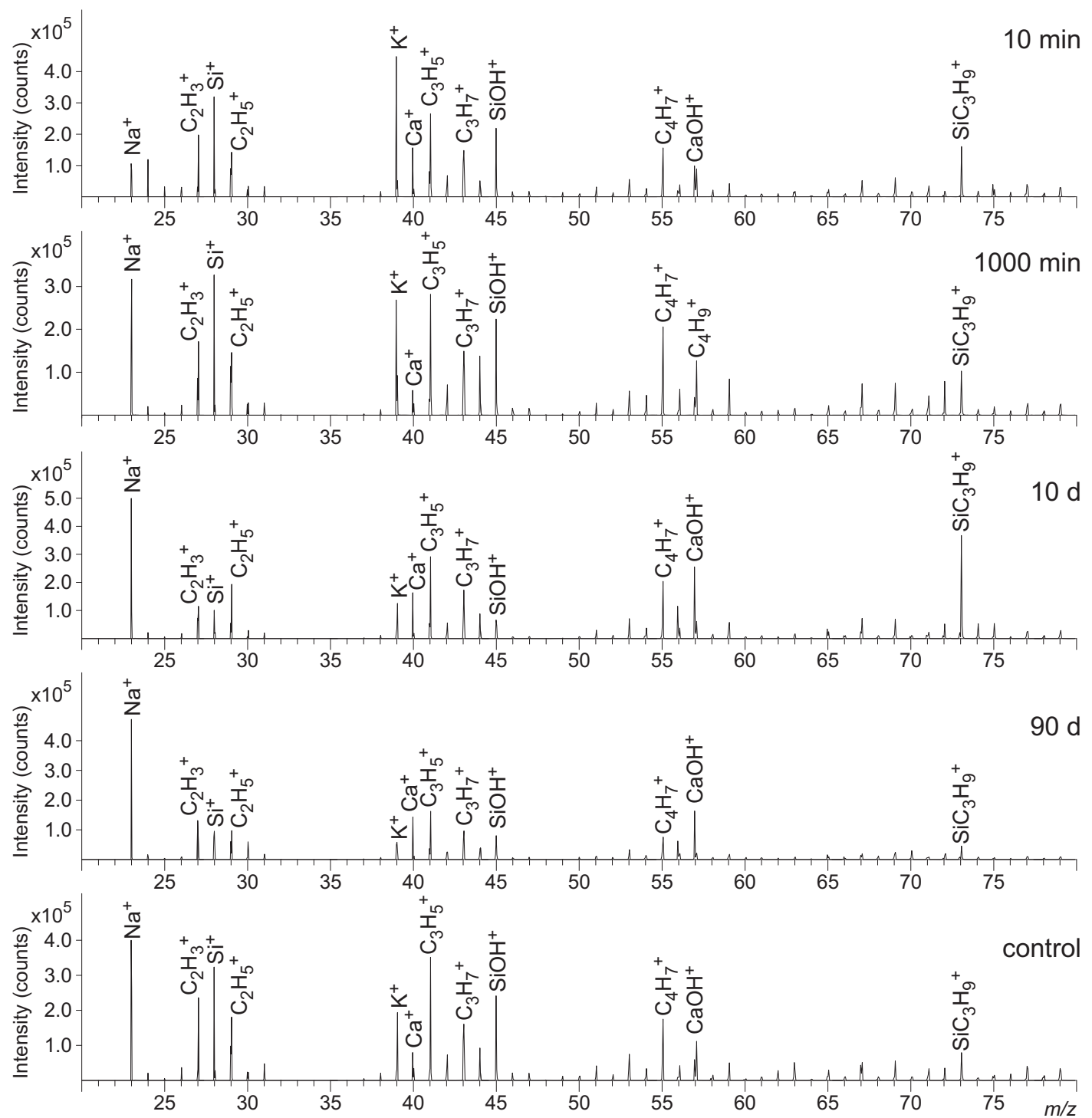

Figure 5-2. Partial positive ion mode spectra $(m / z 20-80)$ of $500 \mu \mathrm{m} \times 500 \mu \mathrm{m}$ areas on the wafers exposed to aquifer water and on the control wafer sample.

\subsubsection{Compound imaging}

Ion images showing the distribution of fragments from three individual organic compound classes, i.e. amino acids, carbohydrates, and carboxylic acids on the surface are displayed in Figure 5-4. The ions which were summed up for the individual ion images are given in Table 5-1. 
On the wafer immersed for $10 \mathrm{~min}$ in aquifer water fragment ions of amino acids, carbohydrates, and carboxylic acids showed a non-uniform distribution (Figure 5-4 a-c) and formed small spots with higher ion intensity of 20-40 $\mu \mathrm{m}$ in diameter.

On the wafers exposed for 1000 min to aquifer water, the summed organic fragment ions showed a more even distribution (Figure 5-4 d-e) compared to the 10 min wafer sample. A similarly even distribution is displayed for the fragment ions on the wafer immersed for $10 \mathrm{~d}$ (Figure 5-4 g-i).
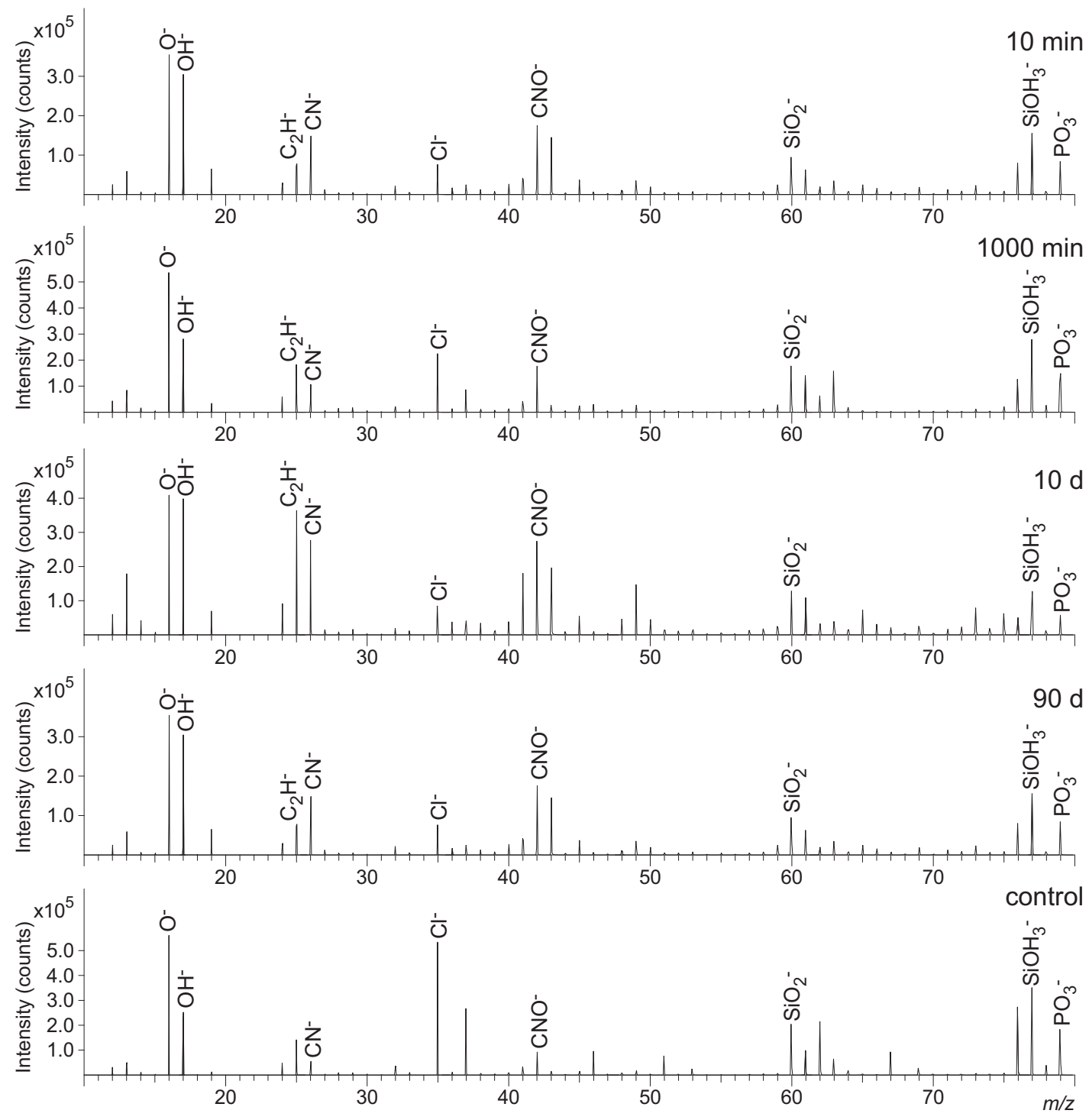

Figure 5-3. Partial negative ion mode spectra $(\mathrm{m} / \mathrm{z}$ 10-80) of $500 \mu \mathrm{m} \times 500 \mu \mathrm{m}$ areas on the wafers exposed to aquifer water and on the control wafer sample. 
By contrast fragment ions of amino acids and carbohydrates showed a patchier distribution on the wafer after $90 \mathrm{~d}$ of immersion in aquifer water (Figure 5-4 j-1). The patches were about 10-20 $\mu \mathrm{m}$ in size. Carboxylic acids showed only a very weak signal on this wafer, but appeared to be more evenly distributed than amino acid and carbohydrate fragments. The control wafers immersed for $1000 \mathrm{~min}$ in ultrapure, autoclaved water showed no chemical contrast in the ion images of the organic fragment ions (Figure 5-4 m-o).

\subsubsection{SEM}

Representative SEM images obtained from the wafer surfaces display organic particles, minerals and microbial cells attached to the wafer surface (Figure 5-5).

On the 10 min wafer exclusively sodium chlorite crystals were found adhering to the surface (Figure 5-5 a, b). The first attached, solitary cells were found after $1000 \mathrm{~min}$ of exposure of the wafer surface to aquifer water (Figure 5-5 c, d). With increasing time of exposure to aquifer water more and more solitary cells had attached to the wafer surface (Figure 5-5 e, f) and succesively formed larger accumulations (10-100 $\mu \mathrm{m}$ in diameter) of cells enclosed in an EPS matrix on the wafer (Figure 5-5 g, h). No cells were found to be attached to the surface of the control sample (Figure 5-5 i, j).

\subsection{Discussion}

The fragment ions of amino acids, carbohydrates, and carboxylic acids showed a nonuniform distribution with spots of higher intensity (10-20 $\mu \mathrm{m}$ in diameter) on the wafer surface already after 10 minutes of immersion of the wafer in aquifer water. As no microbial cells were found to be attached to the wafer surface and known artificial contaminants such as PDMS were not colocalized with these spots, an initially forming conditioning film appears to be a plausible source of these ions.

With increasing exposition time (1000 $\mathrm{min})$ carbohydrates and amino acid fragment ions show a more continous coverage of the wafer surface. This is consistent with a report stating that the primary film forming on stainless steel surfaces immersed for $24 \mathrm{~h}$ in sea water is composed of proteins and shows a uniform distribution in the ion images (Poleunis et al., 2002). 

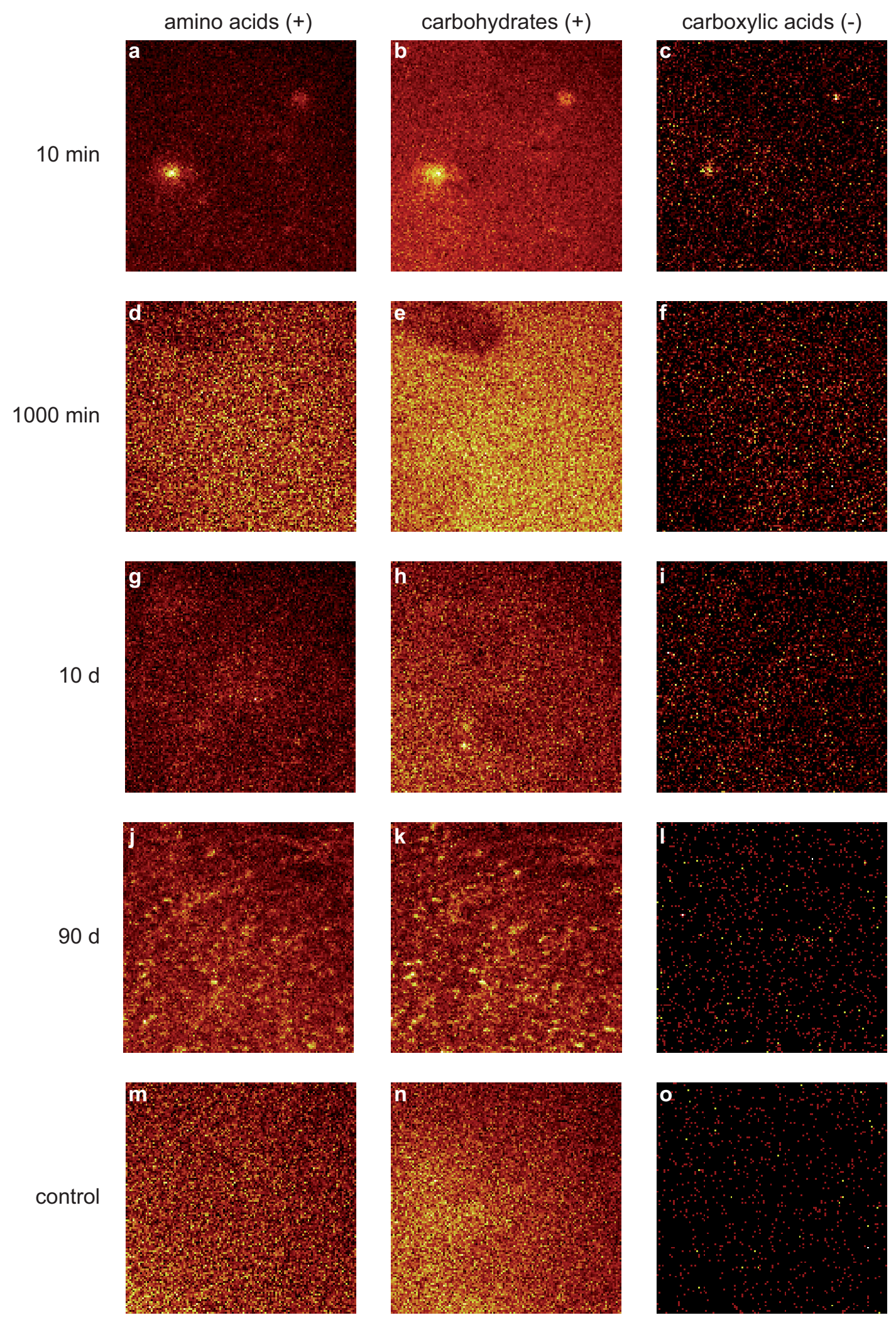

Figure 5-4. Secondary ion images of summed fragment ions of amino acids (a, d, g, j, m), carbohydrates (b, e, h, k, n), and carboxylic acids (c, f, i, l, o) obtained from $500 \mu \mathrm{m} \times 500 \mu \mathrm{m}$ areas on the wafers exposed to aquifer water (a-l) and on the control wafer sample (m-o). 

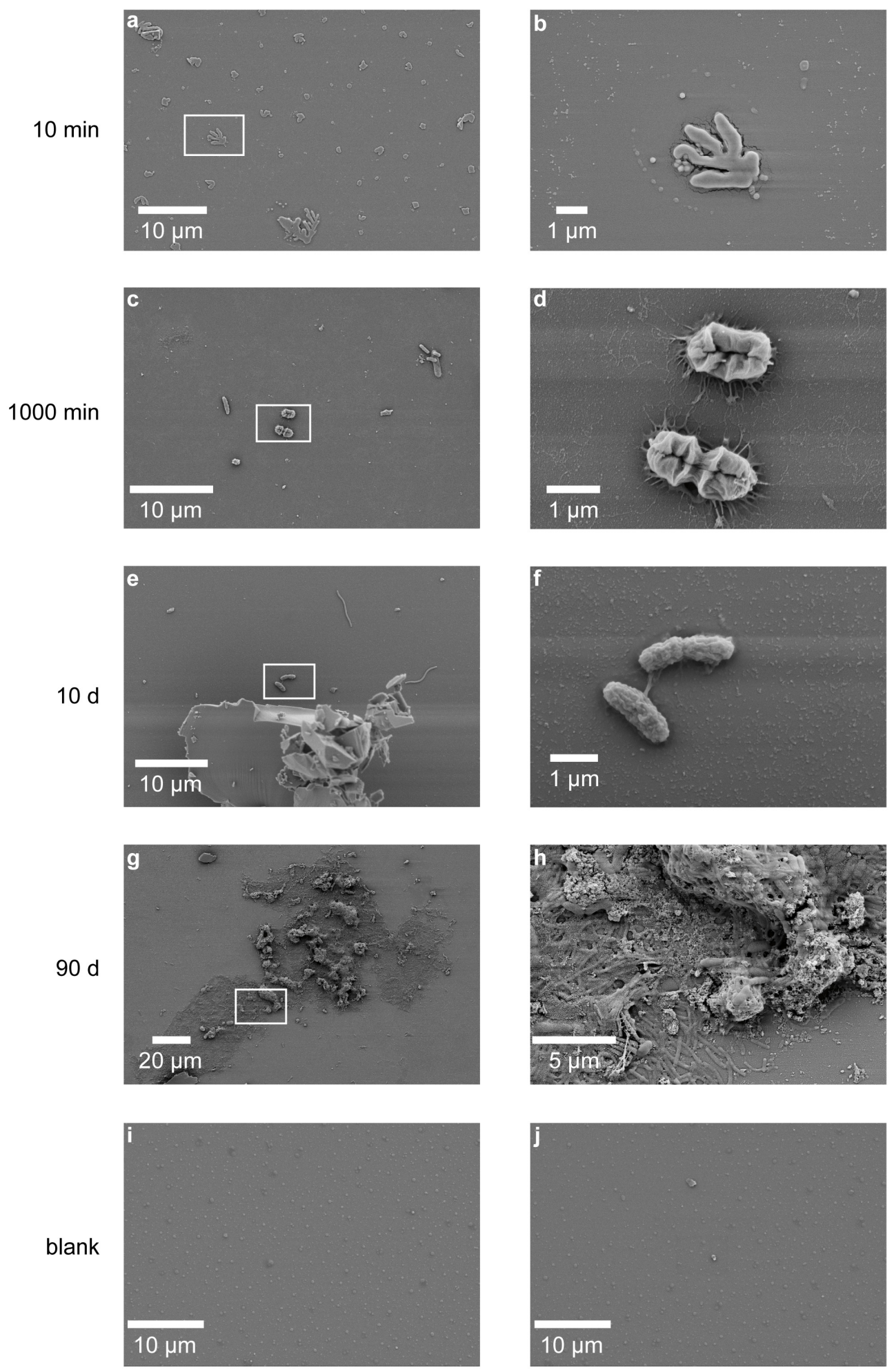

Figure 5-5. SEM images of wafer surfaces. (a) wafer exposed for $10 \mathrm{~min}$ to aquifer water, white frame marks area enlarged in (b) showing a sodium chlorite crystal, (c) wafer exposed for 1000 min to aquifer water, white frame marks area enlarged in (d) showing two solitary cells attached to the surface, (e) wafer exposed for $10 \mathrm{~d}$ to aquifer water, white frame marks area enlarged in (f) showing two solitary cells attached to the surface, (g) wafer exposed for $90 \mathrm{~d}$ to aquifer water, white frame marks area enlarged in (h) showing biofilmlike accumulation of cells enclosed in extracellular polymeric substances, ( $i$ and $j$ ) control wafer samples showing no attachment of microbial cells. 
However, it has to be considered that potential inhomogenities may have been below the limit of lateral resolution $(\sim 4 \mu \mathrm{m})$ of this ToF-SIMS analysis. In fact from atomic force microscopy analyses of stainless steal surfaces immersed in seawater it has been concluded that proteins are initially adsorbed in the form of "islands" of 20-100 nm in diameter (Pradier et al., 2000), which are to small to be resolved in ToF-SIMS ion images. Similarly the first attachment of solitary microbial cells to the wafer surface observed in the SEM images after 1000 min of immersion may not have become visible in the ion images due to the low lateral resolution of the ToFSIMS analysis. No major changes in the distribution of the organic compounds can be observed between the ion images obtained from the wafer samples exposed for $1000 \mathrm{~min}$ and $10 \mathrm{~d}$, respectively, to aquifer water. From the SEM images it can be concluded, that in this time interval solitary cells increasingly attached to the surface. However, these cells are too small to be resolved in ToF-SIMS ion images. In the time interval between $10 \mathrm{~d}$ and $90 \mathrm{~d}$ of immersion in aquifer water, the cells started to form larger accumulations of cells and to secret EPS. Succesively the EPS enclosed the microorganism and biofilmlike structures were formed. The EPS matrix secreted around the cells is likely reflected in the ion images by the patchy distribution of fragments of amino acids and carbohydrates.

\subsection{Conclusions}

The combined application of ToF-SIMS and SEM used in this study gave an insight into the chemistry of an initial conditioning film, and the subsequent biofilm formation under exposition of a wafer surface to aquifer water. The first organic compounds to adhere in small patches to the surface of the wafer prior to any attachment of microbial cells were found to be amino acids, carbohydrates and carboxylic acids. Following this initial stage, the conditioning film began to cover the substrate surface more homogenously and microbial cells attached after a few hours. The formation of biofilmlike accumulations of cells enclosed in EPS took place in the time interval between $10 \mathrm{~d}$ and $90 \mathrm{~d}$ of immersion in aquifer water. 


\section{Acknowledgements}

We acknowledge with gratitude D. Hause-Reitner for assistance with scanning electron microscopy. We furthermore wish to thank E. Johansson, M. Kronberg, K. Nilsson, and M. Lundqvist from SKB for technical and logistic support at the Äspö Hard Rock Laboratory. We are grateful to L. Laake and his team for the construction of the flow reactors and the uv-ozone cleaning apparatus. This study was financially supported by the German Research Foundation (DFG; Grant Th 713/5-1).

\section{References}

Amend J. P., Teske A. (2005) Expanding frontiers in deep subsurface microbiology. Palaeogeography, Palaeoclimatology, Palaeoecology 219, 131-155.

Anderson C. R., Pedersen K. (2003) In situ growth of Gallionella biofilms and partitioning of lanthanides and actinides between biological material and ferric oxyhydroxides. Geobiology 1, 169-178.

Baier R. (1980) Substrate influences on adhesion of microorganisms and their resultant new surface properties. In Adsorption of microorganisms to surfaces (eds. G. Bitton, K. C. Marshall). John Wiley \& Sons. New York, pp. 59-104.

Beech I. B., Zinkevich V., Tapper R., Gubner R., Avci R. (1999) Study of the interaction of sulphate-reducing bacteria exopolymers with iron using X-ray photoelectron spectroscopy and time-of-flight secondary ionisation mass spectrometry. Journal of Microbiological Methods 36, 3-10.

Beech, I B., Sunner, J A., Arciola, C R., Cristiani, P (2006) Microbially-influenced corrosion: damage to prostheses, delight for bacteria. The International Journal of Artificial Organs 29, 443-452.

Belu A. M., Graham D. J., Castner D. G. (2003) Time-of-flight secondary ion mass spectrometry. Biomaterials 24, 3635-3653.

Benninghoven A. (1994) Chemical analysis of inorganic and organic surfaces and thin films by static time-of-flight secondary ion mass spectrometry (TOF-SIMS). Angewandte Chemie International Edition in English 33, 1023-1043.

Cooksey K. E., Wigglesworth-Cooksey B. (1995) Adhesion of bacteria and diatoms to surfaces in the sea: a review. Aquatic Microbial Ecology 9, 87-96.

Donlan R. M. (2001) Biofilms and device-associated infections. Emerging Infectious Diseases 7, 277-281.

Donlan R. M., Costerton J. W. (2002) Biofilms. Clinical Microbiology Reviews 15, 167193. 
Jørgensen B. B., Boetius A. (2007) Feast and famine - microbial life in the deep-sea bed. Nature Reviews Microbiology 5, 770-781.

Kotelnikova S., Pedersen K. (1998) Distribution and activity of methanogens and homoacetogens in deep granitic aquifers at Äspö Hard Rock Laboratory, Sweden. FEMS Microbiology Ecology 26, 121-134.

Loeb G. I., Neihof R. A. (1975) Marine conditioning films. Advances in Chemistry, 145, 319-335.

Montaggioni L. F., Camoin G. F. (1993) Stromatolites associated with coralgal communities in Holocene high-energy reefs. Geology 21, 149-152.

Passarelli M. K., Winograd N. (2011) Lipid imaging with time-of-flight secondary ion mass spectrometry (ToF-SIMS). Biochimica et Biophysica Acta (BBA) - Molecular and Cell Biology of Lipids 1811, 976-990.

Pedersen K., Arlinger J., Ekendahl S., Hallbeck L. (1996) 16S rRNA gene diversity of attached and unattached bacteria in boreholes along the access tunnel to the Äspö hard rock laboratory, Sweden. FEMS Microbiology Ecology 19, 249-262.

Poleunis C., Compère C., Bertrand P. (2002) Time-of-flight secondary ion mass spectrometry. Journal of Microbiological Methods 48, 195-205.

Poleunis C., Rubio C., Compère C., Bertrand P. (2003) ToF-SIMS chemical mapping study of protein adsorption onto stainless steel surfaces immersed in saline aqueous solutions. Applied Surface Science 203-204, 693-697.

Pradier C. M., Bertrand P., Bellon-Fontaine M. N., Compère C., Costa D., Marcus P., Poleunis C., Rondot B., Walls M. G. (2000) Adsorption of proteins on an AISI 316 stainless-steel surface in natural seawater. Surface and Interface Analysis 30, 45-49.

Schopf J. W., Kudryavtsev A. B., Czaja A. D., Tripathi A. B. (2007) Evidence of Archean life: Stromatolites and microfossils. Precambrian Research 158, 141-155.

Sjövall P., Lausmaa J., Johansson B.-L., Andersson M. (2004) Surface chemical analysis of carbohydrate materials used for chromatography media by time-of-flight secondary ion mass spectrometry. Analytical Chemistry 76, 1857-1864.

Taylor G. T., Zheng D., Lee M., Troy P. J., Gyananath G., Sharma S. K. (1997) Influence of surface properties on accumulation of conditioning films and marine bacteria on substrata exposed to oligotrophic waters. Biofouling: The Journal of Bioadhesion and Biofilm Research 11, 31-57.

Thiel V., Heim C., Arp G., Hahmann U., Sjövall P., Lausmaa J. (2007) Biomarkers at the microscopic range: ToF-SIMS molecular imaging of Archaea-derived lipids in a microbial mat. Geobiology 5, 413-421.

Tice M. M., Thornton D. C., Pope M. C., Olszewski T. D., Gong J. (2011) Archean microbial mat communities. Annual Review of Earth and Planetary Sciences. 39, 297319. 
Trevors J.T. (2002) The subsurface origin of microbial life on the Earth. Research in Microbiology 153, 487-491.

van Loosdrecht M. C., Lyklema J., Norde W., Zehnder A. J. (1990) Influence of interfaces on microbial activity. Microbiological Reviews 54, 75-87.

Wald J., Müller C., Wahl M., Hoth-Hannig W., Hannig M., Kopnarski M., Ziegler C. (2010) ToF-SIMS investigations of adsorbed proteins on dental titanium. Physica Status Solidi (a) 207, 831-836.

Walker J. J., Pace N. R. (2007) Endolithic microbial ecosystems. Annual Review of Microbiology 61, 331-347.

Winograd N., Garrison B. J. (2010) Biological cluster mass spectrometry. Annual Review of Physical Chemistry 61, 305-322. 
6.

\section{Summary and conclusions}

In this thesis ToF-SIMS was applied to the study of geobiological samples. Except for a few pioneering studies, ToF-SIMS has rarely been used in the field of geobiology and thus only a limited number of SIMS reference spectra for biogeochemical relevant compounds has as yet been published. One major goal of this thesis was to extend the spectral library by compounds particularly used as molecular markers in the analysis of geobiological systems. Consequently in the first study reference spectra of eight different glycerolipids functioning as important membrane constituents in eukaryotes, bacteria, and archaea, were presented and their detection in an extract and cryosections of microbial mats demonstrated. The analyses of the standard compounds showed that the detection of fragment ions, in particular from headgroups and alkyl chains, is particularly important for the reliable identification of glycerolipids in complex, environmental samples.

As a follow-up study, ten cyclic lipid standards were analyzed by ToF-SIMS. These cyclic lipids are known as important membrane constituents or fulfill a protective function from oxidative stress in eukaryotes, bacteria, or archea. The results obtained showed that most of the compounds can reliably be analyzed in only one of the two polarity modes. In addition the study demonstrated, that not all fragment ions detected in the analyses of the standard compounds can be expected to be detectable in environmental samples containing this compound in complex mixtures with other organic molecules.

The knowledge gained in the analysis of standard compounds was used to study a phototrophic microbial mat in detail for their lipid biomarker content by a combining ToF-SIMS, optical microscopy and GC-MS analyses. ToF-SIMS analyses of a cryosection of the microbial mat showed, that a wide range of lipids and pigments, e.g. acylglycerols, carotenoids and chlorophyll $a$, were present in the microbial mat. Testing the limits of the lateral resolution of the ToF-SIMS instrument, the burst alignment mode was used, to probe single cells for their biomarker content. By subsequent optical microscopy these cells were identified as the diatom species Planothidium lanceolatum and as a major source of lipids and pigments in the 
microbial mat. The results of the Tof-SIMS analyses were consistent with the diatom specific fatty acid pattern obtained from GC-MS analyses of the bulk microbial mat. This study demonstrated a potential future application of ToF-SIMS in biomarker related research, namely as a tool for the rapid, clear-cut assignment of biomarkers to specific microbial sources in complex environmental samples. This technique could be particularly useful for biomarker studies on the majority of microorganisms, which can as yet not be grown in pure cultures. However, it should be noted that most prokaryotic cells are by an order of magnitude smaller than the diatom cells analyzed in this study and thus more effort has to be spent on increasing the useful lateral resolution of ToF-SIMS imaging.

In the last study ToF-SIMS was applied in combination with SEM to the analysis of thin organic films, i.e. conditioning films, forming on solid surfaces exposed to aquifer water prior to the attachment of microorganisms. The results showed that the initial conditioning film forming after a few minutes of exposure to aquifer water was inhomogenous and composed of amino acids, carbohydrates, and fatty acids. With increasing time, the film became more homogenous and microorganism had attached to the surface after a few hours. After 90 days biofilm like accumulations of cells enclosed in extracellular polymeric substances had formed on the wafer surface. This study gave an insight into the chemistry and growth rates of conditioning films and biofilms forming in aquifers in the subsurface and demonstrated the applicability of ToF-SIMS for the analysis of very low amounts of organic material in environmental samples.

The studies comprised in this thesis showed that ToF-SIMS can offer unique analytical capabilities for the analyses of large organic ions in environmental samples. Nonetheless, it has been shown that ToF-SIMS is best used in combination with other techniques providing complementary information on the molecular structure of the analyzed compounds or the structure of the sample. With the recent techniqual developments in SIMS, such as the introduction of MS/MS or gentle SIMS (G-SIMS) capability, it can be foreseen that structural identification of ion species in SIMS spectra will become more reliable in the future. The main factor currently limiting the useful lateral resolution of ToF-SIMS imaging and thus the application to the analysis of single, prokaryotic cells is the overall low secondary ion yield. Protocols leading to increase in the secondary ion yield, e.g. by matrix enhacenment 
or metal addition, are currently under investigation by various research groups. It can thus be expected that ToF-SIMS analyses of single prokaryotic cells in environmental may become feasible in the near future. 



\section{CURRICULUM VITAE}

Name: $\quad$ Tim Leefmann

Geburtstag: $\quad 31.03 .1982$

Geburtsort: $\quad$ Lüneburg, Deutschland

\section{STUDIUM}

07/2008 Seit 01.07.2008 Doktorand und wissenschaftlicher Mitarbeiter in der Abteilung Geobiologie und im Courant Research Centre Geobiology am Geowissenschaftlichen Zentrum der GeorgAugust-Universität Göttingen

05/2008 Diplom im Studiengang Geowissenschaften - Titel der Diplomarbeit: „Raman spectroscopy of biosignatures in methane-related microbialites"

05/2006 Bachelor of Science im Studiengang Geowissenschaften - Titel der Bachelorarbeit: „Lipidbiomarker in Methankarbonaten des Hydratrückens (Kontinentalhang vor Oregon, USA)“

10/2002 Aufnahme des Studiums der Geowissenschaften am Geowissenschaftlichen Zentrum der Georg-August-Universität Göttingen

\section{ZIVILDIENST}

2001-2002 Zivildienst im mobilen, sozialen Hilfsdienst des Arbeiter Samariter Bundes Lüneburg

SCHULE

1995 - 2001 Gymnasium Johanneum Lüneburg, Abschluss: Abitur

1988 - 1995 Rudolf-Steiner-Schule Lüneburg 